ÉRICA SANTOS MATOS

ESTUDO DA INFLUÊNCIA DO POSICIONAMENTO DE BARREIRAS RÍGIDAS CENTRAIS NA VISIBILIDADE DE PROJETO EM RODOVIAS DE PISTA DUPLA 
ÉRICA SANTOS MATOS

\section{ESTUDO DA INFLUÊNCIA DO POSICIONAMENTO DE BARREIRAS RÍGIDAS CENTRAIS NA VISIBILIDADE DE PROJETO EM RODOVIAS DE PISTA DUPLA}

Dissertação apresentada à Escola Politécnica da Universidade de São Paulo como requisito para obtenção do título de Mestre em Engenharia.

Área de concentração: Engenharia de Transportes

Orientador: Prof. ${ }^{a}$ Dr. ${ }^{a}$ Ana Paula Camargo Larocca

São Paulo 
Este exemplar foi revisado e corrigido em relação à versão original, sob responsabilidade única do autor e com a anuência de seu orientador.

São Paulo, de abril de 2013.

Assinatura do autor

Assinatura do orientador

FICHA CATALOGRÁFICA

Matos, Érica Santos

Estudo da influência do posicionamento de barreiras rígidas centrais na visibilidade de projeto em rodovias de pista dupla / E.S. Matos. -- versão corr. -- São Paulo, 2013. $186 \mathrm{p}$.

Dissertação (Mestrado) - Escola Politécnica da Universidade de São Paulo. Departamento de Engenharia de Transportes.

1. Segurança rodoviária 2. Infra-estrutura de transportes 3. Rodovias I. Universidade de São Paulo. Escola Politécnica. Departamento de Engenharia de Transportes II. t. 


\section{DEDICATÓRIA}

Aos meus pais, meus grandes mestres,

em todos os dias da minha vida. 


\section{AGRADECIMENTOS}

Agradeço primeiramente a Deus, pelo dom da vida que me permitiu a realizar este trabalho, sem Ele nada é possível e tudo só vêm por Ele.

À minha família, pelo apoio constante mesmo nas sinuosidades do percurso. Obrigado por serem meus alicerces, o meu porto seguro, em todos os momentos.

À minha orientadora Prof. ${ }^{\underline{a}}$ Dr. ${ }^{\underline{a}}$ Ana Paula C. Larocca por acreditar em mim e nas minhas capacidades, antes mesmo de mim. Obrigada pelo incentivo e pela motivação durante este trabalho. Aprendi a ser muito mais do que era antes.

Aos meus colegas de curso pela amizade e companhia nos estudos, trabalhos e disciplinas: Erly, Émerson, Ely, Janaína, Eliane, Carlos, Patrícia, Aurenice, Pedro, Luiz e todos os colegas que tive oportunidade de conhecer e conviver nestes anos.

Aos companheiros do Laboratório de Topografia e Geodésia (LTG): Wagner, Sônia, Ana Cristina, Gabriel, Jhonnes e Adalberto, pelos momentos que partilhamos juntos.

Aos Prof.. Dr. Jorge Pimentel Cintra, Prof.ำ Dr. Denizar Blitzkow e Prof.ำ Dr. Edvaldo Simões da Fonseca Júnior, por todos os ensinamentos ministrados, científicos ou de vida.

Ao Prof. - Dr. Felipe Issa Kabbach Júnior, por toda ajuda prestada na execução deste trabalho, com conselhos, sugestões e críticas sempre estimulando o alcance de um resultado melhor.

Ao Eng. Msc. Marcelo Missato pelo tempo dedicado no auxílio e apoio durante a execução do trabalho

À PLANSERVI Engenharia, pela disponibilização da infraestrutura e dados para a execução do estudo de caso.

E a todos que direta ou indiretamente participaram desta jornada, o meu muito obrigada. 
"Por vezes sentimos que aquilo que fazemos não é senão uma gota de água no mar. Mas o mar seria menor se lhe faltasse uma gota."

Madre Teresa de Calcutá 


\section{RESUMO}

A distância de visibilidade de parada deve ser garantida ao longo de toda a extensão de uma rodovia por questões de segurança. Elementos da seção transversal podem se tornar obstruções que interferem nas distâncias de visibilidade do projeto. Este é o caso do uso de barreiras ao invés de canteiros centrais em rodovias bidirecionais, especialmente ao longo de curvas à esquerda. Desta forma, este trabalho analisa o posicionamento de barreiras em cenários hipotéticos - aclives planos e declives com uso de simulações gráficas tridimensionais. $O$ afastamento lateral da barreira, em relação à pista de rolamento, foi definido em função de cada velocidade de projeto e de cada raio de curva horizontal analisados. Os diagramas gerados foram comparados com modelo de afastamento de objetos fixos em curvas horizontais, presente como recomendações em manuais nacionais. As diferenças encontradas indicam a viabilidade da metodologia utilizada, em que o projeto foi considerado como um todo, o qual se desenvolve tridimensionalmente.

Palavras-chave: Distância de Visibilidade de Parada; Barreira; Projeto Geométrico Viário. 


\begin{abstract}
Stopping Sight Distance must be guaranteed throughout of a highway for safety reasons. However, cross section elements can become obstructions which interfere on design sight distances. This occurs when barriers are used instead of medians on bidirectional highways, especially along left curves. Therefore, this paper analyzes the barriers placement on hypothetical scenarios - upgrades, plans and downgrades - using three-dimensional graphics simulations. The lateral offset of the barrier in relation to the roadway was defined according to each design speed and each radius of the horizontal curve analysis. For each scenario were generated diagrams, which use compared with offset model of fixed objects on horizontal curves presents as recommendation in national manuals. The differences indicate the viability of the methodology used, where the project was considered as a whole, which develops three-dimensionally.
\end{abstract}

Key-words: Stopping Sight Distance; Barrier; Highway Geometric Design. 


\section{Lista de Figuras}

Figura 2.1. Taxa de Ocorrência de Acidentes em função da Distância de Visibilidade disponível. ..... 21 Figura 2.2. Necessidade de defensa ou barreira rígida em canteiros centrais - DNER (atual DNIT). . 33 Figura 2.3. Necessidade de defensa ou barreira rígida em canteiros centrais - NBR 6971 .............. 33

Figura 2.4. Necessidade de defensa ou barreira rígida em canteiros centrais - AASHTO. ................. 34

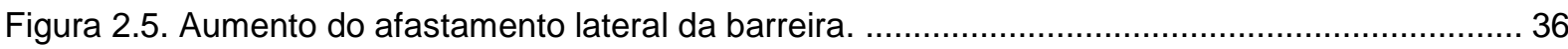

Figura 2.6. Distância de Visibilidade Necessária para Paradas (A) e Refúgio interno necessário (B) DER-SC (2000)

Figura 2.7. Análise do posicionamento de barreiras e visibilidade utilizada no estudo de Hassan e Sarhan (2012) 40

Figura 3.1. Afastamento lateral da barreira $(a L)$. Foto: SP-088, Google ${ }^{\circledR} 2012$. ................................ 42

Figura 3.2. Exemplo de uso de simulação computacional para estudos de visibilidade. ..................... 43

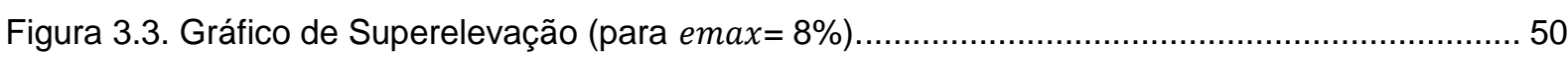

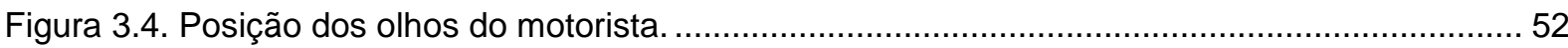

Figura 3.5. Seção transversal hipotética adotada em trecho curvilíneo. .............................................. 55

Figura 3.6. Esquema das barreiras adotadas com alturas de $0,81 \mathrm{~m}, 1,00 \mathrm{~m}$ e $1,40 \mathrm{~m}$.................... 57

Figura 3.7. Dimensões da barreira dupla New Jersey conforme ABNT. ........................................... 57

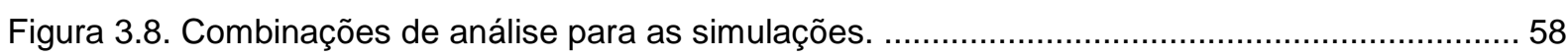

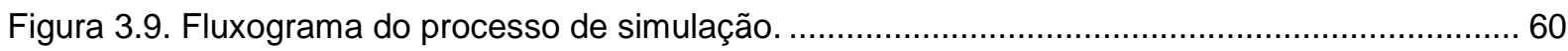

Figura 3.10. Curva vertical simulada ao invés de rampa constante para cenário com altura de barreira de $0,81 \mathrm{~m}$. 62

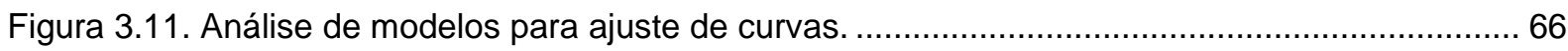

Figura 3.12. Grupo A - Resíduos - Histogramas e Curvas de distribuição normal de Gauss............. 80

Figura 3.13. Grupo B - Resíduos - Histogramas e Curvas de distribuição normal de Gauss............. 81

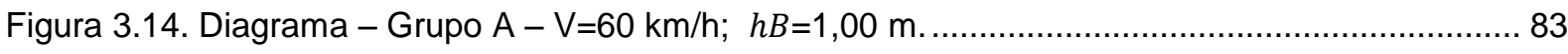

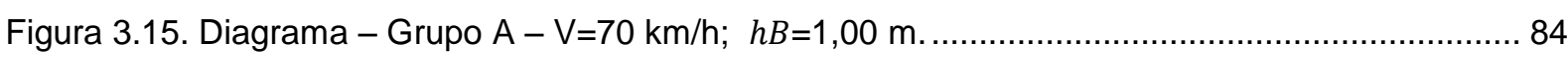

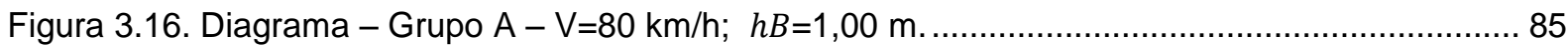

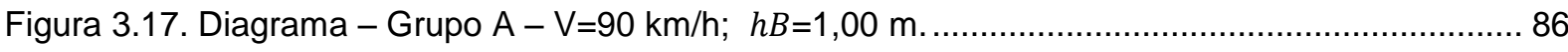

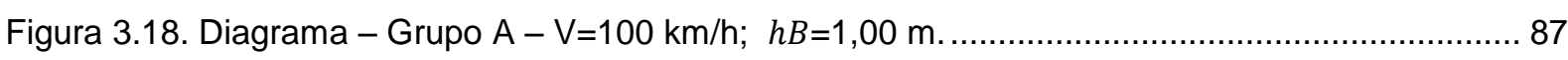

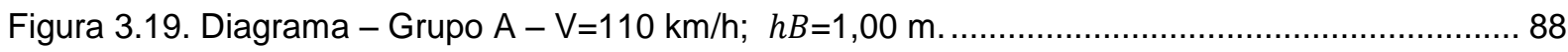

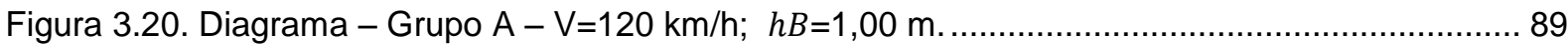

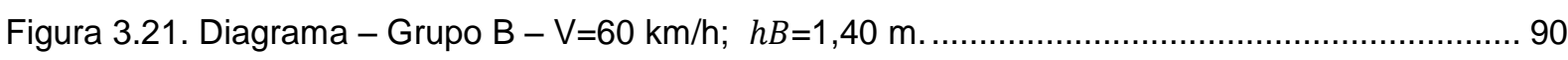

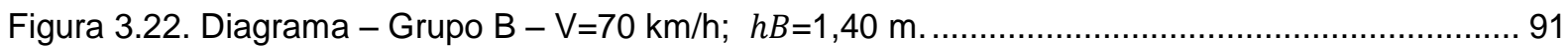

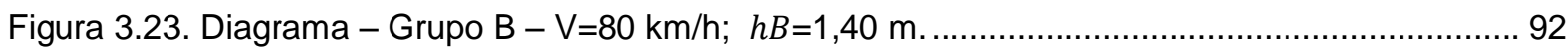

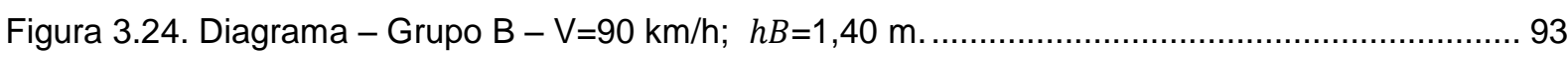

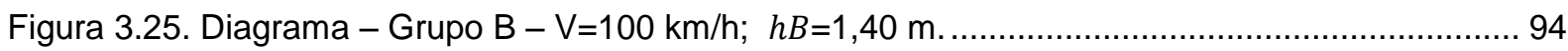

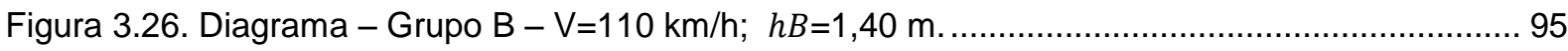

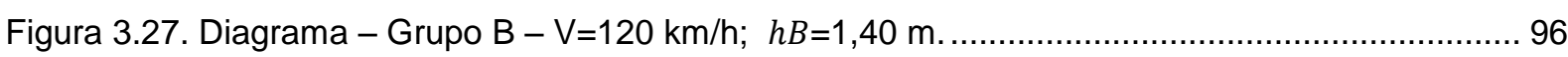


Figura 4.1. Delimitação de regiões de combinações válidas para a garantia da DVP analisada -

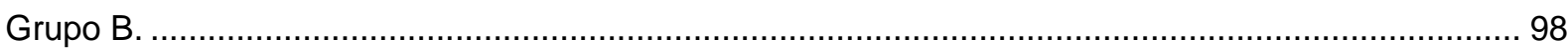

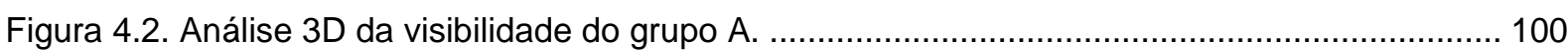

Figura 4.3. Delimitação de regiões de combinações válidas para a garantia da DVP analisada -

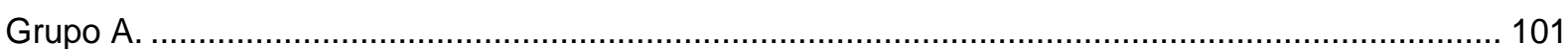

Figura 4.4. Modelo M - Afastamento lateral de objetos fixos em curvas horizontais........................ 103

Figura 4.5. Parâmetros envolvidos na transformação de referencial. .............................................. 103

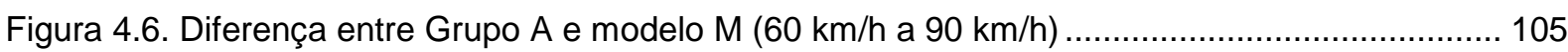

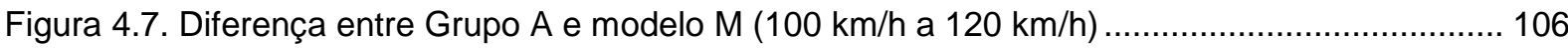

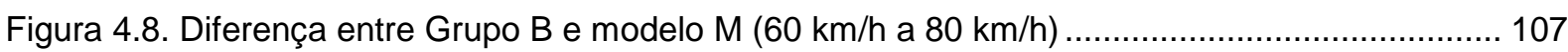

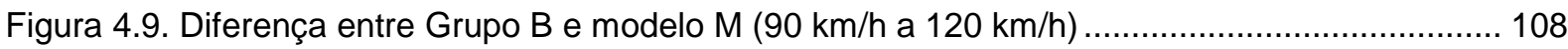

Figura 4.10. Diferenciação do uso da DVP como corda $(w)$ e arco.................................................. 109

Figura 4.11. Estudo gráfico sobre a adoção da DVP como corda da curva horizontal. ..................... 110

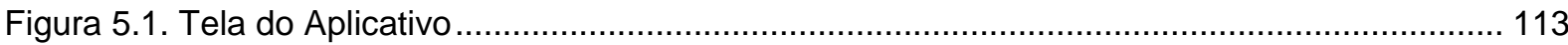

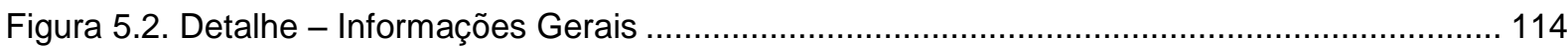

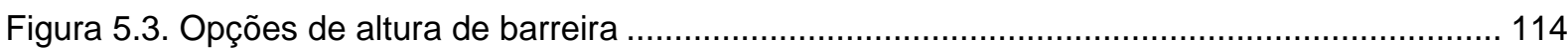

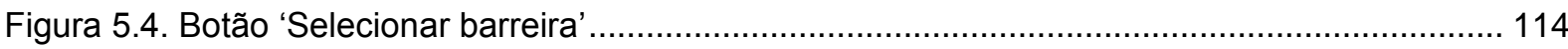

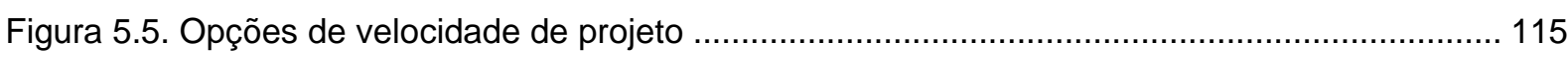

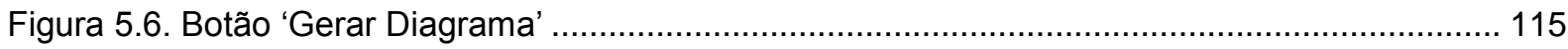

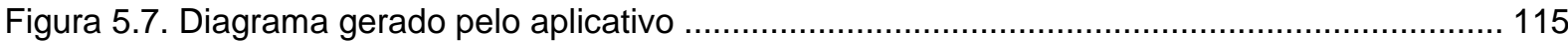

Figura 5.8. Opções de declividade de greide ............................................................................. 116

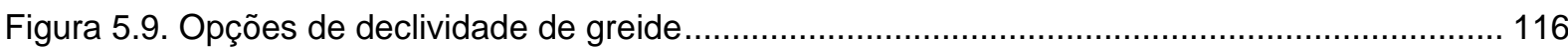

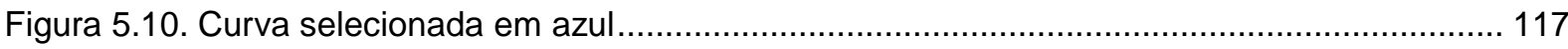

Figura 5.11. Etapa de estimativa de valor do afastamento lateral da barreira ................................ 117

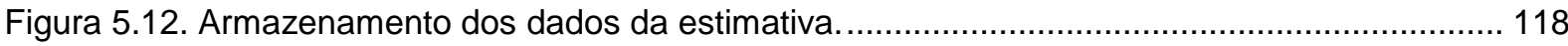

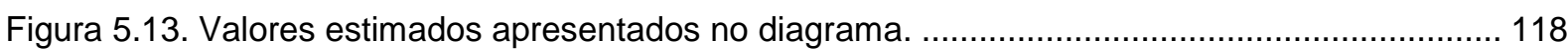

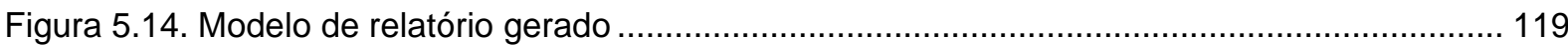

Figura 6.1. Trecho de análise entre BR-232 e BR-408 - Estudo de traçado Arco Metropolitano de

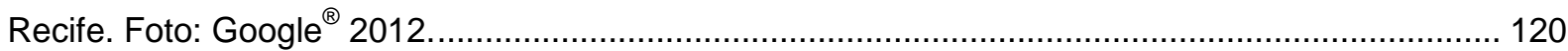

Figura 6.2. Curva A. Problema de Visibilidade - afastamento lateral da barreira de $0,60 \mathrm{~m} \ldots \ldots \ldots \ldots . . .121$

Figura 6.3. Curva A. Problema de Visibilidade - afastamento lateral da barreira de 1,30 m............ 122

Figura 6.4. Curva A. DVP garantida - afastamento lateral da barreira de $1,90 \mathrm{~m}$.......................... 123

Figura 6.5. Curva B. Problema de Visibilidade - afastamento lateral da barreira de 1,45 m............ 124

Figura 6.6. Curva B. DVP garantida - afastamento lateral da barreira de $1,85 \mathrm{~m}$............................ 124

Figura 6.7. Curva C. DVP garantida - afastamento lateral da barreira de $1,90 \mathrm{~m} \ldots \ldots \ldots \ldots \ldots \ldots \ldots \ldots \ldots . . . . . . . . . . . .126$

Figura 6.8. Curva C. Problema de Visibilidade - afastamento lateral da barreira de $1,70 \mathrm{~m} \ldots \ldots \ldots \ldots . .126$

Figura 6.9. Curva D. DVP garantida - afastamento lateral da barreira de $1,05 \mathrm{~m}$............................. 127

Figura 6.10. Curva D. Problema de Visibilidade - afastamento lateral da barreira de 0,95 m.......... 128

Figura 6.11. Curva E. DVP garantida - afastamento lateral da barreira de 1,55 m......................... 129

Figura 6.12. Curva E. Problema de Visibilidade - afastamento lateral da barreira de 1,45 m.......... 129 


\section{Lista de Tabelas}

Tabela 2.1. Valores de fator de atrito longitudinal pneu-pavimento - Espanha. ................................. 26

Tabela 2.2. Mínimas Distâncias de Visibilidade de Parada, veículos leves - Austrália. ...................... 27

Tabela 2.3. Afastamento Lateral sugerido no Roadside Design Guide........................................... 35

Tabela 3.1. Velocidades Diretrizes para projeto em função da classe da rodovia e tipo de relevo ..... 47

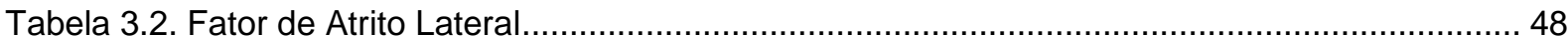

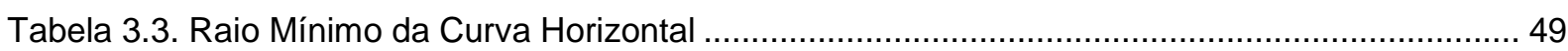

Tabela 3.4. Valores de superelevação utilizados nas simulações.................................................... 51

Tabela 3.5. Valores Mínimos de Projeto para DVP ........................................................................ 54

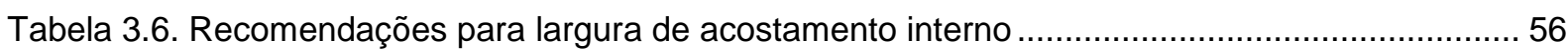

Tabela 3.7. Resultados considerando concordância com curva vertical côncava ............................... 63

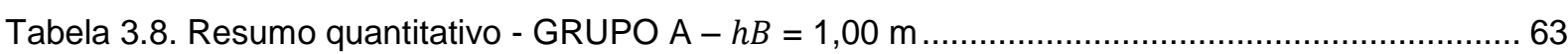

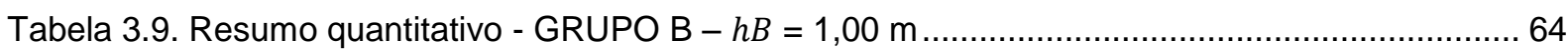

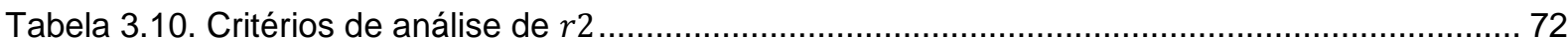

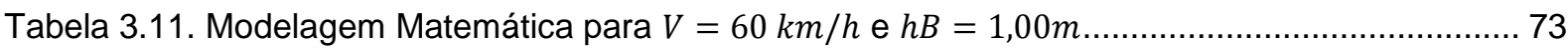

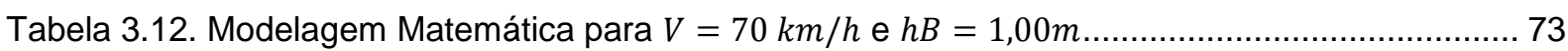

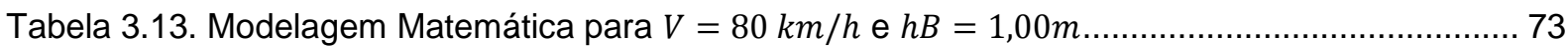

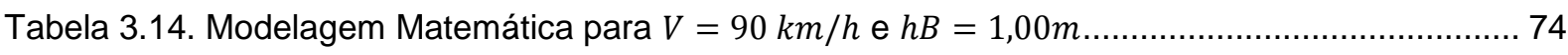

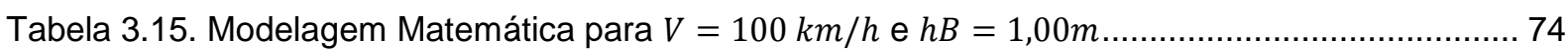

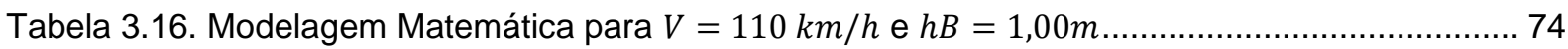

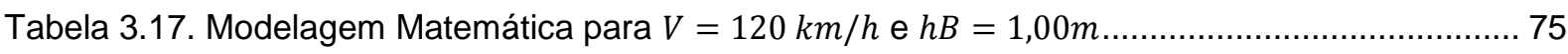

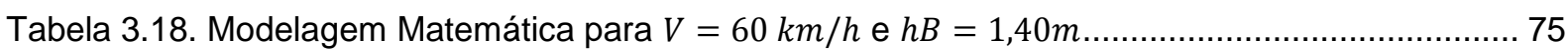

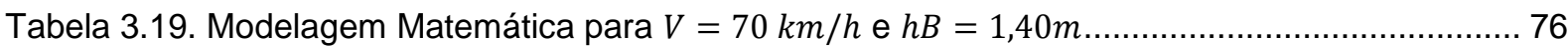

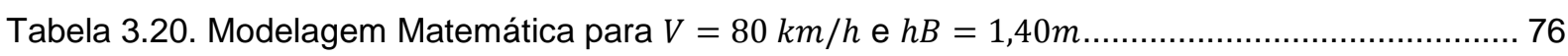

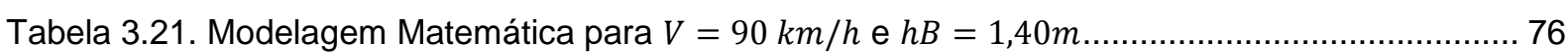

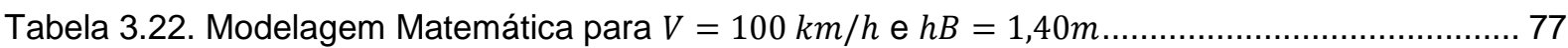

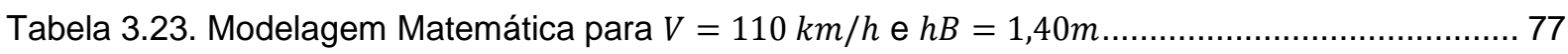

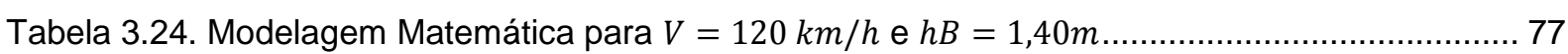

Tabela 3.25. Parâmetros estatísticos dos resíduos dos grupos A e B. ............................................... 78

Tabela 4.1. Exemplo - Consideração da DVP como corda da curva horizontal. ................................. 111

Tabela 4.2. Exemplo - Valores a serem inseridos no programa para gerar arcos com comprimento igual ao valor da DVP 


\section{Lista de Abreviaturas e Siglas}

$\begin{array}{ll}\text { AASHTO } & \text { American Association of State Highway and Transportation Officials } \\ \text { ABNT } & \text { Associação Brasileira de Normas Técnicas } \\ \text { DER-SC } & \text { Departamento de Estradas de Rodagem do Estado de Santa Catarina } \\ \text { DER-SP } & \text { Departamento de Estradas de Rodagem do Estado de São Paulo } \\ \text { DNER } & \text { Departamento Nacional de Estradas de Rodagem } \\ \text { DNIT } & \text { Departamento Nacional de Infraestrutura de Transportes } \\ \text { DVP } & \text { Distância de Visibilidade de Parada } \\ \text { DVTP } & \text { Distância de Visibilidade para Tomada de Decisão } \\ \text { DVU } & \text { Distância de Visibilidade de Ultrapassagem } \\ \text { TAC } & \text { Transportation Association of Canada } \\ \text { NCHRP } & \text { National Cooperative Highway Research Program } \\ \text { NBR } & \text { Norma Brasileira - ABNT } \\ \text { 2D } & \text { Bidimensional } \\ \text { 3D } & \text { Tridimensional } \\ \text { EPUSP } & \text { Escola Politécnica da Universidade de São Paulo } \\ \text { PTR } & \text { Departamento de Transportes da EPUSP } \\ & \end{array}$




\section{Lista de Símbolos}

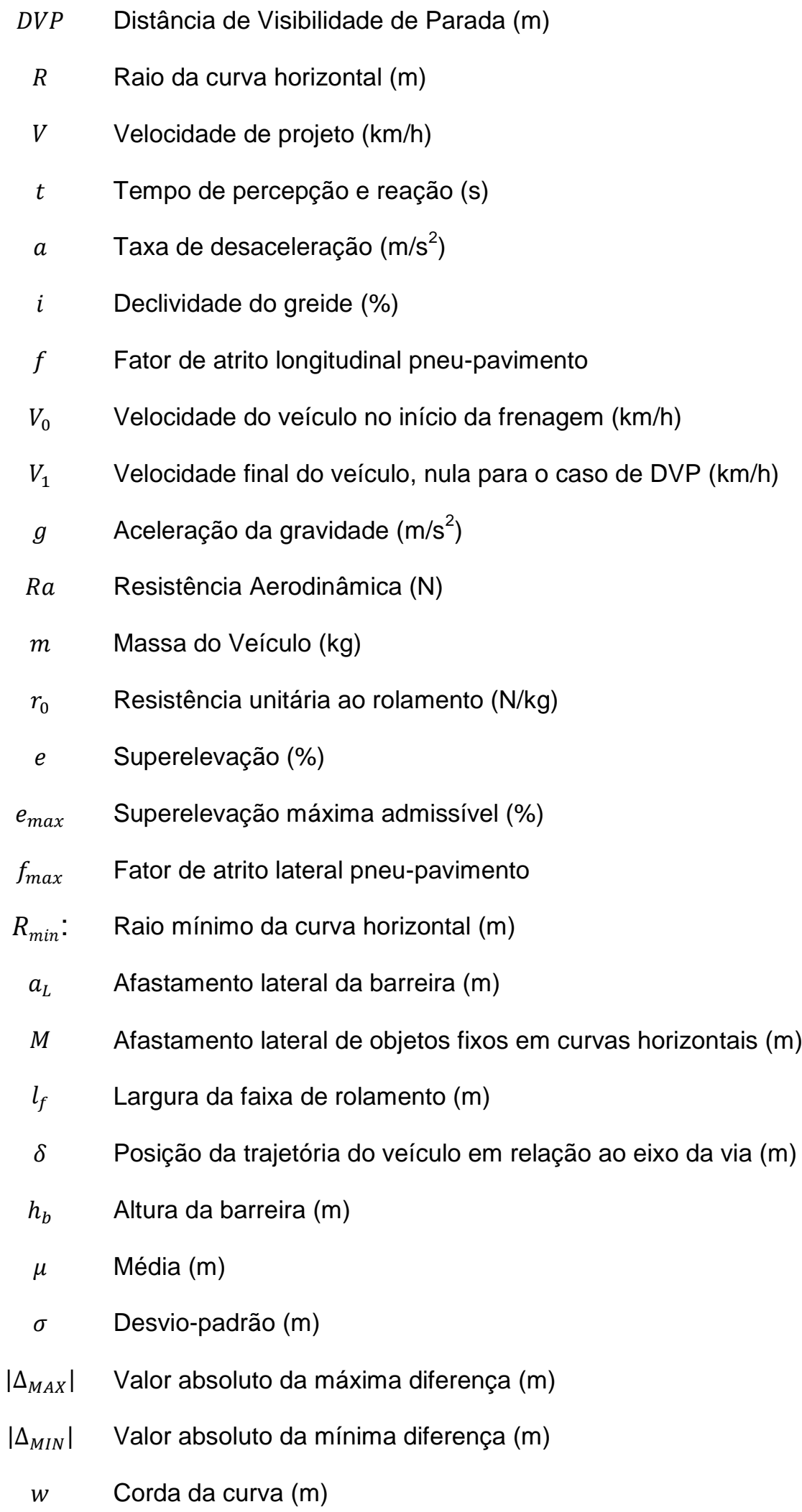




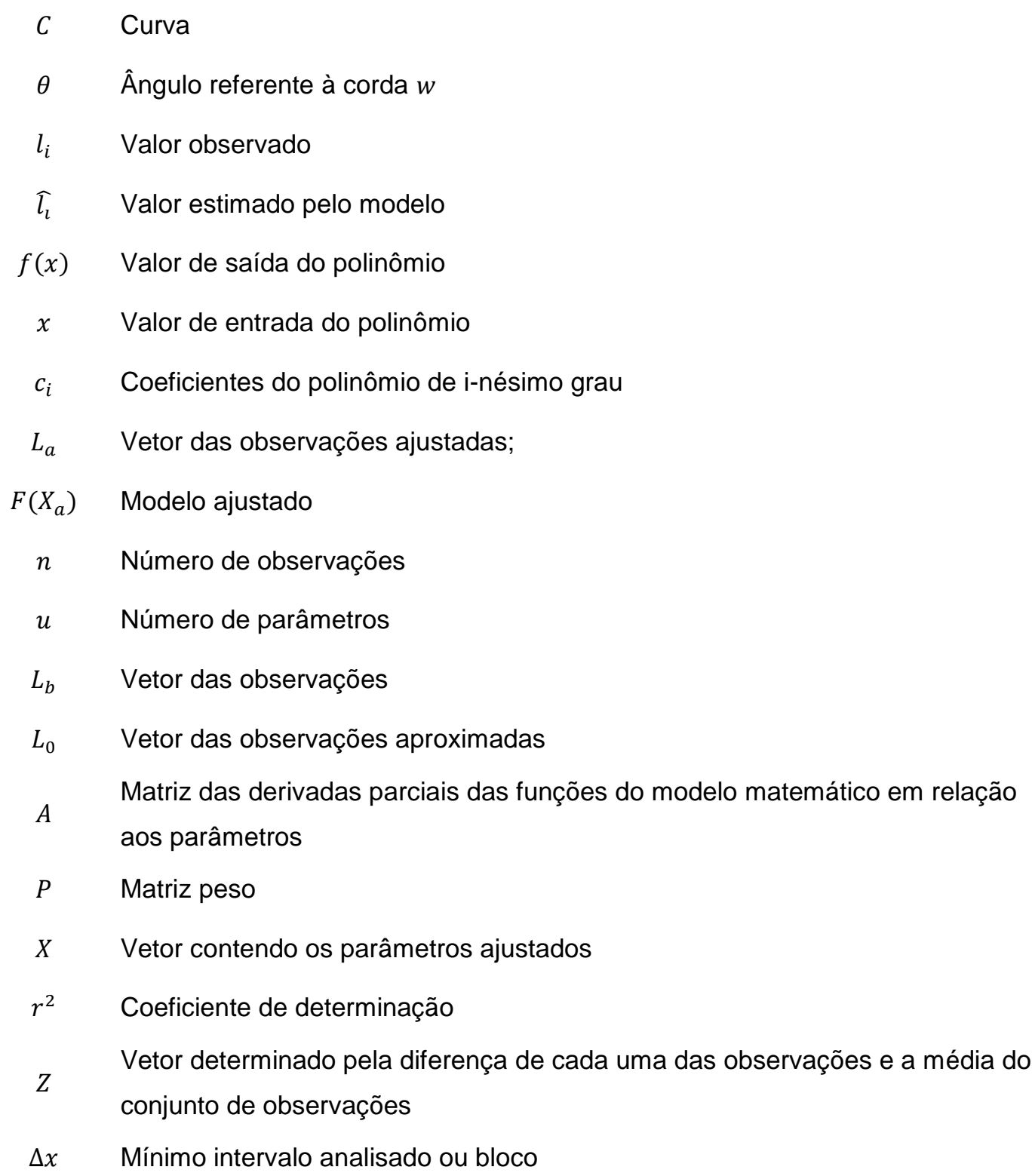




\section{SUMÁRIO}

1. INTRODUÇÃO ................................................................................17

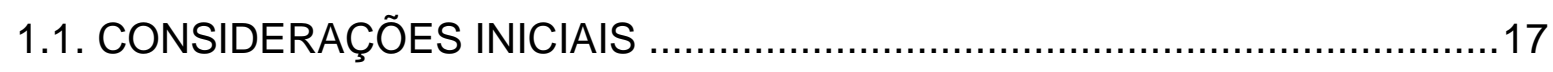

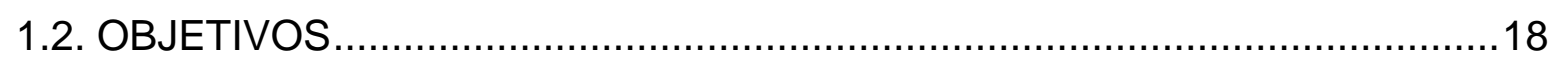

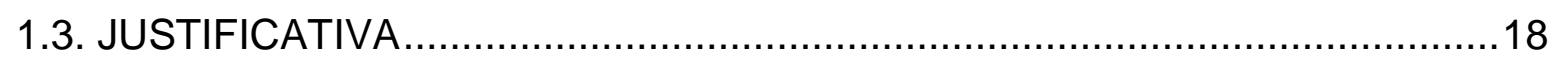

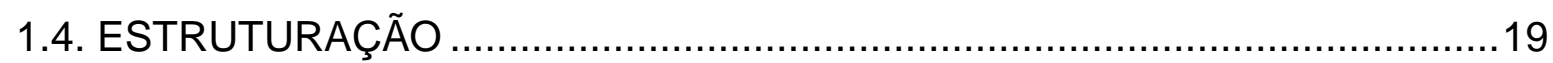

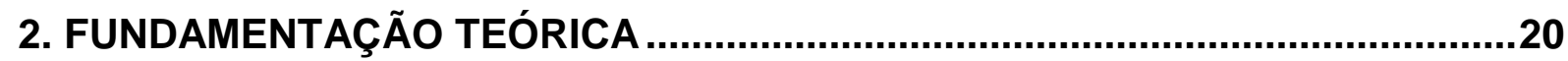

2.1. A VISIBILIDADE E O PROJETO GEOMÉTRICO .......................................20

2.1.1. Parâmetros Mensuráveis de Condições de Visibilidade de uma Rodovia22

2.1.2. Distância de Visibilidade de Parada (DVP) ..........................................23

2.1.2.1. Variações da parametrização da DVP em diversos países ...............25

2.1.3. Visualização, Modelagem e Análise de Visibilidade...............................29

2.2. Barreiras Rígidas - Aspectos Gerais .......................................................

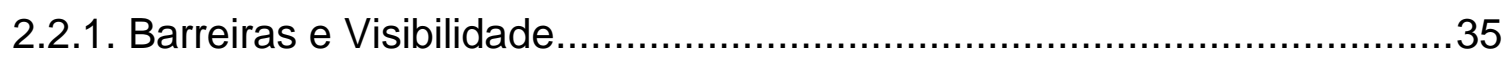

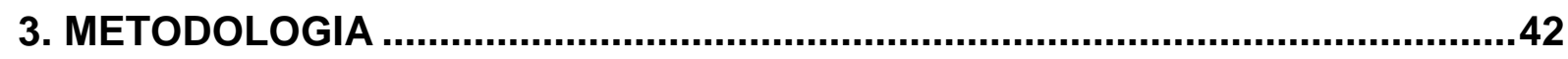

3.1. Apresentação do Problema …………………....................................... 42

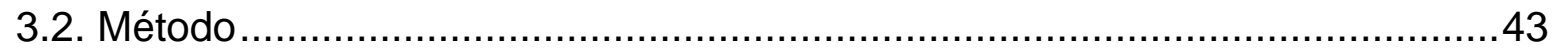

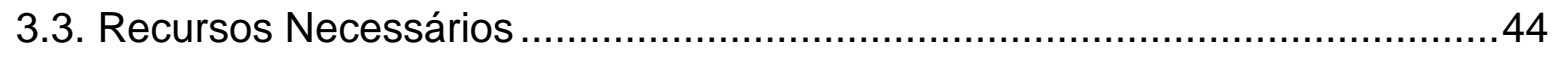

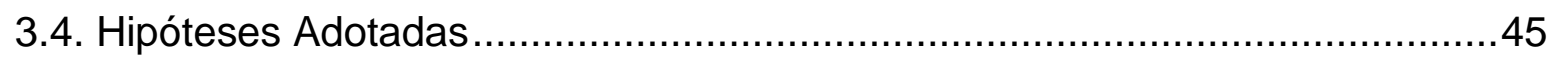

3.4.1. Tipo de Rodovia e de Geometria ...................................................... 46

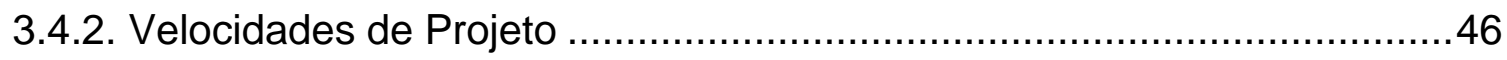

3.4.3. Raio da Curva Horizontal e Superelevação ............................................47

3.4.4. Altura dos olhos do motorista e altura do objeto …...................................51

3.4.5. Distância de Visibilidade de Parada ......................................................53 


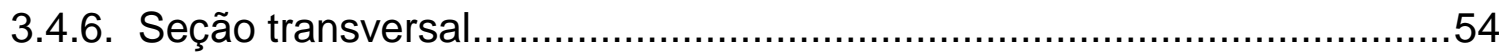

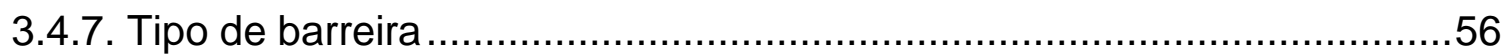

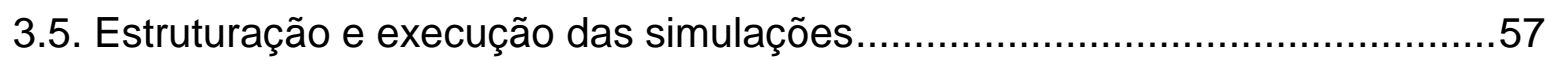

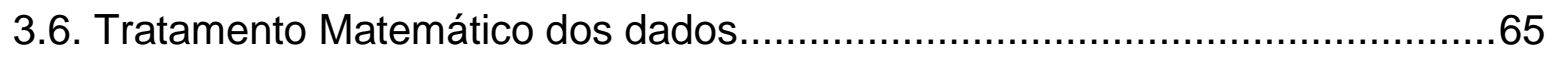

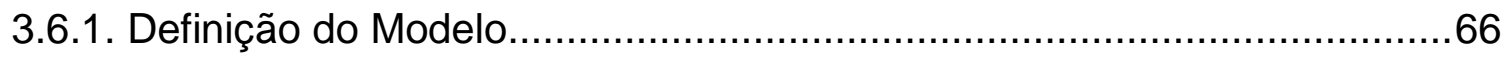

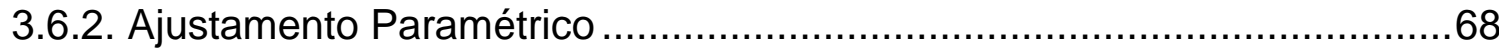

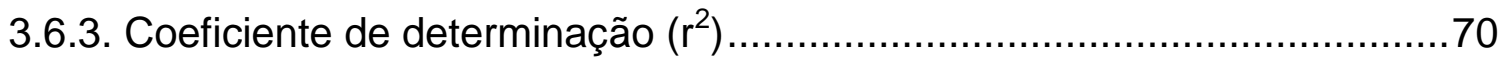

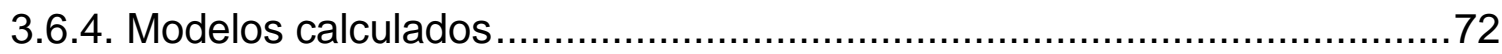

3.6.4.1. Modelos - Grupo A - altura da barreira igual a $1,00 \mathrm{~m} \ldots \ldots \ldots \ldots \ldots \ldots \ldots . . .72$

3.6.4.2. Modelos - Grupo B - altura da barreira igual a $1,40 \mathrm{~m}$......................75

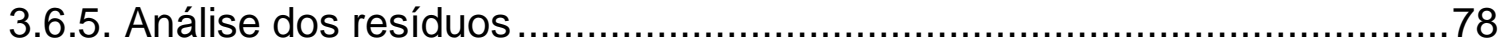

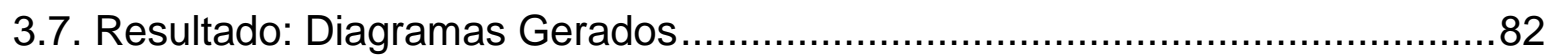

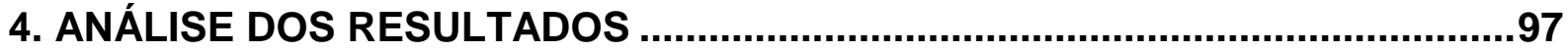

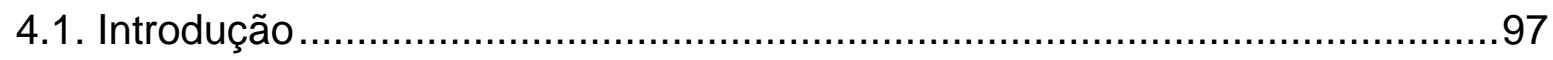

4.2. Comparação dos resultados com o modelo de afastamento de objetos fixos em curvas horizontais $(M)$ presente nas normas nacionais ..............................102

4.3. Funcionamento da Ferramenta de Análise Utilizada - AutoCAD ${ }^{\circledR}$ Civil3D ${ }^{\circledR}$..109

5. APLICATIVO

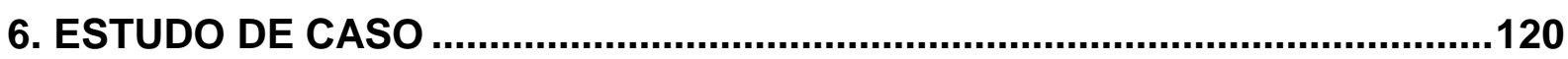

6.1. Análises do grupo A - Altura da barreira igual a 1,00 m............................121

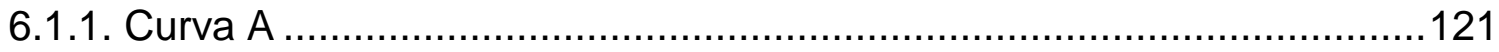

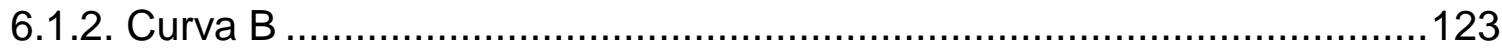

6.2. Análises do grupo B - Altura da barreira igual a $1,40 \mathrm{~m} \ldots \ldots \ldots \ldots \ldots \ldots \ldots \ldots \ldots \ldots . . . . .125$

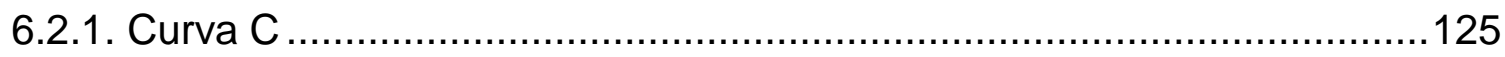

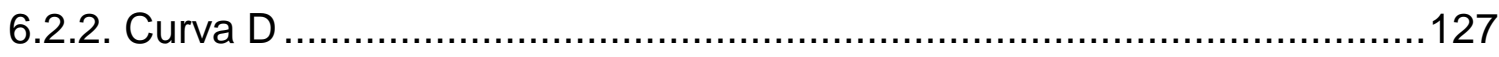


6.2.3. Curva E 128

7. CONCLUSÕES E RECOMENDAÇÕES .131 REFERÊNCIAS BIBLIOGRÁFICAS. 135

ANEXO I - DADOS BRUTOS DAS SIMULAÇÕES .140

ANEXO II - GRÁFICOS DE RESÍDUOS .148

ANEXO III - LINHAS CÓDIGO DO APLICATIVO. 163 ANEXO IV - APLICATIVO (CD-ROM) .185 


\section{INTRODUÇÃO}

\subsection{CONSIDERAÇÕES INICIAIS}

O uso de barreiras rígidas como separadores físicos em rodovias bidirecionais é recorrente em estradas nacionais. Nas regiões serranas, por exemplo, a adoção destes separadores ao invés de canteiros centrais é uma solução para as limitações físicas da plataforma da via. O mesmo ocorre nos processos de duplicação, em que o espaço físico disponível para o desenvolvimento do projeto é restrito. A inserção de novos elementos - neste caso barreiras rígidas - em projetos existentes ou em desenvolvimento gera novas preocupações e cuidados nos quesitos de qualidade e segurança, principalmente no que tange às condições de visibilidade para o motorista. O motorista, quando dispõe de uma distância de visibilidade adequada, tem condições de captar as informações sobre a via e sobre o tráfego, interpretá-las, imprimir ao veículo trajetória e velocidade adequadas, tomar decisões a tempo e com segurança, e inclusive ser capaz de imobilizar o veículo ou mesmo realizar outro tipo de manobra adequado quando surge algum obstáculo inesperado à sua frente (DER-SP, 2006). Sendo assim, para análises de visibilidade significativas, é necessário considerar a altura dos olhos do motorista e altura do objeto, que represente uma situação de perigo conforme recomendações e manuais vigentes.

Todavia, o posicionamento de dispositivos deve atender às suas funções específicas, como segurança e sinalização, concomitantemente com a manutenção da visibilidade ao longo de toda a extensão da via. Logo, as interferências da composição geométrica de todos os elementos envolvidos devem ser analisadas e consideradas, visando conciliar funcionalidade com os padrões mínimos de visibilidade necessários.

Neste contexto, o intuito deste estudo foi investigar o posicionamento de barreiras rígidas para que não ocorram interferências na distância de visibilidade de parada necessária ao motorista durante o tráfego em determinada via. $O$ cenário escolhido 
para análise são trechos de curvas à esquerda, onde a barreira tem maior probabilidade de obstruir a visibilidade, quando utilizada como separador físico. Aspectos inerentes às suas funções de segurança da barreira, como dimensionamento estrutural e tipo de material construtivo, foram desconsiderados. $A$ abordagem adotada neste trabalho foi 0 emprego de ferramentas gráficas computacionais para a geração de cenários hipotéticos.

\subsection{OBJETIVOS}

O objetivo principal deste estudo é investigar o posicionamento de barreiras rígidas centrais em rodovias de pista dupla considerando a visibilidade de projeto baseandose na análise de simulações gráficas tridimensionais. Devido às possibilidades de variações de projeto, hipóteses foram consideradas visando restringir o universo de estudo, admitindo-se duas vertentes: uma para barreiras baixas e outra para barreiras altas.

O artificio adotado na investigação foi construir modelos tridimensionais de projetos viários, em ambiente virtual, e sobre estes, interferir na parametrização para a compreensão da relação da barreira central com a visibilidade existente na via. Os dados foram posteriormente validados pelas normativas existentes e através de estudo de caso real. Além disto, toda informação gerada foi condensada em aplicativo próprio desenvolvido de modo a fornecer indicativos auxiliadores nas tomadas de decisões no projeto geométrico.

\subsection{JUSTIFICATIVA}

O conhecimento da interferência de elementos usualmente utilizados, como barreiras rígidas ou qualquer outra feição tridimensional, na visibilidade vêm subsidiar novas alternativas e auxiliar na tomada de decisões relacionadas ao 
projeto geométrico. A garantia de visibilidade ao trafegar em uma via têm relação direta na manutenção de padrões mínimos de segurança e dirigibilidade do motorista. Por isso, a visibilidade é tema recorrente na literatura, não sendo menos importante a conexão com o posicionamento de barreira sobre a via, onde inúmeros trabalhos são discutidos analisando o tipo de dispositivo, a capacidade de contenção e absorção de impactos e inclusive seu posicionamento na via. Hassan e Sarhan (2012), Arndt et al. (2010), Sanchez (1994) e Leisch (1989) são exemplos de trabalhos sobre este questionamento. A proposta foi de criar ferramentas para apoio à tomada de decisão nos projetos, disponibilizando indicativos no quesito do posicionamento da barreira e sua influência na Distância de Visibilidade de Parada (DVP).

\subsection{ESTRUTURAÇÃO}

O capítulo 2 sintetiza a fundamentação teórica inerente ao prospecto em estudo. No capítulo 3 é apresentada a metodologia adotada no estudo, que apresentam o detalhamento das simulações realizadas, abordando as hipóteses e o processo de execução, além do tratamento matemático ao qual os dados foram submetidos, e os diagramas gerados. A análise dos resultados é discutida no capítulo 4 . O capítulo 5 contempla o aplicativo desenvolvido, enquanto no capítulo 6 é tratado o estudo de caso usado na validação dos dados. Por fim, conclusões e recomendações são apresentadas no capítulo 7 . 


\section{FUNDAMENTAÇÃO TEÓRICA}

\subsection{A VISIBILIDADE E O PROJETO GEOMÉTRICO}

A visibilidade do motorista é um dos fatores mais importantes para a segurança e para a eficiência operacional de um veículo que trafega em qualquer via (Chou et al., 2010) . Fato é que o motorista precisa ter espaço livre suficiente para quando estiver em situação controversa (um obstáculo, por exemplo) ser capaz de imobilizar o veículo ou alterar sua trajetória, tendo consciência de sua ação. Além disso, deve-se atender a requisitos decorrentes das características do comportamento de parcela significativa dos motoristas e também do conjunto formado pelo veículo e pela pista (freios, suspensão, pneus, condições da superfície de rolamento), sobre determinadas condições (Pellegrini, 2006; DER-SP, 2006; DNER ${ }^{1}$, 1999).

As características do projeto geométrico são fatores determinantes na definição da condição de visibilidade existente (Ismail e Sayed, 2007). Esta é limitada pelas recorrentes mudanças de declividade e direção ao longo do desenvolvimento da via, com destaque para as curvas horizontais em trechos de corte e para as curvas verticais convexas. As curvas verticais côncavas apresentam restrições às condições de visibilidade da via no período noturno que, em geral, é definida como função da altura dos faróis dos veículos (Pellegrini, 2006; DER-SP, 2006).

No alinhamento horizontal, principalmente nos trechos de curvas, as restrições nas condições de visibilidade nem sempre resultam na fixação de padrões mínimos para o projeto de geometria, já que é possível minimizá-las - como, por exemplo, por meio do alargamento da plataforma de terraplenagem, ou pelo abatimento do ângulo

\footnotetext{
${ }^{1}$ O DNER foi extinto em 2001, com a reestruturação do sistema de transportes rodoviário, aquaviário e ferroviário, sendo substituído pelo atual DNIT (Departamento Nacional de Infraestrutura de Transportes). Fonte: BRASIL, 2001.
} 
de inclinação de taludes em região de corte. Reduções de velocidade são verificadas para curvas horizontais com pequenos raios de curvatura (Pellegrini, 2006; DER-SP, 2006). Em contrapartida, neste trabalho pretende-se intervir na disposição dos elementos da seção transversal como solução.

Adicionalmente, outro ponto a ser considerado é visto em estudo apresentado por Lamm et al. (1999) em que as condições de visibilidade têm influência na taxa de ocorrência de acidentes, cujos resultados são explicitados na Figura 2.1.

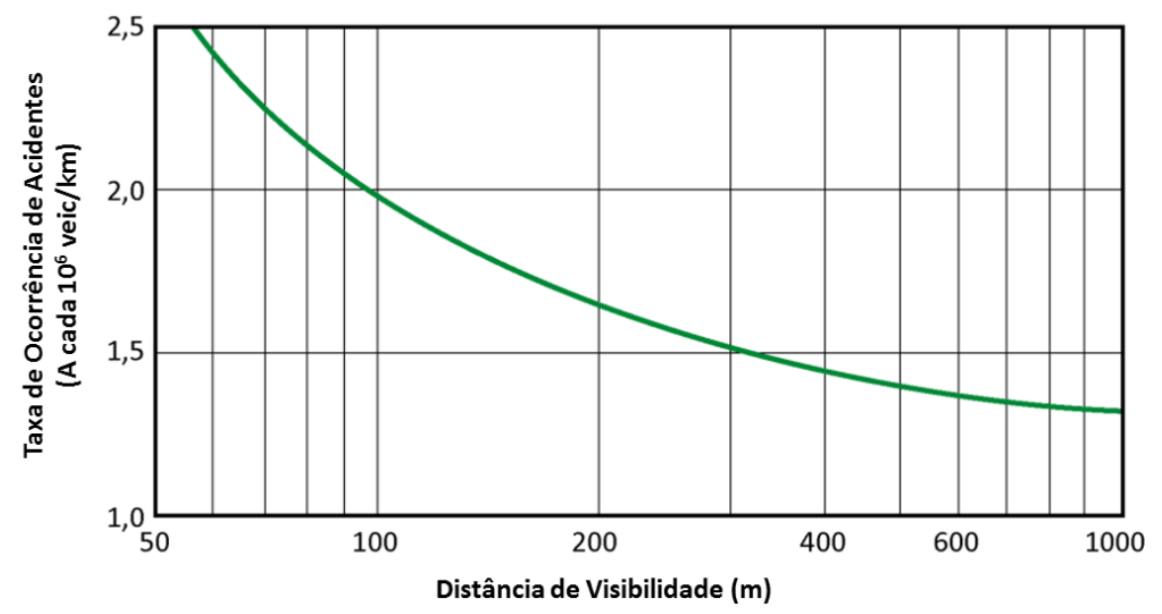

Figura 2.1. Taxa de Ocorrência de Acidentes em função da Distância de Visibilidade disponível.

Fonte: Adaptado de Lamm et al. (1999)

Através da análise da Figura 2.1 permite-se afirmar que a taxa de ocorrência de acidentes decresce à medida que a distância de visibilidade aumenta. Além disso, os autores observaram que:

- Altas taxas de ocorrência de acidentes estão relacionadas a visibilidades inferiores a $100 \mathrm{~m}$;

- Para visibilidades entre 100 e 200 m, as taxas de acidentes são 25\% inferiores àquelas verificadas para visibilidade inferior a $100 \mathrm{~m}$;

- Para visibilidades acima de 200 m é menor a taxa de redução de ocorrência de acidentes. 
Desta forma é necessário, sempre que possível, que o projeto geométrico de uma rodovia vise à maximização das distâncias de visibilidade do motorista, em prol de critérios de segurança, qualidade e conforto desde que a haja espaço físico e viabilidade econômica para tal.

\subsubsection{Parâmetros Mensuráveis de Condições de Visibilidade de uma Rodovia}

Os parâmetros mensuráveis das condições de visibilidade considerados na elaboração de projetos geométricos de via se resumem à Distância de Visibilidade de Parada (DVP), à Distância de Visibilidade de Ultrapassagem (DVU) e à Distância de Visibilidade para Tomada de Decisão (DVTD). A primeira possui caráter obrigatório no qual o projeto deve garantir um valor mínimo a ser atendido em qualquer ponto da rodovia (AASHTO, 2011a). As demais possuem valores recomendados que, quando atendidos, elevam o padrão técnico da via.

A Distância de Visibilidade de Parada é definida como a soma de duas outras distâncias: a distância percorrida pelo veículo desde o instante que o motorista avista um obstáculo que necessite de parada e acione o sistema de freio (distância de percepção e reação) e a distância percorrida pelo veículo desde o início do acionamento dos freios até a parada total do veículo (distância de frenagem).

A Distância de Visibilidade de Ultrapassagem, por sua vez, é a extensão necessária para a realização de uma manobra de ultrapassagem de um veículo com maior velocidade sobre outro veículo que circula com velocidade inferior em rodovias bidirecionais de pista simples.

Por último, têm-se a Distância e Visibilidade para Tomada de Decisão que é a distância necessária para que um motorista tome consciência de uma situação potencialmente perigosa, inesperada ou difícil de perceber, avalie o problema encontrado, selecione o caminho a seguir e a velocidade a empregar e execute a manobra necessária com eficiência e segurança (DNER, 1999). 


\subsubsection{Distância de Visibilidade de Parada (DVP)}

A Distância de Visibilidade de Parada é parâmetro importante no projeto, que interfere no projeto da rodovia, já que seus requisitos afetam todos os elementos geométricos envolvidos - alinhamentos horizontal e vertical, além da seção transversal (Neuman, 1989).

Conforme mencionado, a Distância de Visibilidade de Parada é definida como a soma de duas outras distâncias - a distância de percepção e reação e a distância de frenagem. Em síntese, a DVP é expressa na composição de duas parcelas:

$$
D V P=d_{1}+d_{2}
$$

Em que

$$
\begin{aligned}
& d_{1} \text { : distância de percepção e reação; e } \\
& d_{2} \text { : distância de frenagem; }
\end{aligned}
$$

A distância de percepção e reação $\left(d_{1}\right)$ usualmente é determinada em função de apenas dois parâmetros: a velocidade de projeto e o tempo de percepção e reação. O tempo de percepção e reação deve ser o tempo necessário para o motorista enxergar o objeto e discernir se o mesmo está imóvel, ou movendo-se lentamente, baseando-se em outros elementos da rodovia. Adota-se o tempo de 2,5 s nas normas nacionais, sem distinção da velocidade de projeto considerada, em concordância com AASHTO (2011a). Porém, alguns manuais e normas consideram que o tempo de percepção e reação é variável, sendo reduzido à medida que a velocidade de projeto aumenta, pelo fato que a atenção exercida pelo motorista em situações de grandes velocidades é maior. A segunda parcela, a distância de frenagem $\left(d_{2}\right)$ possui uma maior gama de variação: podem ser considerados parâmetros do projeto bem como parâmetros do veículo. A formulação considerada 
neste trabalho para o cálculo da Distância de Visibilidade de Parada é a mesma adotada pelo Green Book ${ }^{2}$ da AASTHO (2011a) e pelo DER-SP (2006), em que:

$$
D V P=0,278 \times V \times t+\frac{V^{2}}{254 \times\left(\left(\frac{a}{9,81}\right)+i\right)}
$$

Onde
DVP: Distância de Visibilidade de Parada (m);
$V$ : Velocidade de projeto $(\mathrm{km} / \mathrm{h})$;
$t$ : Tempo de percepção e reação (s);
$a$ : Taxa de desaceleração $\left(\mathrm{m} / \mathrm{s}^{2}\right) ; \mathrm{e}$
$i$ : Declividade do greide (\%);

Além de escolher um modelo para o cálculo da DVP, as análises de visibilidade precisam considerar o fato de que o motorista deve enxergar um objeto a uma dada distância necessária. Logo, sempre é necessário definir (a) uma distância mensurável - neste caso a DVP, (b) as características da posição do motorista e (c) características inerentes ao objeto que se pretende visualizar. Neste trabalho, em concordância com os valores recomendados por AASHTO (2011a), DNIT (2010) e DER-SP (2006), a altura dos olhos do motorista considerada é de 1,08 m enquanto a altura do objeto é de 0,60 m, posição média das lanternas traseiras de um veículo de passeio, que consistem no obstáculo com maior ocorrência de acidentes graves nas rodovias, quando na ausência de iluminação da via. Valores inferiores a 0,60 m, para AASTHO (2011a), poderiam aumentar os custos de implantação da estrada, já

\footnotetext{
${ }^{2}$ Green Book é como ficou conhecida a publicação "A Policy on Geometric Design of Highways and Streets" da AASTHO - American Association of State Highway and Transportation Officials.
} 
que o traçado deveria ser adequado, além de que haveria dificuldades por parte do motorista em detectar objetos desta dimensão sobre a via. O subitem a seguir (2.1.2.1) apresenta resumo sobre outros valores e modelos adotados em diversos países e manuais para o cálculo da DVP.

2.1.2.1. Variações da parametrização da DVP em diversos países

O cálculo da DVP não é unificado entre as normas e manuais de diversos países e instituições relacionadas com a área de transportes. As considerações sobre parâmetros, formulações e valores assumidos restringem-se ao ambiente de cada país, com características climáticas, de frota e normativas específicas. Duas vertentes são observadas: (1) os modelos baseados na parametrização americana, também empregados no Brasil e (2) os modelos adotados na Europa e Canadá.

A formulação adotada pela AASHTO (2011a) nos EUA e amplamente difundida nas referências em âmbito nacional foi apresentada no item anterior. Tanto o modelo quanto parâmetros para o cálculo de DVP foram adotados como referência para este trabalho, devido à difusão nos projetos geométricos em âmbito nacional.

Dentre as referências pesquisadas, os países Espanha, Austrália, Canadá e França, apresentam formulação da DVP similar, que podendo ser sintetizada por:

$$
D V P=\frac{V \times t}{3,6}+\frac{V^{2}}{254 \times(f+i)}
$$

Onde

DVP: Distância de Visibilidade de Parada $(\mathrm{m})$;

$V$ : Velocidade de projeto $(\mathrm{km} / \mathrm{h})$;

t: Tempo de percepção e reação (s);

$a$ : Taxa de desaceleração $\left(\mathrm{m} / \mathrm{s}^{2}\right)$; 
$i$ : Declividade do greide (\%);

$f$ : Fator de atrito longitudinal pneu-pavimento.

Esta formulação é o modelo simplificado para o cálculo da DVP. As diferenciações provêm da forma como parametrizar as correções devido à declividade do greide e dos valores das constantes utilizadas.

O Canadá adota o mesmo modelo (TAC, 1999) acima. Dentre os parâmetros adotados, têm-se o tempo de reação e percepção de 2,5 s e a altura dos olhos do motorista igual a 1,05 m. A altura do objeto é variável em função da aplicabilidade da DVP. No geral, recomenda-se o uso da altura do objeto igual a 0,38 $\mathrm{m}$, sendo conservador. Pode-se flexibilizar a parametrização adotando altura do objeto entre $0,10 \mathrm{~m}$ a $0,15 \mathrm{~m}$ que representa um objeto ${ }^{3}$ na via que acarrete risco ao motorista.

A Espanha, por exemplo, com informações baseadas na Norma 3.1-IC Trazado, de 2001, considera no cálculo os valores de fator de atrito longitudinal entre pneu e pavimento tabelados e definidos em função da velocidade, conforme Tabela 2.1, para o caso de veículos leves. A DVP assume ainda diferenciação em função da declividade do greide. Em declives a DVP é aumentada, em aclives, o contrário.

Tabela 2.1. Valores de fator de atrito longitudinal pneu-pavimento - Espanha.

\begin{tabular}{c|c|c|c|c|c|c|c|c|c|c|}
\hline $\mathrm{V}(\mathrm{km} / \mathrm{h})$ & 40 & 50 & 60 & 70 & 80 & 90 & 100 & 110 & 120 & 130 \\
$\mathrm{f}$ & 0,432 & 0,411 & 0,390 & 0,369 & 0,348 & 0,334 & 0,320 & 0,306 & 0,291 & 0,277 \\
\hline \multicolumn{8}{c|}{ Fonte: adaptado de Espanha (2001). }
\end{tabular}

\footnotetext{
${ }^{3}$ TAC(1999) relaciona o objeto deste porte como sendo representativo de pedras, árvores caídas, detritos de obras ou até mesmo uma pessoa caída sobre a via.
} 
O valor para a altura dos olhos do motorista é de 1,10 m, considerando que a altura do objeto é de apenas 0,20 m. O tempo de percepção e reação considerado é de 2,0 s. Outro ponto interessante, que consta na norma é o posicionamento do motorista e objeto no qual serão realizadas as verificações de visibilidade de parada. A verificação é feita sobre linha paralela ao eixo central da estrada, a 1,5 $\mathrm{m}$ da borda direita de cada faixa de rolamento, internamente.

Na Austrália utiliza-se a mesma formulação conforme consta em Austroads (2003). Todavia, os valores do fator de atrito pneu-pavimento diferem (Tabela 2.2) dos espanhóis, para o caso de veículos leves. A altura dos olhos do motorista é de 1,05 m. A altura do objeto é variável dependendo de cada situação. Usualmente adota-se o valor de $0,20 \mathrm{~m}$. A Tabela 2.2 foi construída atendendo a estas características e apresenta as correções na DVP em função da declinação do greide.

Tabela 2.2. Mínimas Distâncias de Visibilidade de Parada, veículos leves - Austrália.

\begin{tabular}{|c|c|c|c|c|c|c|c|c|c|c|}
\hline & \multicolumn{10}{c|}{ Velocidade $(\mathrm{km} / \mathrm{h})$} \\
\hline \multirow{2}{*}{$\boldsymbol{f}$} & 50 & 60 & 70 & 80 & 90 & 100 & 110 & 120 & 130 \\
\hline DVP * $(\mathrm{m})$ & 0,52 & 0,48 & 0,45 & 0,43 & 0,41 & 0,39 & 0,37 & 0,35 & 0,35 \\
\cline { 2 - 12 } & 54 & 71 & 91 & 114 & 140 & 170 & 205 & 245 & 280 \\
\hline $2 \%$ & 0 & -1 & -2 & -3 & -4 & -5 & -7 & -9 & -11 \\
\hline $4 \%$ & -1 & -2 & -4 & -5 & -7 & -9 & -13 & -17 & -21 \\
\hline $6 \%$ & -2 & -3 & -5 & -7 & -10 & -14 & -18 & -24 & -31 \\
\hline $8 \%$ & -3 & -4 & -7 & -9 & -13 & -17 & -23 & -30 & -38 \\
\hline$-2 \%$ & 0 & 1 & 2 & 3 & 4 & 6 & 7 & 10 & 14 \\
\hline$-4 \%$ & 2 & 3 & 4 & 6 & 8 & 12 & 16 & 21 & 27 \\
\hline$-6 \%$ & 3 & 4 & 7 & 10 & 13 & 18 & 25 & 34 & 44 \\
\hline$-8 \%$ & 4 & 6 & 9 & 13 & 19 & 26 & 36 & 48 & 62 \\
\hline
\end{tabular}

${ }^{*}$ Considera-se a altura dos olhos do motorista de $1,05 \mathrm{~m}$, a altura do objeto de $0,20 \mathrm{~m}$ e $\mathrm{o}$ tempo de reação e percepção de 2,5 s. Fonte: Adaptado de Austroads (2003). 
Com formulação simplificada ${ }^{4}$, a Alemanha adota como parâmetros a altura dos olhos do motorista em um veículo leve é entre 1,00 m a 1,15 m e altura do objeto de até $0,45 \mathrm{~m}$ para altas velocidades. O tempo de percepção e reação, por sua vez, é de $2,0 \mathrm{~s}$.

Por fim, Sétra (2006) apresenta resumo dos principais parâmetros geométricos para o projeto de vias na França. Em relação à DVP, a altura dos olhos do motorista a ser considerada é de $1,0 \mathrm{~m}$ transladada de $2,0 \mathrm{~m}$ da borda direita da faixa de rolamento. O objeto considerado tem altura mínima de $0,35 \mathrm{~m}$, podendo ser reduzido para $0,15 \mathrm{~m}$ em regiões onde há quedas de pedras. Em vias expressas, têm-se adotado o valor de 0,60 $\mathrm{m}$ (altura das luzes traseiras) ao invés de 0,35m. O tempo de percepção e reação é variável. Assume o valor de 2,0 s para velocidades inferiores a $100 \mathrm{~km} / \mathrm{h}$ e $1,8 \mathrm{~s}$ para velocidades superiores a este limite.

Na Itália, aprovada em 2001, a Norme Funzionali e Geometriche per la Costruzione delle Strade apresenta fórmula complexa para o cálculo da DVP:

$$
D V P=\frac{V_{0}}{3,6} \times t-\frac{1}{3,6^{2}} \int_{V_{0}}^{V_{1}} \frac{V}{g \times\left[f \pm \frac{i}{100}\right]+\frac{R a}{m}+r_{0}} d V
$$

Onde

DVP: Distância de Visibilidade de Parada (m);

$V_{0}$ : Velocidade do veículo no início da frenagem $(\mathrm{km} / \mathrm{h})$;

$V_{1}$ : Velocidade final do veículo, nula para o caso de DVP $(\mathrm{km} / \mathrm{h})$;

t: Tempo de percepção e reação (s);

$i$ : Declividade do greide (\%);

\footnotetext{
${ }^{4}$ A Alemanha possui modelagem mais complexa que pode ser encontrada em Lamm et al. (1999).
} 
$g$ : Aceleração da gravidade $\left(\mathrm{m} / \mathrm{s}^{2}\right)$;

$R a$ : Resistência Aerodinâmica (N);

m: Massa do Veículo (kg);

$f$ : Fator de atrito longitudinal pneu-pavimento;

$r_{0}$ : Resistência unitária ao rolamento $(\mathrm{N} / \mathrm{kg})$.

O tempo de percepção e reação é variável em função da velocidade. À medida que a velocidade cresce, o tempo de reação e percepção decresce, pois a atenção empregada por motorista é maior. A relação entre o tempo de percepção e reação $(t)$ e a velocidade $(V)$ é:

$$
t=2,8-0,01 \times V
$$

A altura dos olhos do motorista é de $1,10 \mathrm{~m}$ e a altura do objeto é de $0,10 \mathrm{~m}$.

\subsubsection{Visualização, Modelagem e Análise de Visibilidade}

Os projetos geométricos compreendem a elaboração de perfis horizontais, perfis verticais, perfis e seções transversais e longitudinais ao longo da extensão da obra viária. Devido a esta separação, há dificuldades em se visualizar o projeto integrado considerando suas peculiaridades técnicas e suas interferências sobre o meio. As técnicas de visualização tridimensional e modelagem começam a suprir tais dificuldades permitindo aos projetistas enxergarem o projeto final com objetividade. $\mathrm{Na}$ Engenharia de Transportes, a visualização pode ser compreendida como a representação estática ou simulação de informações espaciais e geométricas das condições reais ou alterações propostas em vias de transportes e seus impactos associados sobre seu entorno como maneira suficiente para expressar ao projetista a realidade da geometria do projeto desenvolvido e ao leigo a real extensão das melhorias (NCHRP, 2006). Além disto, seu uso permite subsidiar decisões de 
alterações no traçado, visando garantir melhores qualidades técnica e estética ao projeto viário (Hixon III, 2007).

O presente trabalho foi baseado em uma investigação gráfica - os resultados foram obtidos através da geometria do modelo e não por um equacionamento analítico. Esta abordagem é encontrada em diversos trabalhos sobre análises de visibilidade, concordância de alinhamentos ou prospectos das aplicabilidades da visualização no desenvolvimento de projetos, como visto em Sanchez (1994); Janikula e Garrick (2002); Han, Middleton e Clayton (2006); Kuhn e Jha (2010); Chou et al. (2010); Hassan e Sarhan (2012). O ganho ao se trabalhar com modelos é a compreensão do projeto como um todo, verificando como os elementos se relacionam entre si. $\mathrm{Na}$ análise de visibilidade, por sua vez, é possível verificar se a DVP é garantida ao longo de todo o trecho de análise, mensurando a amplitude de áreas sem obstrução ou ainda, quando for o caso, indicando áreas oclusas ao campo de visão do motorista.

A maior parte das normas e manuais vigentes indicam que as análises de distâncias de visibilidade devem ser efetuadas em projeções 2D, ou seja, através da verificação gráfica sobre os alinhamentos horizontal e vertical, separadamente (Ismail e Sayed, 2007).

Hassan, Easa e Abd EI Halim (1997) compararam análises 2D e 3D e notaram que as distâncias de visibilidade disponíveis podem ser subestimadas ou superestimadas quando o método empregado é bidimensional. A tendência indicada por pesquisadores é expandir as análises em 3D (Chou et al., 2010), impulsionada pelo aprimoramento computacional necessário (tanto em hardware quanto em software).

Atualmente no mercado, estão disponíveis programas que possuem módulos específicos para análise de visibilidade como o caso do AutoCAD Civil $3 D^{\circledR}$, Inroads ${ }^{\circledR}$ e $C L I P^{\circledR}$. Se conhecidos os valores para análise (a distância de visibilidade de parada e as características do motorista e do objeto), os programas verificam tridimensionalmente se a visibilidade mínima necessária é garantida ao longo de trecho da rodovia verificando as interseções da linha de visão do motorista com 
outros objetos do projeto ou do próprio terreno, simulados através de modelos digitais.

\subsection{Barreiras Rígidas - Aspectos Gerais}

O Manual de Projeto Geométrico do DNER, de 1999, apresenta a sucinta definição para barreira rígida:

"Estrutura rígida, indeformável, geralmente de concreto, disposta longitudinalmente à pista com o objetivo de impedir que veículos desgovernados saiam da plataforma, choquem-se com objetos fixos ou invadam outras pistas adjacentes, e, ainda, desejavelmente, de reorientar o veículo para a trajetória correta com o mínimo de dados para o motorista e passageiros. Também denominado separador físico rígido".

Por definição barreira é um dispositivo de segurança da via. Aspectos inerentes a esta função como tipo, dimensionamento estrutural, processo construtivo serão desconsiderados neste trabalho e a barreira será tratada como um elemento tridimensional que ocorre e interfere na visibilidade de uma rodovia. A barreira pode ser empregada como separador físico, geralmente em casos onde não é possível a implantação de canteiros centrais devido a limitações da plataforma, em casos de duplicação de rodovias, ou ainda como delimitadores longitudinais. Segundo a NBR 15486:2007, dispositivos de contenção central são definidos como dispositivos utilizados basicamente para separar o tráfego de passagem do tráfego local ou separar faixas exclusivas das faixas de uso geral (ABNT, 2007).

Na publicação Roadside Design Guide, da AASTHO (2011b), são encontradas descrições e aplicações dos diversos tipos de barreiras existentes. Usualmente são classificadas em três grupos: flexível, semirrígida e rígida. O parâmetro básico para 
esta classificação é o grau de deflexão decorrente do impacto (DER-SP, 2006). No caso de canteiros centrais, em geral, aplica-se barreiras do tipo rígido ${ }^{5}$ com diferentes perfis de configuração geométrica em sua seção transversal; pois apresentam baixa necessidade de manutenção em função de suas características e, por praticamente não sofrerem danos sob impacto dos veículos, são normalmente empregados em vias com elevados volumes de tráfego.

A escolha por canteiros centrais deve sobrepor à utilização das barreiras rígidas, principalmente em cenários de tráfego intenso e vias de alto padrão de qualidade. Muitas vezes, o emprego de barreiras ocorre simultaneamente com a existência do canteiro central, sendo conveniente a adoção da barreira em vias arteriais de tráfego rápido, pois fazem a separação real do tráfego além de mitigar travessias inadequadas de pedestres (DNIT, 2010). DER-SP (2006) apresenta ábaco (Figuras 2.2, 2.3 e 2.4) para auxiliar a escolha ou não do uso de barreiras elaborados pelo extinto DNER (atual DNIT), ABNT e AASTHO. No ábaco do DNER (1999), a necessidade da implantação de defensa ou barreira é definida em função da largura do canteiro central e do volume médio diário previsto para a via para os próximos 5 anos. São estipulados três casos possíveis, a necessidade ou não da implantação de barreira e casos onde a implantação fica a critério do projetista. Similar ao ábaco do DNER existe o apresentado na NBR 6971 apud DER-SP (2006), em que as variáveis envolvidas para a definição da necessidade ou não de barreiras são as mesmas (Figura 2.3).

O ábaco da AASHTO (Figura 2.4) indica que para canteiros com largura inferior a 10 $\mathrm{m}$, associados a elevados volumes de tráfego diário, deve-se obrigatoriamente instalar barreira. Além disso, o uso de barreira deve ser considerado em trechos que possuam histórico de acidentes com cruzamento total do canteiro. Para os demais casos, onde a instalação não é necessária ou é opcional, fica a cargo do projetista analisar a necessidade em função da geometria existente e da probabilidade de

\footnotetext{
${ }^{5}$ O tipo de barreira rígida mais difundido no Brasil são as de perfil New Jersey.
} 
acidentes, principalmente em regiões restritas, com curvas de raios horizontais pequenos associadas a acentuadas declividades.

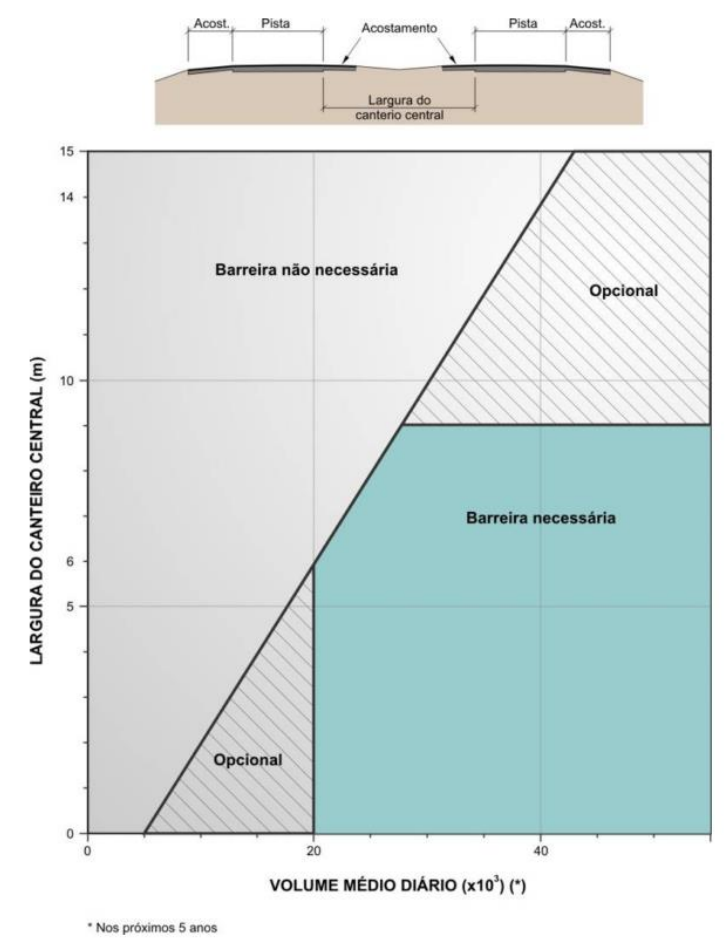

Figura 2.2. Necessidade de defensa ou barreira rígida em canteiros centrais - DNER (atual DNIT).

Fonte: DER-SP (2006).

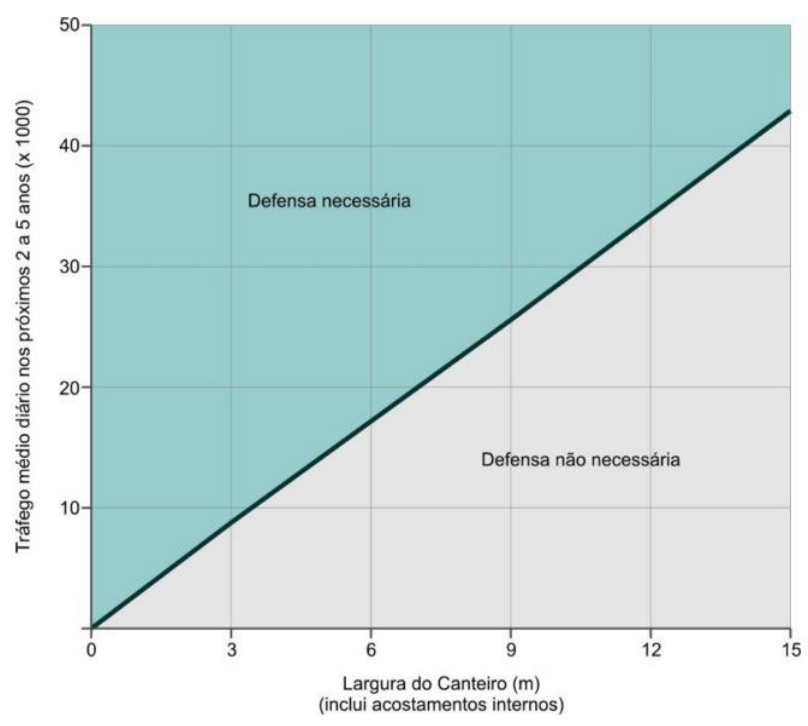

Figura 2.3. Necessidade de defensa ou barreira rígida em canteiros centrais - NBR 6971.

Fonte: DER-SP (2006) 

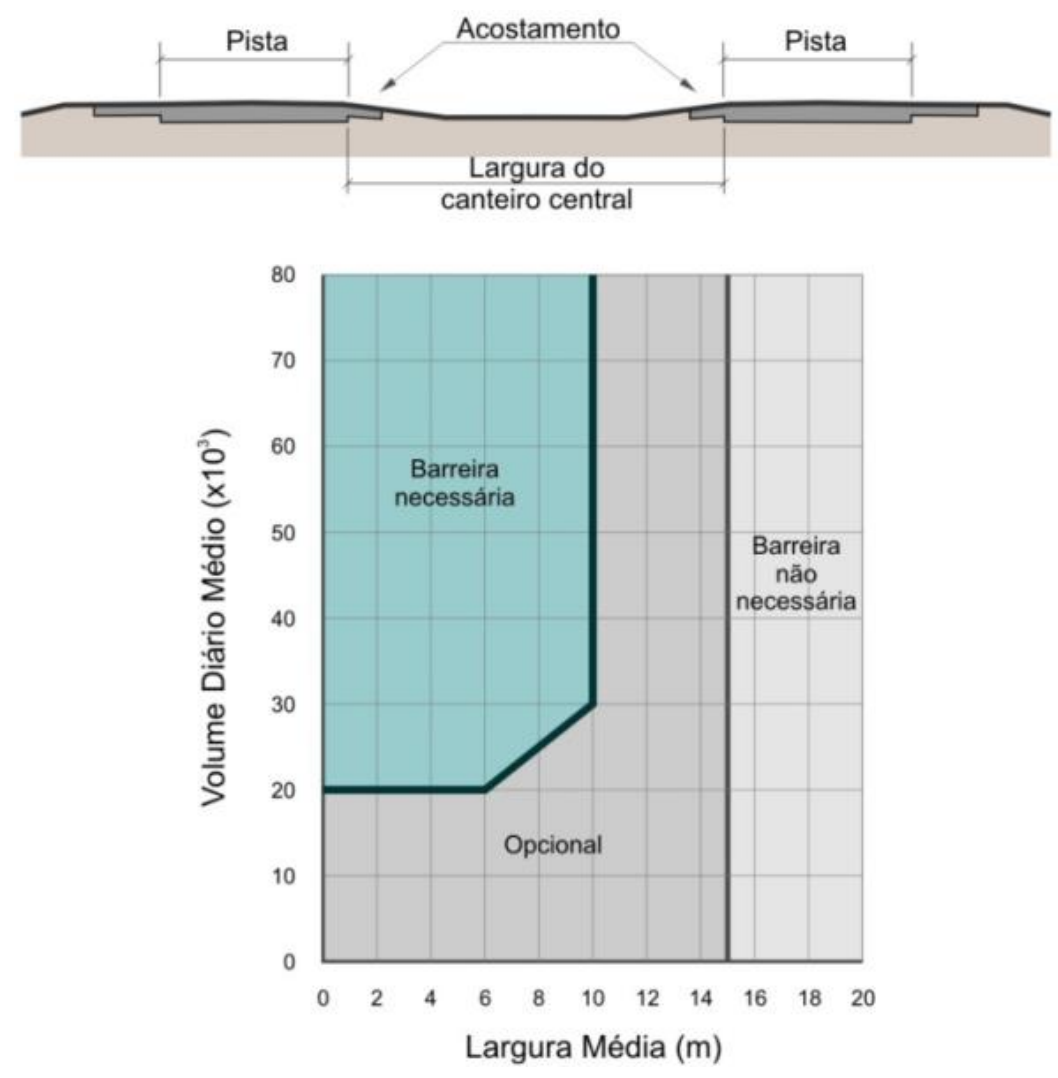

Figura 2.4. Necessidade de defensa ou barreira rígida em canteiros centrais - AASHTO.

Fonte: DER-SP (2006).

A barreira pode inferir na DVP, reduzindo-a, particularmente quando está situada no lado interno de uma curva (DNIT, 2010). AASHTO (2011b) apresenta várias considerações sobre o posicionamento de barreiras. $\mathrm{O}$ afastamento lateral, além do quesito visibilidade, deve ser imposto para que o motorista ao dirigir, não perceba a proximidade da barreira como um obstáculo e devido a isto, reduza a velocidade aplicada ou altere a trajetória do veículo. Os valores (Tabela 2.3) são relacionados com a velocidade de projeto e visam maior conforto e segurança no tráfego, além de auxiliar na manutenção de áreas limpas para a linha de visão de motorista. O termo apresentado para este afastamento lateral é linha de intimidação (do inglês shy line, segundo o Roadside Design Guide) ou linha de preocupação conforme a ABNT (NBR 15486:2007). 
Tabela 2.3. Afastamento Lateral sugerido no Roadside Design Guide.

\begin{tabular}{|c|c|}
\hline Velocidade de Projeto & Afastamento \\
\hline $130 \mathrm{~km} / \mathrm{h}$ & $3,7 \mathrm{~m}$ \\
\hline $120 \mathrm{~km} / \mathrm{h}$ & $3,2 \mathrm{~m}$ \\
\hline $110 \mathrm{~km} / \mathrm{h}$ & $2,8 \mathrm{~m}$ \\
\hline $100 \mathrm{~km} / \mathrm{h}$ & $2,4 \mathrm{~m}$ \\
\hline $90 \mathrm{~km} / \mathrm{h}$ & $2,2 \mathrm{~m}$ \\
\hline $80 \mathrm{~km} / \mathrm{h}$ & $2,0 \mathrm{~m}$ \\
\hline $70 \mathrm{~km} / \mathrm{h}$ & $1,7 \mathrm{~m}$ \\
\hline $60 \mathrm{~km} / \mathrm{h}$ & $1,4 \mathrm{~m}$ \\
\hline $50 \mathrm{~km} / \mathrm{h}$ & $1,1 \mathrm{~m}$ \\
\hline
\end{tabular}

Fonte: AASTHO (2011b).

Outro ponto enfatizado por AASHTO (2011b) é a aplicação dos valores da tabela anterior. $O$ uso é sugerido quando a extensão longitudinal da barreira é curta, em pontos isolados da via, onde a percepção do objeto pelo motorista é prejudicada. Em grandes extensões, é comum no trecho inicial de implantação da barreira posicionála a uma distância maior da faixa de rolamento, impondo uma aproximação gradual auxiliando a percepção, não sendo crítico o não uso dos valores da Tabela 2.3. Neste estudo, os valores sugeridos por AASHTO (2011b) não foram considerados para o estudo do afastamento lateral da barreira por causa de dois motivos: (1) que apenas serão considerados casos onde a barreira é presente em grandes extensões da via e (2) tais valores não são aplicados expressivamente em âmbito nacional.

\subsubsection{Barreiras e Visibilidade}

Leisch (1989) apresentou um dos primeiros questionamentos sobre o posicionamento de barreiras e a garantia de visibilidade nas vias, nos casos de curvas à esquerda. Para o autor, a solução é prover um afastamento variável entre faixa de rolamento e a barreira, quando posicionada na área central. Possui visão generalizada do tema e enfatiza que cada caso deve ser analisado isoladamente. 
Sanchez (1994) realizou estudo sobre o posicionamento de barreiras e a visibilidade, por meio de simulações utilizando modelos tridimensionais. A quantidade de modelos utilizada no estudo foi limitada e o foco do autor estava em mensurar a DVP tridimensionalmente ao invés de utilizar os métodos bidimensionais tradicionais da época. O autor ainda realizou algumas ponderações sobre os afastamentos da barreira, considerando variações no perfil vertical, em casos de presença de curvas.

Arndt et al. (2010) avançam com o problema do posicionamento de barreiras e visibilidade. Primeiramente, os autores listam as três técnicas mais empregadas como solução em trechos com barreiras:

1. Aplicar os modelos normais de DVP. Logo, o afastamento lateral da barreira necessário é ampliado para garantir a visibilidade (Figura 2.5). Porém, alguns dos efeitos negativos são as limitações construtivas (problemas de espaço e custo) e uso inadequado por parte dos motoristas. Se o refúgio for superior a 3,6 m (AASHTO, 2011a), a área pode ser usada para tráfego de veículos ou para manobras de ultrapassagem. Além disso, devido ao amplo afastamento entre a barreira e a faixa de rolamento, aumenta-se probabilidade de ocorrer choques de veículos com ângulos de incidência grandes contra a barreira, projetada inicialmente para absorver e redirecionar a trajetória veículos em impactos com ângulo de incidência menores.

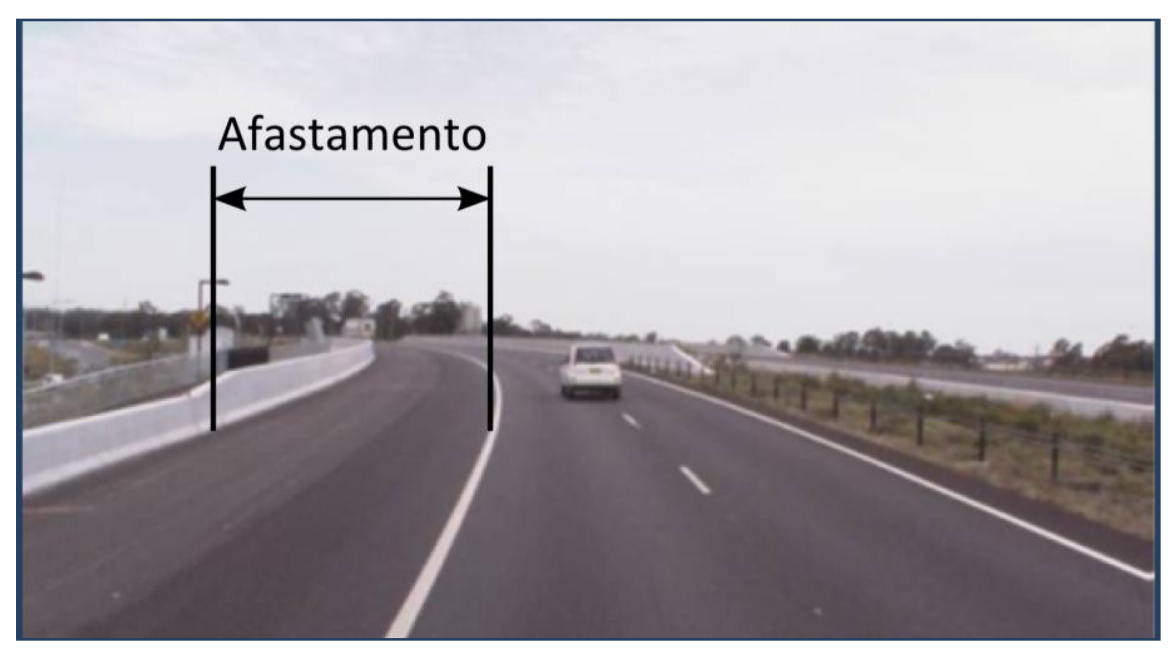

Figura 2.5. Aumento do afastamento lateral da barreira.

Fonte: Adaptado de Arndt et al. (2010). 
2. Desconsiderar as recomendações de DVP. A DVP é desprezada e apenas uma pequena faixa de segurança no trecho é adotada. Porém, diversos estudos apresentados por Arndt et al. (2010) e Lamm et al. (1999) indicam que a diminuição da visibilidade disponível ao motorista aumenta a ocorrência de acidentes. Os acidentes mais comuns são aqueles causados por objetos caídos de outros veículos (como caminhões) ou colisões traseiras, que em vias principais, ocorrem geralmente em conversões à esquerda.

3. Assumir velocidade de projeto inferior no trecho. Desta forma, a DVP necessária é inferior a do resto do projeto. Porém, adotar diversas velocidades em uma rodovia não é adequado, pois interfere mais nas velocidades operacionais envolvidas do que na garantia de distâncias de visibilidade adequadas.

Como solução, os autores apresentam um novo critério que consiste basicamente em utilizar os modelos de distâncias de visibilidade, com parâmetros menos conservadores, porém mais realistas. Algumas das alterações propostas são: o aumento da altura do objeto e da taxa de desaceleração, a redução da velocidade considerada, diminuição do tempo de percepção e reação em rodovias de alto padrão. Para ilustrar, este novo critério foi empregado para dimensionar o refúgio entre a faixa de rolamento e barreira em estudo de caso. O cenário foi trecho de curva horizontal à esquerda $(R=170 \mathrm{~m})$ em declive $(i=-3 \%)$ delimitada por barreiras rígidas de altura de 1,4 $\mathrm{m}$. A condição de análise foi a manutenção da DVP para veículo leve, no trecho, assumindo a velocidade de $70 \mathrm{~km} / \mathrm{h}$. Para os modelos tradicionais uma DVP de $81 \mathrm{~m}$ é necessária e, portanto, um refúgio de 2,7 m de largura; para o novo critério a DVP seria de $68 \mathrm{~m}$ e um refúgio de 1,2 $\mathrm{m}$ seria suficiente. A redução indica resultados satisfatórios na comparação entre os modelos tracionais e o novo critério proposto.

Este estudo foi incorporado às normas australianas (Austroads, 2010), como item específico que trata dos requisitos de distância de visibilidade em curvas horizontais quando na presença de barreiras, muros de contenção ou estruturas de pontes. Segundo Austroads (2010) quando há visibilidade sobre a barreira, deve-se prover 
um afastamento lateral mínimo de 2,50 m até a faixa de rolamento interna da curva, quando analisado a DVP para veículo leve. Para veículos pesados, o afastamento mínimo é de $3,50 \mathrm{~m}$. Em casos onde não é possível a visibilidade, as normas sugerem o estudo de novos traçados horizontal e vertical de modo que o problema minimizado ou solucionado quando possível.

O extinto Departamento de Estradas de Rodagem de Santa Catarina (DER-SC) ${ }^{6}$, na publicação "Diretrizes para Concepções de Estradas" de 2000, também contém tópico dedicado à garantia de obtenção de DVP para curvas à esquerda em pistas de único sentido, similar ao proposto neste estudo, quando na presença de objetos contínuos laterais. A posição do motorista e do objeto é de 1,80 $\mathrm{m}$ da borda esquerda da faixa de rolamento. O texto correlaciona a DVP com diversas velocidades e distancias existentes considerando efeitos de declividade do greide e raio da curva horizontal na forma de ábaco (Figura 2.6), onde é possível determinar o afastamento que deve ter um obstáculo visual em relação à borda da faixa de rolamento esquerda para que seja cumprida a condição de visibilidade. Maiores detalhes da concepção do ábaco não são citados no documento.

\footnotetext{
${ }^{6}$ Pela Lei Complementar n. ${ }^{\circ} 244$, de 30 de janeiro de 2003, foi criado o Departamento Estadual de Infraestrutura (DEINFRA) , oriundo da fusão do Departamento de Estradas de Rodagem (DER-SC) com o Departamento de Edificações e Obras Hidráulicas (DEOH) ambos vinculados ao Governo do Estado de Santa Catarina.
} 


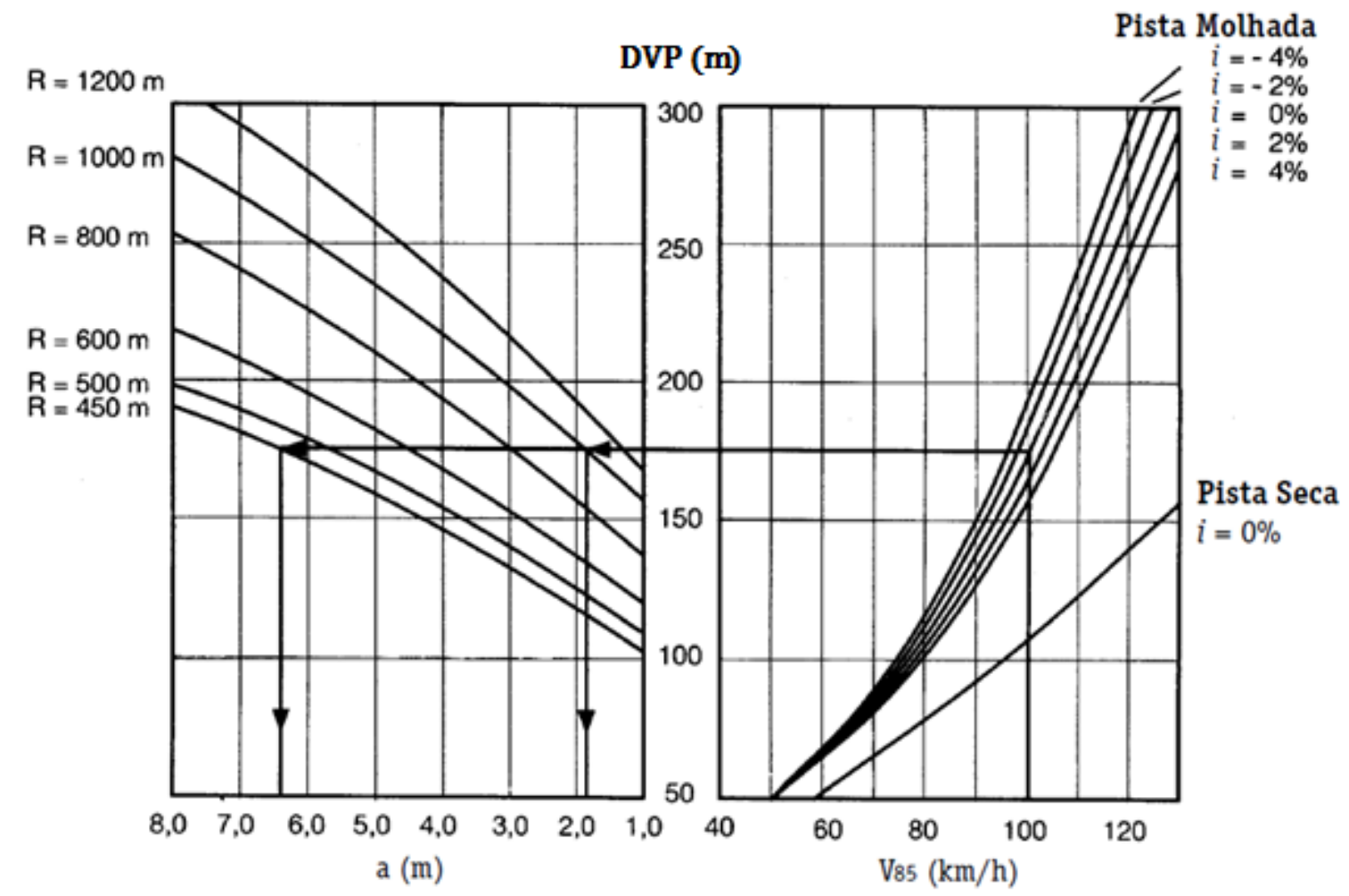

Figura 2.6. Distância de Visibilidade Necessária para Paradas (A) e Refúgio interno necessário (B) DER-SC (2000)

Em relação ao afastamento lateral de objetos ao longo de vias, Yang et al. (2012) constatou que os motoristas tendem a se mover longe do obstáculo (barreira) ou reduzir a velocidade temporariamente, por interpretar a barreira como fonte de risco à sua segurança. Rosey e Auberlet (2012) afirmam que as expectativas do motorista e consistência geométrica são quesitos importantes em segurança rodoviária, pois inconsistências no projeto geométrico podem surpreender motoristas e levar a erros que aumentam o risco de acidente. Ainda segundo os autores, a variabilidade da posição do motorista lateralmente na pista pode ser um indicador de deficiência na geometria da via, causado, por exemplo, pela posição da barreira. Ou seja, a solução é prover afastamento tal que o motorista sinta segurança ao dirigir, sem alterar sua trajetória, especialmente em condições atmosféricas e de visibilidade adversas (Yang et al., 2012; Chen et al., 2012). 
Hassan e Sarhan (2012) investigaram os efeitos do alinhamento vertical nas distâncias de visibilidade de parada, com o foco no posicionamento de barreiras de concreto ao longo de curvas horizontais. A barreira utilizada no estudo tem altura de 0,81 m. Em aplicativo gráfico desenvolvido pelos autores, foram gerados modelos tridimensionais de projeto genérico considerando a concordância do alinhamento horizontal e vertical e, como neste estudo, alterações foram impostas no modelo de modo a garantir a visibilidade ao longo da via. $\mathrm{O}$ aplicativo valida incremental e automaticamente afastamentos laterais para a análise de DVP. A figura 2.7 apresenta exemplo da tela de análise elaborada pelos autores.

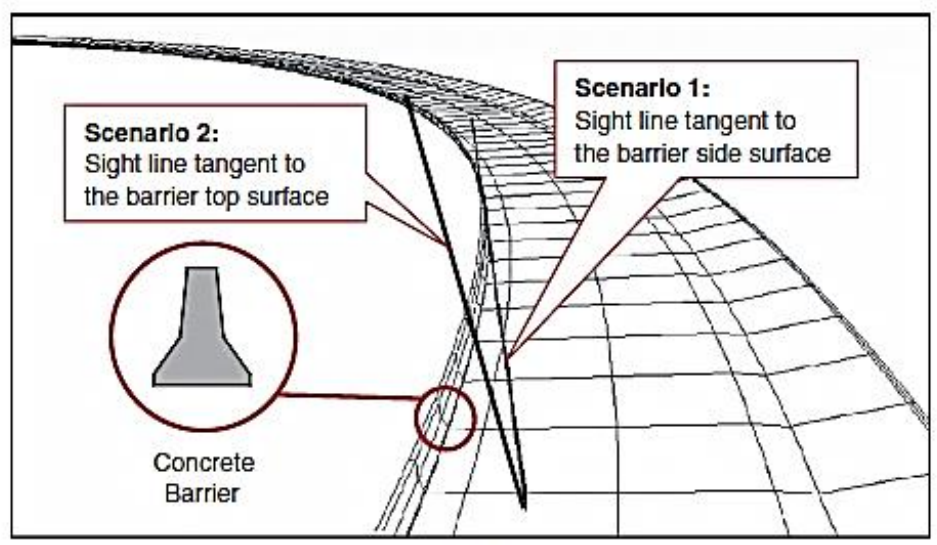

(a)

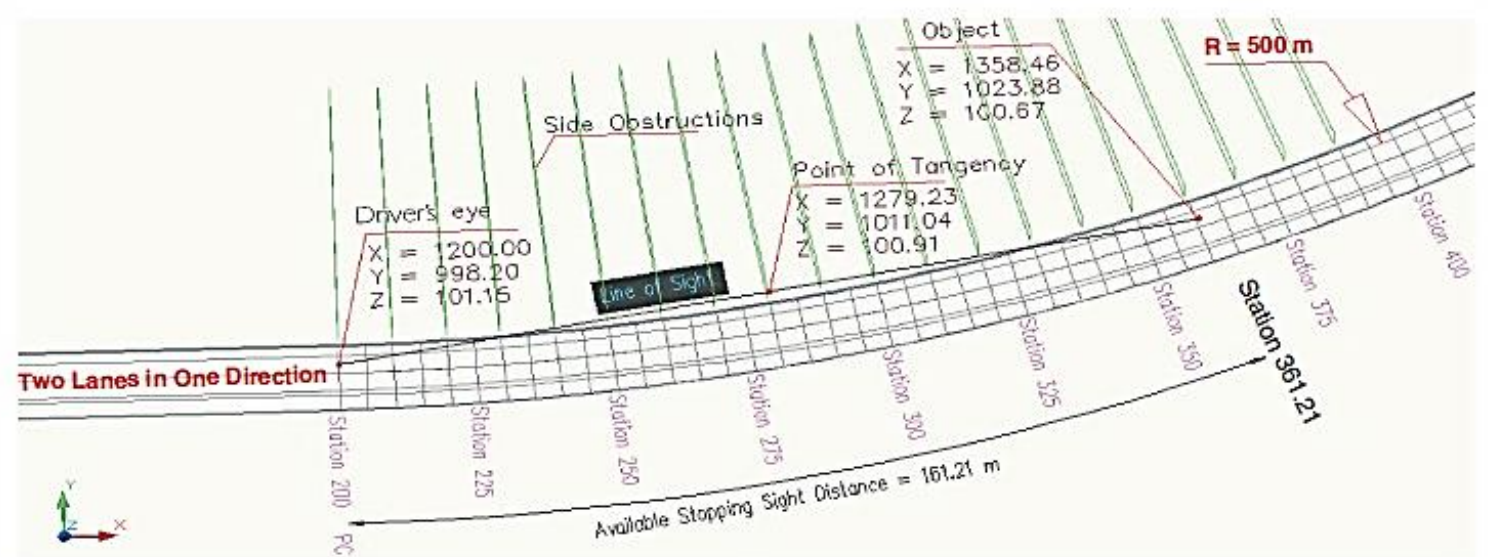

(b)

Figura 2.7. Análise do posicionamento de barreiras e visibilidade utilizada no estudo de Hassan e Sarhan (2012).

Em seus resultados, os autores concluem que os valores fornecidos para a linha de intimação segundo o Roadside Design Guide (AASTHO, 2011b) provêm valores de 
distância de visibilidade inferiores à DVP necessária para a segurança do motorista. O estudo também confirmou que a DVP disponível em curvas com obstrução na forma de barreiras é dependente da coordenação com o alinhamento vertical. A sugestão dos autores é de expandir as análises da contribuição das características dos alinhamentos horizontal e vertical, propor novas modelagens de barreiras através de programas computacionais que permitam a análise tridimensional do projeto.

A forma da concepção do estudo de Hassan e Sarhan (2012) muito se assemelha ao empregado nesta dissertação, contudo a parametrização adotada foi distinta. Os autores enfatizaram os efeitos do alinhamento vertical, enquanto o presente trabalho prioriza as características das normativas nacionais vigentes com a adoção de declividades do greide constantes como simplificação à presença de curvas verticais. 


\section{METODOLOGIA}

\subsection{Apresentação do Problema}

Leisch (1989) ressalta que o uso de barreiras de concreto em rodovias pode gerar inadequadas distâncias de visibilidade de parada, principalmente em curvas e em áreas próximas a pontes e túneis. Para o autor, uma solução seria aumentar o espaçamento entre a faixa de rolamento e a barreira. Neste contexto, o foco do estudo foi investigar o posicionamento de barreiras rígidas centrais para que não exista interferência na distância de visibilidade de parada necessária ao motorista durante o tráfego em determinada via, em trechos de conversão à esquerda. $O$ posicionamento da barreira foi sintetizado pelo dimensionamento do refúgio espaço entre a faixa de rolamento interna da via e a barreira rígida central - aqui denominado afastamento lateral da barreira $\left(a_{L}\right)$, como ilustrado na Figura 3.1.

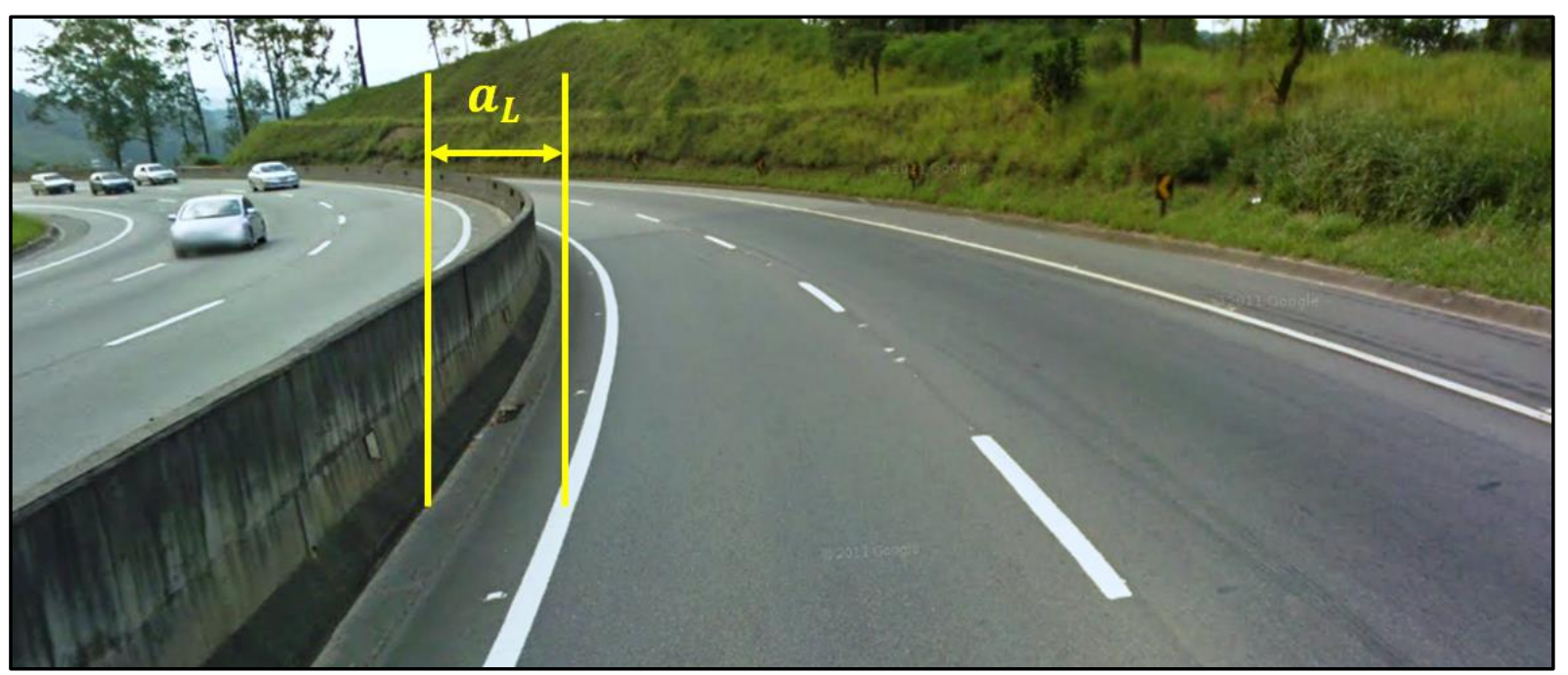

Figura 3.1. Afastamento lateral da barreira $\left(a_{L}\right)$. Foto: SP-088, Google ${ }^{\circledR} 2012$. 


\subsection{Método}

O método aplicado neste estudo é o uso de simulações gráficas tridimensionais. Nas simulações, cenários hipotéticos são criados e analisados em ambiente computacional. Deste modo, buscou-se reconstruir as características reais de uma rodovia em ambiente virtual, tendo controle sobre modificações e alterações de parâmetros em virtude dos propósitos do estudo.

A facilidade de alteração de um parâmetro em função de necessidades específicas, ainda na fase de projeto, são ponderadores da escolha de simulações - já que o impacto de alterações sobre o projeto é reduzido. O uso similar de ferramentas computacionais é visto em Sanchez (1994). Para a compreensão, segue um exemplo de análise realizada em ambiente computacional (Figura 3.2).

A

B

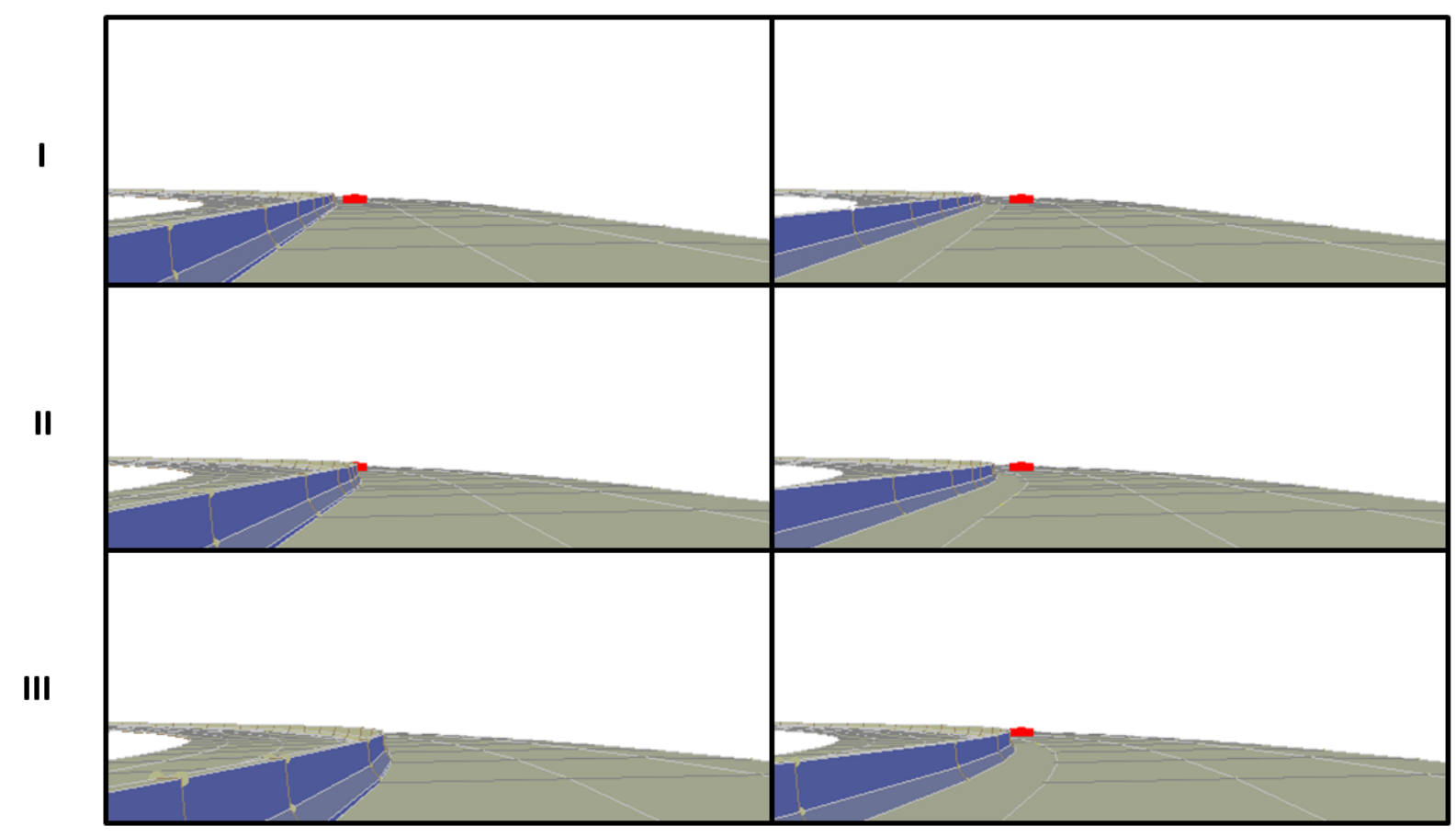

Figura 3.2. Exemplo de uso de simulação computacional para estudos de visibilidade. 
A Figura 3.1 mostra a visualização do objeto vermelho, a uma dada distância necessária - a DVP, em três instantes (I, II e III) durante a transição de trecho em tangente para trecho curvilíneo para dois projetos (A e B) com seções transversais distintas. O ideal é que o objeto seja visto em qualquer ponto ao longo da trajetória garantindo que a DVP exista ao longo do trecho estudado. No caso (A) o objeto desaparece do campo de visão em (III-A) indicando a deficiência no traçado. Com uma pequena alteração na seção transversal em (B) - deslocamento da barreira para esquerda - o objeto é percebido pelo motorista e o problema de visibilidade é solucionado (III-B).

A abrangência das simulações é próxima ao do exemplo da Figura 3.2. Programa voltado a projetos viários será utilizado, no qual as análises específicas de visibilidade já foram implantadas computacionalmente. Em suma, a estratégia de investigação baseia-se na seguinte formulação lógica:

1. Simulações - Testar em escritório condições possíveis de ocorrer em um projeto real;

2. Comparações - Comparar os resultados obtidos no item anterior com parâmetros existentes nas normas relacionados com o posicionamento de barreiras ou outros elementos de projeto;

3. Estudo de caso - Empregar os resultados obtidos em estudo de caso real de trecho de rodovia com características geométricas próximas aos trechos simulados no item 1.

Além disso, a demanda gerada de informações das simulações foi estruturada através de aplicativo desenvolvido, o qual será detalhado posteriormente no Capítulo 9.

\subsection{Recursos Necessários}

As etapas de concepção e análise dos projetos viários foram realizadas no programa AutoCAD ${ }^{\circledR}$ Civil 3D ${ }^{\circledR}$ desenvolvido pela Autodesk ${ }^{\circledR}$. O programa é uma solução 
computacional voltada para projetos e documentação de engenharia civil. A escolha do uso para a execução deste trabalho é o fato de que o programa baseia-se em modelos tridimensionais que são atualizados dinamicamente à medida que alterações no projeto são impostas. É possível gerar simulações e análises tridimensionais para melhor avaliar as características do projeto. A licença utilizada é disponibilizada gratuitamente à comunidade acadêmica pela Autodesk ${ }^{\circledR}$.

O tratamento dos dados provenientes das simulações e a elaboração do aplicativo foram feitos com uso do programa MATLAB ${ }^{\circledR}$ da MathWorks ${ }^{\circledR}$. Trata-se de uma solução computacional de linguagem de alto nível através de um ambiente interativo para computação numérica, visualização e programação. Possibilita analisar dados, desenvolver algoritmos, e criar modelos e aplicações.

Para o adequado uso de ambos os programas foi necessário utilizar computador com hardware e software compatíveis com os requisitos dos programas, disponibilizado pelo Departamento de Transportes (PTR) da Escola Politécnica da Universidade de São Paulo (EPUSP).

\subsection{Hipóteses Adotadas}

Em função da amplitude de parâmetros, foram adotadas hipóteses e simplificações no intuito de restringir abrangência do universo de estudo, onde apenas casos expressivos foram considerados - aqueles em que a incidência de problemas de visibilidade devido a barreiras tem maior probabilidade de ocorrer. Nos itens subsequentes é apresentada a estruturação das simulações realizadas, abordando as hipóteses adotadas, o conjunto de análise e as restrições inferidas nas simulações. 


\subsubsection{Tipo de Rodovia e de Geometria}

As rodovias neste estudo são aquelas enquadradas nas Classes 0 e I-A definidas por DNER (1999) ${ }^{7}$. A Classe 0 abrange vias expressas, projetadas com elevado padrão técnico e controle total de acesso. Por sua vez, a classe I-A engloba rodovias de pista dupla com controle parcial de acesso.

Deste conjunto de vias serão considerados trechos de curvas horizontais à esquerda - onde é suposto que a influência de objetos dispostos na região interna das curvas na visibilidade do motorista é mais recorrente. O projeto ideal seria associar as curvas do alinhamento horizontal com as do alinhamento vertical. Por restrição das hipóteses, rampas de declividade constante foram adotadas como simplificação das características do alinhamento vertical. Tal combinação é utilizada para compensar grandes desníveis de altitude, como casos de trechos de rodovias em regiões montanhosas. Serão consideradas variações na declividade do greide incorporando trechos planos, em aclives e declives. As declividades do greide adotadas foram de $9 \%,-6 \%,-3 \%, 0 \%, 3 \%, 6 \%$ e $9 \%$.

\subsubsection{Velocidades de Projeto}

A premissa de considerar como objeto de estudo rodovias de classes 0 e I-A, segundo DNER, adotou-se no estudo velocidades de projeto estabelecidas segundo recomendações de manuais nacionais vigentes. A Tabela 3.1 apresenta as velocidades diretrizes em função da classe da rodovia e do tipo do relevo segundo DNER (1999).

\footnotetext{
7 Para maior detalhamento das características técnicas de ambas as classes escolhidas vide DNER (1999).
} 
Tabela 3.1. Velocidades Diretrizes para projeto em função da classe da rodovia e tipo de relevo

\begin{tabular}{|c|c|c|c|}
\hline \multirow{2}{*}{$\begin{array}{c}\text { Classe de } \\
\text { Projeto }\end{array}$} & \multicolumn{3}{|c|}{ Velocidades diretrizes para projeto $(\mathrm{km} / \mathrm{h})$} \\
\cline { 2 - 4 } & Plano & Ondulado & Montanhoso \\
\hline Classe 0 & 120 & 100 & 80 \\
\hline Classe I & 100 & 80 & 60 \\
\hline Classe II & 100 & 70 & 50 \\
\hline Classe III & 80 & 60 & 40 \\
\hline Classe IV & $80-60$ & $60-40$ & $40-30$ \\
\hline
\end{tabular}

FONTE: DNER (1999).

No estudo, serão consideradas faixas de velocidades para cada variação da declividade do greide. A faixa de interesse abrange velocidades entre $60 \mathrm{~km} / \mathrm{h}$ a 120 $\mathrm{km} / \mathrm{h}$, com taxa de variação de $10 \mathrm{~km} / \mathrm{h}$.

\subsubsection{Raio da Curva Horizontal e Superelevação}

Os valores de raios para as curvas horizontais considerados são de 200 a 2000 m, incrementados a cada $100 \mathrm{~m}$. O limite superior de raio igual a $2000 \mathrm{~m}$ foi escolhido já que o problema de visibilidade em curvas horizontais à esquerda é pouco recorrente quando se assume grandes raios horizontais. Os limites inferiores, por sua vez, coincidem com o raio mínimo da curva horizontal para cada velocidade de projeto. Por definição, o raio mínimo da curva horizontal $\left(R_{\min }\right)$ é o menor raio de uma curva que, apresentando taxa máxima de superelevação, possa ser percorrida na velocidade de projeto com condições favoráveis de segurança e conforto. É dado por:

$$
R_{\min }=\frac{V^{2}}{127 \times\left(f_{\max }+e_{\max }\right)}
$$

Onde

$R_{\min }:$ Raio mínimo da curva horizontal (m); 
$V$ : Velocidade de projeto $(\mathrm{km} / \mathrm{h})$;

$f_{\max }:$ Fator de atrito lateral pneu-pavimento; e

$e_{\max }$ : Superelevação máxima admissível.

A superelevação máxima admissível $\left(e_{\max }\right)$ adotada neste estudo foi igual a $8 \%$. Este valor é compatível com as rodovias das classes 0 e I-A, que podem ser descritas como rodovias de padrão elevado ou intermediário. A adoção deste valor como limítrofe para restes casos tende a reduzir a probabilidade de que condutores mais lentos sejam submetidos, por efeito da força peso, a deslocamentos transversais em direção à parte interna da curva, o que pode exigir esforços excessivos e afetar a dirigibilidade (DER-SP, 2006). O fator de atrito lateral pneupavimento caracteriza a aderência entre pneu e pavimento, condicionado por vários fatores dentre os quais se destaca a velocidade do veículo, o tipo e as condições de pavimento, bem como os tipos e condições do pneu do veículo. Os valores assumidos estão de acordo com os pressupostos pelo DNIT (Tabela 3.2).

Tabela 3.2. Fator de Atrito Lateral

\begin{tabular}{|c|c|c|c|c|c|c|c|}
\hline Velocidade de Projeto $(\mathbf{k m} / \mathbf{h})$ & 60 & 70 & 80 & 90 & 100 & 110 & 120 \\
\hline Fator de Atrito Lateral & 0,15 & 0,15 & 0,14 & 0,14 & 0,13 & 0,12 & 0,11 \\
\hline
\end{tabular}

FONTE: DNER (1999).

Logo, sendo conhecidos a superelevação máxima admissível e os fatores de atrito lateral é possível determinar os raios mínimos da curva horizontal para cada velocidade de projeto analisada. Os valores definidos constam da Tabela 3.3. 
Tabela 3.3. Raio Mínimo da Curva Horizontal

\begin{tabular}{|c|c|c|c|c|c|}
\hline \multicolumn{7}{|c|}{ Raio Mínimo da Curva Horizontal } \\
$\mathbf{V} \mathbf{V}(\mathbf{k m} / \mathbf{h})$ & $\mathbf{e}_{\mathbf{m a}}$ & $\mathbf{f}_{\max }$ & $\begin{array}{c}\text { Valor } \\
\text { Calculado }(\mathbf{m})\end{array}$ & $\begin{array}{c}\text { Valor } \\
\text { Adodo (m) }\end{array}$ & $\begin{array}{c}\text { Valor mínimo da } \\
\text { simulação (m) }\end{array}$ \\
\hline 60 & $8 \%$ & 0,15 & 123,25 & $\mathbf{1 2 5}$ & $\mathbf{2 0 0}$ \\
\hline 70 & $8 \%$ & 0,15 & 167,75 & $\mathbf{1 7 0}$ & $\mathbf{2 0 0}$ \\
\hline 80 & $8 \%$ & 0,14 & 229,06 & $\mathbf{2 3 0}$ & $\mathbf{3 0 0}$ \\
\hline 90 & $8 \%$ & 0,14 & 289,91 & $\mathbf{2 9 0}$ & $\mathbf{3 0 0}$ \\
\hline 100 & $8 \%$ & 0,13 & 374,95 & $\mathbf{3 7 5}$ & $\mathbf{4 0 0}$ \\
\hline 110 & $8 \%$ & 0,12 & 476,38 & $\mathbf{4 7 5}$ & $\mathbf{5 0 0}$ \\
\hline 120 & $8 \%$ & 0,11 & 596,77 & $\mathbf{5 9 5}$ & $\mathbf{6 0 0}$ \\
\hline
\end{tabular}

Em casos que o raio da curva horizontal seja superior ao raio mínimo, é necessário dimensionar a superelevação, já que a ação da aceleração centrífuga diminui e não há necessidade da adoção do valor superelevação máxima. A hipótese considerada é a redução gradual dos valores de superelevação, em função do aumento do raio, até atingir valor mínimo admissível. A superelevação mínima utilizada é igual a $2 \%$ visando facilitar a drenagem das águas pluviais sobre a via. Assim, valores de superelevação $e$ a serem adotados são calculados por:

$$
e=e_{\max } \times\left(\frac{2 \times R_{\min }}{R}-\frac{R_{\text {min }}^{2}}{R^{2}}\right)
$$

Onde

$e$ : Superelevação a adotar;

$e_{\max }$ : Superelevação Máxima admissível;

$R_{\min }$ : Raio mínimo da curva horizontal relacionado com $e_{\max }$ para velocidade de projeto em questão $(\mathrm{m})$; e

$R$ : Raio da Curva Horizontal (m). 
Além disso, os valores de superelevação podem ser obtidos graficamente, com o uso de ábacos definidos em função da superelevação máxima admissível, similares ao da Figura 3.3, apresentado por DNER (1999).

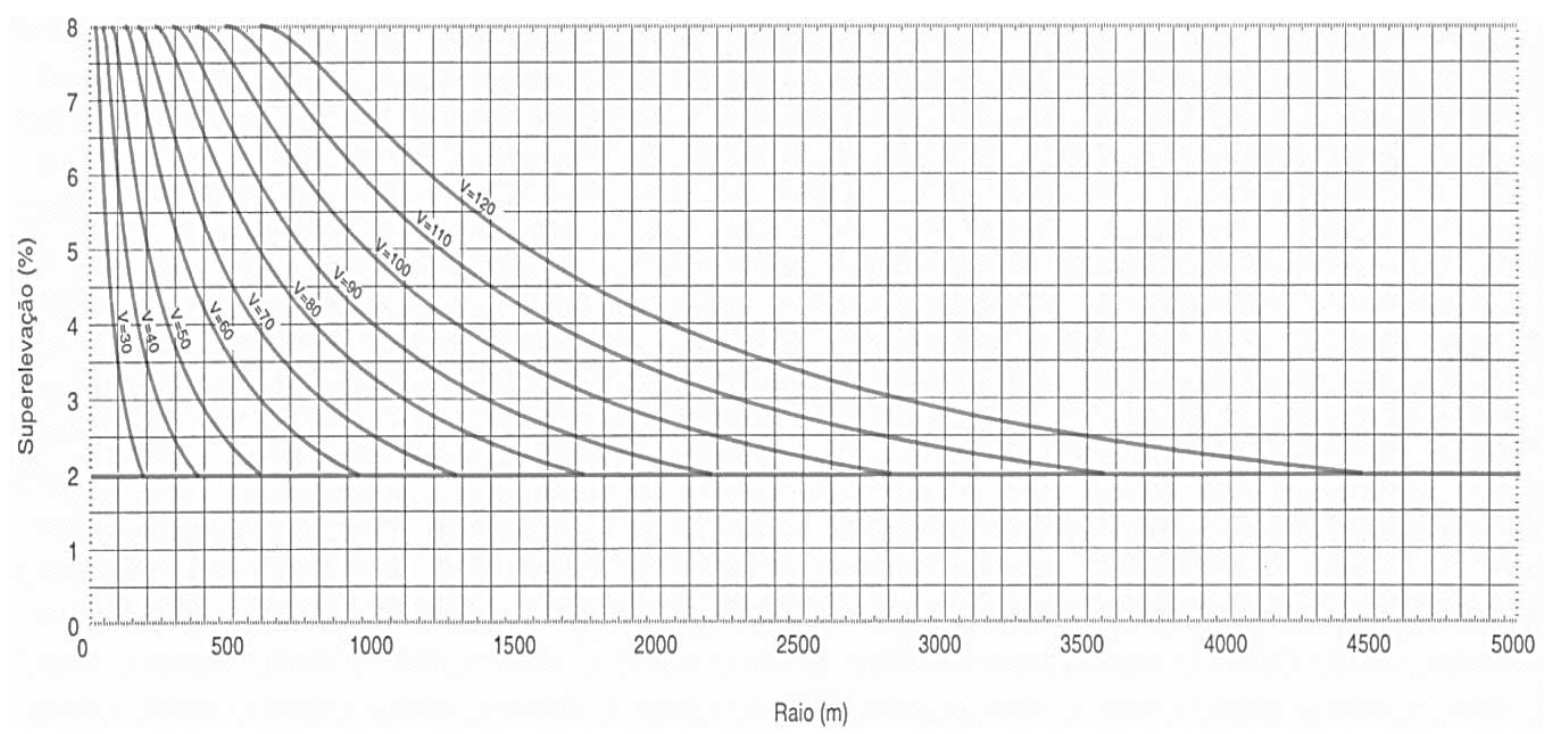

Figura 3.3. Gráfico de Superelevação (para $e_{\max }=8 \%$ ). Fonte: DNER (1999).

Os raios da curva horizontal e as superelevações, para cada velocidade de projeto, foram então estabelecidos em função dos raios mínimos e das superelevações máxima e mínima admissível. Os valores utilizados são apresentados a seguir (Tabela 3.4). 
Tabela 3.4. Valores de superelevação utilizados nas simulações.

\begin{tabular}{|c|c|c|c|c|c|c|c|c|}
\hline & \multicolumn{7}{|c|}{ Superelevação (para $e_{\max }=8 \%$ ) } \\
\hline & & \multicolumn{7}{|c|}{ Velocidade de Projeto (km/h) } \\
\hline & & 60 & 70 & 80 & 90 & 100 & 110 & 120 \\
\hline \multirow{19}{*}{ 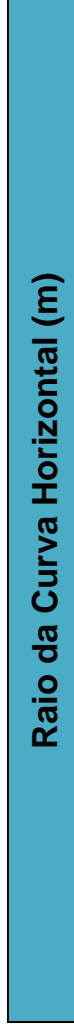 } & 200 & $6,9 \%$ & $7,8 \%$ & & & & & \\
\hline & 300 & $5,3 \%$ & $6,5 \%$ & $7,6 \%$ & $8,0 \%$ & & & \\
\hline & 400 & $4,2 \%$ & $5,4 \%$ & $6,6 \%$ & $7,4 \%$ & $8,0 \%$ & & \\
\hline & 500 & $3,5 \%$ & $4,5 \%$ & $5,7 \%$ & $6,6 \%$ & $7,5 \%$ & $8,0 \%$ & \\
\hline & 600 & $3,0 \%$ & $3,9 \%$ & $5,0 \%$ & $5,9 \%$ & $6,9 \%$ & $7,7 \%$ & $8,0 \%$ \\
\hline & 700 & $2,6 \%$ & $3,4 \%$ & $4,4 \%$ & $5,3 \%$ & $6,3 \%$ & $7,2 \%$ & $7,8 \%$ \\
\hline & 800 & $2,3 \%$ & $3,0 \%$ & $3,9 \%$ & $4,7 \%$ & $5,7 \%$ & $6,7 \%$ & $7,5 \%$ \\
\hline & 900 & $2,1 \%$ & $2,7 \%$ & $3,6 \%$ & $4,3 \%$ & $5,3 \%$ & $6,2 \%$ & $7,1 \%$ \\
\hline & 1000 & $2,0 \%$ & $2,5 \%$ & $3,3 \%$ & $4,0 \%$ & $4,9 \%$ & $5,8 \%$ & $6,7 \%$ \\
\hline & 1100 & $2,0 \%$ & $2,3 \%$ & $3,0 \%$ & $3,7 \%$ & $4,5 \%$ & $5,4 \%$ & $6,3 \%$ \\
\hline & 1200 & $2,0 \%$ & $2,1 \%$ & $2,8 \%$ & $3,4 \%$ & $4,2 \%$ & $5,1 \%$ & $6,0 \%$ \\
\hline & 1300 & $2,0 \%$ & $2,0 \%$ & $2,6 \%$ & $3,2 \%$ & $3,9 \%$ & $4,8 \%$ & $5,6 \%$ \\
\hline & 1400 & $2,0 \%$ & $2,0 \%$ & $2,4 \%$ & $3,0 \%$ & $3,7 \%$ & $4,5 \%$ & $5,4 \%$ \\
\hline & 1500 & $2,0 \%$ & $2,0 \%$ & $2,3 \%$ & $2,8 \%$ & $3,5 \%$ & $4,3 \%$ & $5,1 \%$ \\
\hline & 1600 & $2,0 \%$ & $2,0 \%$ & $2,1 \%$ & $2,6 \%$ & $3,3 \%$ & $4,0 \%$ & $4,8 \%$ \\
\hline & 1700 & $2,0 \%$ & $2,0 \%$ & $2,0 \%$ & $2,5 \%$ & $3,1 \%$ & $3,8 \%$ & $4,6 \%$ \\
\hline & 1800 & $2,0 \%$ & $2,0 \%$ & $2,0 \%$ & $2,4 \%$ & $3,0 \%$ & $3,7 \%$ & $4,4 \%$ \\
\hline & 1900 & $2,0 \%$ & $2,0 \%$ & $2,0 \%$ & $2,3 \%$ & $2,8 \%$ & $3,5 \%$ & $4,2 \%$ \\
\hline & 2000 & $2,0 \%$ & $2,0 \%$ & $2,0 \%$ & $2,2 \%$ & $2,7 \%$ & $3,3 \%$ & $4,1 \%$ \\
\hline
\end{tabular}

\subsubsection{Altura dos olhos do motorista e altura do objeto}

No Capítulo 2, foram apresentados os valores da altura dos olhos do motorista e da altura do objeto utilizados em diversos países, inclusive no Brasil. Serão considerados os valores de 1,08 m para altura dos olhos do motorista e de 0,60 m para a altura do objeto a ser visualizado na via neste estudo (DNIT, 2010; DER-SP, 2006; AASHTO, 2011a).

O valor de 0,60 m representa a altura média das lanternas traseiras de um veículo leve, que deve ser adotado em casos onde não há fonte de iluminação adequada na 
via. Em vias iluminadas, entretanto, a altura do objeto pode ser considerada maior que 0,60 m, já que as condições de visibilidade do motorista são favorecidas.

A posição tanto do motorista quanto do objeto é de $2 \mathrm{~m}$ da borda direita da faixa de rolamento interna da via ${ }^{8}$, conforme ilustrado na Figura 3.4.

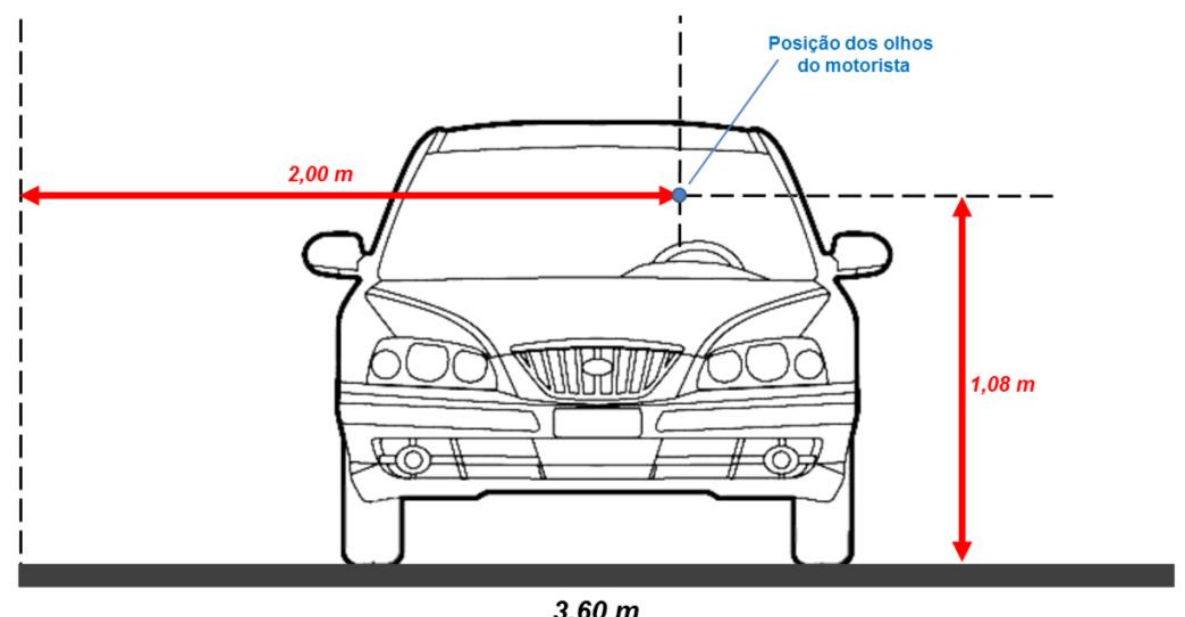

Figura 3.4. Posição dos olhos do motorista.

No estudo, adotou-se como trajetória do motorista o comportamento ideal do motorista na via, ou seja, a distância constante do eixo central da pista. Contudo, Spacek (2005) apud Jamieson (2012) apresenta cinco possíveis formas de um motorista executar a trajetória do veículo em uma curva. O comportamento ideal corresponde a apenas 1\% dos motoristas, mas devido à restrição das ferramentas foi a trajetória adotada no estudo.

\footnotetext{
${ }^{8}$ Poucos manuais tratam da posição relativa do motorista ou objeto e a via para verificação de visibilidade. No capítulo 2, o valor do deslocamento em relação à borda direita da faixa é encontrado nas normas francesas (igual a 2,0 m) e espanholas (1,5 m). A escolha por $2 \mathrm{~m}$ foi arbitrária.
} 


\subsubsection{Distância de Visibilidade de Parada}

A formulação para o cálculo da Distância de Visibilidade de Parada é a mesma apresentada no Capítulo 2, adotada pela AASTHO (2011a) e pelo DER-SP (2006):

$$
D V P=0,278 \times V \times t+\frac{V^{2}}{254 \times\left(\left(\frac{a}{9,81}\right)+i\right)}
$$

Onde

DVP: Distância de Visibilidade de Parada (m);

V: Velocidade de projeto $(\mathrm{km} / \mathrm{h})$;

t: Tempo de percepção e reação (s);

a: Taxa de desaceleração $\left(\mathrm{m} / \mathrm{s}^{2}\right)$; e

i: Declividade do greide (\%);

O valor recomendado pela AASTHO para o tempo de percepção e reação é de $2,5 \mathrm{~s}$ e para a taxa de desaceleração é de $3,4 \mathrm{~m} / \mathrm{s}^{2}$. Baseado na formulação acima, o DER-SP apresenta valores mínimos de DVP a serem adotados, considerando a condição de pavimento molhado e velocidade de percurso igual à velocidade de projeto (Tabela 3.5). 
Tabela 3.5. Valores Mínimos de Projeto para DVP

\begin{tabular}{|c|c|c|c|c|c|c|c|}
\hline \multicolumn{8}{|c|}{ Valores Mínimos de Projeto para DVP (m) } \\
\hline \multirow{2}{*}{$\begin{array}{l}\text { Velocidade } \\
\qquad(\mathrm{km} / \mathrm{h})\end{array}$} & \multicolumn{7}{|c|}{ Declividade do Greide } \\
\hline & $-9 \%$ & $-6 \%$ & $-3 \%$ & $0 \%$ & $3 \%$ & $6 \%$ & $9 \%$ \\
\hline 60 & 97 & 92 & 87 & 85 & 80 & 77 & 75 \\
\hline 70 & 124 & 116 & 110 & 105 & 100 & 97 & 93 \\
\hline 80 & 154 & 144 & 136 & 130 & 123 & 118 & 114 \\
\hline 90 & 187 & 174 & 164 & 160 & 148 & 141 & 136 \\
\hline 100 & 223 & 207 & 194 & 185 & 174 & 167 & 160 \\
\hline 110 & 262 & 243 & 227 & 220 & 203 & 194 & 186 \\
\hline 120 & 304 & 281 & 263 & 250 & 234 & 223 & 214 \\
\hline
\end{tabular}

FONTE: DER-SP (2006).

\subsubsection{Seção transversal}

Em função da adoção de rodovias Classe 0 e Classe I-A, adotou-se seção transversal compatível com o padrão destas vias. Desta forma, a seção transversal é caracterizada por pista dupla em ambos os sentidos. Usualmente, em rodovias destas classes é comum a adoção de canteiro central o mais largo possível. Contudo no enfoque deste trabalho o importante foi a distância relativa da barreira ao bordo da faixa interna de rolamento, independente do canteiro central ser restrito, ou mais largo com exigência de barreira, em função do volume de tráfego, por exemplo. Sendo assim, adotou-se seção transversal hipotética vista na Figura 3.5, baseada nos padrões mínimos exigidos pelo DER-SP (2005). 


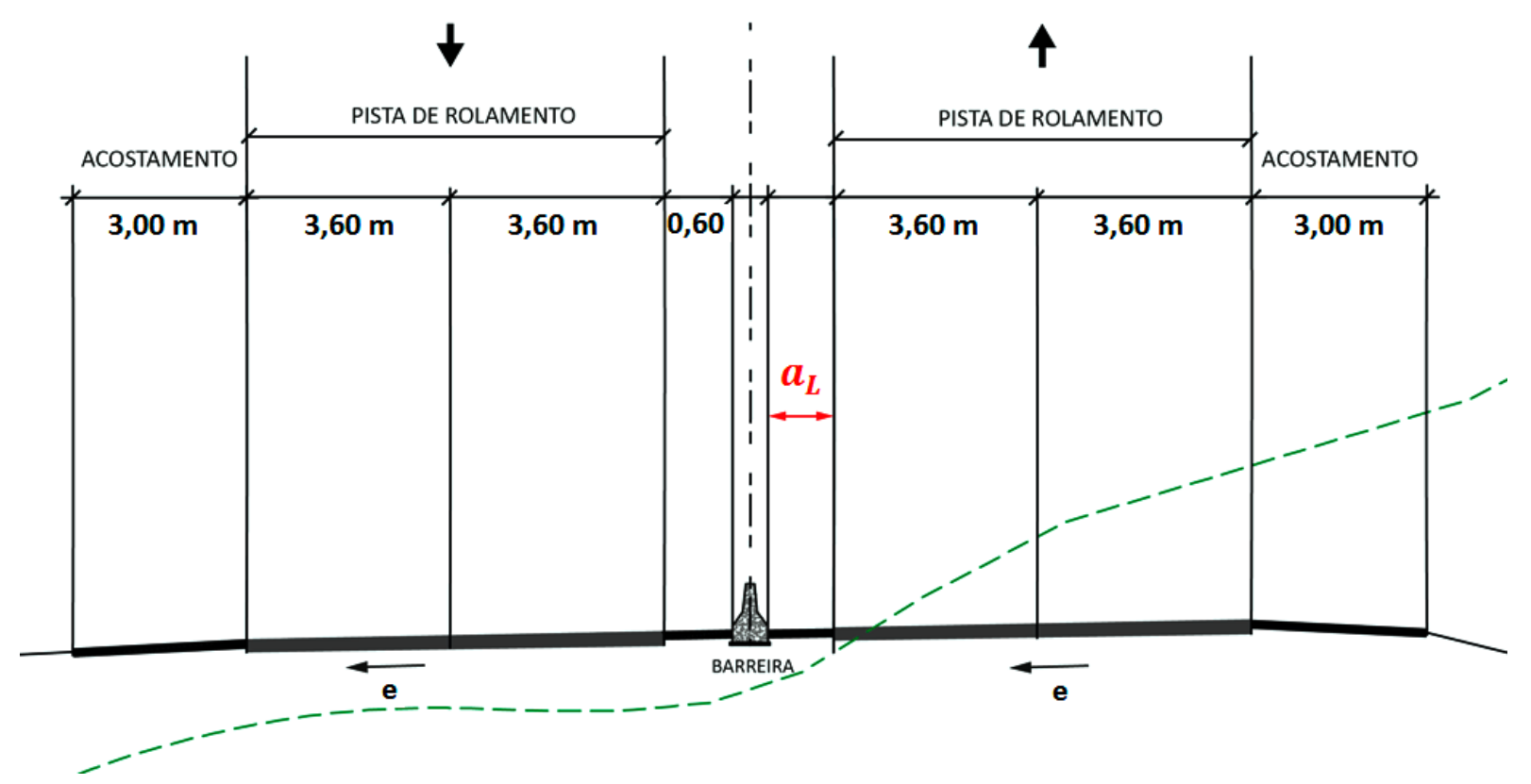

Figura 3.5. Seção transversal hipotética adotada em trecho curvilíneo. FONTE: DER-SP (2005).

Desta seção os elementos variáveis foram: (a) o afastamento lateral da barreira $\left(a_{L}\right)$ - o objeto de estudo, (b) o valor da altura da barreira e (c) o valor da superelevação (e), em sentido único ao longo da curva. O refúgio - ou afastamento lateral da barreira - da pista de sentido contrário foi considerado fixo e igual a $0,60 \mathrm{~m}$, valor mínimo tolerável conforme a NBR 15486:2007.

No que tange a seção transversal, o trabalho tratará o refúgio ou acostamento interno como afastamento lateral da barreira.

A Tabela 3.6 apresenta um comparativo de diversas publicações sobre a dimensão do acostamento interno para rodovias de alto padrão. DNER (1999) recomenda para rodovia similar a estudada, que o acostamento interno seja de $0,60 \mathrm{~m}$ a 1,20 m para duas faixas de rolamento. A mesma recomendação é apresentada por DNIT (2010) para duas ou três faixas de tráfego. O Green Book (AASHTO, 2011a) recomenda o valor mínimo de 0,60 m para baixo volume de tráfego, sendo desejável acostamento de $1,80 \mathrm{~m}$ a 2,40 m. Neste estudo, adotou-se o valor do afastamento lateral da barreira - distância entre a barreira à borda da faixa interna de rolamento - variável entre $0,00 \mathrm{~m}$ e $2,50 \mathrm{~m}$ que abrange as recomendações acima, considerando 
afastamentos não adequados (menores de 0,60 m) as condições de segurança, mas necessários para a investigação científica através das simulações realizadas.

Tabela 3.6. Recomendações para largura de acostamento interno

Recomendações para largura de acostamento interno

DNER (1999)

\begin{tabular}{|c|c|c|c|}
\hline & Plano & Ondulado & Montanhoso \\
\hline 2 faixas & $1,20 m-0,60 m$ & $1,00 m-0,60 m$ & $0,60 m-0,50 m$ \\
\hline 3 faixas & $3,00 m-2,50 m$ & $2,50 m-2,00 m$ & $2,50 m-2,00 m$ \\
\hline$\geq 4$ faixas & $3,00 m$ & $3,00 m-2,50 m$ & $3,00 m-2,50 m$ \\
\hline
\end{tabular}

DNIT (2010)

\begin{tabular}{|c|c|}
\hline 2 ou 3 faixas & $1,20 \mathrm{~m}(0,60 \mathrm{~m})$ \\
\hline$\geq 4$ faixas & $3,00 \mathrm{~m}(1,00 \mathrm{~m})$ \\
\hline \multicolumn{2}{|c|}{} \\
\hline \multicolumn{2}{|c|}{ AASHTO (2011a) } \\
\hline Mínimo & $0,60 \mathrm{~m}$ (para baixo volume de tráfego) \\
\hline Desejável & $1,80 \mathrm{~m}-2,40 \mathrm{~m}$ \\
\hline Tráfego pesado & $3,00 \mathrm{~m}$ \\
\hline
\end{tabular}

\subsubsection{Tipo de barreira}

No Brasil é comum o uso de barreiras rígidas de concreto com perfil New Jersey como separador físico de fluxo em regiões onde há impossibilidade de implantação de canteiros centrais. A altura dessas barreiras é variável, sendo usual a de altura igual a 0,81 m.. No estudo, optou-se por utilizar modelos de barreiras duplas deste tipo, com três alturas distintas: 0,81 m, 1,00 m e 1,40 m, para situações hipotéticas de contenção de veículos leves e pesados, respectivamente (Figura 3.6). As dimensões foram consideradas como consta na norma NBR 14885:2004 (Figura 3.7) para o caso de barreiras dupla com perfil New Jersey. 


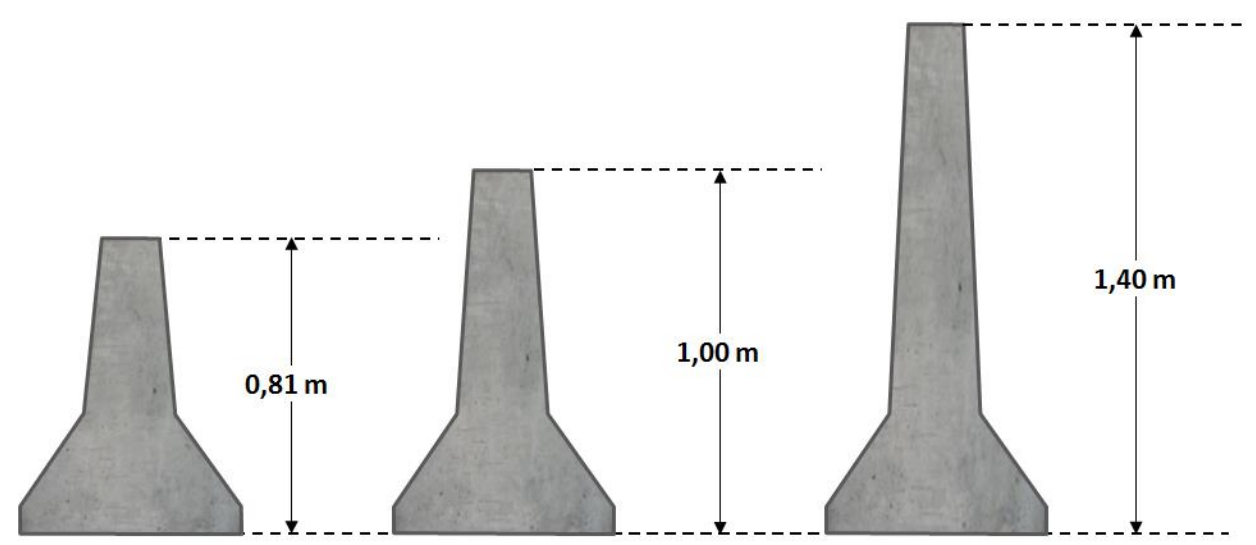

Figura 3.6. Esquema das barreiras adotadas com alturas de 0,81 m, 1,00 m e 1,40 m.

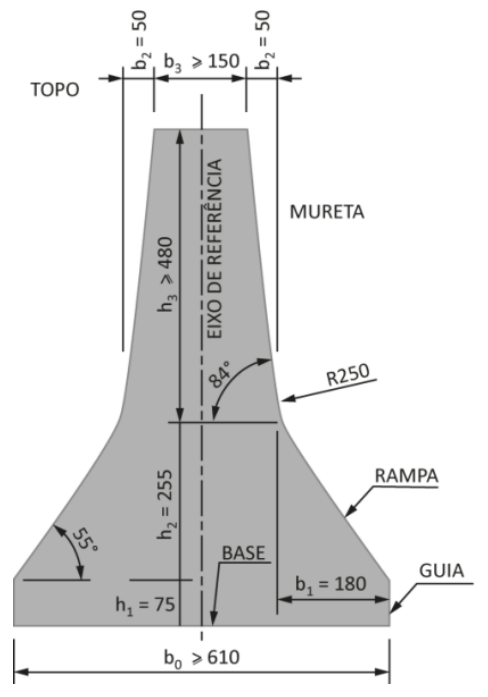

\begin{tabular}{|c|c|c|c|}
\hline ARESTA & NOMINAL & MíNIMO & MÁXIMO \\
\hline $\mathrm{h}_{1}$ & 75 & 75 & 80 \\
\hline $\mathrm{h}_{2}$ & 255 & 250 & 260 \\
\hline$h_{3}$ & 480 & 480 & $\geq 480$ \\
\hline \multirow{2}{*}{$b_{1}$} & 180 & 173 & 185 \\
\hline & $0,70 \mathrm{~h}_{2}$ & $0,69 \mathrm{~h}_{2}$ & $0,75 \mathrm{~h}_{2}$ \\
\hline \multirow{2}{*}{$b_{2}$} & 50 & 48 & $\geq 53$ \\
\hline & $0,105 \mathrm{~h}_{3}$ & $0,100 \mathrm{~h}_{3}$ & $0,110 \mathrm{~h}_{3}$ \\
\hline$b_{3}$ & 150 & 150 & $\geq 150$ \\
\hline
\end{tabular}

Figura 3.7. Dimensões da barreira dupla New Jersey conforme ABNT. Fonte: NBR 14885:2004

\subsection{Estruturação e execução das simulações}

Com base nas hipóteses adotadas no item anterior, os parâmetros variáveis considerados são: velocidade de projeto $(V)$, raio da curva horizontal $(R)$, a declividade do greide $(i)$, a altura da barreira $\left(h_{B}\right)$ e indiretamente a superelevação (e), que é definida em função de $R$ e $i$. Dois grupos de investigação foram definidos em função da altura da barreira. Em cada grupo, os valores de velocidade de projeto 
definiram cenários de análise. Em cada cenário, por sua vez, foram alterados a declividade do greide - e o raio da curva horizontal, que definem valores de DVP e superelevação caso a caso. A Figura 3.8 ilustra as combinações de análise para as simulações.

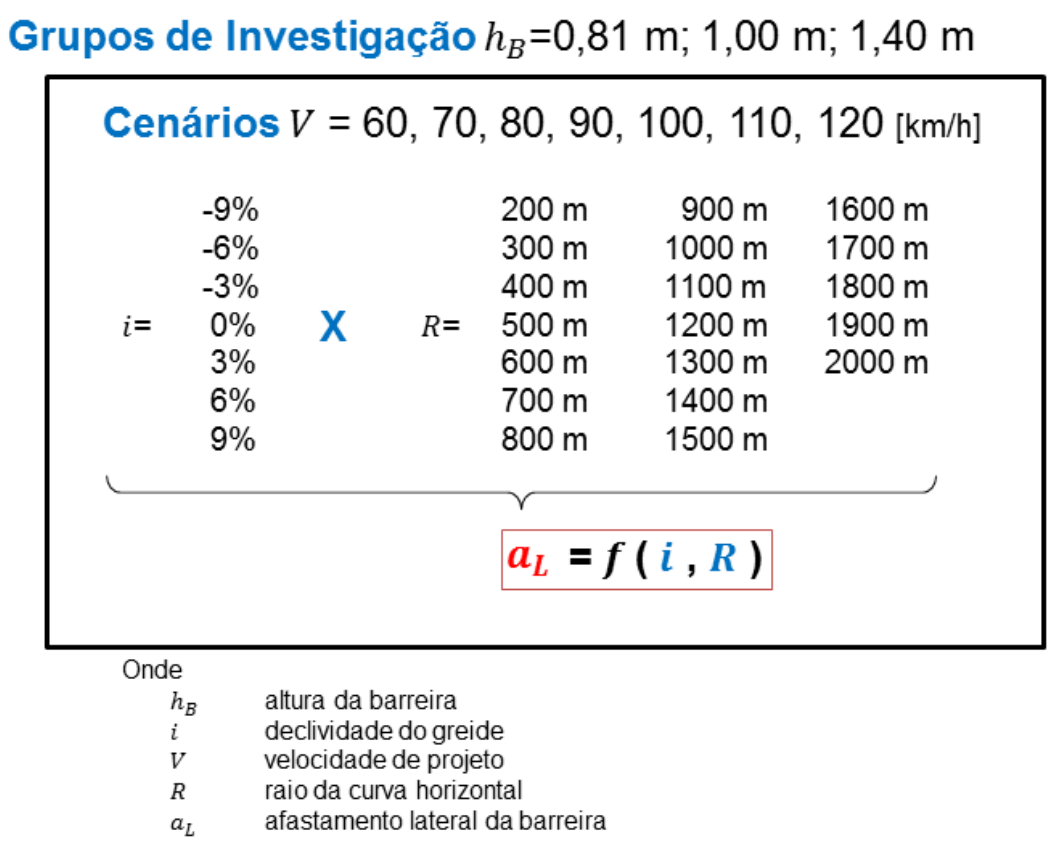

Figura 3.8. Combinações de análise para as simulações.

Para cada grupo de investigação, sete cenários foram simulados referentes às velocidades de $60 \mathrm{~km} / \mathrm{h}$ a $120 \mathrm{~km} / \mathrm{h}$ - onde foram variados a declividade do greide e o raio da curva horizontal para determinar um afastamento lateral da barreira, no qual a DVP é garantida. Para limitar a amplitude das simulações, considerou-se o valor máximo para o afastamento lateral sendo igual a $2,50 \mathrm{~m}$, valor mediano aos encontrados na literatura. A NBR 15486:2007 considera o valor máximo de 3,60 m entre a barreira e a faixa de rolamento, assim como estudo apresentado por Arndt et al. (2010), em concordância com a AASHTO (2011a). Contudo, casos onde o afastamento lateral da barreira assumia valores maiores que 2,50 m foram desprezados do cenário de análise. 
Em cada cenário, o desenvolvimento das simulações seguiu o fluxograma apresentado na Figura 3.9. O ponto de partida consiste na definição dos cenários em função da altura da barreira e da velocidade de projeto. No estágio inicial cria-se um modelo de terreno arbitrário e o projeto viário fictício, no qual alterações serão realizadas em função da garantia de visibilidade. Em cada raio da curva horizontal, são testadas se a DVP referente à velocidade e à declividade do greide é satisfeita. Caso tal não ocorra, o posicionamento da barreira na seção transversal é modificado (afastamento lateral) até que se obtenha resposta positiva. O processo termina quando todo o conjunto de cenários for testado.

Adotou-se como critério de precisão do afastamento da barreira sendo igual a $\pm 0,05$ $\mathrm{m}$, valor este satisfatório ao considerar a precisão construtiva de uma rodovia. A visibilidade foi analisada a cada $10 \mathrm{~m}$ ao longo do trecho de estudo. 


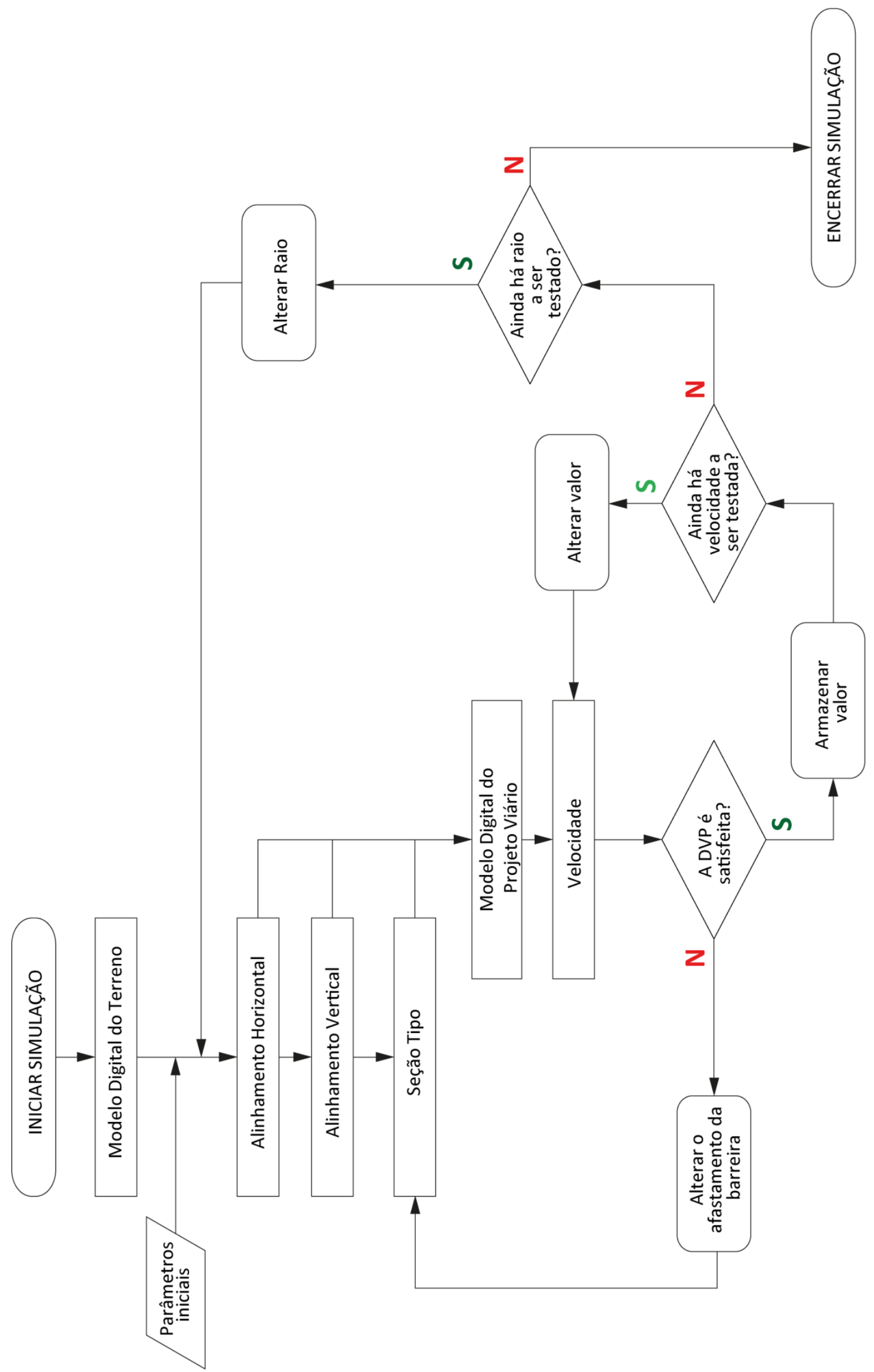

Figura 3.9. Fluxograma do processo de simulação. 
As simulações foram feitas no AutoCAD ${ }^{\circledR}$ Civil3D ${ }^{\circledR}$. Inicialmente criou-se um modelo digital de terreno hipotético, através de um conjunto de pontos cotados, necessário para o processo de simulação no programa. Nas análises, contudo, a informação do terreno foi desprezada, já que os fatores considerados como obstrução foram oriundos apenas de elementos do projeto geométrico, sem incorporar taludes e outras modificações no relevo. Em relação ao traçado, os trechos de projeto elaborados possuem extensão média de $3 \mathrm{~km}$, abrangendo duas tangentes fixas. As curvas de análise foram adequadas a estas duas tangentes, sem a adição de curvas de transição. Adotou-se um sistema métrico arbitrário de coordenadas e orientação, já que o interesse estava na posição relativa entre as feições no projeto viário.

O ângulo central das curvas foi de $90^{\circ}$ para qualquer raio analisado. Previamente, ângulos centrais distintos, maiores e menores que $90^{\circ}$, foram testados. Não foram constatadas diferenças significativas, ou seja, superior a precisão de $0,05 \mathrm{~m}$ estipulada para a execução das simulações. $O$ fato que nos demais casos testados o desenvolvimento em curva sempre foi maior do que a DVP analisada, não interferindo na acomodação da DVP sobre a via, durante a análise de visibilidade. Situações que a DVP seja superior que o desenvolvimento da curva devem ser analisadas caso a caso.

Nos cenários construídos analisou-se para as hipóteses premissas se a DVP era satisfeita. A análise foi feita visualmente quando a obstrução era óbvia e por relatório gerado pelo programa que indica as coordenadas dos pontos onde há obstrução para a distância de visibilidade testada. Ao encontrar problema na visibilidade, altera-se a seção transversal, incrementando $0,05 \mathrm{~m}$ no afastamento lateral da barreira, e realiza novo teste para verificar se o problema foi solucionado. Em casos que a visibilidade era satisfeita, testava-se o valor inferior do afastamento lateral para garantir que o valor encontrado representasse o menor afastamento possível para que a DVP fosse garantida.

As simulações realizadas considerando as hipóteses apresentadas e barreiras de $0,81 \mathrm{~m}$ retornaram para todos os casos afastamentos laterais da barreira nulos. Não significa ausências de problemas de obstrução com barreiras desta altura, E sim que a metodologia proposta foi incapaz de modelar os fatores que podem interferir na análise de visibilidade. 
A questão levantada é se caso a consideração de coordenação com curvas verticais tivesse sido uma das hipóteses premissas o resultado seria mais próximo do real. Para tal, cenários foram criados com curvas à esquerda englobando as hipóteses anteriores e a ocorrência de curvas verticais - côncavas e convexas. As distâncias de visibilidade foram testadas e os afastamentos laterais definidos. Em curvas côncavas, os afastamentos laterais da barreira mínimos continuaram nulos para a garantia da DVP. Já em curvas côncavas, problemas de visibilidade foram constatados. Os maiores valores de DVP assumidos na análise pois referem ao menor valor declividade, pois analisar a transição de valores de DVP entre declividades diferentes é uma limitação da metodologia proposta.

Seja curva com raio horizontal igual a $500 \mathrm{~m}$ em que foi imposta curva vertical côncava para suprir a variação da declividade do greide de $+3 \%$ a $-2 \%$ (Figura 3.10) de raio aproximado de $15700 \mathrm{~m}$ com desenvolvimento de $550 \mathrm{~m}$, superior a qualquer valor de DVP a ser analisado. .

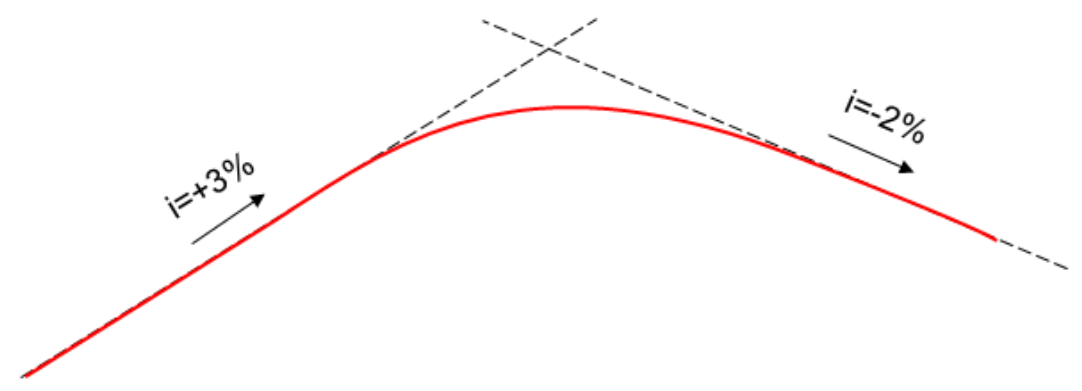

Figura 3.10. Curva vertical simulada ao invés de rampa constante para cenário com altura de barreira de $0,81 \mathrm{~m}$.

Ao analisar a DVP com seção transversal com barreira de altura igual a 0,81 m constata-se que para afastamentos laterais nulos existem problemas de obstrução da linha de visão do motorista. A Tabela 3.7 apresenta síntese dos resultados encontrados. Afastamentos laterais não nulos foram determinados para $100 \mathrm{~km} / \mathrm{h}$ e $90 \mathrm{~km} / \mathrm{h}$, com medidas de $0,15 \mathrm{~m}$ e $0,60 \mathrm{~m}$, respectivamente. 
Tabela 3.7. Resultados considerando concordância com curva vertical côncava

\begin{tabular}{|c|c|c|}
\hline \multicolumn{3}{|c|}{ Análise da simulação supondo coordenação com curva vertical côncava } \\
\hline Velocidade & DVP & Afastamento Lateral da Barreira \\
\hline $100 \mathrm{~km} / \mathrm{h}$ & $222 \mathrm{~m}$ & $0,00 \mathrm{~m}$ \\
\hline $100 \mathrm{~km} / \mathrm{h}$ & $190 \mathrm{~m}$ & $0,15 \mathrm{~m}$ \\
\hline $90 \mathrm{~km} / \mathrm{h}$ & $160 \mathrm{~m}$ & $0,60 \mathrm{~m}$ \\
\hline
\end{tabular}

Outras curvas diferentes foram analisadas, com resultados semelhantes a Tabela 3.7 (afastamentos não nulos) constatando-se a limitação da metodologia para casos de barreira de altura de 0,81 $\mathrm{m}$. Assim sendo, apenas os dados das barreiras de altura de $1,00 \mathrm{~m}$ e $1,40 \mathrm{~m}$ foram tratados neste trabalho, definindo-se assim dois grupos de análise denominados de A e B.

O grupo $A$ compreendeu as simulações referentes à barreira de altura igual a 1,00 $\mathrm{m}$, com sete cenários de análise conforme apresentado no capítulo anterior. A Tabela 3.8 apresenta resumo quantitativo dos valores amostrados para o grupo A. No total obtiveram-se 586 valores de afastamento lateral da barreira definidos em função da velocidade de projeto, declividade do greide e raio da curva horizontal. Ressalta-se que, para cada valor final obtido, foram simuladas em média outras três possibilidades, para mais ou para menos, em função da precisão estipulada de \pm 0,05 m, de modo que o número de análises é superior a 1700 possibilidades para o grupo A.

Tabela 3.8. Resumo quantitativo - GRUPO A - $h_{B}=1,00 \mathrm{~m}$

\begin{tabular}{|c|c|c|c|c|c|c|c|c|c|}
\hline & \multicolumn{8}{|c|}{ GRUPO A $-h_{B}=1,00 \mathrm{~m}$} \\
\hline & & \multicolumn{7}{|c|}{ Declividade do greide } & \multirow{2}{*}{$\begin{array}{l}\text { Quantidade por } \\
\text { velocidade }\end{array}$} \\
\hline & & $-9 \%$ & $-6 \%$ & $-3 \%$ & $0 \%$ & $3 \%$ & $6 \%$ & $9 \%$ & \\
\hline \multirow{7}{*}{ 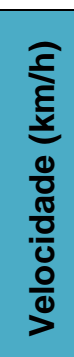 } & 60 & 6 & 5 & 5 & 5 & 4 & 4 & 3 & 32 \\
\hline & 70 & 10 & 9 & 8 & 7 & 6 & 6 & 6 & 52 \\
\hline & 80 & 15 & 13 & 11 & 10 & 8 & 8 & 7 & 72 \\
\hline & 90 & 18 & 18 & 17 & 16 & 14 & 12 & 11 & 106 \\
\hline & 100 & 17 & 17 & 17 & 17 & 17 & 17 & 15 & 117 \\
\hline & 110 & 11 & 16 & 16 & 16 & 16 & 16 & 16 & 107 \\
\hline & 120 & 10 & 15 & 15 & 15 & 15 & 15 & 15 & 100 \\
\hline
\end{tabular}


Por sua vez, o grupo B abrangeu as simulações referentes à barreira de altura igual a 1,40 m, com os mesmos cenários do grupo anterior. A Tabela 3.9 apresenta resumo quantitativo dos valores amostrados para o grupo B. Este grupo totalizou 335 valores de afastamento lateral. Assim como o grupo anterior, estima-se que a quantidade de análises realizadas foi superior a três vezes este total.

Tabela 3.9. Resumo quantitativo - GRUPO B $-h_{B}=1,00 \mathrm{~m}$

\begin{tabular}{|c|c|c|c|c|c|c|c|c|c|}
\hline & \multicolumn{8}{|c|}{ GRUPO B $-h_{B}=1,40 \mathrm{~m}$} \\
\hline & & \multicolumn{7}{|c|}{ Declividade do greide } & \multirow{2}{*}{$\begin{array}{l}\text { Quantidade por } \\
\text { velocidade }\end{array}$} \\
\hline & & $-9 \%$ & $-6 \%$ & $-3 \%$ & $0 \%$ & $3 \%$ & $6 \%$ & $9 \%$ & \\
\hline \multirow{7}{*}{ 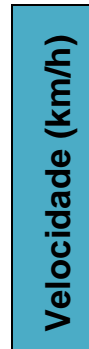 } & 60 & 5 & 5 & 4 & 4 & 4 & 4 & 3 & 29 \\
\hline & 70 & 7 & 7 & 6 & 5 & 6 & 5 & 5 & 41 \\
\hline & 80 & 11 & 9 & 9 & 8 & 7 & 6 & 7 & 57 \\
\hline & 90 & 10 & 12 & 12 & 11 & 10 & 9 & 8 & 72 \\
\hline & 100 & 6 & 8 & 10 & 11 & 12 & 12 & 11 & 70 \\
\hline & 110 & 1 & 3 & 6 & 6 & 9 & 10 & 10 & 45 \\
\hline & 120 & 0 & 0 & 0 & 2 & 5 & 6 & 7 & 20 \\
\hline & & & & & & & & & 334 \\
\hline
\end{tabular}

No grupo $\mathrm{B}$ duas situações devem ser destacadas. A primeira refere-se à velocidade de projeto de $120 \mathrm{~km} / \mathrm{h}$. Não houve valor inferior a 2,50 m para o afastamento da barreira que atendesse aos critérios da DVP nos casos de declive - declividade do greide igual a $-9 \%,-6 \%$ e $-3 \%$. Em segundo, para velocidade de projeto de $110 \mathrm{~km} / \mathrm{h}$ e declividade do greide igual $-9 \%$ apenas um valor foi definido, sendo descartado das análises posteriores por não ser representativo.

Os dados brutos observados compreendem o Anexo I deste texto. Finalizada a etapa de simulações, iniciou-se o processo tratamento matemático dos dois conjuntos de dados para que viabilizasse as análises posteriores sobre as informações geradas. 


\subsection{Tratamento Matemático dos dados}

As simulações resultaram em conjuntos de valores estimados do afastamento lateral da barreira em função do raio da curva horizontal geradas para cada situação analisada, definidas em função da declividade do greide, velocidade e altura da barreira. Sendo assim, modelos matemáticos foram ajustados a cada curva visando à manutenção da representatividade da distribuição dos dados provenientes do experimento.

O ajuste de curvas adotado fundamentou-se no princípio do Método dos Mínimos Quadrados (MMQ), definido por Gauss e Legendre, onde a melhor estimativa para uma grandeza $X$ é a que torna mínima a soma dos quadrados dos seus resíduos ${ }^{9}$ e forma a maximizar grau de ajuste do modelo aos dados observações, onde:

$$
\sum_{i}^{n}\left(l_{i}-\widehat{l}_{l}\right)^{2}=\text { mínimo }
$$

Onde

$$
\begin{aligned}
& l_{i} \text { é o valor observado; e } \\
& \widehat{l}_{l} \text { é o valor estimado pelo modelo. }
\end{aligned}
$$

Assim, adotou-se um modelo explícito para ajuste, também difundido com ajustamento paramétrico de observações, deduzido com maior detalhamento em Gemael (1994) e Dalmolin (2010).

\footnotetext{
${ }^{9}$ Considere o termo resíduo para a diferença entre o valor observado e o valor estimado dado pelo modelo ajustado.
} 


\subsubsection{Definição do Modelo}

A escolha do modelo matemático deve considerar a distribuição dos dados e suas tendências comportamentais. Assim, ajustes à diversos modelos foram criados graficamente com auxílio da planilha eletrônica Excel ${ }^{\circledR}$, onde se analisou qual destes modelos seria o mais adequado em função da natureza dos dados do experimento. A Figura 3.11 apresenta o ajuste de uma das curvas obtidas para um mesmo conjunto de dados do experimento.

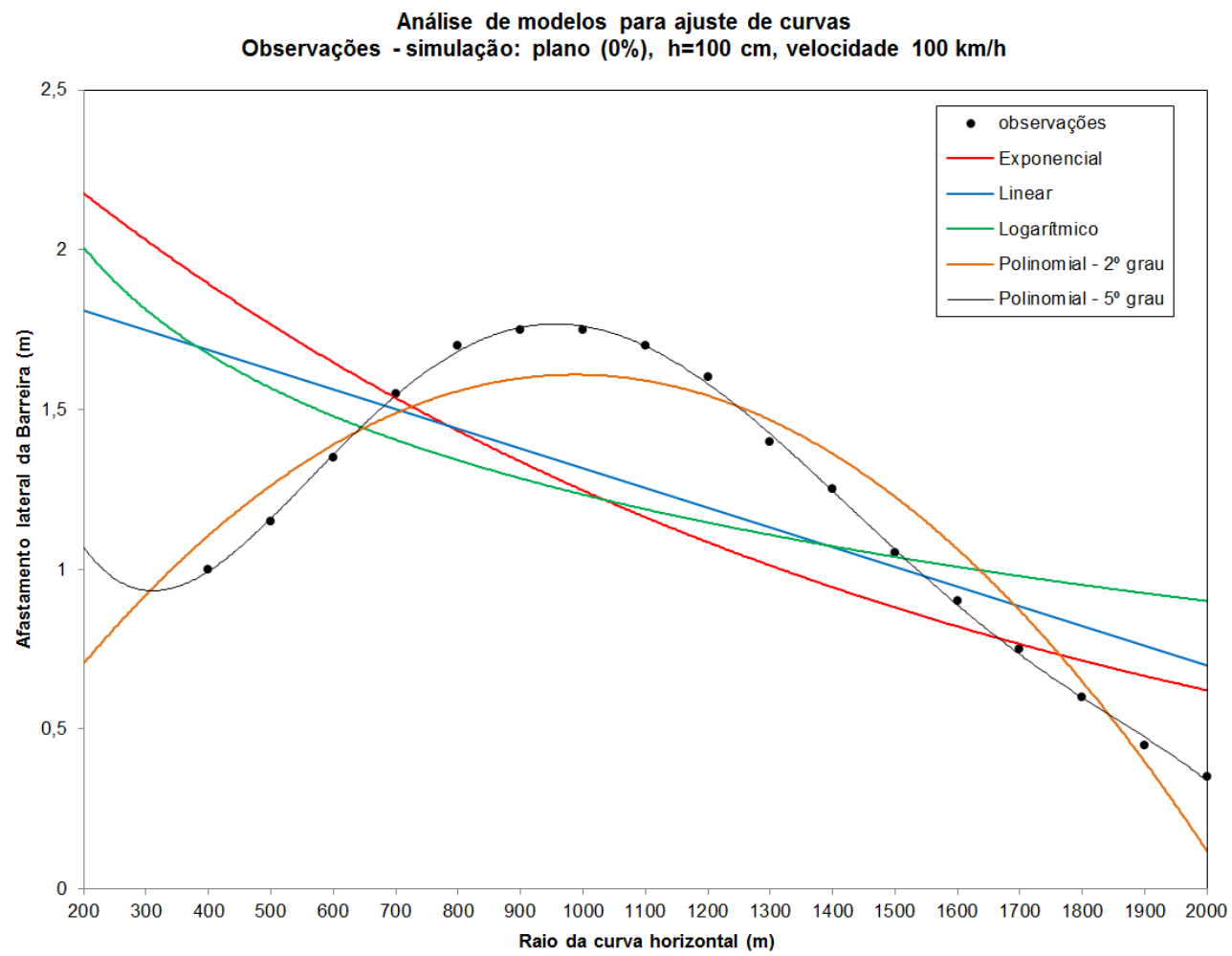

Figura 3.11. Análise de modelos para ajuste de curvas.

Modelos simples, como observado nos casos dos ajustes linear, exponencial ou potencial, não possuem variações compatíveis para se moldar com as 
peculiaridades dos dados do experimento. Observa-se que os melhores ajustes aos dados ocorreram nos casos de modelos definidos por funções polinomiais (linhas preta e laranja). Quanto maior a ordem do polinômio, melhor este se ajustará as características dos dados que definem morros e vales ao longo da distribuição. Logo, como critério adotou-se como modelo uma função polinomial univariada de $5^{\circ}$ grau dada por:

$$
f(x)=c_{0}+c_{1} \cdot x+c_{2} \cdot x^{2}+c_{3} \cdot x^{3}+c_{4} \cdot x^{4}+c_{5} \cdot x^{5}
$$

Onde

$f(x)$ é o valor de saída do polinômio;

$x$ é o valor de entrada do polinômio; e

$c_{0}, c_{1}, c_{2}, c_{3}, c_{4}, c_{5}$ são os coeficientes do polinômio de $5^{\circ}$ grau.

No caso deste estudo, o valor de saída do polinômio será a estimativa do afastamento lateral da barreira $\left(a_{L}\right)$ quando é fornecido o valor do raio da curva horizontal $R$ como entrada. Portanto, o modelo genérico adotado é:

$$
a_{L}=c_{0}+c_{1} \cdot R+c_{2} \cdot R^{2}+c_{3} \cdot R^{3}+c_{4} \cdot R^{4}+c_{5} \cdot R^{5}
$$

Onde

$a_{L}$ é o valor estimado do afastamento lateral da barreira; e

$R$ é o raio da curva horizontal. 
Para cada conjunto de dados $^{10}$ foi definida uma equação da forma do polinômio acima. Casos onde o conjunto de dados não possui quantidade significativa para ajuste de polinômio de $5^{\circ}$ grau, foram tratados como exceções à regra e, adotaramse polinômios de grau inferior até que o ajuste seja possível.

\subsubsection{Ajustamento Paramétrico}

Um ajustamento é dito paramétrico quando o modelo matemático é verificado:

$$
L_{a}=F\left(X_{a}\right)
$$

Em que

$$
\begin{aligned}
& L_{a} \text { é o vetor das observações ajustadas; e } \\
& X_{a} \text { é o vetor dos parâmetros ajustados. }
\end{aligned}
$$

Sendo o modelo funcional apresentado no item anterior:

$$
a_{L}=c_{0}+c_{1} \cdot R+c_{2} \cdot R^{2}+c_{3} \cdot R^{3}+c_{4} \cdot R^{4}+c_{5} \cdot R^{5}
$$

O número de observações $(n)$ será o total de afastamento lateral da barreira que foi definido para cada conjunto de dados. O número de parâmetros (u) é igual a seis, o total de coeficientes do polinômio de $5^{\circ}$ grau a ser adotado. É requisito que haja

${ }^{10} \mathrm{O}$ conjunto de dados é definido por observações que tenham sido originadas dos mesmos valores de parâmetros do projeto: declividade do greide, altura da barreira e velocidade de projeto. Apenas sendo variável o raio da curva horizontal. 
superabundância de observações onde $(n>u)$; caso contrário, polinômios de grau inferior serão adotados até que o requisito seja atendido.

Logo, temos a definição do vetor das observações $\left(L_{b}\right)$, que consiste nos valores de afastamento lateral da barreira definidos em cada conjunto de dados, podendo ser escrito na forma:

$$
L_{b}=\left[\begin{array}{c}
a_{L_{1}}^{o b s} \\
a_{L_{2}}^{o b s} \\
a_{L_{3}^{o b s}}^{o b} \\
\vdots \\
a_{L_{n}^{o b s}}^{o b}
\end{array}\right]
$$

$E$

$$
L=L_{0}-L_{b}=0-L_{b} \rightarrow L=-L_{b}
$$

Onde $L_{0}$ é o vetor das observações aproximadas, adotado como nulo, e $L$ é um vetor numérico calculado a partir de $L_{0}$ e $L_{b}$, possuindo as mesmas dimensões destes vetores.

Ainda para os cálculos é necessário definir $A$ que é a matriz das derivadas parciais das funções do modelo matemático em relação aos parâmetros.

$$
\begin{aligned}
A=\frac{\partial F}{\partial \text { Parametros }}= & =\left[\begin{array}{ccccccc}
\frac{\partial a_{L_{1}}}{\partial c_{0}} & \frac{\partial a_{L_{1}}}{\partial c_{1}} & \frac{\partial a_{L_{1}}}{\partial c_{2}} & \frac{\partial a_{L_{1}}}{\partial c_{3}} & \frac{\partial a_{L_{1}}}{\partial c_{4}} & \frac{\partial a_{L_{1}}}{\partial c_{5}} \\
\frac{\partial a_{L_{2}}}{\partial c_{0}} & \frac{\partial a_{L_{2}}}{\partial c_{1}} & \frac{\partial a_{L_{2}}}{\partial c_{2}} & \frac{\partial a_{L_{2}}}{\partial c_{3}} & \frac{\partial a_{L_{2}}}{\partial c_{4}} & \frac{\partial a_{L_{2}}}{\partial c_{5}} \\
\frac{\partial a_{L_{n}}}{\partial c_{0}} & \frac{\partial a_{L_{n}}}{\partial c_{1}} & \frac{\partial a_{L_{n}}}{\partial c_{2}} & \frac{\partial a_{L_{n}}}{\partial c_{3}} & \frac{\partial a_{L_{n}}}{\partial c_{4}} & \frac{\partial a_{L_{n}}}{\partial c_{5}}
\end{array}\right] \\
A & =\left[\begin{array}{ccccccc}
1 & R_{1} & R_{1}^{2} & R_{1}^{3} & R_{1}^{4} & R_{1}^{5} \\
1 & R_{2} & R_{2}^{2} & R_{2}^{3} & R_{2}^{4} & R_{2}^{5} \\
1 & R_{n} & R_{n}^{2} & R_{n}^{3} & R_{n}^{4} & R_{n}^{5}
\end{array}\right]
\end{aligned}
$$


A matriz $P$ é uma matriz quadrada $(n x n)$ que representa o peso das observações. Foi adotada como sendo a matriz identidade $I$, ou seja, as observações não diferem de importância. Logo, o vetor dos parâmetros ajustados é dado por:

$$
\begin{gathered}
X=-\left(A^{T} P A\right)^{-1}\left(A^{T} P L\right) \\
X=-\left[-\left(A^{T} I A\right)^{-1}\left(A^{T} I L_{b}\right)\right]
\end{gathered}
$$

Então

$$
X=\left(A^{T} A\right)^{-1}\left(A^{T} L_{b}\right)
$$

$X$ é um vetor contendo os parâmetros ajustados. Neste caso, são os coeficientes do polinômio apresentados conforme a ordem das derivadas parciais que compõe a matriz $A$.

$$
X=\left[\begin{array}{l}
c_{1} \\
c_{2} \\
c_{3} \\
c_{4} \\
c_{5} \\
c_{6}
\end{array}\right]
$$

Por fim, é possível estruturar a equação da curva ajustada utilizando o modelo funcional apresentado no início do processo de ajuste.

\subsubsection{Coeficiente de determinação $\left(r^{2}\right)$}

Para averiguar a qualidade na determinação do modelo, adota-se a análise do coeficiente de determinação $r^{2}$. O coeficiente de determinação indica o percentual de observações que estão sendo explicitadas pelo modelo. É calculado pela fórmula matricial, utilizando valores definidos durante o ajustamento paramétrico: 


$$
r^{2}=\frac{X^{T} A^{T} P Z}{Z^{T} Z}
$$

Onde:

$r^{2}$ é o coeficiente de determinação;

$X$ é o vetor dos parâmetros ajustados;

$A$ é a matriz com os coeficientes das incógnitas;

$P$ é a matriz dos pesos; e

$Z$ é o vetor determinado pela diferença de cada uma das observações e a média do conjunto de observações.

Ou ainda o coeficiente de determinação pode ser calculado por:

$$
r^{2}=1-\frac{\sum\left(l_{i}-\widehat{l}_{l}\right)^{2}}{\left(\sum\left(l_{i}^{2}\right)-\frac{\left(\sum l_{i}\right)^{2}}{n}\right)}
$$

Em que

$l_{i}$ é o valor observado;

$\widehat{l}_{l}$ é o valor estimado pelo modelo ajustado; e

$n$ é a quantidade total de observações existentes.

Quanto mais próximo o valor do coeficiente é da unidade melhor é a correlação entre o modelo e dados de origem. Na prática, simplifica-se esta análise pelos critérios apresentados na Tabela 3.10. 
Tabela 3.10. Critérios de análise de $r^{2}$

\begin{tabular}{cc}
\hline Valor de $r^{2}$ & Correlação \\
\hline$r^{2}=0$ & Nula \\
$0,00<r^{2} \leq 0,30$ & Fraca \\
$0,30<r^{2} \leq 0,60$ & Média \\
$0,60<r^{2} \leq 0,90$ & Forte \\
$0,90<r^{2} \leq 0,99$ & Fortíssima \\
$r^{2}=1$ & Perfeita \\
\hline
\end{tabular}

\subsubsection{Modelos calculados}

Os cálculos apresentados em 3.6.2 e 3.6.3 foram executados por meio de rotina desenvolvida no $M A T L A B^{\circledR}$, devido à sua facilidade no cálculo matricial. $O$ valor do raio da curva horizontal foi considerado em quilômetros, para viabilizar a determinação das inversas das matrizes. Devido à quantidade de dados, os modelos adotados para as curvas com velocidade igual a $60 \mathrm{~km} / \mathrm{h}$ e $70 \mathrm{~km} / \mathrm{h}$ foram de $3^{\circ}$ e $4^{\circ}$ grau respectivamente.

Os modelos calculados e os respectivos valores de coeficiente de regressão são apresentados nas tabelas subsequentes, organizadas em função da dos grupos de análise. Os modelos calculados atendem às hipóteses discutidas no item 3.4

3.6.4.1. Modelos - Grupo A - altura da barreira igual a 1,00 m

As Tabelas 3.11 a 3.17 apresentam os modelos obtidos através da regressão matemática para cada velocidade de projeto analisada no grupo A. Além disso, a cada curva está associado seu respectivo valor de coeficiente de determinação. Em todos os modelos gerados os valores de $r^{2}$ foram próximos a 1 , indicando boa aderência dos modelos ao comportamento dos conjuntos de dados ou iguais a 1 indicando o modelo como solução única encontrada devido ao conjunto limitado de pontos, como observado na Tabela 3.11 para a velocidade de $60 \mathrm{~km} / \mathrm{h}$. 
Tabela 3.11. Modelagem Matemática para $V=60 \mathrm{~km} / \mathrm{h}$ e $h_{B}=1,00 \mathrm{~m}$

\begin{tabular}{|c|c|c|c|c|c|c|c|}
\hline \multirow{3}{*}{ CURVA } & \multicolumn{5}{|c|}{$a_{L}=c_{0}+c_{1} \cdot R+c_{2} \cdot R^{2}+c_{3} \cdot R^{3}$} & \multicolumn{2}{|c|}{ ( $R$ em quilômetros) } \\
\hline & \multicolumn{6}{|c|}{ Coeficientes do modelo polinomial ajustado } & \multirow{2}{*}{$\mathbf{r}^{2}$} \\
\hline & $c_{0}$ & $c_{1}$ & $c_{2}$ & $c_{3}$ & $c_{4}$ & $c_{5}$ & \\
\hline$i=-9 \%$ & $-2,4786$ & 29,2956 & $-69,8214$ & 47,2222 & - & - & 0,9955 \\
\hline$i=-6 \%$ & $-3,0900$ & 35,3690 & $-90,3571$ & 66,6667 & - & - & 0,9994 \\
\hline$i=-3 \%$ & $-1,9600$ & 27,6964 & $-78,2143$ & 62,5000 & - & - & 1,0000 \\
\hline $\boldsymbol{i}=\mathbf{0} \%$ & $-1,2600$ & 22,8810 & $-69,6429$ & 58,3333 & - & - & 0,9993 \\
\hline$i=3 \%$ & $-0,5000$ & 18,0833 & $-67,5000$ & 66,6667 & - & - & 1,0000 \\
\hline$i=6 \%$ & $-1,2500$ & 24,5833 & $-90,0000$ & 91,6667 & - & - & 1,0000 \\
\hline$i=9 \%$ & 0,9214 & 0,6848 & $-5,4473$ & $-5,0585$ & - & - & 1,0000 \\
\hline
\end{tabular}

Tabela 3.12. Modelagem Matemática para $V=70 \mathrm{~km} / \mathrm{h}$ e $h_{B}=1,00 \mathrm{~m}$

\begin{tabular}{|c|c|c|c|c|c|c|c|}
\hline \multirow{3}{*}{ CURVA } & \multicolumn{5}{|c|}{$a_{L}=c_{0}+c_{1} \cdot R+c_{2} \cdot R^{2}+c_{3} \cdot R^{3}+c_{4} \cdot R^{4}$} & \multicolumn{2}{|c|}{ ( $R$ em quilômetros) } \\
\hline & \multicolumn{6}{|c|}{ Coeficientes do modelo polinomial ajustado } & \multirow{2}{*}{$\mathbf{r}^{2}$} \\
\hline & $c_{0}$ & $c_{1}$ & $c_{2}$ & $c_{3}$ & $c_{4}$ & $c_{5}$ & \\
\hline $\boldsymbol{i}=-\mathbf{9} \%$ & $-2,2955$ & 21,0817 & $-36,7089$ & 21,3772 & $-3,3508$ & - & 0,9932 \\
\hline$i=-6 \%$ & $-1,4778$ & 15,6459 & $-24,7290$ & 7,3750 & 3,2051 & - & 0,9930 \\
\hline$i=-3 \%$ & $-0,5310$ & 8,9123 & $-8,0492$ & $-13,2576$ & 13,2576 & - & 0,9991 \\
\hline $\boldsymbol{i}=\mathbf{0} \%$ & $-0,7607$ & 11,8360 & $-19,6591$ & 1,5152 & 7,5758 & - & 0,9978 \\
\hline$i=\mathbf{3} \%$ & $-0,4036$ & 10,1052 & $-18,2292$ & $-0,6944$ & 10,4167 & - & 0,9999 \\
\hline$i=6 \%$ & 1,1571 & $-5,5437$ & 38,1250 & $-90,2778$ & 62,5000 & - & 0,9996 \\
\hline$i=\mathbf{~ 9 \%}$ & $-0,5357$ & 14,6766 & $-41,2500$ & 30,5556 & 0,0000 & - & 0,9913 \\
\hline
\end{tabular}

Tabela 3.13. Modelagem Matemática para $V=80 \mathrm{~km} / \mathrm{h}$ e $h_{B}=1,00 \mathrm{~m}$

\begin{tabular}{|c|c|c|c|c|c|c|c|}
\hline \multirow{3}{*}{ CURVA } & \multicolumn{5}{|c|}{$a_{L}=c_{0}+c_{1} \cdot R+c_{2} \cdot R^{2}+c_{3} \cdot R^{3}+c_{4} \cdot R^{4}+c_{5} \cdot R^{5}$} & \multicolumn{2}{|c|}{ ( $R$ em quilômetros) } \\
\hline & \multicolumn{6}{|c|}{ Coeficientes do modelo polinomial ajustado } & \multirow{2}{*}{$\mathbf{r}^{2}$} \\
\hline & $c_{0}$ & $c_{1}$ & $c_{2}$ & $c_{3}$ & $c_{4}$ & $c_{5}$ & \\
\hline $\boldsymbol{i}=-\mathbf{9} \%$ & $-1,4987$ & 7,9785 & 3,8829 & $-21,8555$ & 16,4341 & $-3,7464$ & 0,9977 \\
\hline$i=-6 \%$ & $-0,2759$ & 0,5386 & 22,5098 & $-47,2272$ & 33,1097 & $-7,8243$ & 0,9980 \\
\hline$i=-3 \%$ & 0,9017 & $-7,7205$ & 46,4219 & $-83,8542$ & 60,0233 & $-15,2244$ & 0,9995 \\
\hline $\boldsymbol{i}=\mathbf{0} \%$ & 2,2936 & $-18,2293$ & 78,5883 & $-134,6707$ & 98,6305 & $-26,2821$ & 0,9994 \\
\hline$i=3 \%$ & 8,5042 & $-75,0007$ & 276,0890 & $-467,3878$ & 368,3712 & $-110,5769$ & 0,9981 \\
\hline$i=6 \%$ & 3,2958 & $-27,5155$ & 116,1269 & $-214,2118$ & 175,1894 & $-52,8846$ & 0,9996 \\
\hline$i=9 \%$ & 1,4893 & $-8,7394$ & 44,2803 & $-88,3523$ & 71,9697 & $-20,8333$ & 0,9998 \\
\hline
\end{tabular}


Tabela 3.14. Modelagem Matemática para $V=90 \mathrm{~km} / \mathrm{h}$ e $h_{B}=1,00 \mathrm{~m}$

\begin{tabular}{|c|c|c|c|c|c|c|c|}
\hline \multirow{3}{*}{ CURVA } & \multicolumn{5}{|c|}{$a_{L}=c_{0}+c_{1} \cdot R+c_{2} \cdot R^{2}+c_{3} \cdot R^{3}+c_{4} \cdot R^{4}+c_{5} \cdot R^{5}$} & \multicolumn{2}{|c|}{ ( $R$ em quilômetros) } \\
\hline & \multicolumn{6}{|c|}{ Coeficientes do modelo polinomial ajustado } & \multirow{2}{*}{$\mathbf{r}^{2}$} \\
\hline & $c_{0}$ & $c_{1}$ & $c_{2}$ & $c_{3}$ & $c_{4}$ & $c_{5}$ & \\
\hline$i=-9 \%$ & 1,2634 & $-9,5785$ & 35,8177 & $-41,5979$ & 19,5086 & $-3,2610$ & 0,9987 \\
\hline$i=-6 \%$ & 0,9693 & $-6,2838$ & 27,8038 & $-35,0264$ & 17,3382 & $-3,0235$ & 0,9961 \\
\hline$i=-3 \%$ & 1,0627 & $-5,8617$ & 26,4446 & $-35,0096$ & 18,1591 & $-3,3093$ & 0,9971 \\
\hline $\boldsymbol{i}=\mathbf{0} \%$ & 1,9531 & $-11,0252$ & 38,5063 & $-48,9954$ & 25,7762 & $-4,8548$ & 0,9981 \\
\hline$i=3 \%$ & 2,2132 & $-11,7580$ & 39,3405 & $-51,8985$ & 28,7776 & $-5,7355$ & 0,9989 \\
\hline$i=6 \%$ & 2,6430 & $-14,2955$ & 46,2230 & $-62,8518$ & 36,7861 & $-7,8243$ & 0,9996 \\
\hline$i=9 \%$ & 3,2524 & $-17,5295$ & 54,1273 & $-74,7997$ & 45,8916 & $-10,4167$ & 0,9982 \\
\hline
\end{tabular}

Tabela 3.15. Modelagem Matemática para $V=100 \mathrm{~km} / \mathrm{h}$ e $h_{B}=1,00 \mathrm{~m}$

\begin{tabular}{|c|c|c|c|c|c|c|c|}
\hline \multirow{3}{*}{ CURVA } & \multicolumn{5}{|c|}{$a_{L}=c_{0}+c_{1} \cdot R+c_{2} \cdot R^{2}+c_{3} \cdot R^{3}+c_{4} \cdot R^{4}+c_{5} \cdot R^{5}$} & \multicolumn{2}{|c|}{ ( $R$ em quilômetros) } \\
\hline & \multicolumn{6}{|c|}{ Coeficientes do modelo polinomial ajustado } & \multirow{2}{*}{$\mathbf{r}^{2}$} \\
\hline & $c_{0}$ & $c_{1}$ & $c_{2}$ & $c_{3}$ & $c_{4}$ & $c_{5}$ & \\
\hline $\boldsymbol{i}=-\mathbf{9} \%$ & 2,4474 & $-13,5742$ & 33,4622 & $-29,7661$ & 11,3321 & $-1,5951$ & 0,9984 \\
\hline$i=-6 \%$ & 0,8509 & $-4,2779$ & 15,1317 & $-13,7394$ & 4,6365 & $-0,5061$ & 0,9987 \\
\hline$i=-3 \%$ & 1,8696 & $-9,4662$ & 26,3503 & $-25,8473$ & 10,5581 & $-1,5604$ & 0,9991 \\
\hline $\boldsymbol{i}=\mathbf{0} \%$ & 2,4188 & $-11,8441$ & 31,2440 & $-31,3728$ & 13,4035 & $-2,0888$ & 0,9992 \\
\hline$i=3 \%$ & 2,5640 & $-11,8384$ & 30,5169 & $-31,1482$ & 13,5623 & $-2,1458$ & 0,9996 \\
\hline$i=6 \%$ & 1,7626 & $-6,6378$ & 19,5876 & $-21,5630$ & 9,7444 & $-1,5703$ & 0,9993 \\
\hline$i=9 \%$ & 3,3406 & $-15,1402$ & 37,1092 & $-39,4191$ & 18,4577 & $-3,1858$ & 0,9988 \\
\hline
\end{tabular}

Tabela 3.16. Modelagem Matemática para $V=110 \mathrm{~km} / \mathrm{h}$ e $h_{B}=1,00 \mathrm{~m}$

\begin{tabular}{|c|c|c|c|c|c|c|c|}
\hline \multirow{3}{*}{ CURVA } & \multicolumn{5}{|c|}{$a_{L}=c_{0}+c_{1} \cdot R+c_{2} \cdot R^{2}+c_{3} \cdot R^{3}+c_{4} \cdot R^{4}+c_{5} \cdot R^{5}$} & \multicolumn{2}{|c|}{ ( $R$ em quilômetros, } \\
\hline & \multicolumn{6}{|c|}{ Coeficientes do modelo polinomial ajustado } & \multirow{2}{*}{$\mathbf{r}^{2}$} \\
\hline & $c_{0}$ & $c_{1}$ & $c_{2}$ & $c_{3}$ & $c_{4}$ & $c_{5}$ & \\
\hline$i=-9 \%$ & 2,9480 & $-13,7851$ & 27,7195 & $-21,4540$ & 7,5233 & $-1,0203$ & 0,9993 \\
\hline$i=-6 \%$ & 3,4092 & $-15,4339$ & 30,8621 & $-24,6534$ & 8,9729 & $-1,2652$ & 0,9990 \\
\hline$i=-3 \%$ & 4,0640 & $-18,1438$ & 36,0157 & $-29,5816$ & 11,0679 & $-1,5902$ & 0,9975 \\
\hline $\boldsymbol{i}=\mathbf{0} \%$ & 3,5480 & $-14,4175$ & 28,0246 & $-21,9579$ & 7,6060 & $-0,9873$ & 0,9959 \\
\hline$i=3 \%$ & 5,2437 & $-22,8765$ & 45,0362 & $-38,8588$ & 15,4414 & $-2,3493$ & 0,9975 \\
\hline$i=6 \%$ & 4,5133 & $-18,1686$ & 34,7283 & $-28,7912$ & 10,7578 & $-1,5108$ & 0,9966 \\
\hline $\boldsymbol{i}=\mathbf{9} \%$ & 5,2383 & $-21,3033$ & 40,5531 & $-34,5472$ & 13,4618 & $-1,9846$ & 0,9979 \\
\hline
\end{tabular}


Tabela 3.17. Modelagem Matemática para $V=120 \mathrm{~km} / \mathrm{h}$ e $h_{B}=1,00 \mathrm{~m}$

\begin{tabular}{|c|c|c|c|c|c|c|c|}
\hline \multirow{3}{*}{ CURVA } & \multicolumn{5}{|c|}{$a_{L}=c_{0}+c_{1} \cdot R+c_{2} \cdot R^{2}+c_{3} \cdot R^{3}+c_{4} \cdot R^{4}+c_{5} \cdot R^{5}$} & \multicolumn{2}{|c|}{ ( $R$ em quilômetros) } \\
\hline & \multicolumn{6}{|c|}{ Coeficientes do modelo polinomial ajustado } & \multirow{2}{*}{$\mathbf{r}^{2}$} \\
\hline & $c_{0}$ & $c_{1}$ & $c_{2}$ & $c_{3}$ & $c_{4}$ & $c_{5}$ & \\
\hline$i=-\mathbf{9} \%$ & 1,5622 & $-1,7037$ & $-4,0050$ & 12,4155 & $-8,7121$ & 1,9231 & 0,9991 \\
\hline$i=-6 \%$ & 4,0584 & $-14,4815$ & 22,7869 & $-14,9267$ & 4,6335 & $-0,5785$ & 0,9992 \\
\hline$i=-3 \%$ & 6,2815 & $-23,9099$ & 38,8285 & $-28,1531$ & 9,8277 & $-1,3654$ & 0,9982 \\
\hline $\boldsymbol{i}=\mathbf{0} \%$ & 9,0190 & $-35,4684$ & 58,1246 & $-43,6738$ & 15,7593 & $-2,2342$ & 0,9955 \\
\hline$i=3 \%$ & 5,0796 & $-17,4657$ & 27,6378 & $-19,2543$ & 6,2815 & $-0,8023$ & 0,9939 \\
\hline$i=6 \%$ & 7,1263 & $-26,6671$ & 44,1803 & $-33,7435$ & 12,3143 & $-1,7623$ & 0,9874 \\
\hline$i=9 \%$ & 9,2015 & $-34,9825$ & 57,1557 & $-43,5983$ & 15,8718 & $-2,2505$ & 0,9855 \\
\hline
\end{tabular}

3.6.4.2. Modelos - Grupo B - altura da barreira igual a 1,40 m

As Tabelas 3.18 a 3.24 apresentam os modelos obtidos para o grupo B. Novamente, cada curva tem associado seu respectivo valor de coeficiente de determinação. Os valores de $r^{2}$ foram próximos a 1 , indicando boa aderência dos modelos ao comportamento dos dados ou iguais a 1 indicando o modelo como solução única, que neste grupo ocorreu em diversas velocidades analisadas. A curva de $\mathrm{i}=-6 \%$, na velocidade de $110 \mathrm{~km} / \mathrm{h}$ e a curva $\mathrm{i}=0 \%$ na velocidade de $120 \mathrm{~km} / \mathrm{h}$ foram definidas por modelos de $1^{\circ}$ e $2^{\circ}$ grau respectivamente devido à insuficiência de pontos.

Tabela 3.18. Modelagem Matemática para $V=60 \mathrm{~km} / \mathrm{h}$ e $h_{B}=1,40 \mathrm{~m}$

\begin{tabular}{|c|c|c|c|c|c|c|c|}
\hline \multirow{3}{*}{ CURVA } & \multicolumn{5}{|c|}{$a_{L}=c_{0}+c_{1} \cdot R+c_{2} \cdot R^{2}+c_{3} \cdot R^{3}$} & \multicolumn{2}{|c|}{ ( $R$ em quilômetros) } \\
\hline & \multicolumn{6}{|c|}{ Coeficientes do modelo polinomial ajustado } & \multirow{2}{*}{$\mathbf{r}^{2}$} \\
\hline & $c_{0}$ & $c_{1}$ & $c_{2}$ & $c_{3}$ & $c_{4}$ & $c_{5}$ & \\
\hline$i=-9 \%$ & 7,9986 & $-28,7619$ & 36,4286 & $-16,6667$ & - & - & 1,0000 \\
\hline$i=-6 \%$ & 6,5214 & $-21,1548$ & 19,8214 & $-4,1667$ & - & - & 0,9996 \\
\hline$i=-3 \%$ & 5,1500 & $-14,5833$ & 5,0000 & 8,3333 & - & - & 1,0000 \\
\hline $\boldsymbol{i}=\mathbf{0} \%$ & 5,3000 & $-16,3333$ & 7,5000 & 8,3333 & - & - & 1,0000 \\
\hline$i=\mathbf{3} \%$ & 7,7500 & $-38,4167$ & 62,5000 & $-33,3333$ & - & - & 1,0000 \\
\hline$i=6 \%$ & 6,5000 & $-29,6667$ & 37,5000 & $-8,3333$ & - & - & 1,0000 \\
\hline$i=\mathbf{9} \%$ & 5,5634 & $-22,2706$ & 13,6290 & 18,1900 & - & - & 1,0000 \\
\hline
\end{tabular}


Tabela 3.19. Modelagem Matemática para $V=70 \mathrm{~km} / \mathrm{h}$ e $h_{B}=1,40 \mathrm{~m}$

\begin{tabular}{|c|c|c|c|c|c|c|c|}
\hline \multirow{3}{*}{ CURVA } & \multicolumn{5}{|c|}{$a_{L}=c_{0}+c_{1} \cdot R+c_{2} \cdot R^{2}+c_{3} \cdot R^{3}+c_{4} \cdot R^{4}$} & \multicolumn{2}{|c|}{ ( $R$ em quilômetros) } \\
\hline & \multicolumn{6}{|c|}{ Coeficientes do modelo polinomial ajustado } & \multirow{2}{*}{$\mathbf{r}^{2}$} \\
\hline & $c_{0}$ & $c_{1}$ & $c_{2}$ & $c_{3}$ & $c_{4}$ & $c_{5}$ & \\
\hline $\boldsymbol{i}=-\mathbf{9} \%$ & 11,4301 & $-35,4601$ & 46,4015 & $-29,7980$ & 7,5758 & - & 1,0000 \\
\hline$i=-6 \%$ & 14,1274 & $-57,9224$ & 101,8750 & $-86,4899$ & 28,4091 & - & 1,0000 \\
\hline $\boldsymbol{i}=-\mathbf{3} \%$ & 10,6869 & $-41,1230$ & 69,3750 & $-59,7222$ & 20,8333 & - & 0,9999 \\
\hline $\boldsymbol{i}=\mathbf{0} \%$ & 15,3000 & $-76,6250$ & 161,8750 & $-162,5000$ & 62,5000 & - & 1,0000 \\
\hline$i=3 \%$ & 12,3000 & $-61,5417$ & 134,3750 & $-145,8333$ & 62,5000 & - & 1,0000 \\
\hline$i=6 \%$ & 10,1500 & $-47,7500$ & 97,0833 & $-100,0000$ & 41,6667 & - & 1,0000 \\
\hline$i=\mathbf{9} \%$ & 14,7000 & $-93,9167$ & 255,8333 & $-333,3333$ & 166,6667 & - & 1,0000 \\
\hline
\end{tabular}

Tabela 3.20. Modelagem Matemática para $V=80 \mathrm{~km} / \mathrm{h}$ e $h_{B}=1,40 \mathrm{~m}$

\begin{tabular}{|c|c|c|c|c|c|c|c|}
\hline \multirow{3}{*}{ CURVA } & \multicolumn{5}{|c|}{$a_{L}=c_{0}+c_{1} \cdot R+c_{2} \cdot R^{2}+c_{3} \cdot R^{3}+c_{4} \cdot R^{4}+c_{5} \cdot R^{5}$} & \multicolumn{2}{|c|}{ ( $R$ em quilômetros) } \\
\hline & \multicolumn{6}{|c|}{ Coeficientes do modelo polinomial ajustado } & \multirow{2}{*}{$\mathbf{r}^{2}$} \\
\hline & $c_{0}$ & $c_{1}$ & $c_{2}$ & $c_{3}$ & $c_{4}$ & $c_{5}$ & \\
\hline $\boldsymbol{i}=-\mathbf{9} \%$ & 12,7079 & $-26,3689$ & 20,8654 & $-5,0809$ & $-1,7483$ & 0,8013 & 0,9997 \\
\hline$i=-6 \%$ & 11,2293 & $-28,2412$ & 34,6511 & $-25,0219$ & 9,8339 & $-1,6026$ & 0,9999 \\
\hline$i=-3 \%$ & 16,8119 & $-59,3409$ & 96,3913 & $-83,7413$ & 36,8590 & $-6,4103$ & 0,9997 \\
\hline $\boldsymbol{i}=\mathbf{0} \%$ & 5,6489 & 7,9004 & $-68,2102$ & 114,6780 & $-80,4924$ & 20,8333 & 0,9999 \\
\hline$i=3 \%$ & 8,5831 & $-21,5947$ & 21,4962 & $-10,2273$ & 1,8939 & 0,0000 & 1,0000 \\
\hline$i=6 \%$ & $-44,0998$ & 346,3905 & $-998,1218$ & 1383,3289 & $-937,4970$ & 249,9992 & 1,0000 \\
\hline $\boldsymbol{i}=\mathbf{9} \%$ & 25,1696 & $-152,4905$ & 408,8542 & $-564,6781$ & 387,3106 & $-104,1667$ & 0,9999 \\
\hline
\end{tabular}

Tabela 3.21. Modelagem Matemática para $V=90 \mathrm{~km} / \mathrm{h}$ e $h_{B}=1,40 \mathrm{~m}$

\begin{tabular}{|c|c|c|c|c|c|c|c|}
\hline \multicolumn{8}{|c|}{$a_{L}=c_{0}+c_{1} \cdot R+c_{2} \cdot R^{2}+c_{3} \cdot R^{3}+c_{4} \cdot R^{4}+c_{5} \cdot R^{5}$} \\
\hline
\end{tabular}


Tabela 3.22. Modelagem Matemática para $V=100 \mathrm{~km} / \mathrm{h}$ e $h_{B}=1,40 \mathrm{~m}$

\begin{tabular}{|c|c|c|c|c|c|c|c|}
\hline \multirow{3}{*}{ CURVA } & \multicolumn{5}{|c|}{$a_{L}=c_{0}+c_{1} \cdot R+c_{2} \cdot R^{2}+c_{3} \cdot R^{3}+c_{4} \cdot R^{4}+c_{5} \cdot R^{5}$} & \multicolumn{2}{|c|}{ ( $R$ em quilômetros) } \\
\hline & \multicolumn{6}{|c|}{ Coeficientes do modelo polinomial ajustado } & \multirow{2}{*}{$\mathbf{r}^{2}$} \\
\hline & $c_{0}$ & $c_{1}$ & $c_{2}$ & $c_{3}$ & $c_{4}$ & $c_{5}$ & \\
\hline $\boldsymbol{i}=-\mathbf{9} \%$ & $-85,5365$ & 115,1885 & 40,7652 & $-128,2589$ & 67,5730 & $-11,3030$ & 1,0000 \\
\hline$i=-6 \%$ & 111,6392 & $-340,2361$ & 431,7561 & $-276,3391$ & 88,2708 & $-11,2160$ & 0,9999 \\
\hline $\boldsymbol{i}=-\mathbf{3} \%$ & 0,0474 & 23,2908 & $-41,6013$ & 29,7904 & $-9,9359$ & 1,2821 & 0,9998 \\
\hline $\boldsymbol{i}=\mathbf{0} \%$ & 11,6911 & $-17,2762$ & 11,5268 & $-4,0210$ & 0,5828 & 0,0000 & 0,9998 \\
\hline$i=3 \%$ & 13,5985 & $-27,0839$ & 26,9257 & $-15,7385$ & 5,0027 & $-0,6599$ & 0,9999 \\
\hline$i=6 \%$ & 13,0703 & $-25,3308$ & 21,7525 & $-9,5712$ & 1,8854 & $-0,0943$ & 0,9998 \\
\hline$i=\mathbf{9} \%$ & 17,6879 & $-46,4486$ & 55,9812 & $-36,2398$ & 12,0192 & $-1,6026$ & 0,9997 \\
\hline
\end{tabular}

Tabela 3.23. Modelagem Matemática para $V=110 \mathrm{~km} / \mathrm{h}$ e $h_{B}=1,40 \mathrm{~m}$

\begin{tabular}{|c|c|c|c|c|c|c|c|}
\hline \multirow{3}{*}{ CURVA } & \multicolumn{5}{|c|}{$a_{L}=c_{0}+c_{1} \cdot R+c_{2} \cdot R^{2}+c_{3} \cdot R^{3}+c_{4} \cdot R^{4}+c_{5} \cdot R^{5}$} & \multicolumn{2}{|c|}{ ( $R$ em quilômetros) } \\
\hline & \multicolumn{6}{|c|}{ Coeficientes do modelo polinomial ajustado } & \multirow{2}{*}{$\mathbf{r}^{2}$} \\
\hline & $c_{0}$ & $c_{1}$ & $c_{2}$ & $c_{3}$ & $c_{4}$ & $c_{5}$ & \\
\hline$i=-9 \%$ & - & - & - & - & - & - & - \\
\hline$i=-6 \%$ & 5,9000 & $-2,0000$ & 0,0000 & \multicolumn{3}{|c|}{$2^{\circ} \mathrm{grau}$} & 1,0000 \\
\hline$i=-3 \%$ & 6,5481 & $-1,5235$ & $-2,2336$ & 1,6555 & $-0,6432$ & 0,1228 & 0,9998 \\
\hline $\boldsymbol{i}=\mathbf{0} \%$ & 73,6840 & $-85,0211$ & $-34,3407$ & 93,4334 & $-47,6885$ & 7,8288 & 1,0000 \\
\hline$i=3 \%$ & $-48,2234$ & 171,6604 & $-219,8310$ & 135,1917 & $-40,6471$ & 4,8077 & 0,9999 \\
\hline$i=6 \%$ & 25,1042 & $-64,4549$ & 80,1564 & $-53,8989$ & 18,5607 & $-2,5641$ & 0,9999 \\
\hline$i=\mathbf{9} \%$ & 67,2271 & $-201,5438$ & 253,3551 & $-160,9858$ & 50,9910 & $-6,4103$ & 0,9999 \\
\hline
\end{tabular}

Tabela 3.24. Modelagem Matemática para $V=120 \mathrm{~km} / \mathrm{h}$ e $h_{B}=1,40 \mathrm{~m}$

\begin{tabular}{|c|c|c|c|c|c|c|c|}
\hline \multirow{3}{*}{ CURVA } & \multicolumn{5}{|c|}{$a_{L}=c_{0}+c_{1} \cdot R+c_{2} \cdot R^{2}+c_{3} \cdot R^{3}+c_{4} \cdot R^{4}+c_{5} \cdot R^{5}$} & \multicolumn{2}{|c|}{ ( $R$ em quilômetros) } \\
\hline & \multicolumn{6}{|c|}{ Coeficientes do modelo polinomial ajustado } & \multirow{2}{*}{$\mathbf{r}^{2}$} \\
\hline & $c_{0}$ & $c_{1}$ & $c_{2}$ & $c_{3}$ & $c_{4}$ & $c_{5}$ & \\
\hline $\boldsymbol{i}=-\mathbf{9} \%$ & - & - & - & - & - & - & - \\
\hline$i=-6 \%$ & - & - & - & - & - & - & - \\
\hline $\boldsymbol{i}=-3 \%$ & - & - & - & - & - & - & - \\
\hline $\boldsymbol{i}=\mathbf{0} \%$ & 6,1500 & $-2,0000$ & \multicolumn{4}{|c|}{$1^{\circ} \mathrm{grau}$} & 1,0000 \\
\hline$i=3 \%$ & $-228,0900$ & 514,4360 & $-424,7730$ & 154,1597 & $-20,8324$ & 0,0000 & 1,0000 \\
\hline$i=6 \%$ & 73,7799 & $-85,0092$ & $-34,3544$ & 93,4412 & $-47,6907$ & 7,8290 & 1,0000 \\
\hline$i=\mathbf{9} \%$ & 344,9801 & $-977,1008$ & 1117,8840 & $-640,0008$ & 182,8604 & $-20,8445$ & 0,9987 \\
\hline
\end{tabular}




\subsubsection{Análise dos resíduos}

Os valores provenientes das simulações dos grupos $A$ e $B$, também foram calculados a partir dos modelos apresentados no item 3.6.4. Assim definiram-se diferenças, ou resíduos, entre o valor proveniente da simulação e o valor oriundo do modelo calculado. Os gráficos de resíduos para cada curva compreendem o Anexo II. Ao analisar a distribuição dos resíduos pelos gráficos notou-se que:

- Para casos onde o coeficiente de determinação é diferente de 1 , os resíduos ocorrem tanto positiva quanto negativamente, sem nenhuma tendência;

- Para casos onde o coeficiente de determinação é igual a 1, os resíduos são nulos, confirmando que o modelo adotado provém de uma solução única, no qual o polinômio se adequa as observações de entrada;

- A amplitude dos resíduos é coerente com a precisão das simulações assumindo na maioria dos casos variação de $\pm 0,05 \mathrm{~m}$, não havendo diferença maior que $0,10 \mathrm{~m}$.

Além disso, parâmetros estatísticos foram determinados para os sete cenários (velocidades de projeto) de cada um dos dois grupos (altura da barreira de 1,00 m e $1,40 \mathrm{~m}$ ) conforme mostra a Tabela 3.25.

Tabela 3.25. Parâmetros estatísticos dos resíduos dos grupos A e B.

\begin{tabular}{|l|c|c|c|c|c|c|c|c|}
\hline \multirow{2}{*}{} & \multicolumn{4}{c}{ GRUPO A } & \multicolumn{4}{c|}{ GRUPO B } \\
\cline { 2 - 9 } & \multicolumn{4}{c|}{$h_{B}=1,00 \mathrm{~m}$} & \multicolumn{3}{c|}{$h_{B}=10 \mathrm{~m}$} \\
\cline { 2 - 9 } & Média & $\begin{array}{c}\text { Desvio } \\
\text { Padrão }\end{array}$ & Amplitude & $\begin{array}{c}\text { Quantidade } \\
\text { de dados }\end{array}$ & Média & $\begin{array}{c}\text { Desvio } \\
\text { Padrão }\end{array}$ & Amplitude & $\begin{array}{c}\text { Quantidade } \\
\text { de dados }\end{array}$ \\
\hline$V=60 \mathrm{~km} / \mathrm{h}$ & 0,01 & 0,03 & 0,14 & 32 & 0,00 & 0,01 & 0,03 & 29 \\
\hline$V=70 \mathrm{~km} / \mathrm{h}$ & 0,00 & 0,04 & 0,17 & 52 & 0,00 & 0,00 & 0,02 & 41 \\
\hline$V=80 \mathrm{~km} / \mathrm{h}$ & 0,00 & 0,02 & 0,10 & 72 & 0,00 & 0,01 & 0,04 & 57 \\
\hline$V=90 \mathrm{~km} / \mathrm{h}$ & 0,00 & 0,03 & 0,15 & 106 & 0,00 & 0,01 & 0,06 & 72 \\
\hline$V=100 \mathrm{~km} / \mathrm{h}$ & 0,00 & 0,02 & 0,08 & 117 & 0,00 & 0,01 & 0,04 & 70 \\
\hline$V=110 \mathrm{~km} / \mathrm{h}$ & 0,00 & 0,02 & 0,07 & 107 & 0,00 & 0,01 & 0,02 & 44 \\
\hline$V=120 \mathrm{~km} / \mathrm{h}$ & 0,00 & 0,02 & 0,09 & 100 & 0,00 & 0,01 & 0,05 & 20 \\
\hline
\end{tabular}


Nos dois grupos, os valores das médias foram próximos à zero. O desvio padrão das curvas do grupo A foram maiores do que a das curvas do grupo B. Porém esta diferença não foi significativa. As amplitudes dos resíduos também foram maiores no grupo A, com variação de quase $20 \mathrm{~cm}$. No grupo B as amplitudes foram menores, com maior quantidade de pontos com resíduo nulo, devido ao maior índice de curvas com solução única $\left(r^{2}=1\right)$ situação a qual os polinômios se adequam perfeitamente as observações, fazendo com que os valores observados e calculados sejam o mesmo.

Histogramas e curvas de distribuição de normal de Gauss também foram elaborados para os cenários do grupo A (Figura 3.12) e do grupo B (Figura 3.13), no intuito de caracterizar o comportamento dos resíduos obtidos. Se os dados assumirem a forma da distribuição normal de Gauss, sem deformações, há indícios de que a probabilidade de valores positivos e negativos ocorrerem é a mesma e que valores menores tem maior probabilidade de ocorrência do que valores maiores. $O$ histograma foi gerado pela frequência de ocorrências em blocos $(\Delta x)$ de $0,01 \mathrm{~m}$. A curva de distribuição normal de Gauss, por sua vez, foi gerada a partir seu modelo matemático, dado por:

$$
f(x)=n \cdot \Delta x \cdot \frac{1}{\sigma \sqrt{2 \pi}} \cdot e^{-\frac{(x-\mu)^{2}}{2 \sigma^{2}}}
$$

Onde

$n$ é quantidade de observações;

$\Delta x$ o mínimo intervalo analisado ou bloco;

$\mu$ é a média das do conjunto observações; e

$\sigma$ é o desvio padrão do conjunto de observações.

Os gráficos do grupo A apresentam maior distribuição das ocorrências dos resíduos do que o grupo $B$, onde as maiores frequências estão concentradas próximas do valor zero. No grupo A existe dispersão dos dados nos gráficos das velocidades de $60 \mathrm{~km} / \mathrm{h}$ e $70 \mathrm{~km} / \mathrm{h}$ tornando a distribuição normal de Gauss achatada, ao invés do formato de "sino" que é usual. Em ambos os grupos, os resultados foram satisfatórios, pois o maior volume dos resíduos está compreendido dentro da faixa de precisão adotada durante as simulações, que é de $\pm 0,05 \mathrm{~m}$. 
GRUPO A

$h_{B}=1,00 \mathrm{~m}$
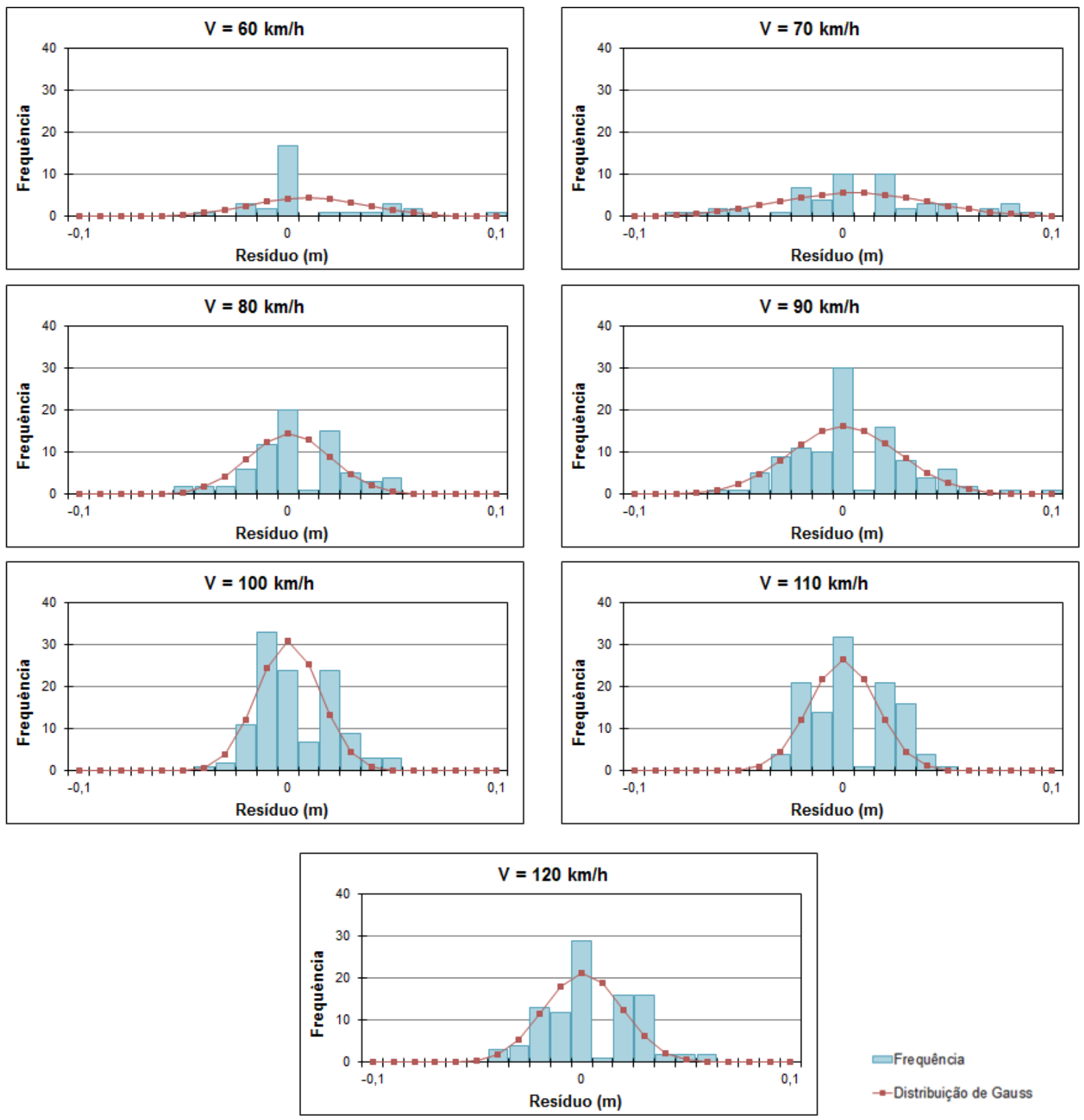

$\square$ Frequência

--Distribuição de Gauss

Figura 3.12. Grupo A - Resíduos - Histogramas e Curvas de distribuição normal de Gauss. 
GRUPO B

$h_{B}=1,40 \mathrm{~m}$
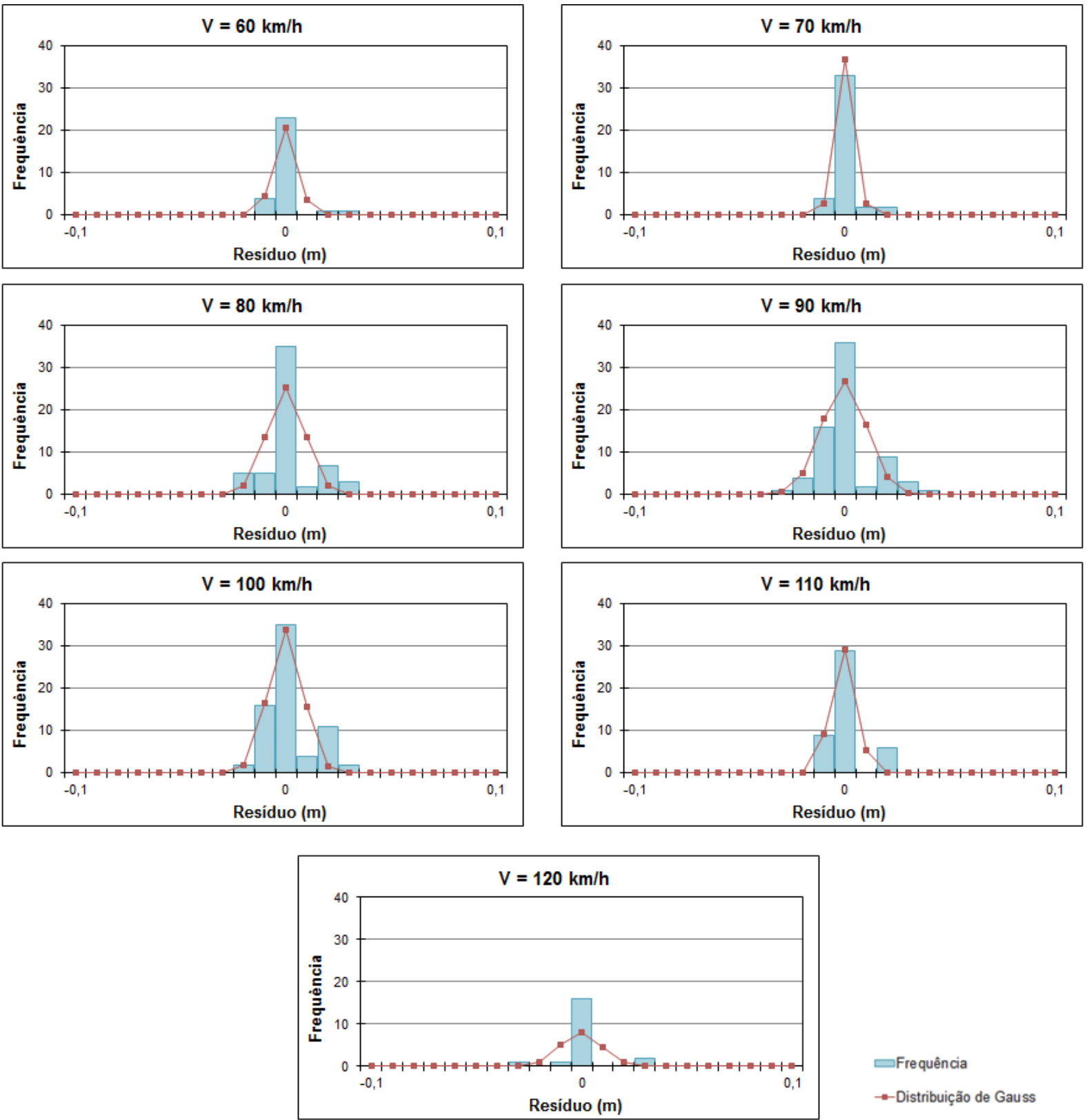

$\square$ Frequência

--Distribuição de Gauss

Figura 3.13. Grupo B - Resíduos - Histogramas e Curvas de distribuição normal de Gauss. 


\subsection{Resultado: Diagramas Gerados}

Diagramas para determinação do afastamento lateral da barreira foram gerados a partir da metodologia apresentada nos itens anteriores. Os diagramas são compostos dos modelos calculados e definidos em 3.6. No total, quatorze diagramas foram elaborados, que são:

\section{GRUPO A}

1. Afastamento lateral da barreira (m)

2. Afastamento lateral da barreira (m)

3. Afastamento lateral da barreira $(\mathrm{m})$

4. Afastamento lateral da barreira $(\mathrm{m})$

5. Afastamento lateral da barreira $(\mathrm{m})$

6. Afastamento lateral da barreira $(m)$

7. Afastamento lateral da barreira (m)

$$
\begin{array}{ll}
V=60 \mathrm{~km} / \mathrm{h} ; & \mathrm{h}_{B}=1,00 \mathrm{~m} \\
\mathrm{~V}=70 \mathrm{~km} / \mathrm{h} ; & \mathrm{h}_{B}=1,00 \mathrm{~m} \\
\mathrm{~V}=80 \mathrm{~km} / \mathrm{h} ; & \mathrm{h}_{B}=1,00 \mathrm{~m} \\
\mathrm{~V}=90 \mathrm{~km} / \mathrm{h} ; & \mathrm{h}_{B}=1,00 \mathrm{~m} \\
\mathrm{~V}=100 \mathrm{~km} / \mathrm{h} ; & \mathrm{h}_{B}=1,00 \mathrm{~m} \\
V=110 \mathrm{~km} / \mathrm{h} ; & \mathrm{h}_{B}=1,00 \mathrm{~m} \\
V=120 \mathrm{~km} / \mathrm{h} ; & \mathrm{h}_{B}=1,00 \mathrm{~m}
\end{array}
$$

GRUPO B

8. Afastamento lateral da barreira (m)

$\mathrm{V}=60 \mathrm{~km} / \mathrm{h} ; \quad \mathrm{h}_{\mathrm{B}}=1,40 \mathrm{~m}$

9. Afastamento lateral da barreira (m)

$\mathrm{V}=70 \mathrm{~km} / \mathrm{h} ; \quad \mathrm{h}_{\mathrm{B}}=1,40 \mathrm{~m}$

10. Afastamento lateral da barreira (m)

$\mathrm{V}=80 \mathrm{~km} / \mathrm{h} ; \quad \mathrm{h}_{\mathrm{B}}=1,40 \mathrm{~m}$

11. Afastamento lateral da barreira (m)

$\mathrm{V}=90 \mathrm{~km} / \mathrm{h} ; \quad \mathrm{h}_{\mathrm{B}}=1,40 \mathrm{~m}$

12. Afastamento lateral da barreira (m)

$V=100 \mathrm{~km} / \mathrm{h} ; \quad \mathrm{h}_{\mathrm{B}}=1,40 \mathrm{~m}$

13. Afastamento lateral da barreira (m)

$\mathrm{V}=110 \mathrm{~km} / \mathrm{h} ; \quad \mathrm{h}_{\mathrm{B}}=1,40 \mathrm{~m}$

14. Afastamento lateral da barreira (m)

$\mathrm{V}=120 \mathrm{~km} / \mathrm{h} ; \quad \mathrm{h}_{\mathrm{B}}=1,40 \mathrm{~m}$

Os diagramas são apresentados na mesma ordem, nas Figuras 3.14 a 3.27. 


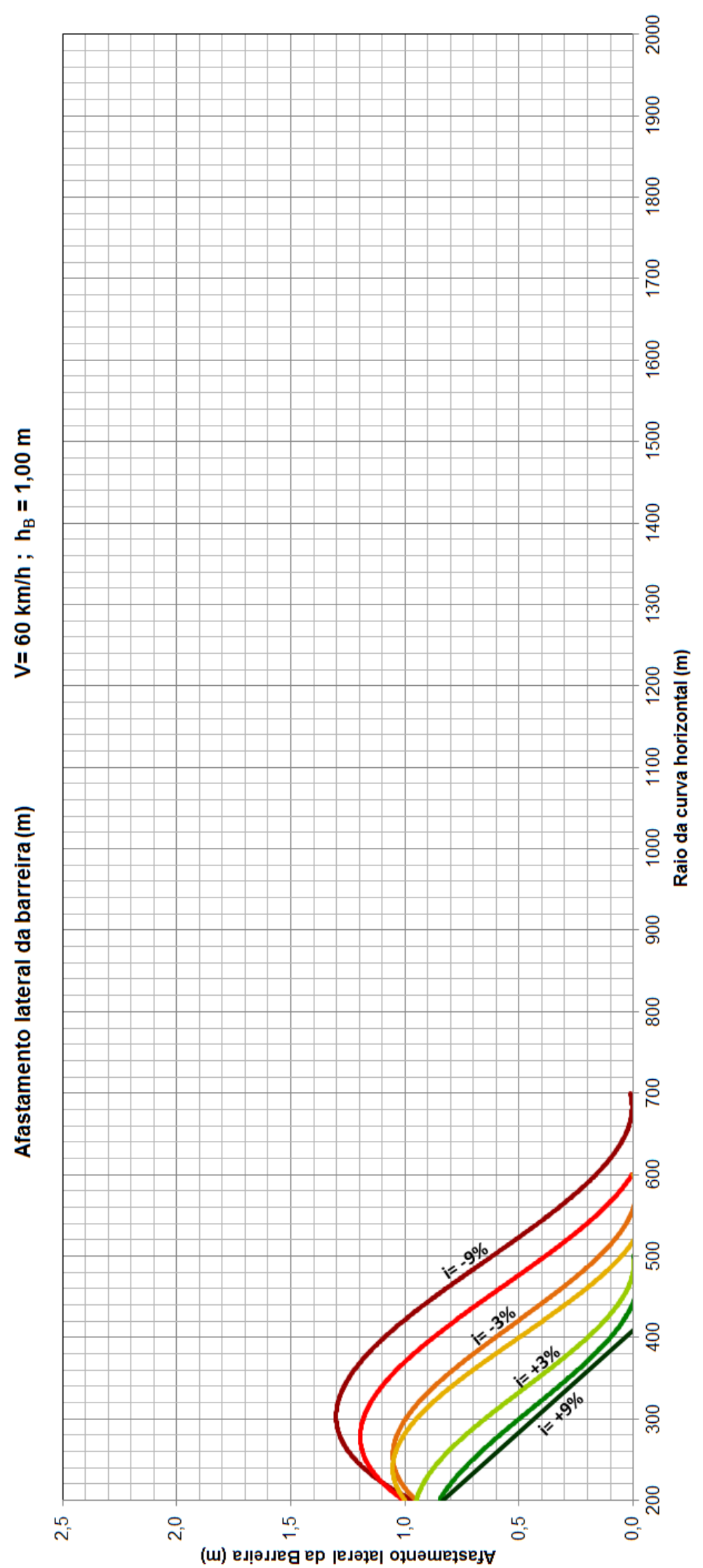

Figura 3.14. Diagrama - Grupo A - V=60 km/h; $h_{B}=1,00 \mathrm{~m}$. 


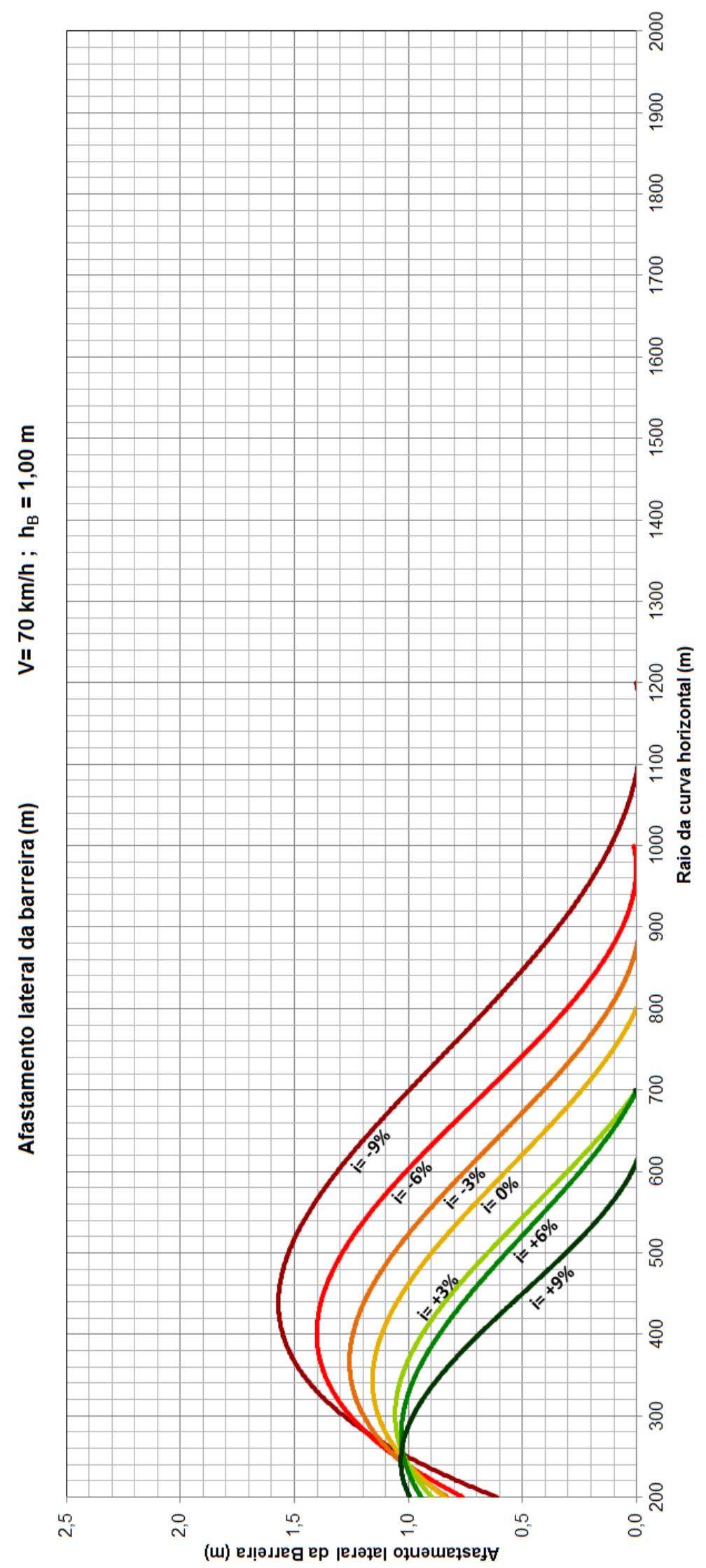

Figura 3.15. Diagrama - Grupo A - V=70 km/h; $h_{B}=1,00 \mathrm{~m}$. 


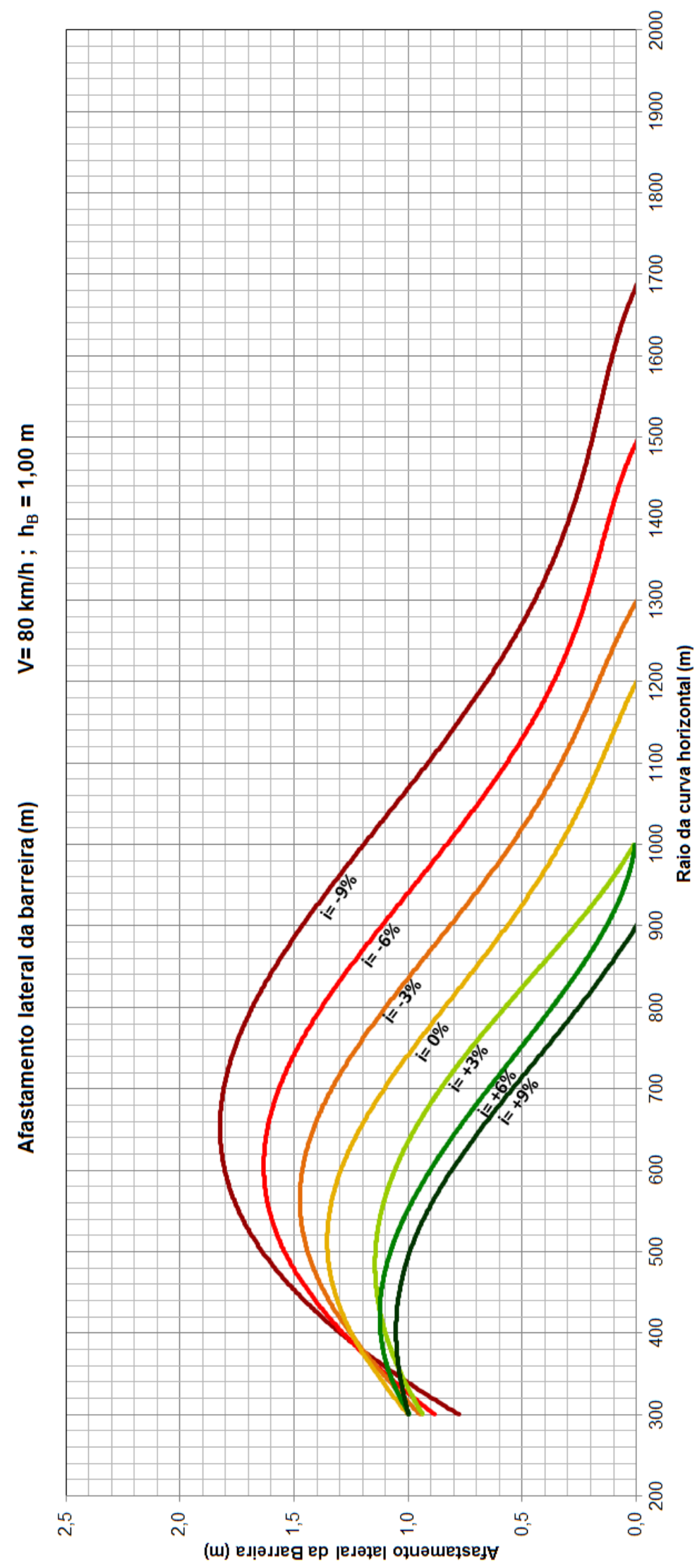

Figura 3.16. Diagrama - Grupo A - V=80 km/h; $h_{B}=1,00 \mathrm{~m}$. 


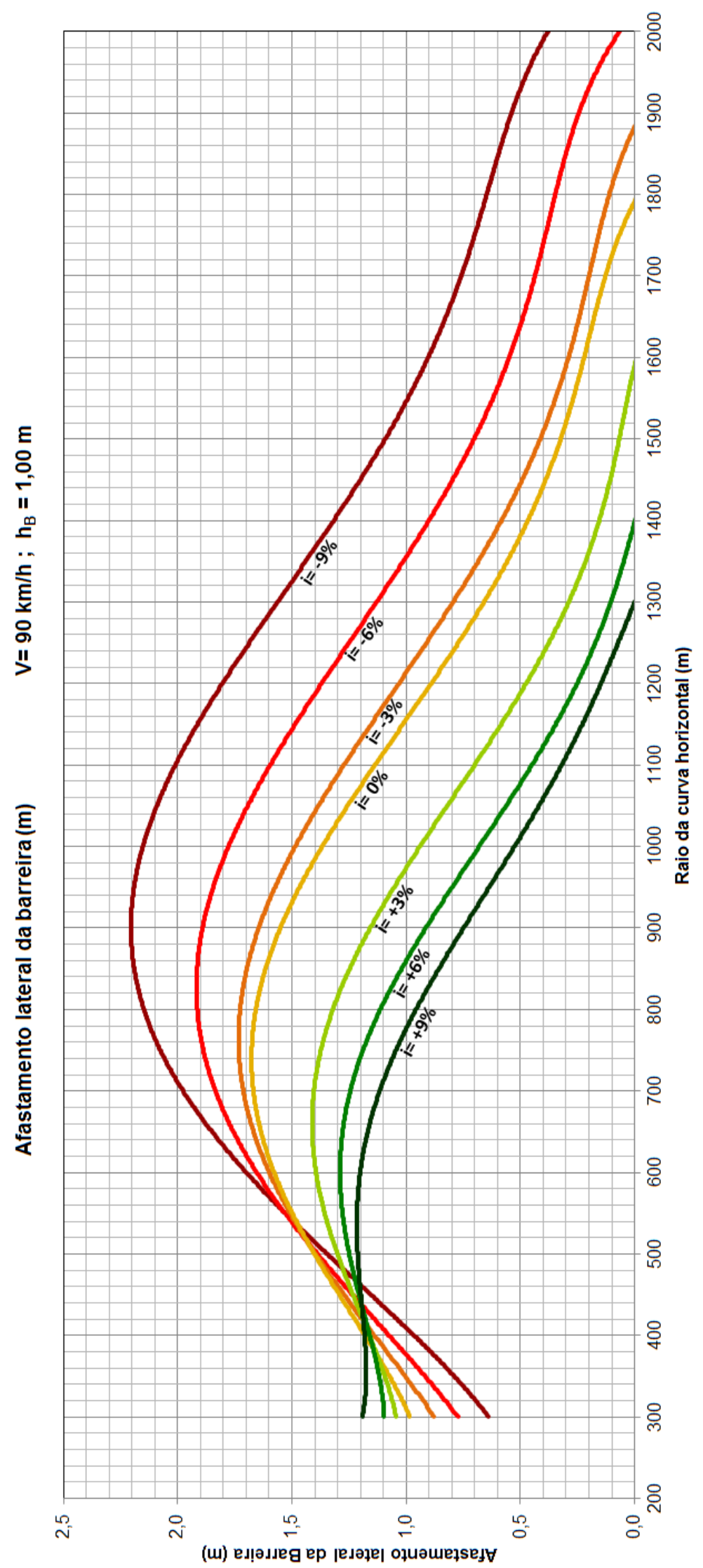

Figura 3.17. Diagrama - Grupo A - V=90 km/h; $h_{B}=1,00 \mathrm{~m}$. 


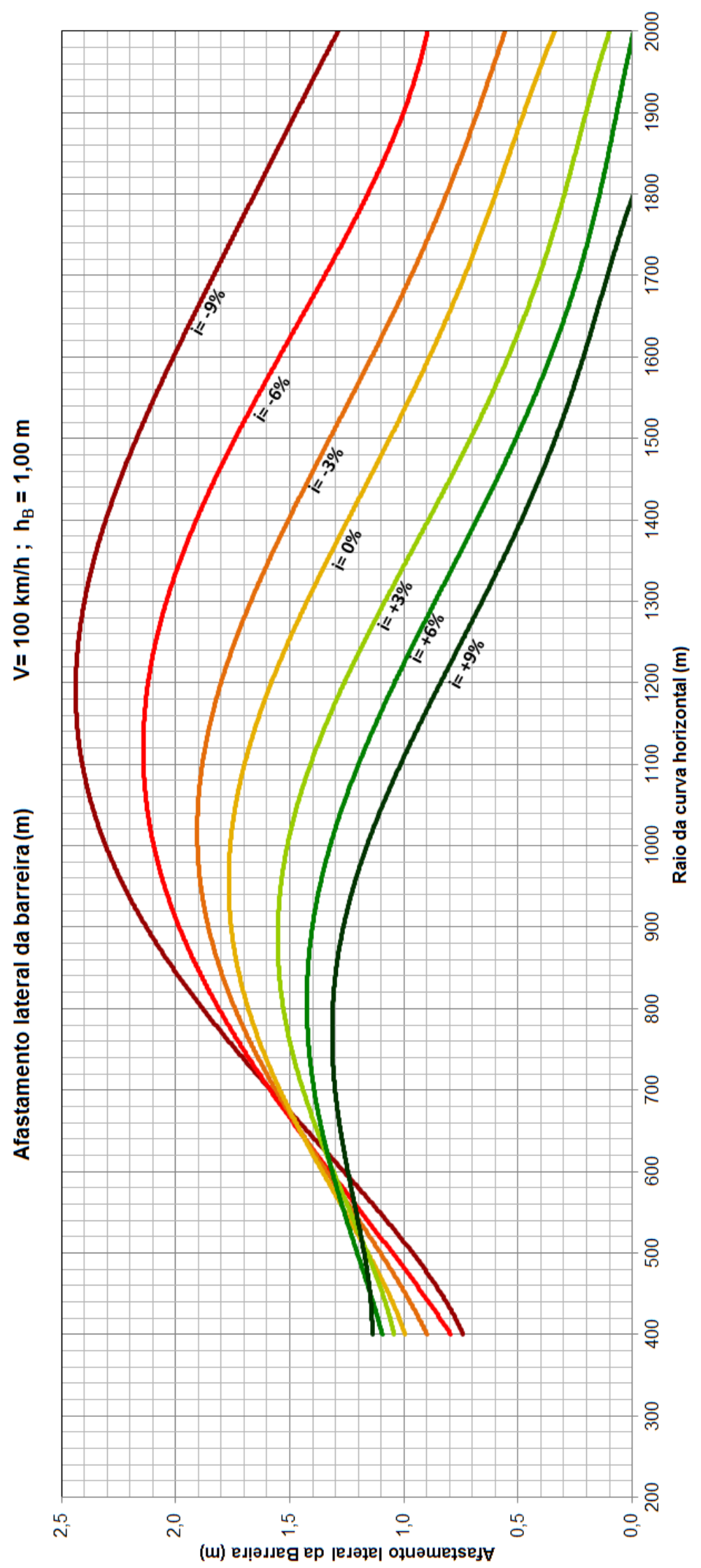

Figura 3.18. Diagrama - Grupo A - V =100 km/h; $h_{B}=1,00 \mathrm{~m}$. 


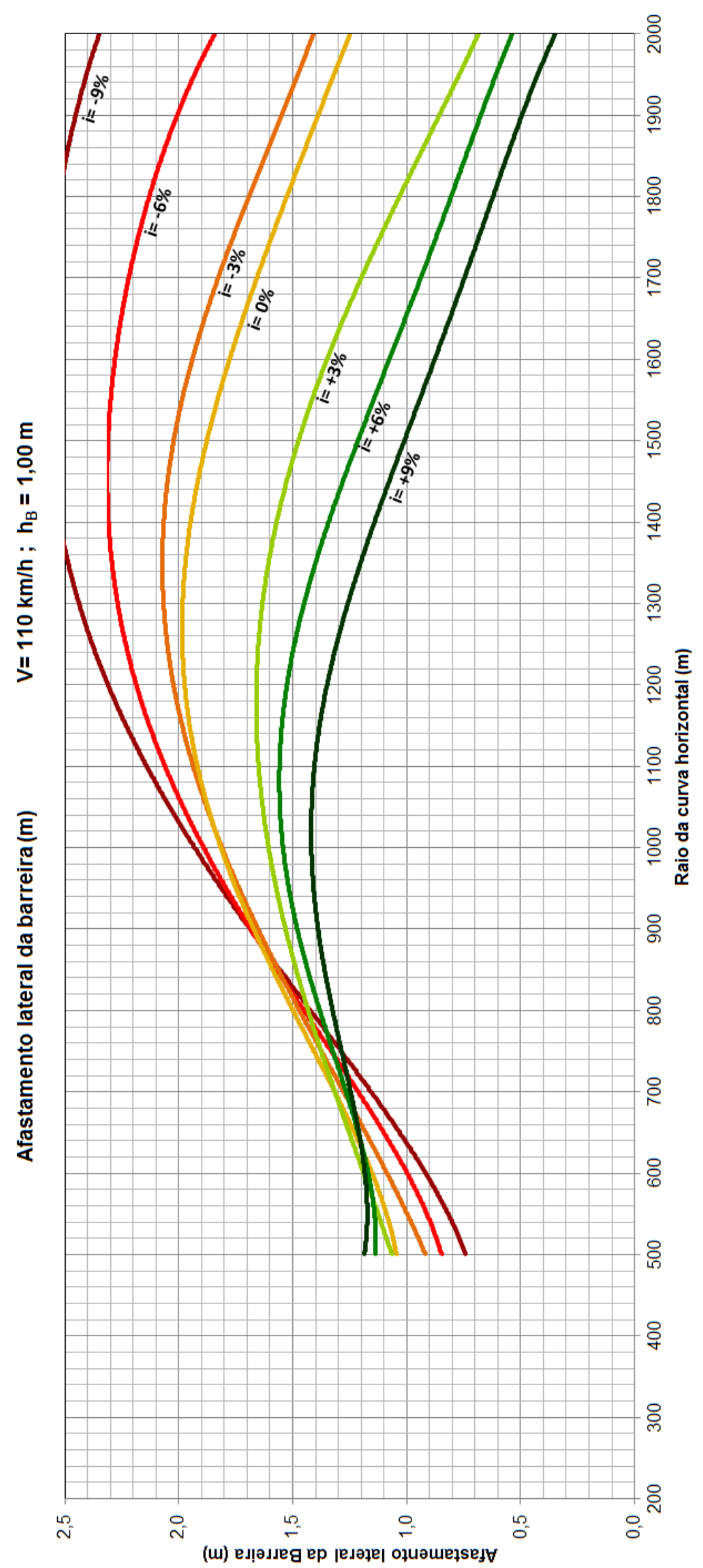

Figura 3.19. Diagrama - Grupo A - V =110 km/h; $h_{B}=1,00 \mathrm{~m}$. 


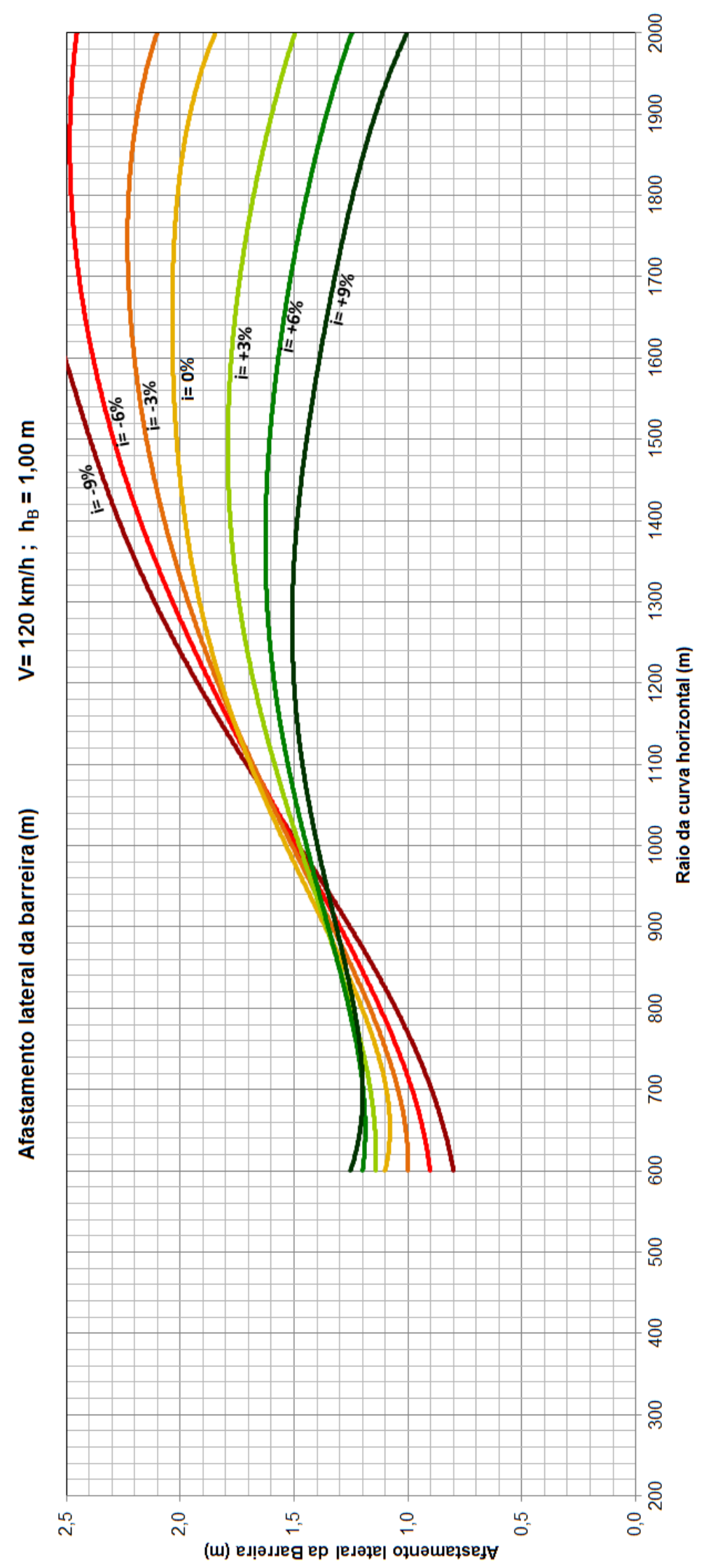

Figura 3.20. Diagrama - Grupo A - V=120 km/h; $h_{B}=1,00 \mathrm{~m}$. 


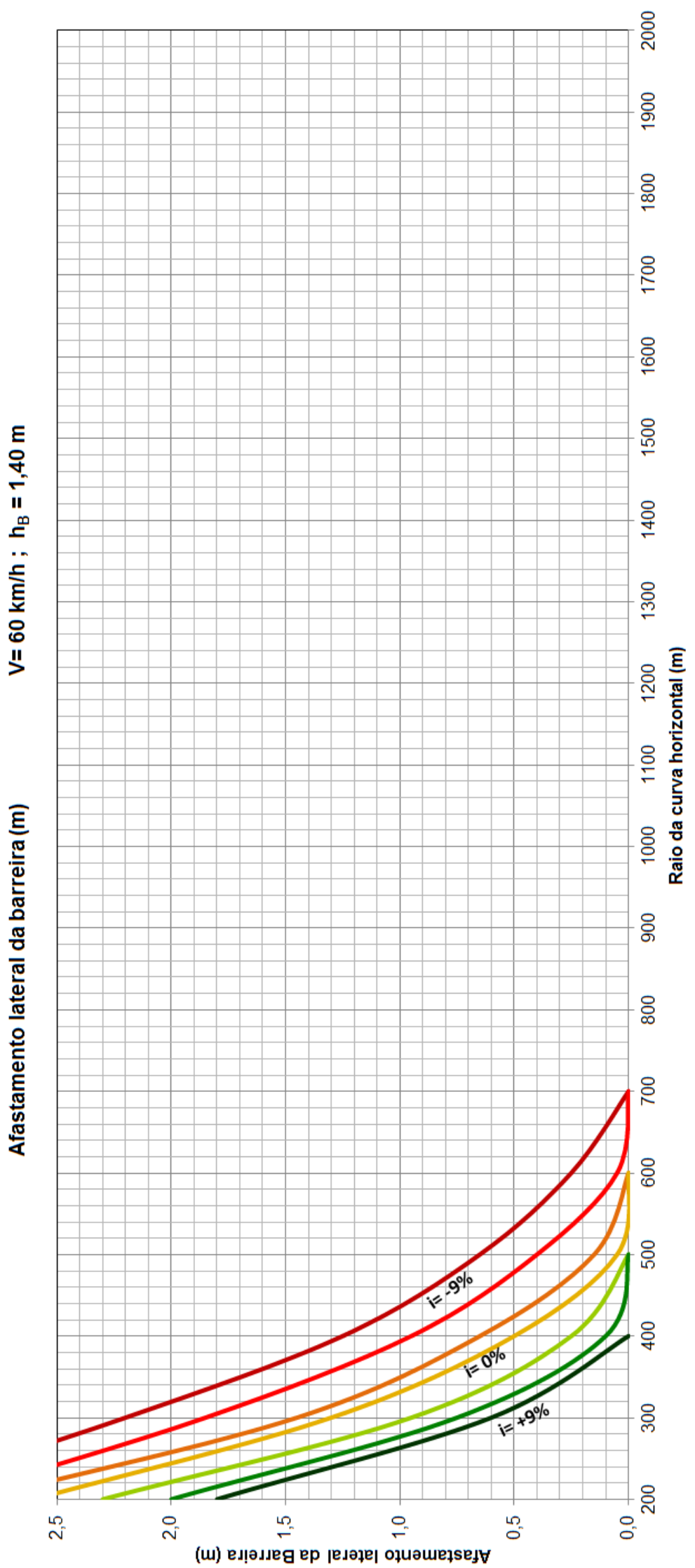

Figura 3.21. Diagrama - Grupo B - V=60 km/h; $h_{B}=1,40 \mathrm{~m}$. 


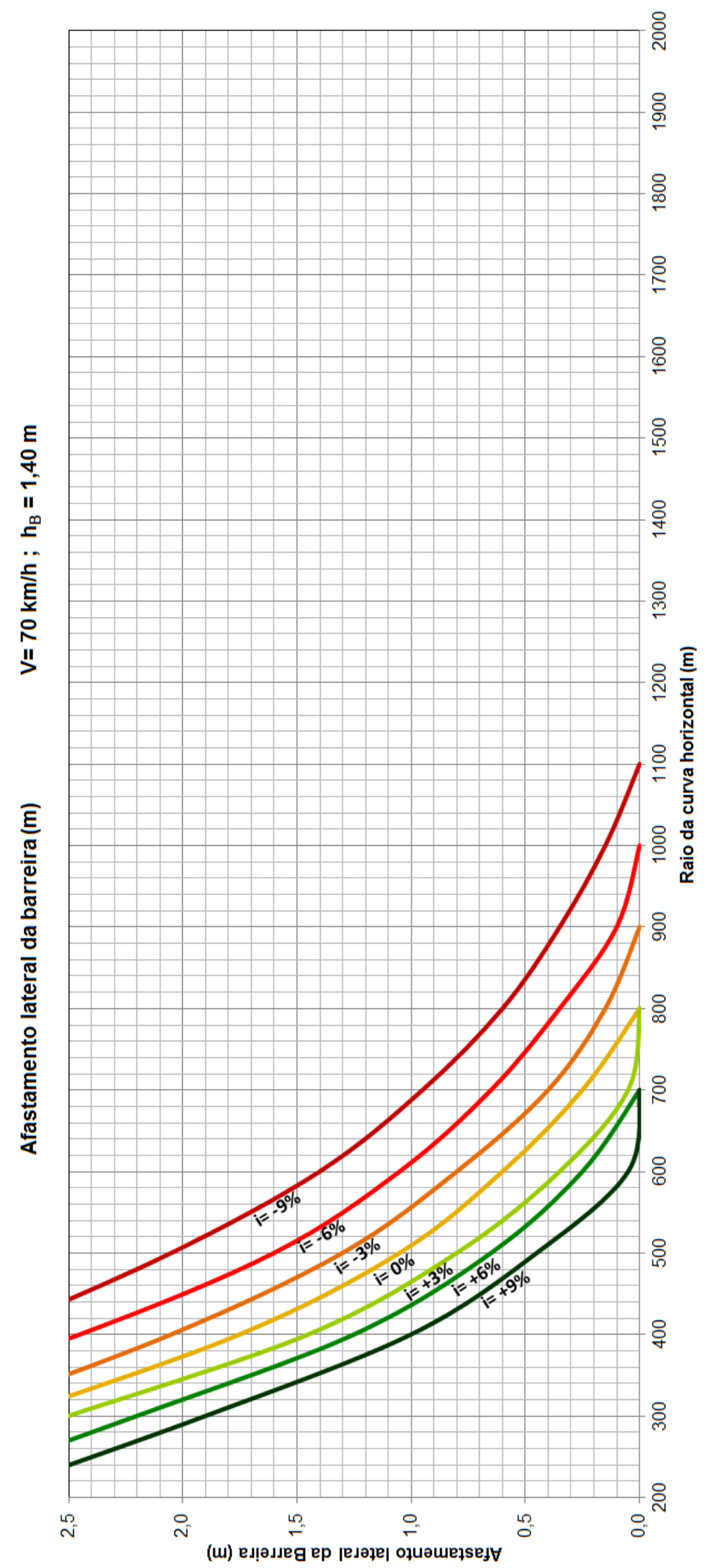

Figura 3.22. Diagrama - Grupo B - V =70 km/h; $h_{B}=1,40 \mathrm{~m}$. 


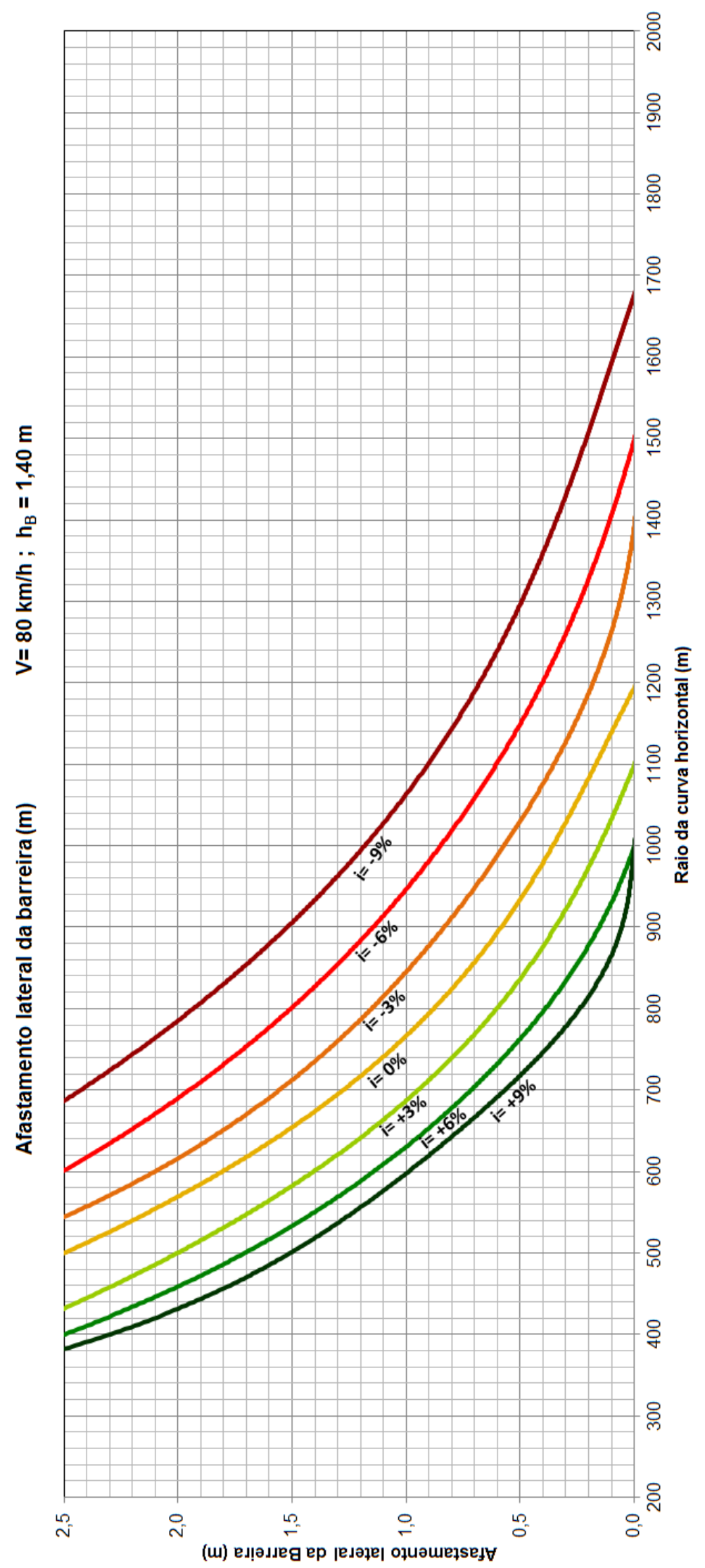

Figura 3.23. Diagrama - Grupo B - V=80 km/h; $h_{B}=1,40 \mathrm{~m}$. 


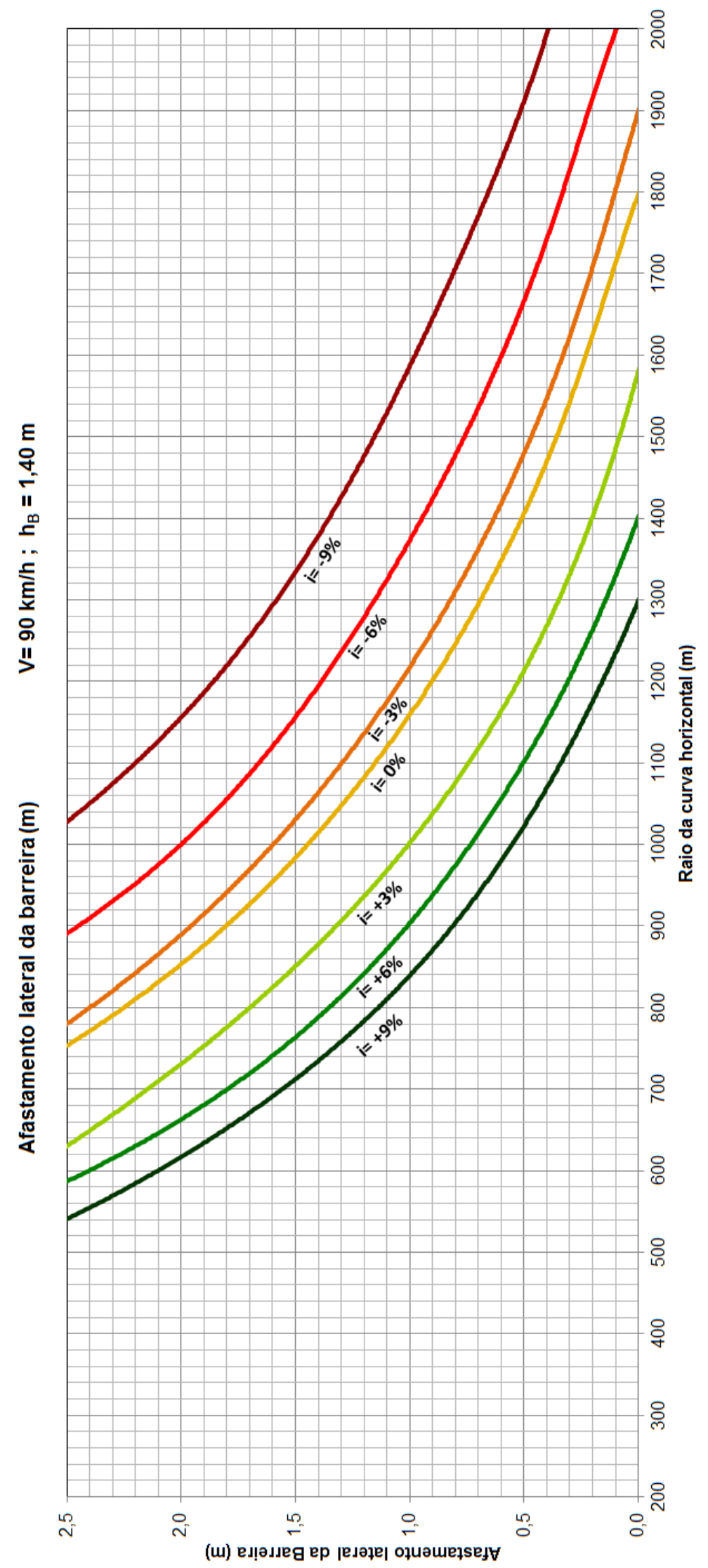

Figura 3.24. Diagrama - Grupo B - V=90 km/h; $h_{B}=1,40 \mathrm{~m}$. 


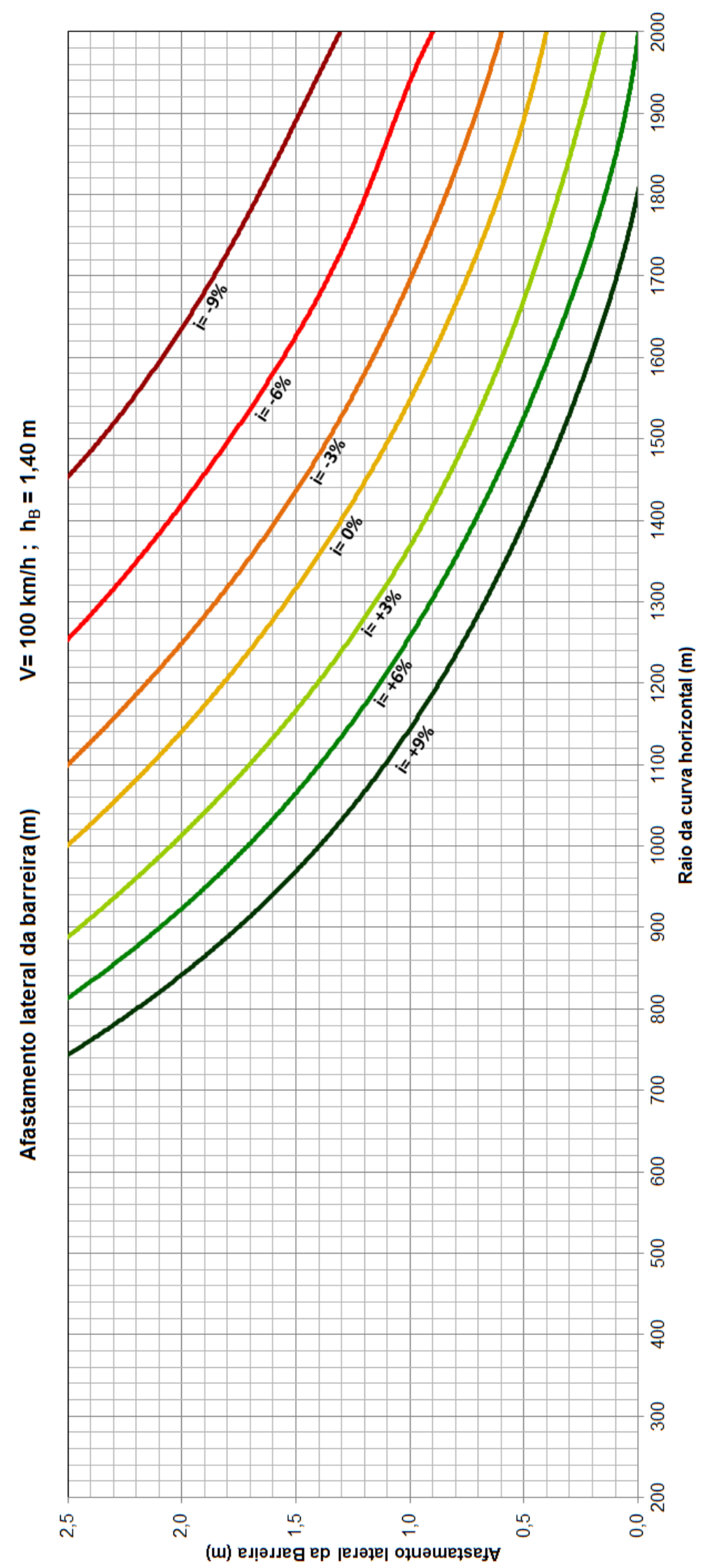

Figura 3.25. Diagrama - Grupo B $-\mathrm{V}=100 \mathrm{~km} / \mathrm{h} ; h_{B}=1,40 \mathrm{~m}$. 


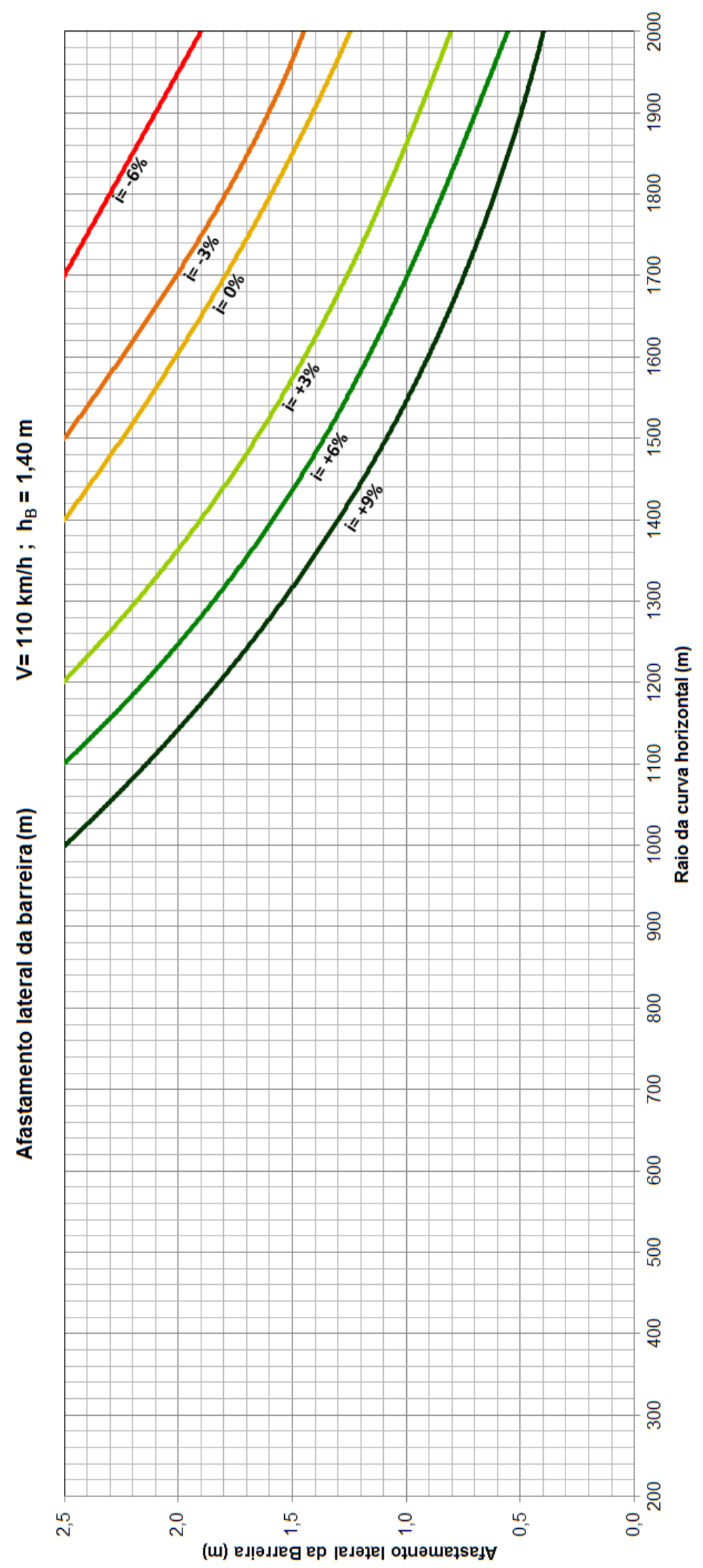

Figura 3.26. Diagrama - Grupo B $-\mathrm{V}=110 \mathrm{~km} / \mathrm{h} ; h_{B}=1,40 \mathrm{~m}$. 


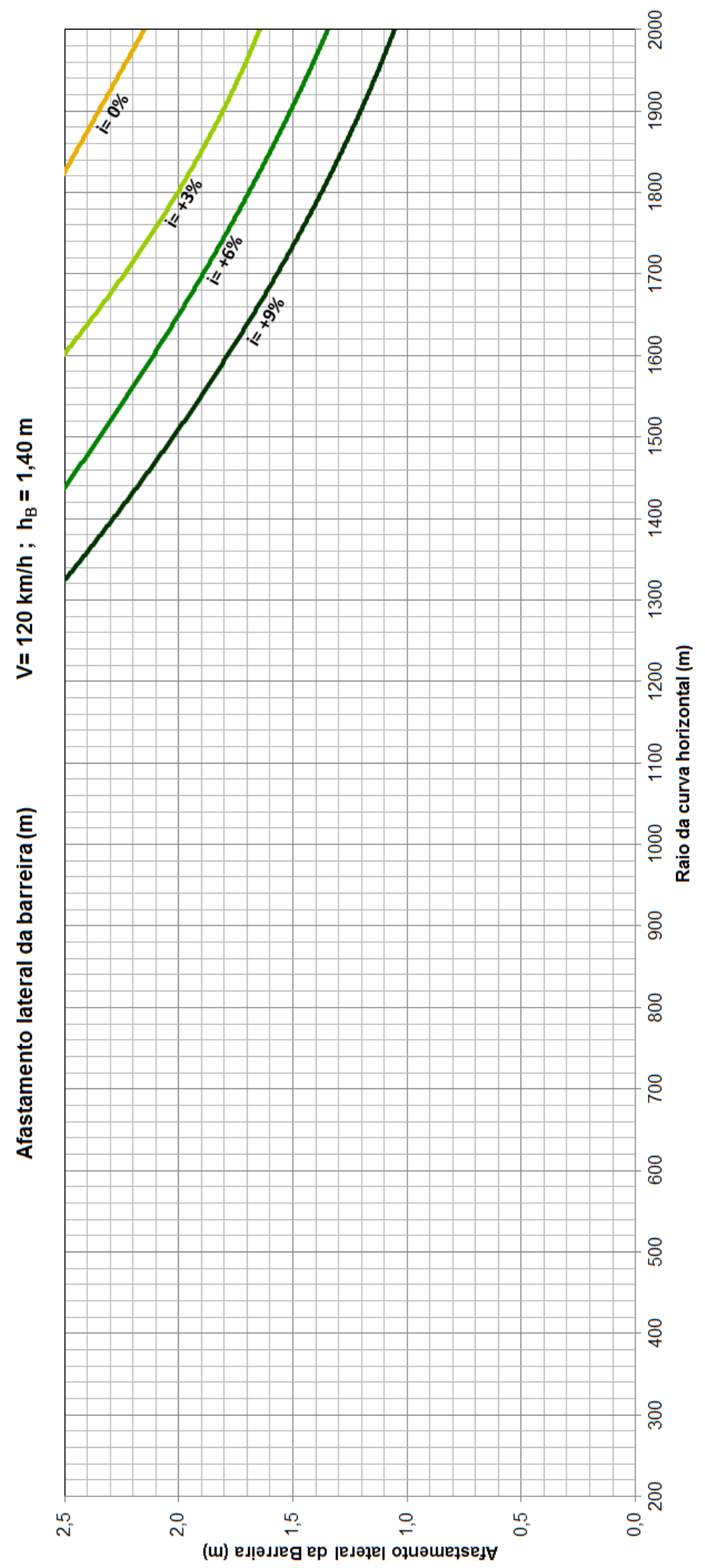

Figura 3.27. Diagrama - Grupo B - V =120 km/h; $h_{B}=1,40 \mathrm{~m}$. 


\section{ANÁLISE DOS RESULTADOS}

\subsection{Introdução}

O comportamento dos dois grupos de diagramas, grupos $\mathrm{A}$ e $\mathrm{B}$, foram distintos entre si.

O grupo $B$, gerado com dados de simulações de barreiras de $1,40 \mathrm{~m}$, resultou em diagramas como era previsto. À medida que o raio da curva horizontal diminui exigese um afastamento lateral de dimensão maior para que seja garantia a DVP em toda a extensão do projeto analisado. A redução ocorre até um ponto onde o afastamento necessário se iguala ao máximo tolerável de 2,50 $\mathrm{m}$, sendo que os raios inferiores são desprezados. A declividade do greide (i) interfere nos valores de DVP diminuindo-os à medida que i aumenta. O resultado visual é que para cada velocidade, as curvas de declividades são dispostas lado a lado, sem sobreposição. Os valores mínimos de raio da curva horizontal a partir do qual não há necessidade de preocupação com a dimensão do afastamento lateral, tratando-se do quesito de visibilidade, são proporcionais aos valores de velocidade de projeto - logo os valores mínimos para a velocidade de $60 \mathrm{~km} / \mathrm{h}$ são inferiores ao da velocidade de $80 \mathrm{~km} / \mathrm{h}$.

Assim, é possível identificar nos diagramas combinações onde sempre a DVP será satisfeita, que são as áreas limitadas inferiormente pelas curvas de cada declividade. Por exemplo, na Figura 4.1, a área verde em destaque mostra as combinações possíveis para que a DVP igual a $148 \mathrm{~m}$ seja satisfeita, que se refere à velocidade de $90 \mathrm{~km} / \mathrm{h}$ e declividade do greide de $3 \%$. Usando o mesmo diagrama, a área vermelha indica as combinações válidas para a DVP $=187 \mathrm{~m}$, referente à declividade de $-9 \%$. A análise é válida para os demais diagramas do grupo $B$. 

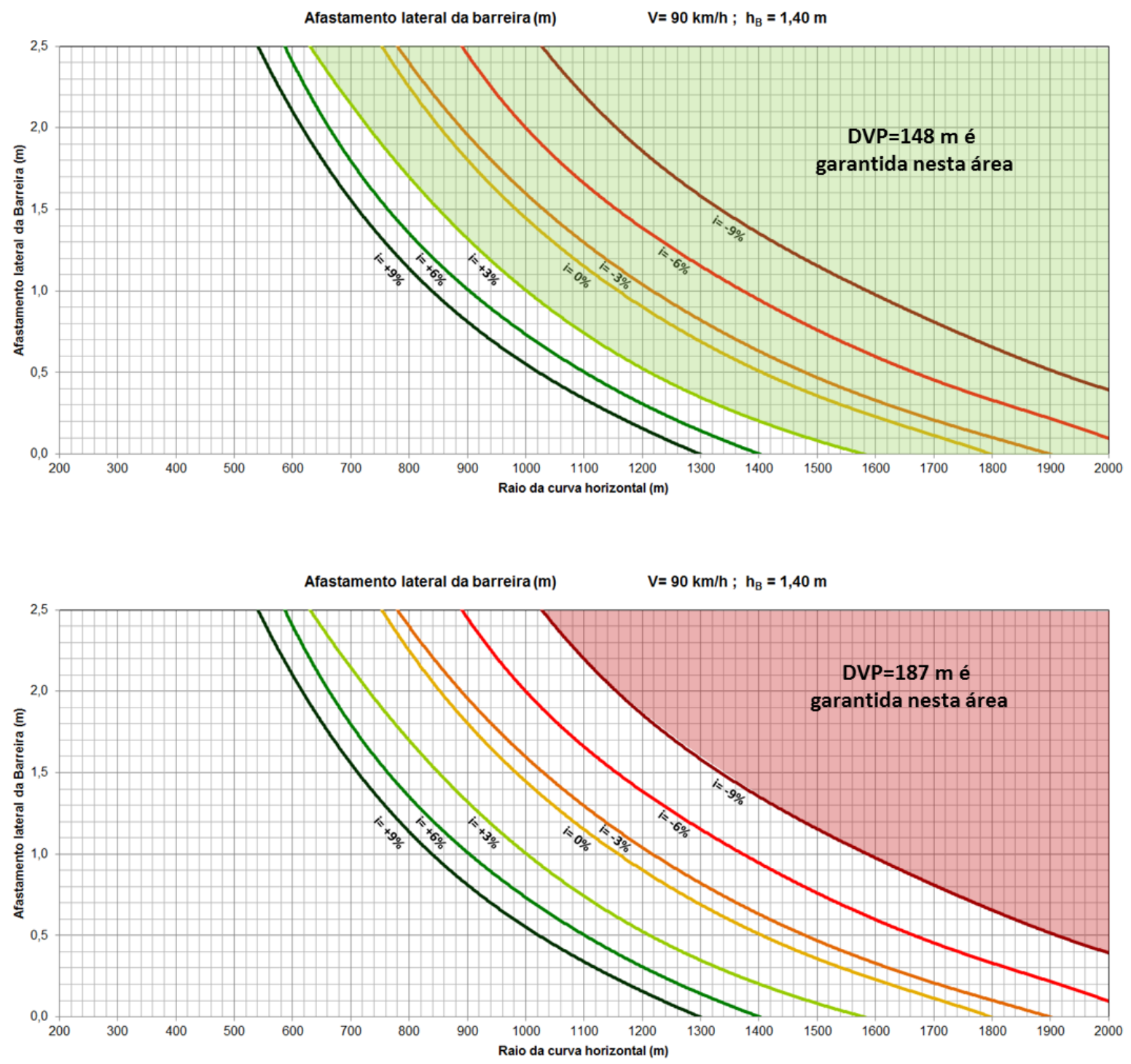

Figura 4.1. Delimitação de regiões de combinações válidas para a garantia da DVP analisada Grupo B.

Os diagramas do grupo A têm comportamento diferente. À medida que o raio da curva horizontal diminui, o afastamento lateral da barreira aumenta, até um ponto crítico onde há inversão deste comportamento, com diminuição dos afastamentos até atingir o raio mínimo de analise. O esperado seria comportamento similar ao do grupo B.

Sendo assim, as causas das formas das curvas dos diagramas foram investigadas: 
1. Revisão da formulação matemática. Não foram identificadas falhas nas formulações matemáticas e parâmetros utilizados para a execução das simulações.

2. Ângulo Central. O ângulo central incide diretamente no desenvolvimento da curva. Realizaram-se testes com ângulos centrais diferentes de 90ㅜ, maiores e menores, e os resultados foram os mesmos, salvo diferenças dentro da precisão de $\pm 0,05 \mathrm{~m}$.

3. Contribuição da superelevação e declividade do greide nas alturas do objeto e do motorista, considerando que o raio da curva horizontal diminui, a superelevação aumenta. A altura dos olhos do motorista e a altura do objeto também têm influência da superelevação à medida que se afastam do eixo central da pista, devido à alteração do afastamento lateral da barreira para que se garanta a DVP. Além disso, o objeto e motorista tem diferença de altura ampliada devido ao distanciamento entre si (DVP) e a declividade do greide. E o mesmo ocorre com a barreira, tem sua posição no espaço influenciada por parâmetros do projeto.

O item 3 traz os indícios do comportamento dos diagramas do grupo A. Fato é que a o modelo analisado tridimensionalmente, com as contribuições dos parâmetros de projeto na posição dos elementos de análise - motorista, objeto e barreira favoreceu a visibilidade de projeto. A barreira com altura de 1,00 m não é uma obstrução significativa que não pode ser compensada com variações de combinações de projeto. A barreira do grupo B, por sua vez, com altura de 1,40 acaba sendo uma obstrução intransponível à visibilidade. Analisando cenas dos modelos tridimensionais dos projetos do grupo A identifica-se que a visibilidade do objeto ocorre sobre a barreira, auxiliado pelo afastamento lateral imposto. A figura 4.2 apresenta duas cenas de um dos modelos tridimensionais do grupo A. 

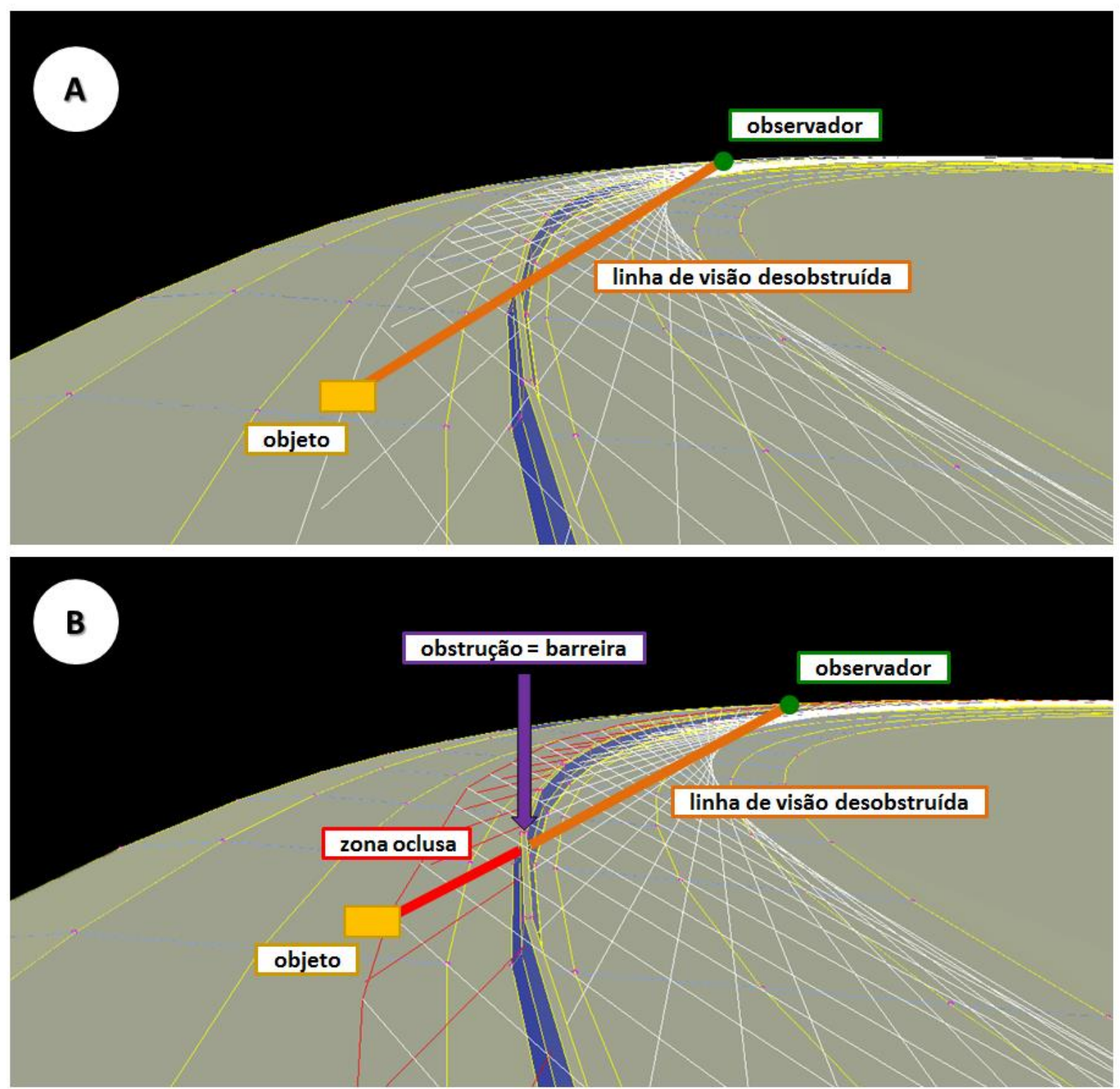

Figura 4.2. Análise 3D da visibilidade do grupo $A$.

$\mathrm{Na}$ figura o ponto verde apresenta o observador - o motorista - e em amarelo encontra-se a representação do objeto. Ambos estão posicionados conforme as hipóteses premissas da simulação. A linha laranja, em destaque em A, apresenta a linha de visão do motorista, passando sobre a barreira sem nenhuma obstrução. Em B é imposta uma leve diminuição do afastamento lateral da barreira, obstruindo a visibilidade do motorista, gerando uma zona oclusa aos seus olhos (em vermelho) na qual se encontra o objeto a ser observado, de modo que o critério de DVP não é 
satisfeito. Em testes realizados, constatou-se que o mesmo comportamento ocorre para barreiras de altura de $0,81 \mathrm{~m}$.

Da mesma forma que o grupo $\mathrm{B}$, áreas sobre as curvas representam combinações onde a DVP é garantida. Na Figura 4.3 a área verde em destaque mostra as combinações possíveis para que a DVP igual a 148 m seja satisfeita, que se refere à velocidade de $90 \mathrm{~km} / \mathrm{h}$ e declividade do greide de $3 \%$. Usando o mesmo diagrama, a área vermelha indica as combinações válidas para a DVP $=187 \mathrm{~m}$, referente à declividade de $-9 \%$. A análise é válida para os demais diagramas do grupo $A$.
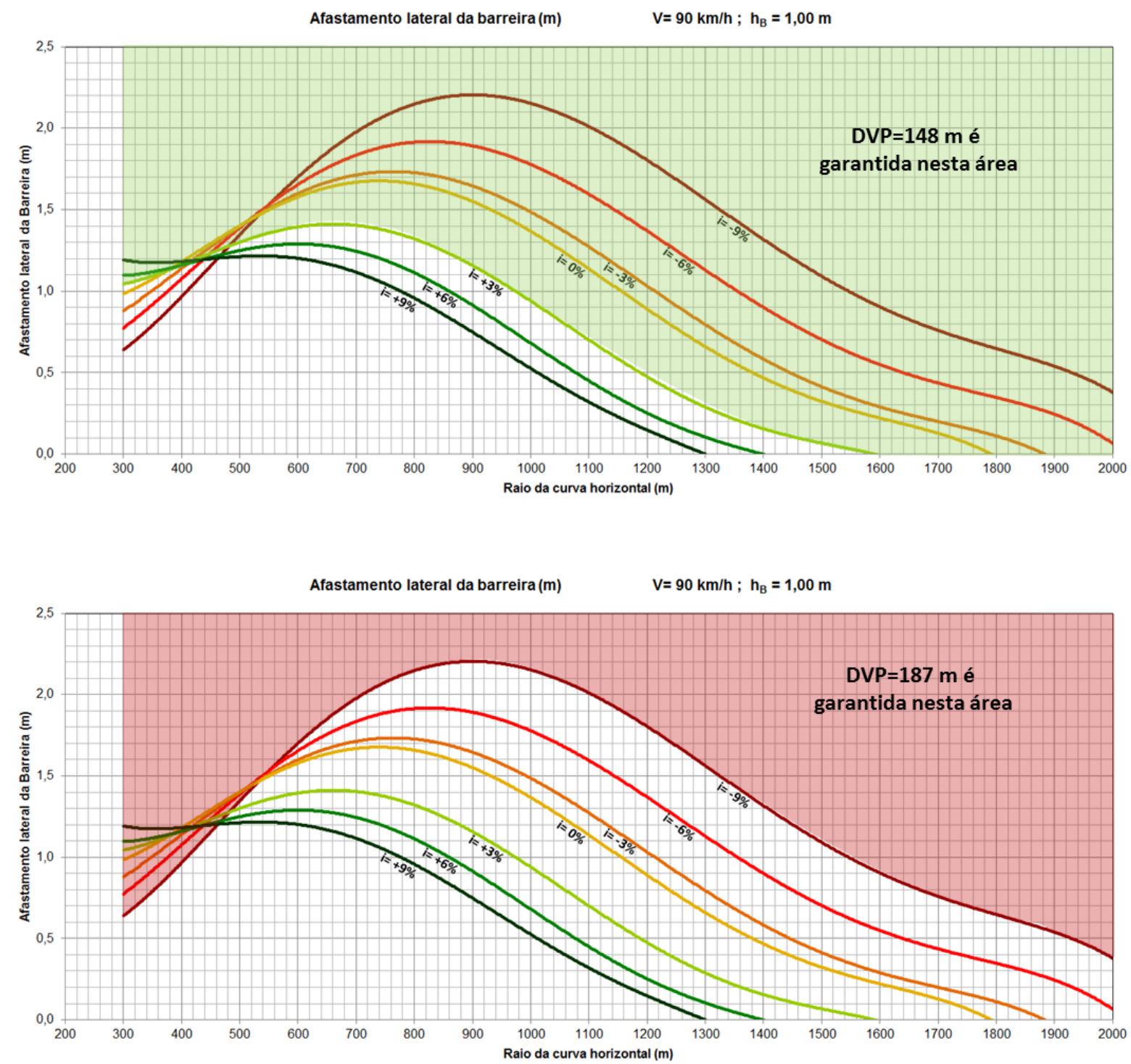

Figura 4.3. Delimitação de regiões de combinações válidas para a garantia da DVP analisada Grupo A. 


\subsection{Comparação dos resultados com o modelo de afastamento de objetos fixos em curvas horizontais $(M)$ presente nas normas nacionais}

Diversas publicações apresentam parametrização para o afastamento de objetos fixos em curvas horizontais (AASTHO, 2011a; DNER, 1999; DER-SP, 2006). Sendo assim, não haveria necessidade de simular a posição da barreira visto que já existem modelos para tal. Porém, a principal limitação destes modelos é o fato de tratarem da visibilidade em um espaço bidimensional. A tridimensionalidade - onde realmente o projeto se desenvolve - é desprezada, e os modelos por sua vez são simplificados. A proposta do estudo foi integrar a parcela tridimensional do projeto na análise de interferência à visibilidade. Por isso, os resultados obtidos das simulações foram comparados com os afastamentos oriundos desses modelos para validar a necessidade de analisar ou não o projeto em três dimensões no quesito visibilidade. O modelo utilizado para comparação foi o encontrado em manuais nacionais (DNER (1999); DER-SP (2006)):

$$
M=R\left(1-\cos \frac{\mathrm{DVP}}{2 R}\right)
$$

Onde

$M$ : Afastamento lateral de objetos fixos em curvas horizontais (m);

DVP: Distância de visibilidade de parada (m); e

$R$ : Raio da curva horizontal $(\mathrm{m})$;

Que é proveniente do esquema apresentado na Figura 4.4. 


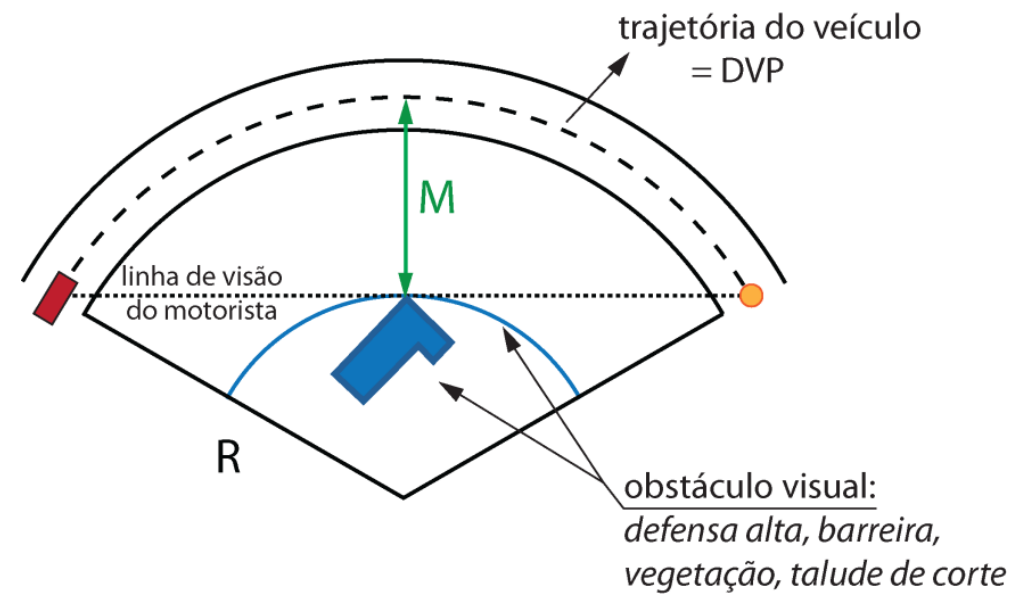

Figura 4.4. Modelo M - Afastamento lateral de objetos fixos em curvas horizontais.

O modelo considera apenas o raio da curva horizontal e a DVP, ignorando outros parâmetros como a altura dos olhos do motorista e altura do objeto (Neuman, 1989). Assim, $M$ é definido como sendo o afastamento da obstrução em relação à trajetória do veículo. O estudo, por sua vez, considera o afastamento em relação à borda externa da faixa de rolamento interna da curva. Portanto, uma transformação algébrica entre os parâmetros foi realizada para unificar os referenciais envolvidos. A Figura 4.5 apresenta todos os parâmetros envolvidos nesta transformação

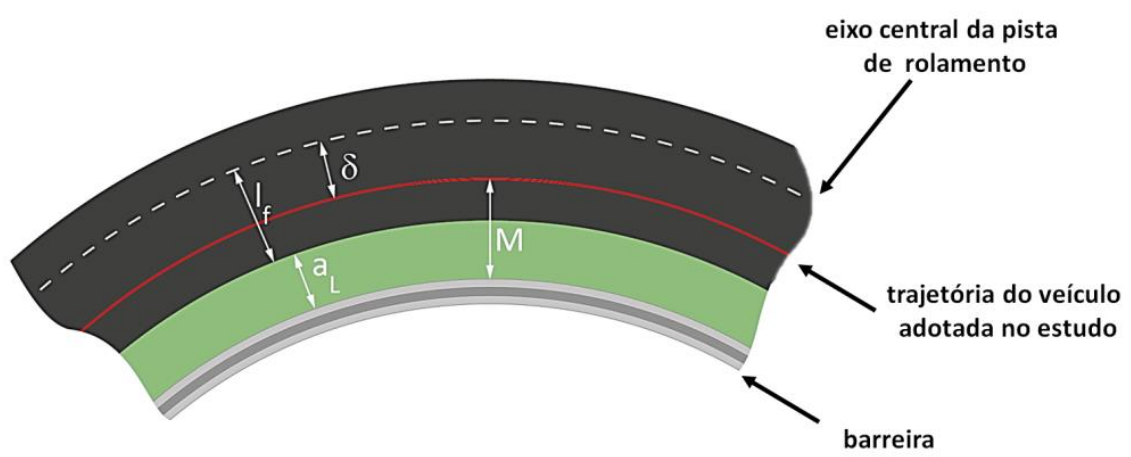

Figura 4.5. Parâmetros envolvidos na transformação de referencial. 
Onde:

$M$ : Afastamento lateral de objetos fixos em curvas horizontais $(\mathrm{m})$;

$l_{f}:$ Largura da faixa de rolamento $(\mathrm{m})$;

$\delta$ : Posição da trajetória veículo na via, adotada no estudo $(\mathrm{m})$; e

$a_{L}$ : Afastamento lateral da barreira $(\mathrm{m})$.

Com simples artifícios algébricos e baseando-se no esquema da Figura 4.5, é possível expressar o valor de $\mathrm{M}$ em função de $a_{L}$, já que os demais parâmetros são conhecidos. A largura da faixa de rolamento é de 3,6 $\mathrm{m}$ e a trajetória percorrida pelo veiculo a ser considerada está deslocada de $2 \mathrm{~m}$ do eixo central da via. Sendo assim foi definida a seguinte relação:

$$
a_{L}=M-1,6 m
$$

Desta forma, os afastamentos laterais foram calculados utilizando o modelo $\mathrm{M} \mathrm{e}$ confrontados com os resultados provenientes das simulações.

As Figuras 4.6 e 4.7 apresentam as diferenças entre os resultados das simulações do grupo A (altura da barreira de $1,00 \mathrm{~m}$ ) e o modelo M. O comportamento das diferenças é similar para todos os diagramas. Em curvas horizontais de raios maiores, os valores são próximos, impondo diferenças próximas à zero. Todavia, o comportamento dos diagramas descrito no item anterior faz com que as diferenças sejam ampliadas significativamente para raios menores, alcançando valores de até $20 \mathrm{~m}$. Diferenças essas causadas pelo fato que o modelo $M$ analisa o problema bidimensionalmente ao contrário das simulações, cujos resultados foram oriundos da análise do projeto como um todo, que ocorre tridimensionalmente no espaço. 
Diferença entre Grupo A e modelo M
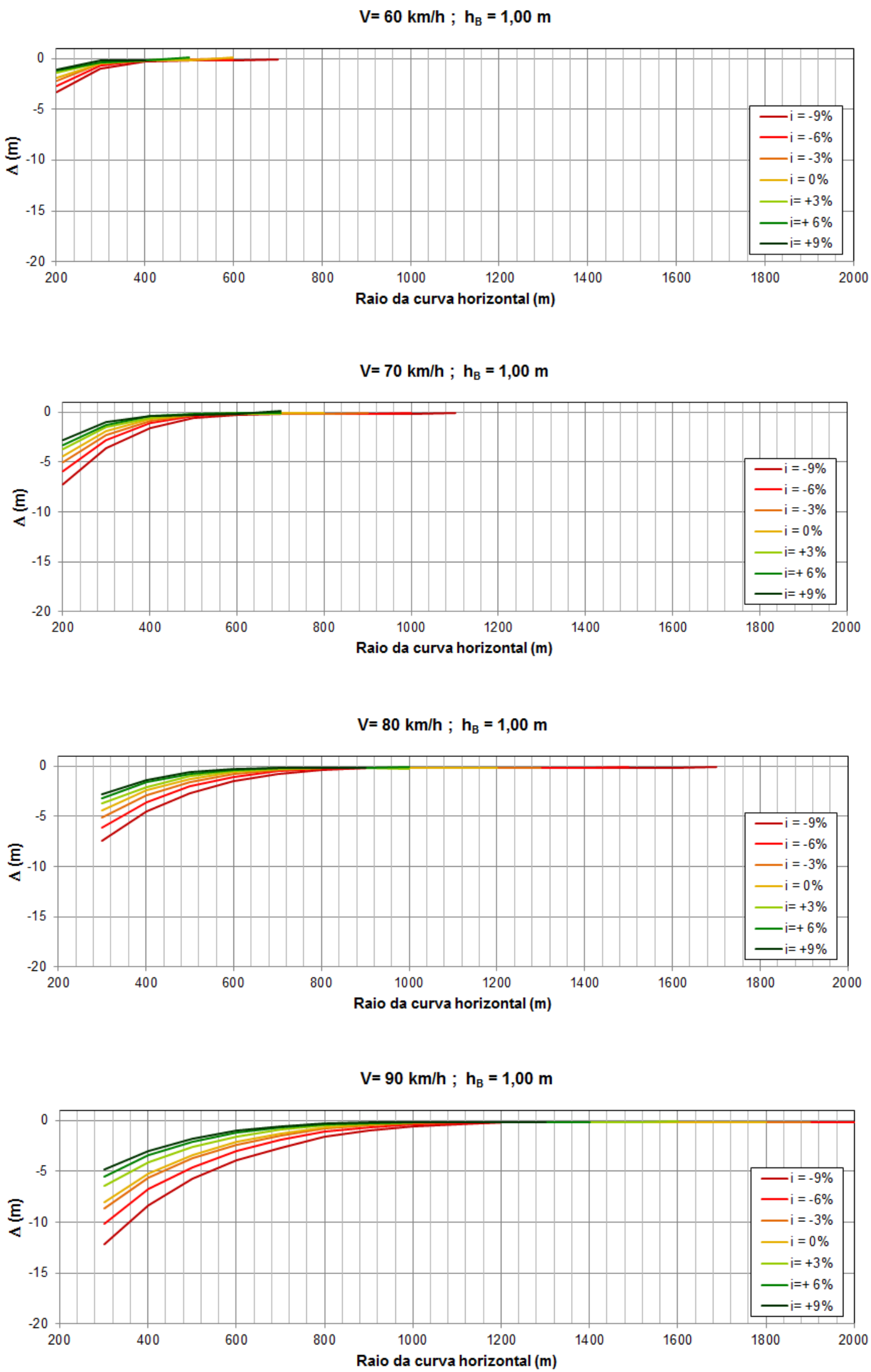

Figura 4.6. Diferença entre Grupo A e modelo $M(60 \mathrm{~km} / \mathrm{h}$ a $90 \mathrm{~km} / \mathrm{h})$ 


\section{Diferença entre Grupo A e modelo M}

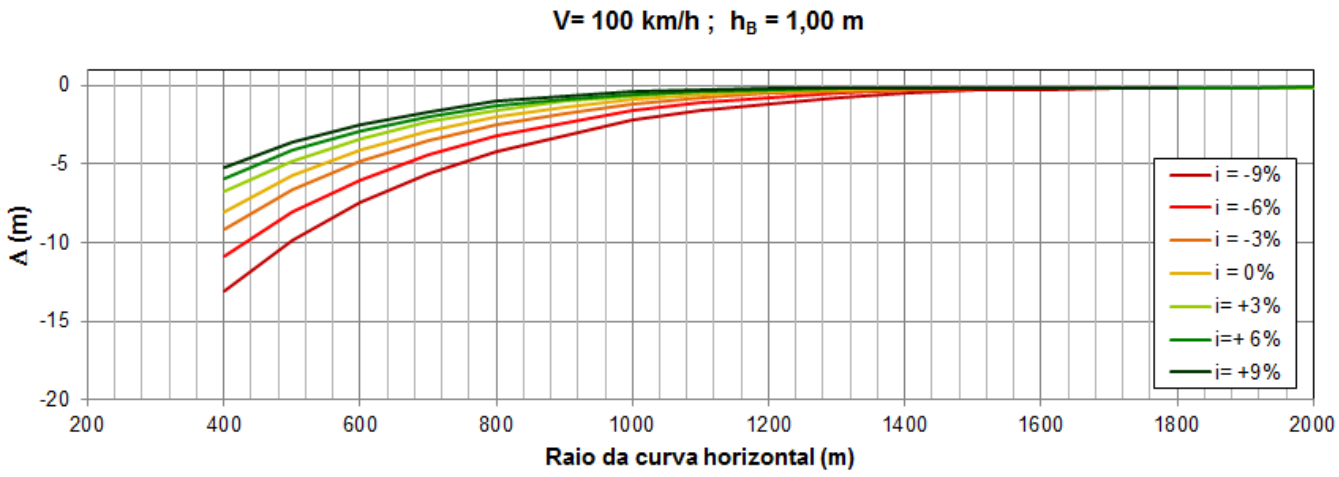

$V=110 \mathrm{~km} / \mathrm{h} ; \mathrm{h}_{\mathrm{B}}=1,00 \mathrm{~m}$

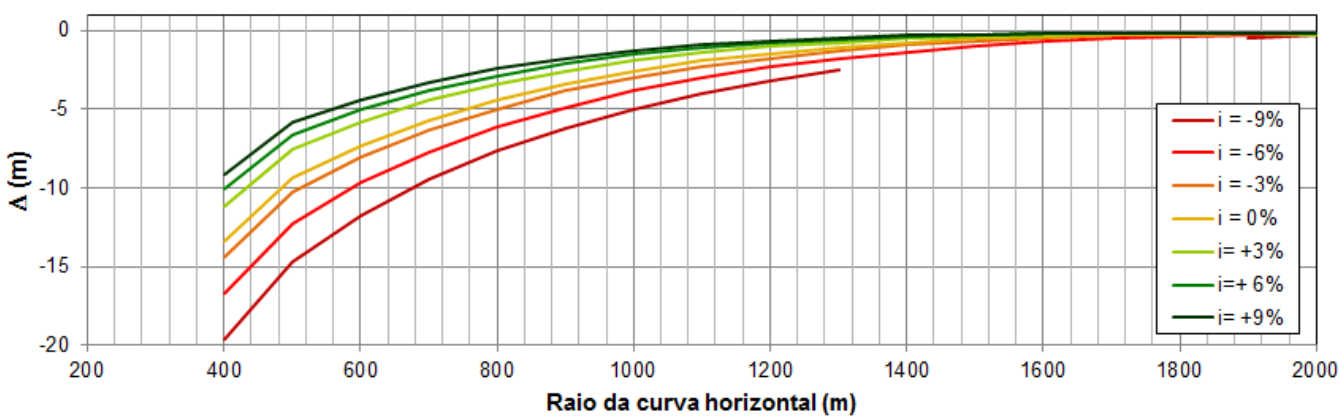

$V=120 \mathrm{~km} / \mathrm{h} ; \mathrm{h}_{\mathrm{B}}=1,00 \mathrm{~m}$

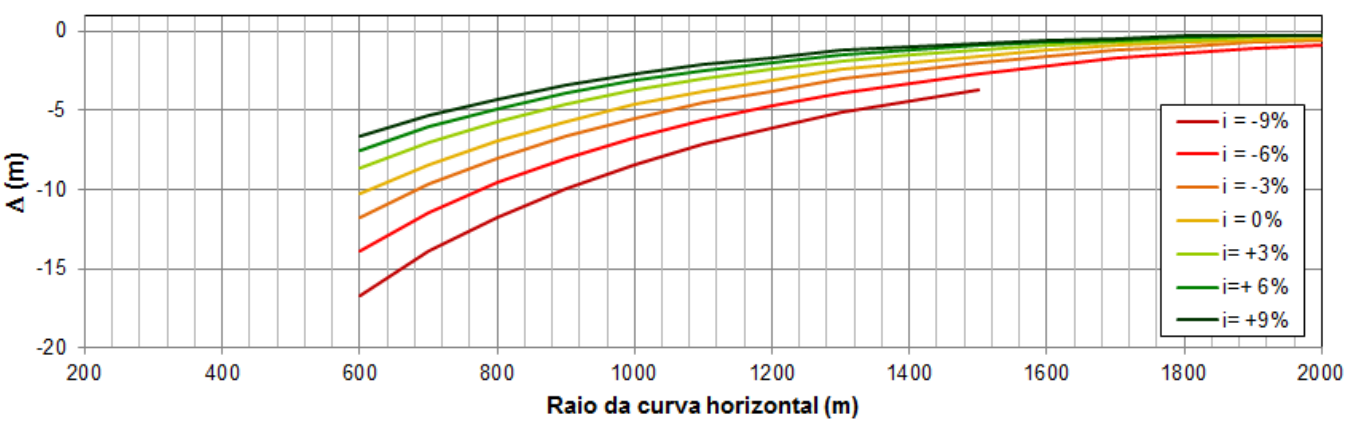

Figura 4.7. Diferença entre Grupo A e modelo $M(100 \mathrm{~km} / \mathrm{h}$ a $120 \mathrm{~km} / \mathrm{h})$

As Figuras 4.8 e 4.9 apresentam as diferenças entre os resultados das simulações do grupo B (altura da barreira de $1,40 \mathrm{~m}$ ) e o modelo M. O comportamento das diferenças é similar para todos os diagramas, cujos valores são inferiores a um metro. Não se observa tendência nos gráficos das velocidades de $60 \mathrm{~km} / \mathrm{h}$ e $70 \mathrm{~km} / \mathrm{h}$ (Figura 4.8). Para velocidades maiores, a simulação obteve em média valor 0,15 m 
menor do que o modelo $M$. As diferenças foram pequenas em relação ao grupo $A$, pois o fato de usar barreira com altura de $1,40 \mathrm{~m}$, que tem altura representativa, torna-a um obstáculo intransponível para a linha de visão do motorista, que ocorre tangente ao obstáculo, de modo que as soluções encontradas são próximas ao do modelo M. A diferença novamente é justificada pela natureza dos dados: $02 \mathrm{D}$ (modelo $\mathrm{M}$ ) versus o 3D (simulações).

\section{Diferença entre Grupo B e modelo M}
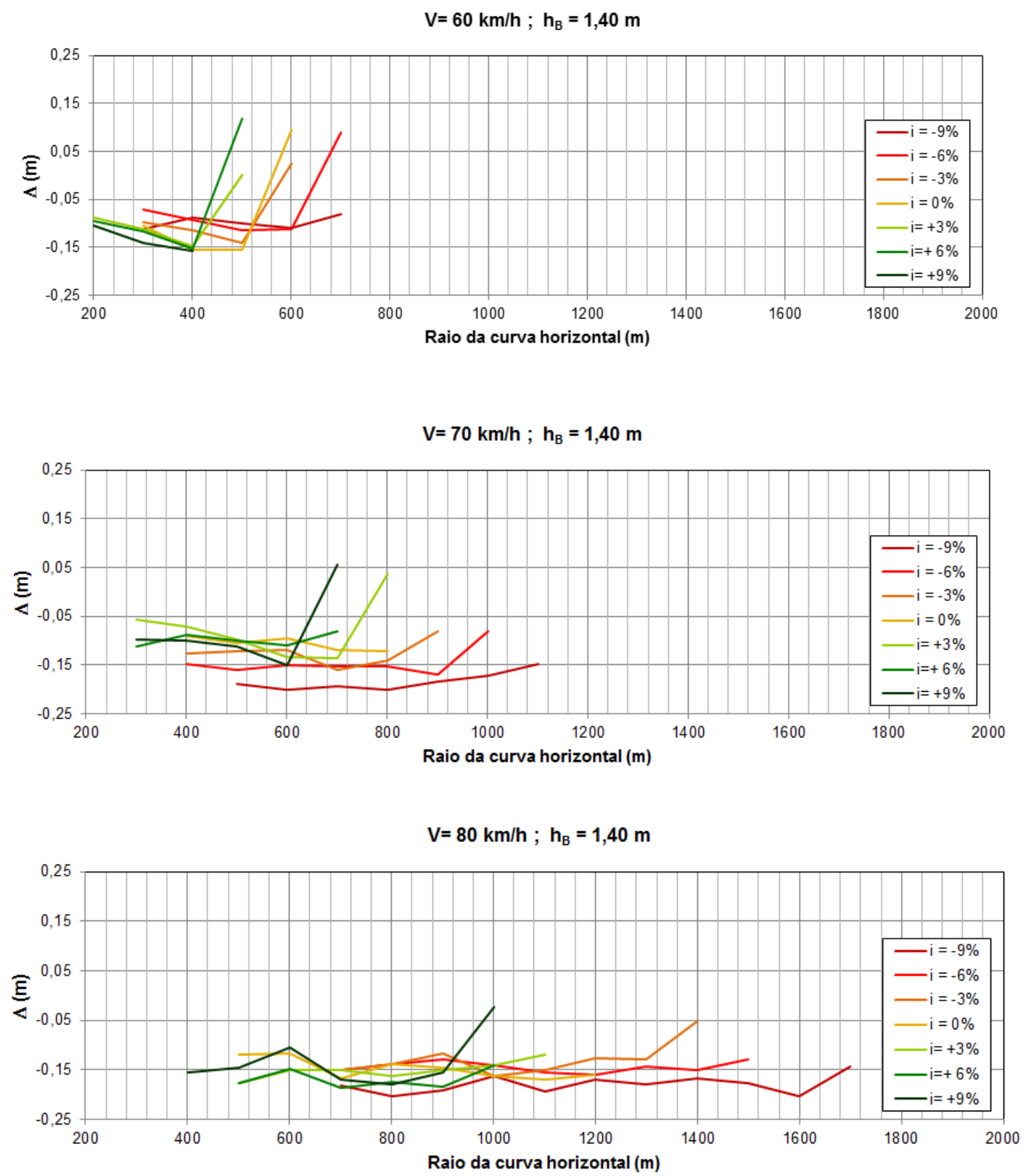

Figura 4.8. Diferença entre Grupo B e modelo $M(60 \mathrm{~km} / \mathrm{h}$ a $80 \mathrm{~km} / \mathrm{h})$ 
Diferença entre Grupo B e modelo M

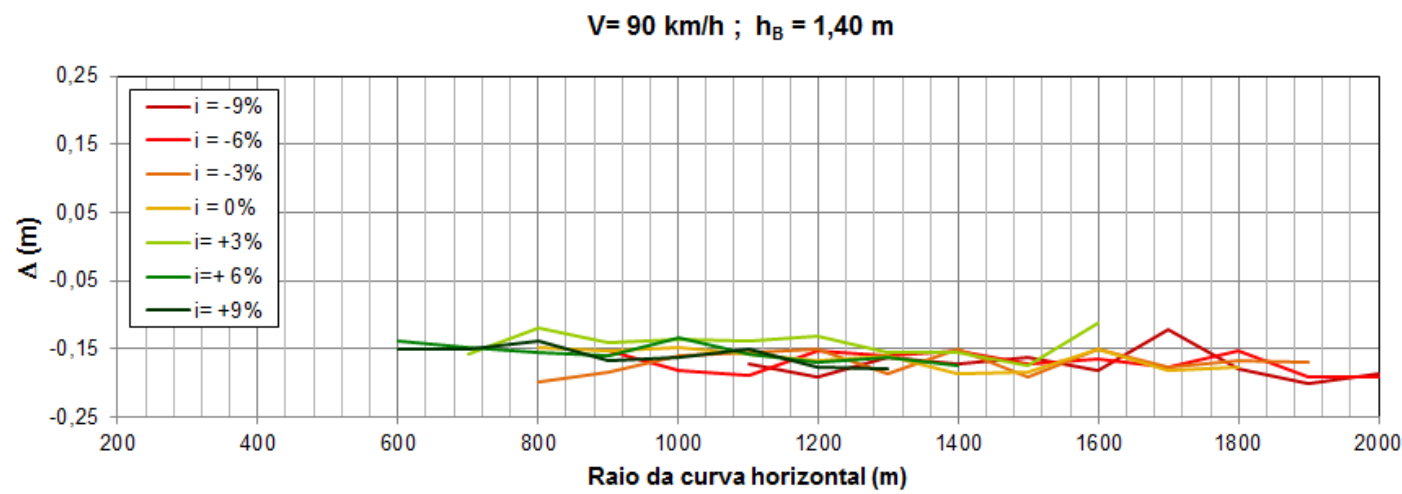

$V=100 \mathrm{~km} / \mathrm{h} ; \mathrm{h}_{\mathrm{B}}=1,40 \mathrm{~m}$

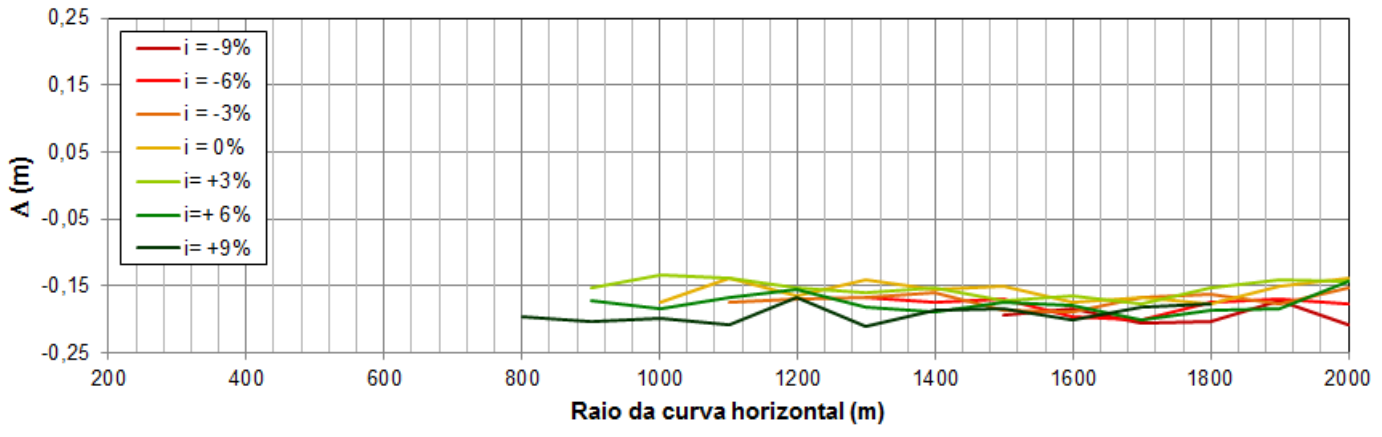

$V=110 \mathrm{~km} / \mathrm{h} ; \mathrm{h}_{\mathrm{B}}=1,40 \mathrm{~m}$

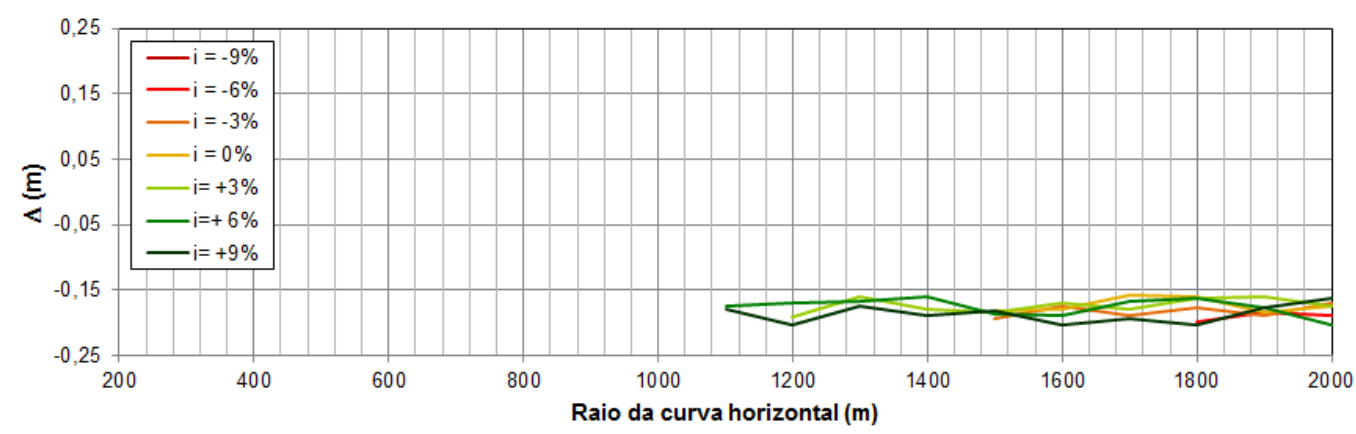

$V=120 \mathrm{~km} / \mathrm{h} ; \mathrm{h}_{\mathrm{B}}=1,40 \mathrm{~m}$

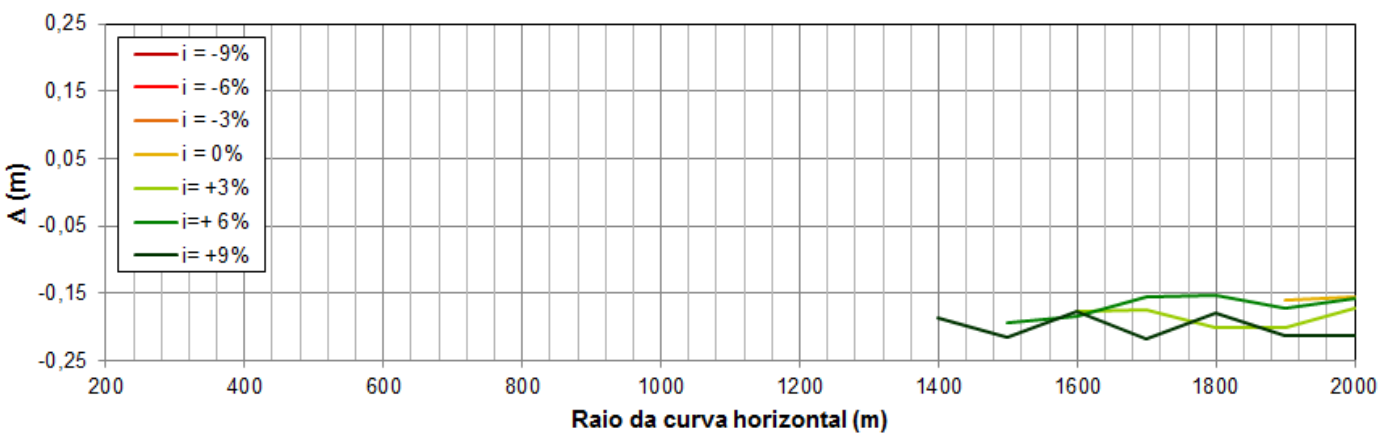

Figura 4.9. Diferença entre Grupo B e modelo $M(90 \mathrm{~km} / \mathrm{h}$ a $120 \mathrm{~km} / \mathrm{h})$ 


\subsection{Funcionamento da Ferramenta de Análise Utilizada - AutoCAD ${ }^{\circledR}$ Civil3D ${ }^{\circledR}$}

$\mathrm{Na}$ execução deste trabalho utilizou-se o programa AutoCAD ${ }^{\circledR}$ Civil3D $^{\circledR}$, da AutoDesk. O programa possui ferramenta para análise de visibilidade do projeto já implantada. A ferramenta é capaz de verificar se distâncias de visibilidade são atendidas ao longo da via sendo fornecidos parâmetros como a altura dos olhos do motorista, a altura do objeto e a posição de ambos ao longo da via. Os resultados são apresentados graficamente e em relatório identificando pontos e regiões onde não há visibilidade adequada ao motorista. O programa analisa linha de visão do motorista em pontos da via, porém foi constatado que o se valor inserido for a DVP, esta não será empregado em concordância com a conceituação. A DVP é uma distância medida ao longo da trajetória do veículo sobre a via. O programa, por sua vez, utiliza esse parâmetro de distância como sendo uma corda da curva horizontal - a linha de visão do motorista - conforme visto na Figura 4.10.

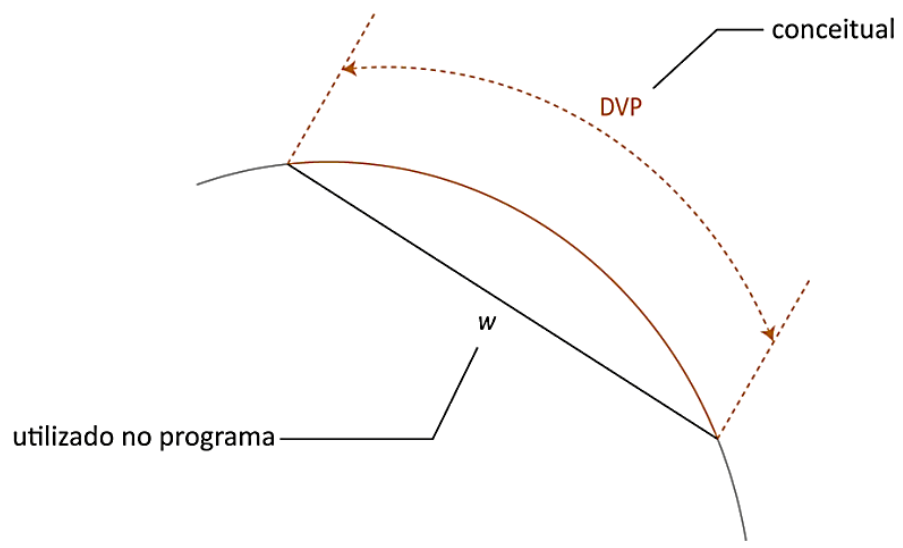

Figura 4.10. Diferenciação do uso da DVP como corda $(w)$ e arco.

O fato de utilizar o valor da DVP em w (corda da curva) não aparenta ser crítico a princípio, pois o valor do arco (neste caso a trajetória) é sempre maior que o valor da corda w. Sendo assim, o espaço disponível ao motorista é sempre superior do que o 
necessário. A distância disponível necessária na via aumenta significativamente, em relação à DVP fornecida pelo projeto, à medida que o raio da curva horizontal diminui. Este aumento interfere na análise de visibilidade, fornecendo indícios de falhas de projeto, pois o traçado não comporta o falso dimensionamento exigido, já que o valor real da DVP é inferior ao verificado pelo programa. A Figura 4.11 apresenta um estudo gráfico sobre a adoção da DVP como sendo uma corda da curva horizontal.

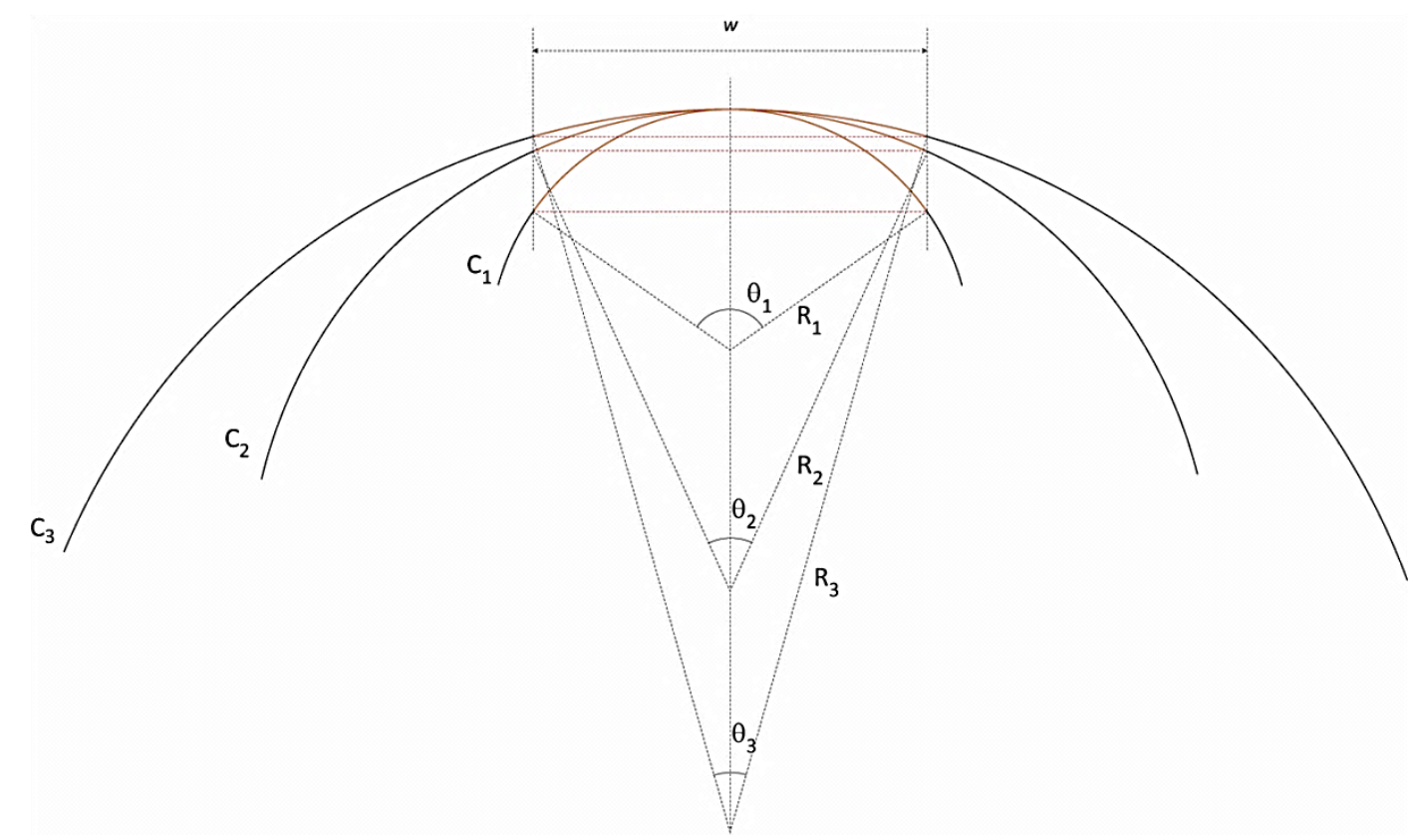

Figura 4.11. Estudo gráfico sobre a adoção da DVP como corda da curva horizontal.

O valor da corda é fixo, já que a DVP é fixa para cada velocidade e inclinação longitudinal. As curvas analisadas possuem o ponto de tangência em comum. À medida que o raio da curva diminui, o ângulo $\theta$ aumenta e, consequentemente, o comprimento do arco definido pela corda aumenta. Por exemplo, seja a DVP igual a $174,00 \mathrm{~m}$. Este valor foi considerado para a corda w e calculou o comprimento do arco $A B$ por ela definida. Assim, foi possível comparar os valores da corda e respectivo arco e estimar o aumento exigido na via para que o projeto fosse aprovado na análise de visibilidade. Os resultados constam na Tabela 4.1. 
Tabela 4.1. Exemplo - Consideração da DVP como corda da curva horizontal.

\begin{tabular}{|c|c|c|c|}
\hline Raio* & DVP (corda)* & $\begin{array}{c}\text { Comprimento } \\
\text { do arco* }\end{array}$ & Aumento \\
\hline 2000 & \multirow{20}{*}{174,00} & 174,05 & $0,03 \%$ \\
\hline 1900 & & 174,06 & $0,03 \%$ \\
\hline 1800 & & 174,07 & $0,04 \%$ \\
\hline 1700 & & 174,08 & $0,04 \%$ \\
\hline 1600 & & 174,09 & $0,05 \%$ \\
\hline 1500 & & 174,10 & $0,06 \%$ \\
\hline 1400 & & 174,11 & $0,06 \%$ \\
\hline 1300 & & 174,13 & $0,07 \%$ \\
\hline 1200 & & 174,15 & $0,09 \%$ \\
\hline 1100 & & 174,18 & $0,10 \%$ \\
\hline 1000 & & 174,22 & $0,13 \%$ \\
\hline 900 & & 174,27 & $0,16 \%$ \\
\hline 800 & & 174,34 & $0,20 \%$ \\
\hline 700 & & 174,45 & $0,26 \%$ \\
\hline 600 & & 174,62 & $0,35 \%$ \\
\hline 500 & & 174,89 & $0,51 \%$ \\
\hline 400 & & 175,40 & $0,81 \%$ \\
\hline 300 & & 176,54 & $1,46 \%$ \\
\hline 200 & & 180,02 & $3,46 \%$ \\
\hline 100 & & 211,04 & $21,29 \%$ \\
\hline
\end{tabular}

No exemplo, é possível verificar o fato que à medida que o raio diminui, o comprimento do arco aumenta para a mesma corda, neste caso, o espaço sobe a via aumenta em relação à necessidade real. Para o menor raio analisado, de $100 \mathrm{~m}$, o aumento ultrapassa $20 \%$ do valor real da DVP. Uma solução é a adoção de valores inferiores à DVP para o programa em cada um dos raios, de modo a ajustar cordas que correspondam a arcos de comprimento igual à DVP exigida, conforme é previsto na Tabela 4.2 . 
Tabela 4.2. Exemplo - Valores a serem inseridos no programa para gerar arcos com comprimento igual ao valor da DVP

\begin{tabular}{|c|c|c|c|}
\hline Raio* & $\begin{array}{c}\text { Valor inserido } \\
\text { (corda) }^{*}\end{array}$ & $\begin{array}{c}\text { Comprimento } \\
\text { do arco (DVP)* }\end{array}$ & $\begin{array}{c}\text { Redução } \\
\text { Prevista }\end{array}$ \\
\hline $\mathbf{2 0 0 0}$ & 173,95 & & $-0,03 \%$ \\
\hline $\mathbf{1 9 0 0}$ & 173,94 & & $-0,03 \%$ \\
\hline $\mathbf{1 8 0 0}$ & 173,93 & & $-0,04 \%$ \\
\hline $\mathbf{1 7 0 0}$ & 173,92 & & $-0,04 \%$ \\
\hline $\mathbf{1 6 0 0}$ & 173,91 & & $-0,05 \%$ \\
\hline $\mathbf{1 5 0 0}$ & 173,90 & & $-0,06 \%$ \\
\hline $\mathbf{1 4 0 0}$ & 173,89 & & $-0,06 \%$ \\
\hline $\mathbf{1 3 0 0}$ & 173,87 & & $-0,07 \%$ \\
\hline $\mathbf{1 2 0 0}$ & 173,85 & & $-0,09 \%$ \\
\hline $\mathbf{1 1 0 0}$ & 173,82 & & $-0,10 \%$ \\
\hline $\mathbf{1 0 0 0}$ & 173,78 & & $-0,13 \%$ \\
\hline $\mathbf{9 0 0}$ & 173,73 & & $-0,16 \%$ \\
\hline $\mathbf{8 0 0}$ & 173,66 & & $-0,20 \%$ \\
\hline $\mathbf{7 0 0}$ & 173,55 & & $-0,26 \%$ \\
\hline $\mathbf{6 0 0}$ & 173,39 & & $-0,35 \%$ \\
\hline $\mathbf{5 0 0}$ & 173,12 & & $-0,50 \%$ \\
\hline $\mathbf{4 0 0}$ & 172,63 & & $-0,79 \%$ \\
\hline $\mathbf{3 0 0}$ & 171,57 & & $-1,40 \%$ \\
\hline $\mathbf{2 0 0}$ & 168,56 & & $-3,12 \%$ \\
\hline $\mathbf{1 0 0}$ & 152,87 & & $-12,15 \%$ \\
\hline
\end{tabular}

Conforme Tabela 4.2, a adoção de cordas ao invés de arcos deve ser feita com ressalvas para raios de curva horizontal pequenos, ou seja, inferiores a 300 metros. Onde a discrepância entre arco e corda aumenta significativamente. Como estudo posterior, sugere-se a investigação a influência deste aspecto da ferramenta nos resultados obtidos, verificando se é significativa ou não, em quais condições e se for o caso, propor medidas corretivas para que não haja inconsistências nas conclusões de análise de visibilidade. 


\section{APLICATIVO}

O volume previsto gerado com a conclusão da etapa de simulações exigiu tratamento diferenciado. Para facilitar o manuseio dos resultados obtidos, foi elaborado aplicativo contendo como base de dados os modelos calculados para cada curva de cada diagrama, sendo capaz de gerar os diagramas automaticamente, realizar estimativas de afastamento lateral da barreira e gerar relatórios das análises, através de eventos ativados por ações do usuário na tela principal do aplicativo. O aplicativo foi desenvolvido utilizando ferramentas do $M A T L A B^{\circledR}$. As linhas de código do programa compõem o Anexo III. Recomenda-se a transição deste aplicativo para outra plataforma de programação, de modo que o torne mais robusto e estável, além de aprimoramentos de interface, portabilidade e tratamento de erros e restrições. O funcionamento será explicado com base no uso hipotético do aplicativo.

A tela do aplicativo é apresentada na Figura 5.1. Por meio desta tela, o usuário será capaz de interagir com aplicativo fornecendo valores de entrada necessários ao seu funcionamento.

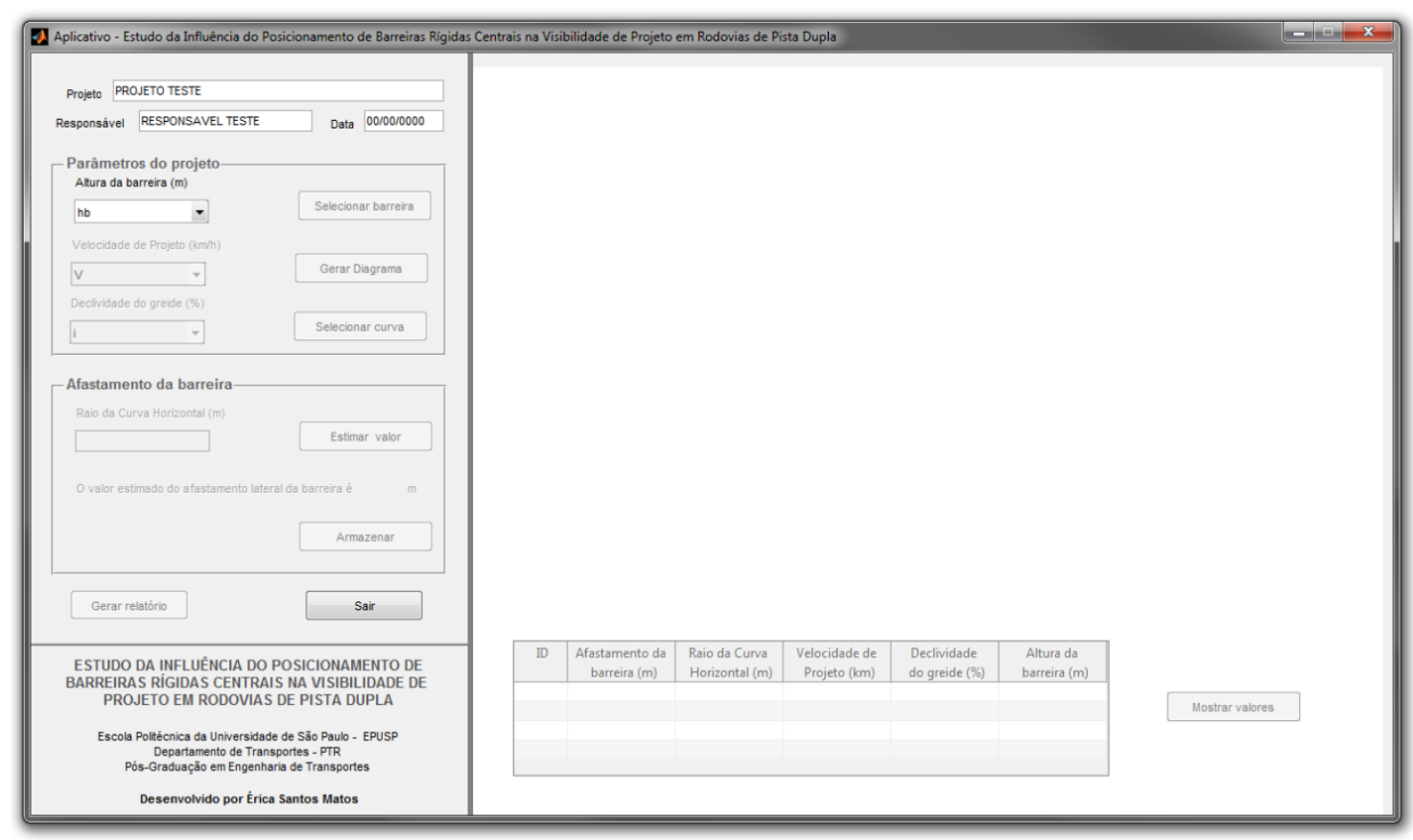


Inicialmente, o usuário pode cadastrar informações sobre a análise que irá fazer como o nome do projeto a qual está vinculada, o responsável e data de execução (Figura 5.2).

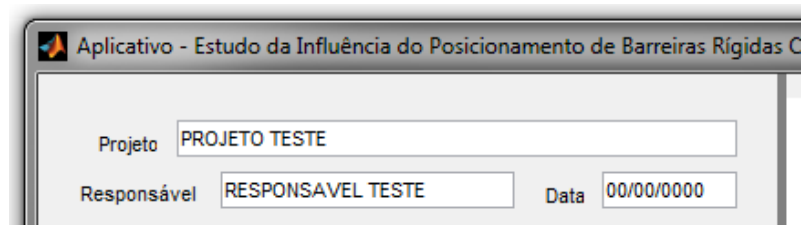

Figura 5.2. Detalhe - Informações Gerais

Após isso, o usuário deve escolher uma altura de barreira: 1,00 m ou 1,40 m (Figura 5.3). Feita uma opção, ao clicar no botão 'Selecionar barreira' (Figura 5.4) o aplicativo irá separar os coeficientes dos modelos referentes à altura selecionada.

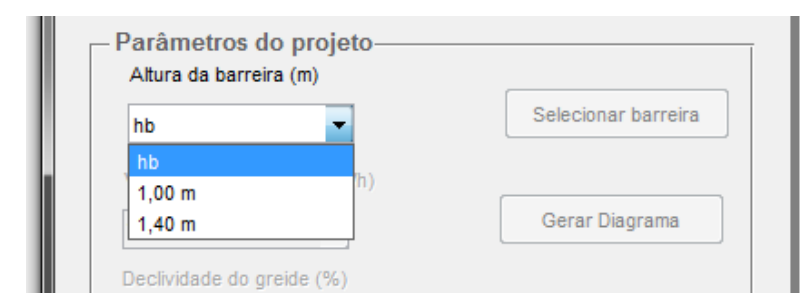

Figura 5.3. Opções de altura de barreira

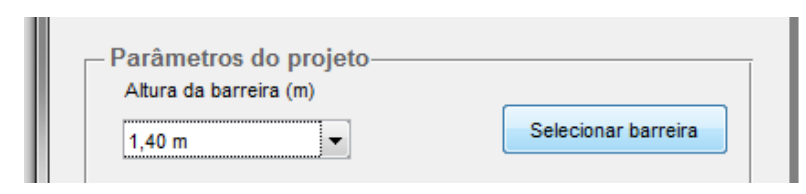

Figura 5.4. Botão 'Selecionar barreira'

Ao selecionar a barreira, o aplicativo ativa a opção para escolha de uma velocidade de projeto. As opções de velocidade de projeto são mostradas (Figura 5.5) e o usuário deve selecionar uma e clicar no botão 'Gerar Diagrama' (Figura 5.6). Feito isso, o diagrama referente à altura da barreira e velocidade de projeto selecionadas 
é gerado automaticamente a partir dos modelos de polinômios calculados no capítulo 3 (Figura 5.7).

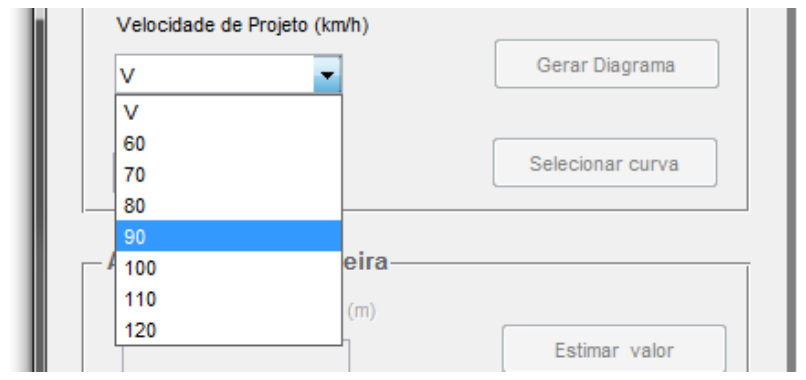

Figura 5.5. Opções de velocidade de projeto

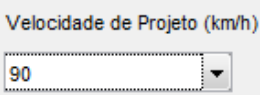

Gerar Diagrama

Figura 5.6. Botão ‘Gerar Diagrama’

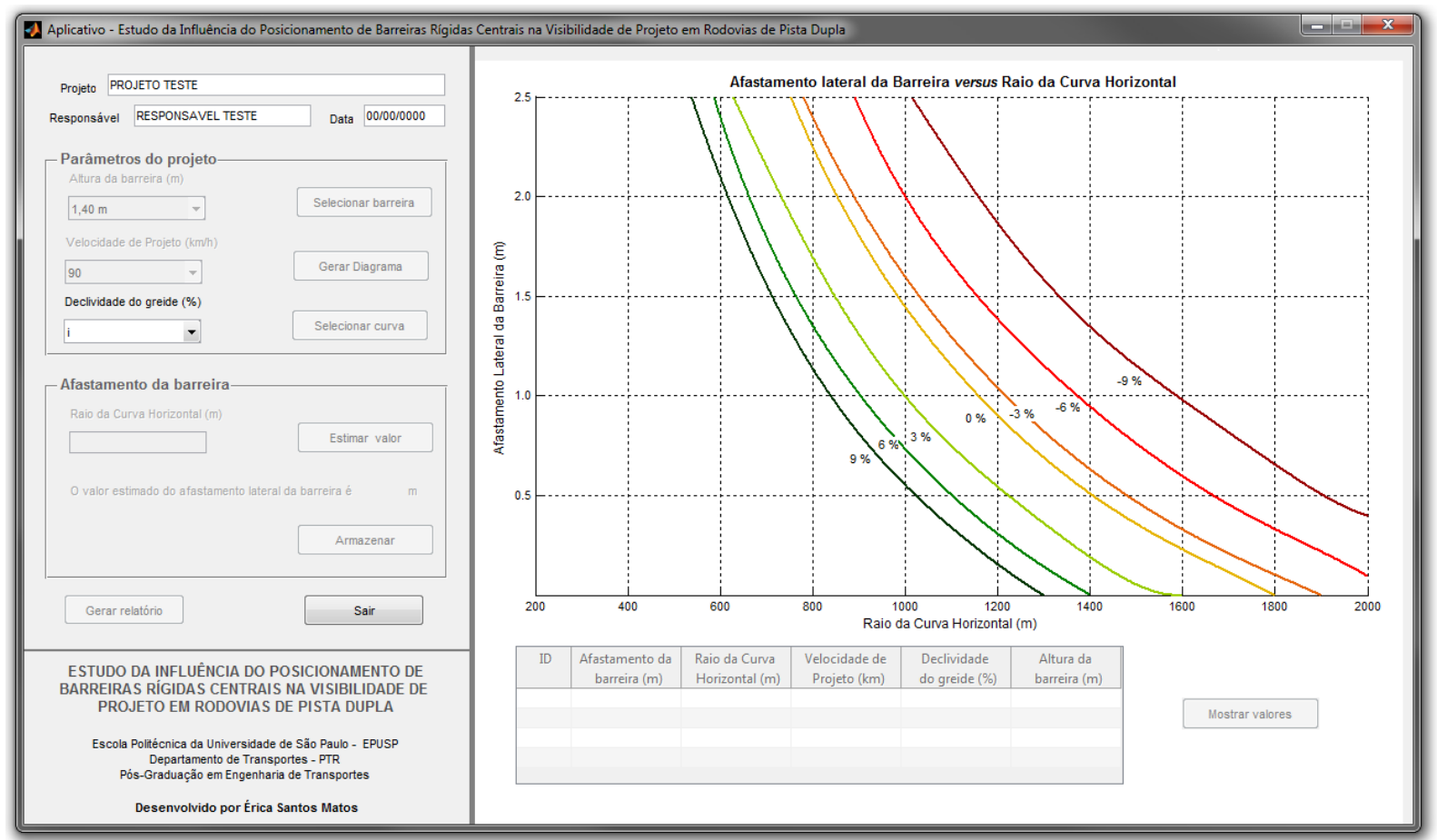

Figura 5.7. Diagrama gerado pelo aplicativo 
Uma vez gerado o não é possível alterá-lo. Para isso, deve-se encerrar e executar novamente o programa. Com o diagrama pronto é preciso definir em qual das curvas será feita a análise do afastamento lateral da barreira. Escolhe-se então uma declividade do greide dentre as opções possíveis (Figura 5.8) e clica no botão 'Selecionar curva' (Figura 5.9).

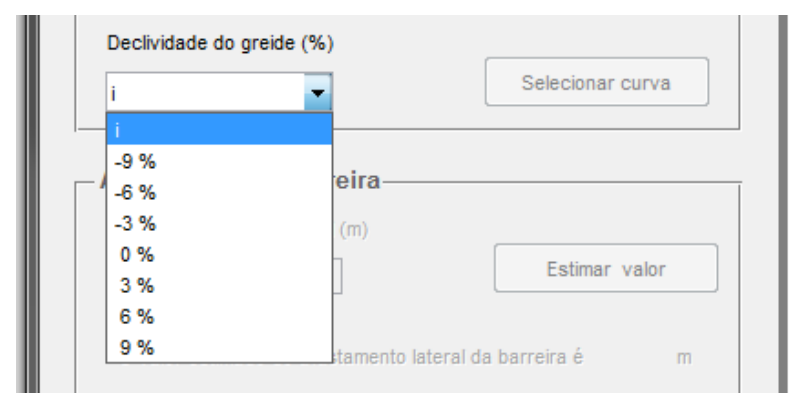

Figura 5.8. Opções de declividade de greide

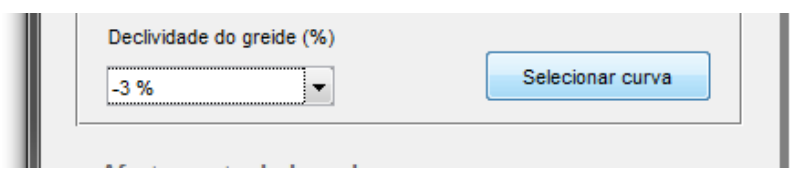

Figura 5.9. Opções de declividade de greide

Automaticamente, a curva de análise selecionada torna-se azul (Figura 5.10) e as opções para estimativa do afastamento lateral da barreira são ativas. Internamente, o aplicativo seleciona os coeficientes a partir de uma matriz e estrutura o polinômio para a estimativa de valor. 


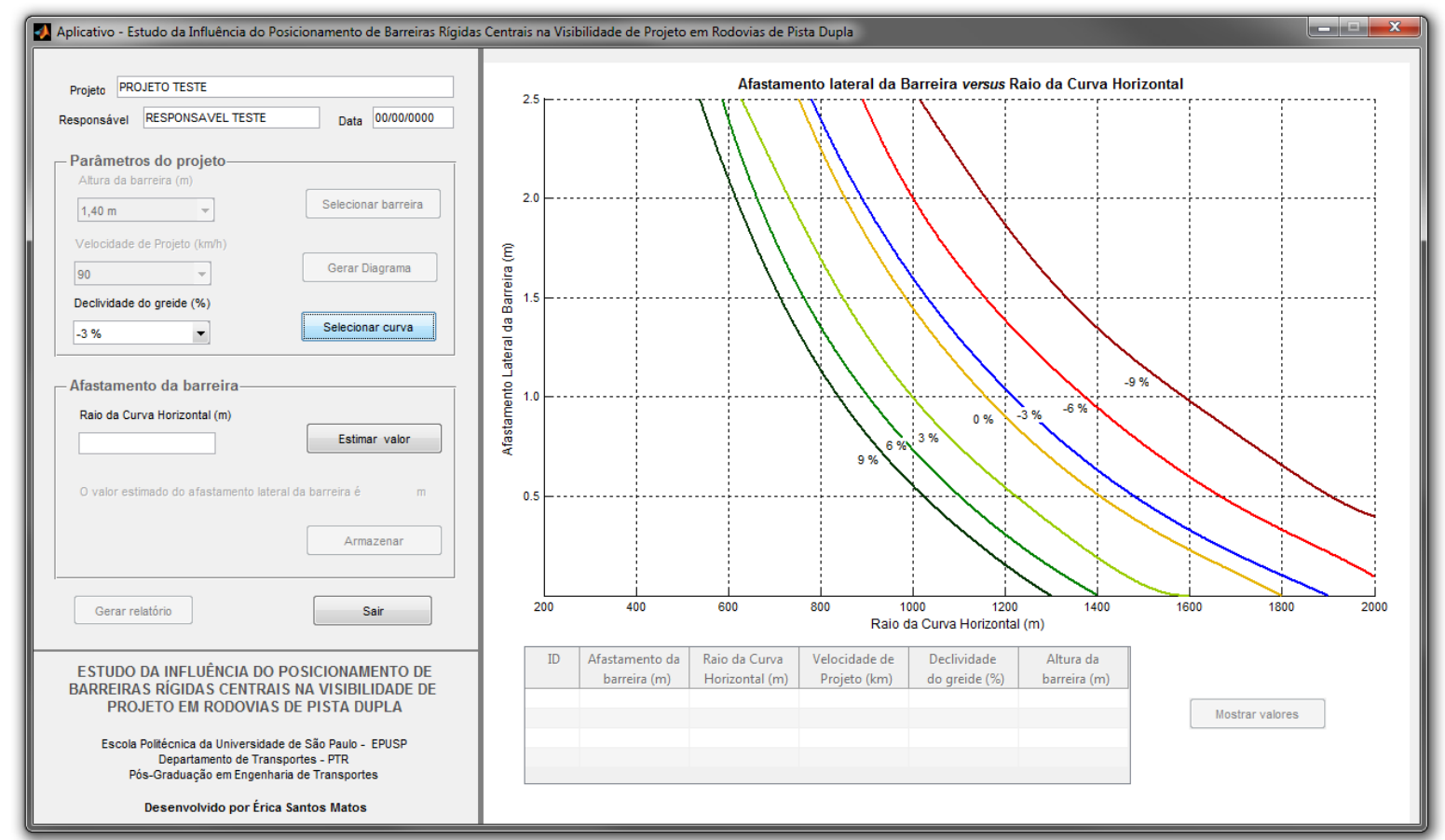

Figura 5.10. Curva selecionada em azul

O aplicativo está preparado para a estimativa de valores. Ao fornecer um valor de raio da curva horizontal, o aplicativo retorna o valor estimado do afastamento lateral da barreira através do polinômio calculado previamente (Figura 5.11).

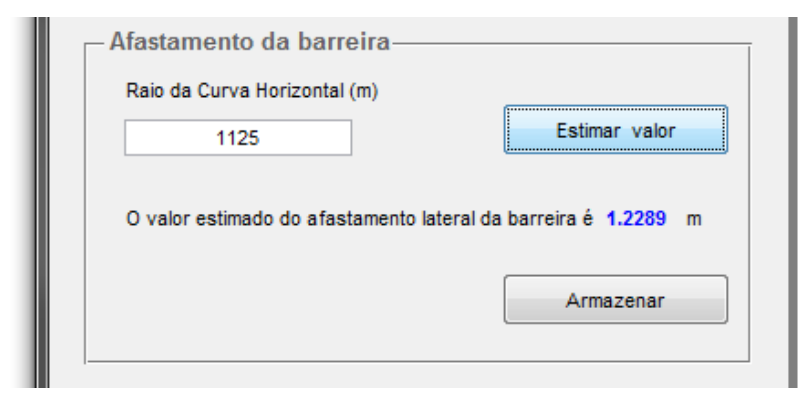

Figura 5.11. Etapa de estimativa de valor do afastamento lateral da barreira

O valor de retorno pode ser armazenado com os demais dados de análise. Caso seja feito isso, os dados são apresentados na tabela na parte inferior direita do aplicativo (Figura 5.12) e ficam disponíveis para a geração do relatório. 


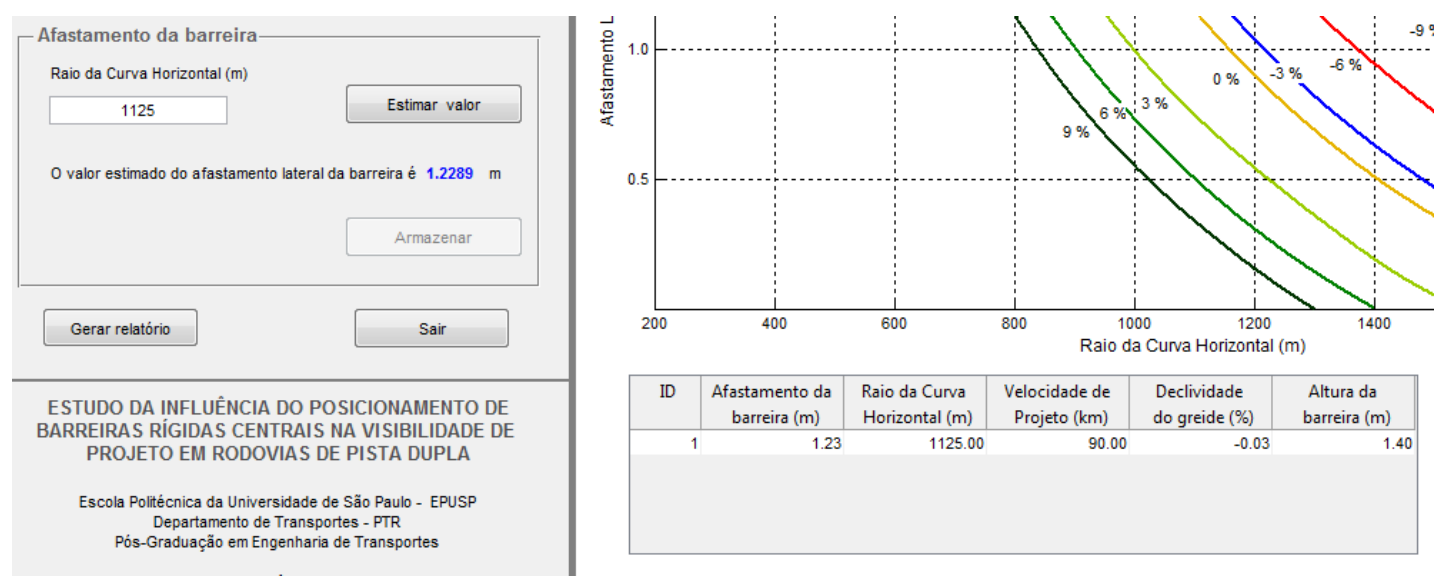

Figura 5.12. Armazenamento dos dados da estimativa.

Outras opções são de realizar uma nova estimativa nesta curva ou de selecionar outra curva do diagrama para analisar. Este processo pode ser feito o quanto for necessário ao usuário. Os dados armazenados podem ser também apresentados no próprio diagrama através do botão 'Mostrar valores' (Figura 5.13).

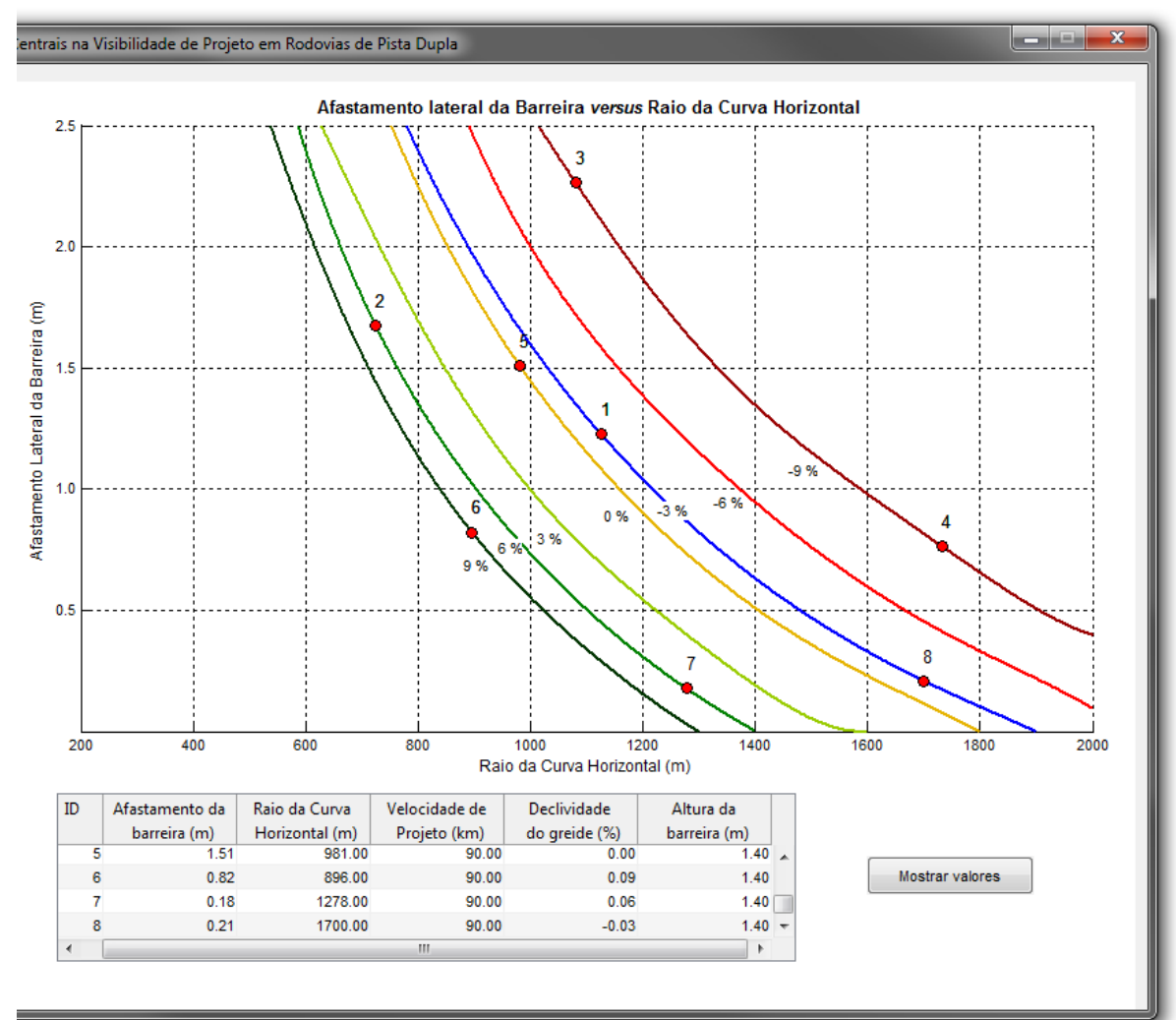

Figura 5.13. Valores estimados apresentados no diagrama. 
Por fim, o usuário é capaz de gerar relatório com informações das análises feitas. O relatório é gerado em formato ASCII, podendo ser visualizado através do bloco de notas do sistema operacional Windows ${ }^{\circledR}$ (Figura 5.14).

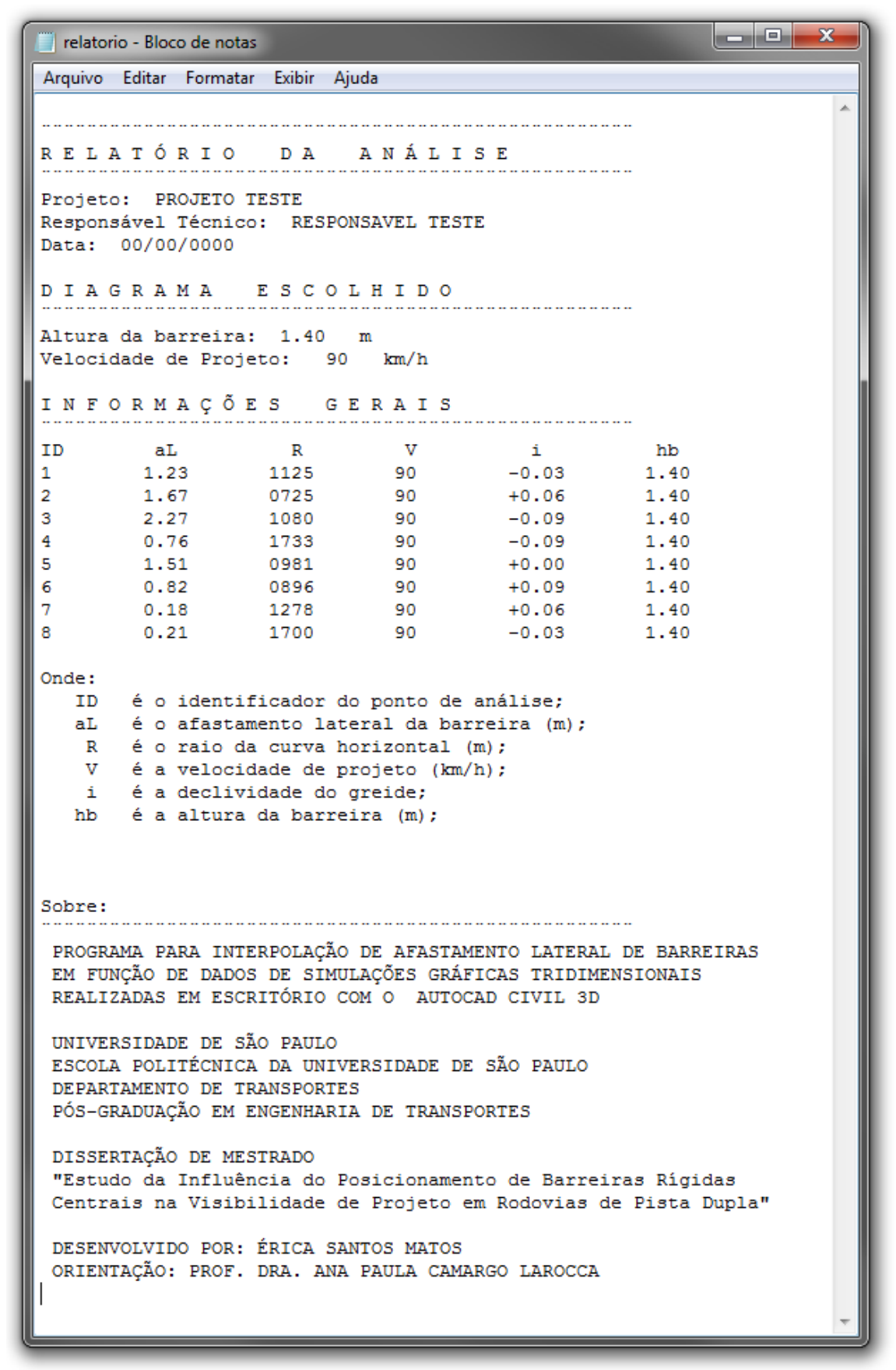

Figura 5.14. Modelo de relatório gerado

O instalador e executável do aplicativo encontra-se na forma de CD-ROM compreendendo o Anexo IV desta dissertação. 


\section{ESTUDO DE CASO}

O estudo de caso baseou-se em projeto viário real, disponibilizado pela PLANSERVI Engenharia. Trata-se de estudo de traçado do arco metropolitano de Recife. As curvas analisadas estão compreendidas entre as intersecções do arco metropolitano com as rodovias federais BR-232 e BR-408 (Figura 6.1), em um trecho de cerca de $10 \mathrm{~km}$.

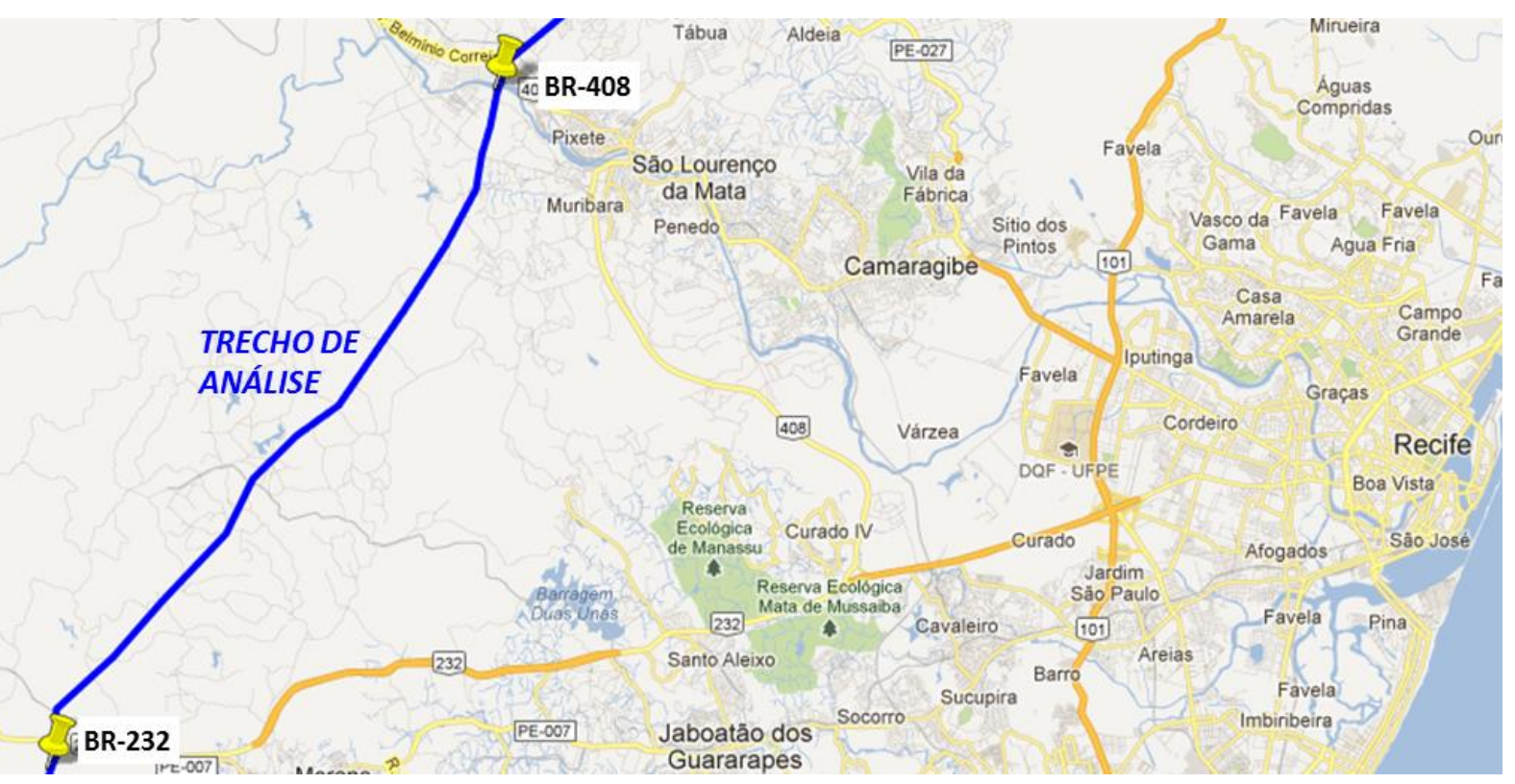

Figura 6.1. Trecho de análise entre BR-232 e BR-408 - Estudo de traçado Arco Metropolitano de Recife. Foto: Google ${ }^{\circledR} 2012$.

A velocidade de projeto considerada é de $100 \mathrm{~km} / \mathrm{h}$. A seção tipo do projeto é de pista dupla, com faixas de rolamento de largura de $3,50 \mathrm{~m}$, com canteiro restrito com barreira rígida, perfil New Jersey, com alturas de 0,81 m e 1,30 m, uma adaptação ao projeto original, em que não há presença de barreira. O refúgio mínimo adotado é de $0,60 \mathrm{~m}$. Demais informações foram omitidas para garantir o sigilo e confidencialidade do projeto e de seus executores, sendo apenas citadas informações coerentes e necessárias a este estudo. 


\subsection{Análises do grupo A - Altura da barreira igual a 1,00 m.}

Inicialmente, as análises foram feitas baseadas nos diagramas gerados durante os estudos de afastamento lateral da barreira de altura de 1,00 m. Este conjunto de dados é o mais próximo da barreira utilizada no projeto, que tem perfil New Jersey com altura padrão de $0,81 \mathrm{~m}$.

\subsubsection{Curva A}

O primeiro caso tratou-se de uma curva com raio horizontal de $600 \mathrm{~m}$ em aclive, com declividade constante do greide de $4 \%$. Para velocidade de $100 \mathrm{~km} / \mathrm{h}$ e $\mathrm{i}=4 \%$, implica em uma DVP igual a $171 \mathrm{~m}$, gerada pela formulação apresentada no item 4.1.5. Para o refúgio mínimo adotado no projeto de $0,60 \mathrm{~m}$, a DVP não é atendida (Figura 6.2)

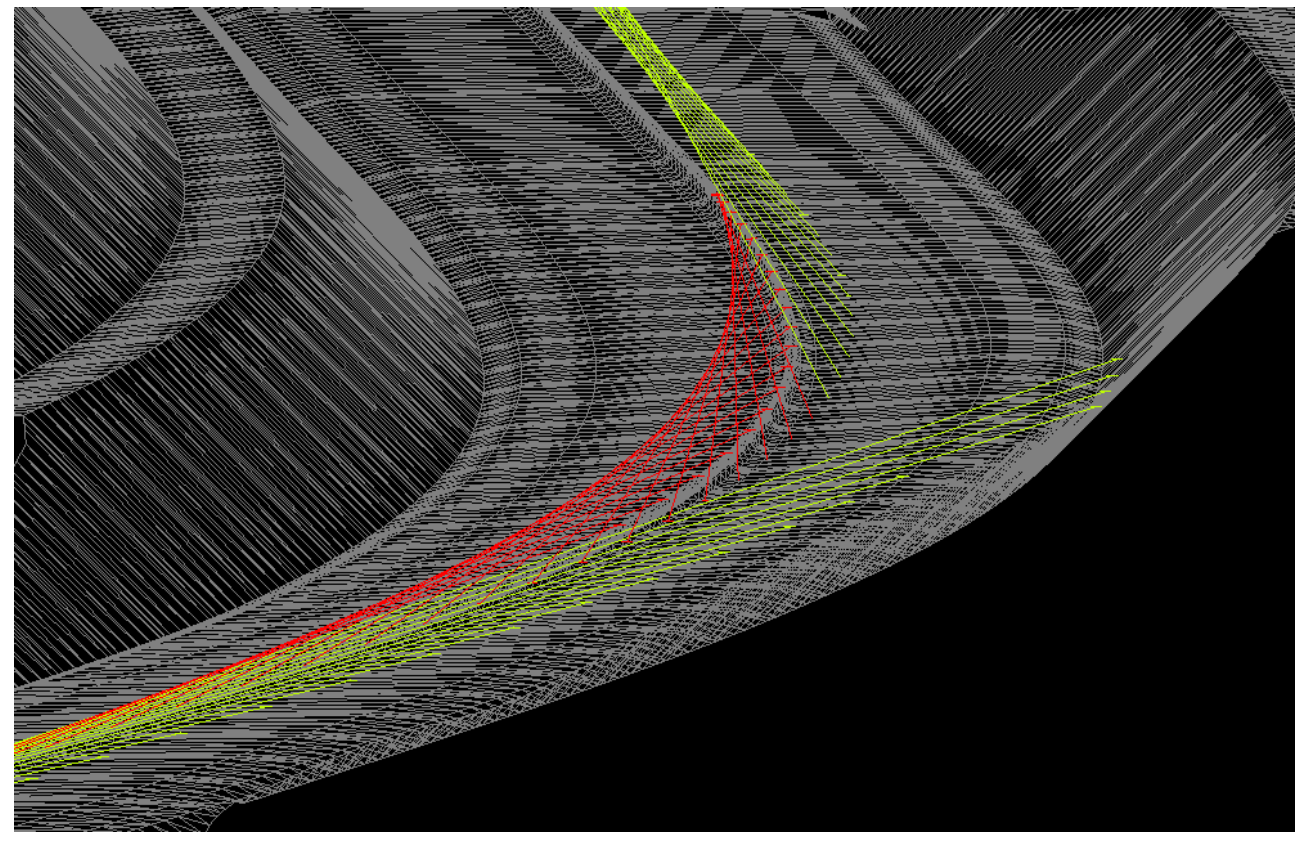

Figura 6.2. Curva A. Problema de Visibilidade - afastamento lateral da barreira de 0,60 m. 
As linhas em vermelho indicam pontos ao longo da trajetória que a linha de visão tem valor inferior a DVP, sempre considerando a mesma posição dos olhos do motorista e do objeto utilizados durante a etapa de simulações.

O próximo valor testado é proveniente do aplicativo gerado considerando como parâmetros de entrada os mesmos valores de velocidade de projeto e raio da curva horizontal e a declividade do greide de $+3 \%$, valor simulado mais próximo ao do projeto real. O afastamento lateral da barreira estimado para estas condições é de 1,30 m. Ao testar a DVP na curva, com este novo valor, os problemas de visibilidade persistem (Figura 6.3).

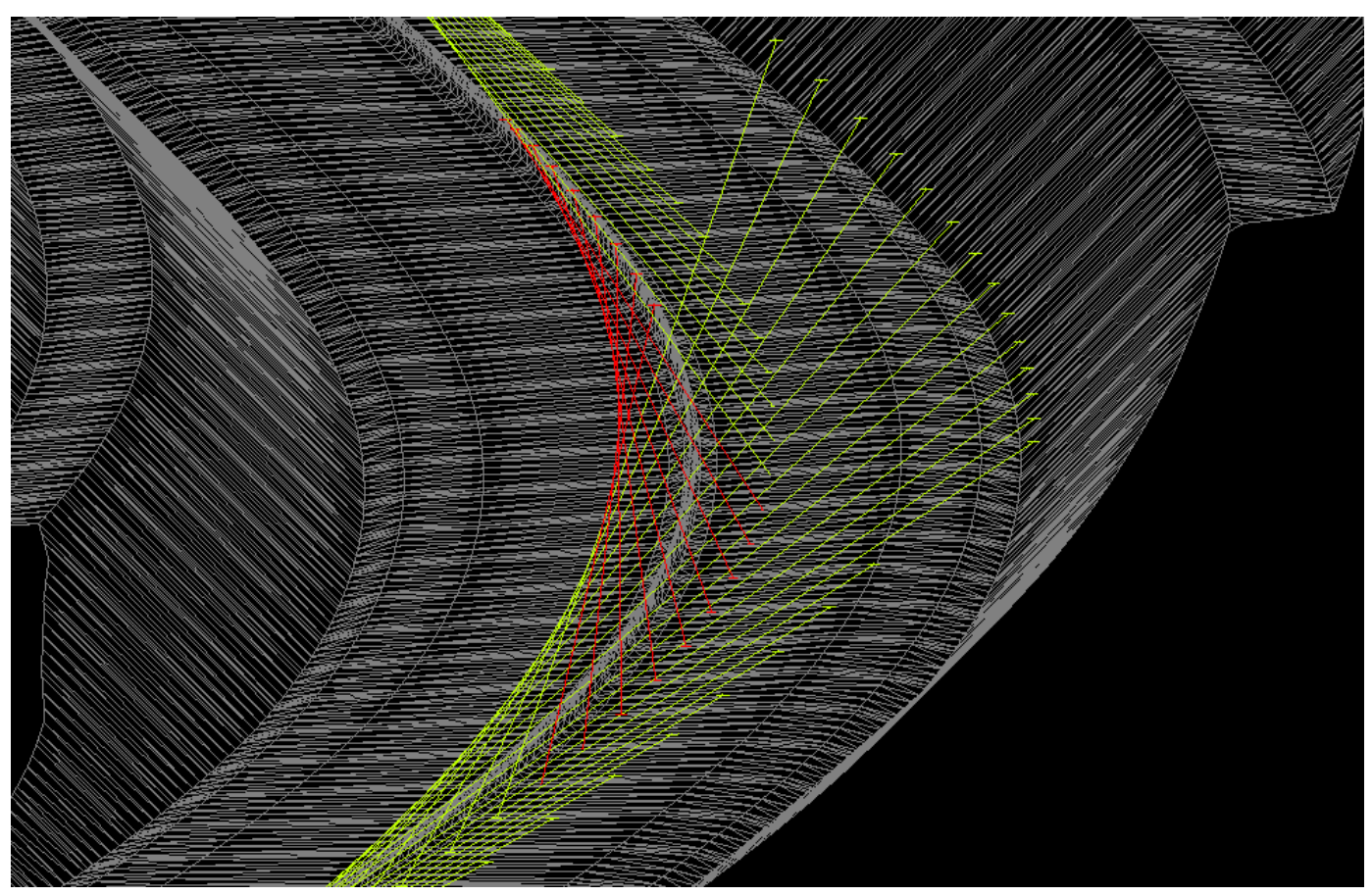

Figura 6.3. Curva A. Problema de Visibilidade - afastamento lateral da barreira de 1,30 m.

O aumento do afastamento lateral da barreira diminuiu a região com problemas de visibilidade (linhas em vermelho) em relação à configuração original da Figura 10.1, porém não foi suficiente para que a DVP fosse totalmente garantida. Após análises de outras configurações, variando apenas a dimensão do refúgio (ou afastamento lateral da barreira), obteve-se resultado positivo para o valor mínimo de 1,90 m (Figura 6.4). 


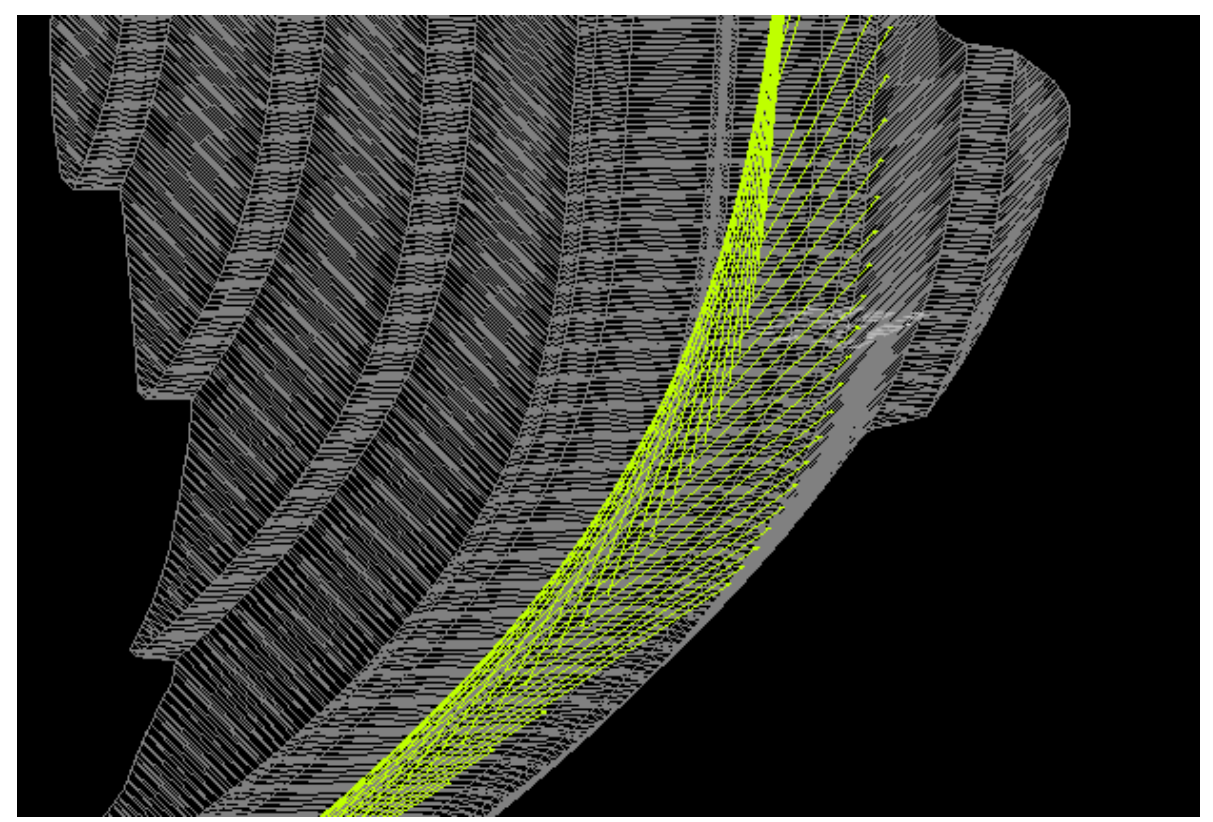

Figura 6.4. Curva A. DVP garantida - afastamento lateral da barreira de $1,90 \mathrm{~m}$.

Neste caso, a DVP foi atendida em toda extensão da curva, sem a ocorrência de obstruções nas linhas de visada. Todavia, corresponde a um acréscimo de 0,60 m no valor estimado no aplicativo, que foi de $1,30 \mathrm{~m}$.

\subsubsection{Curva B}

O segundo trecho analisado foi mais complexo que a curva $A$. Neste caso, a curva horizontal de raio de 1050 m ocorre concomitantemente a uma curva vertical, que faz a transição das rampas com declividade de greide igual a 3,5\% para $0,5 \%$. A velocidade de projeto continua a mesma de $100 \mathrm{~km} / \mathrm{h}$, que implicou na DVP de 171 m considerando a declividade mais significativa da curva $(i=3,5 \%)$.

Ao considerar o valor mínimo do projeto com afastamento lateral da barreira de 0,60 m a DVP não foi garantida. Pelo aplicativo, considerando a mesma velocidade e o mesmo raio da curva horizontal, com declividade do greide igual a 3\%, fixo devido à restrições das hipóteses do método adotado, retornando o valor estimado foi de 1,45 
m. Ao testar a DVP com esse valor, os problemas de visibilidade persistiram (Figura 6.5)

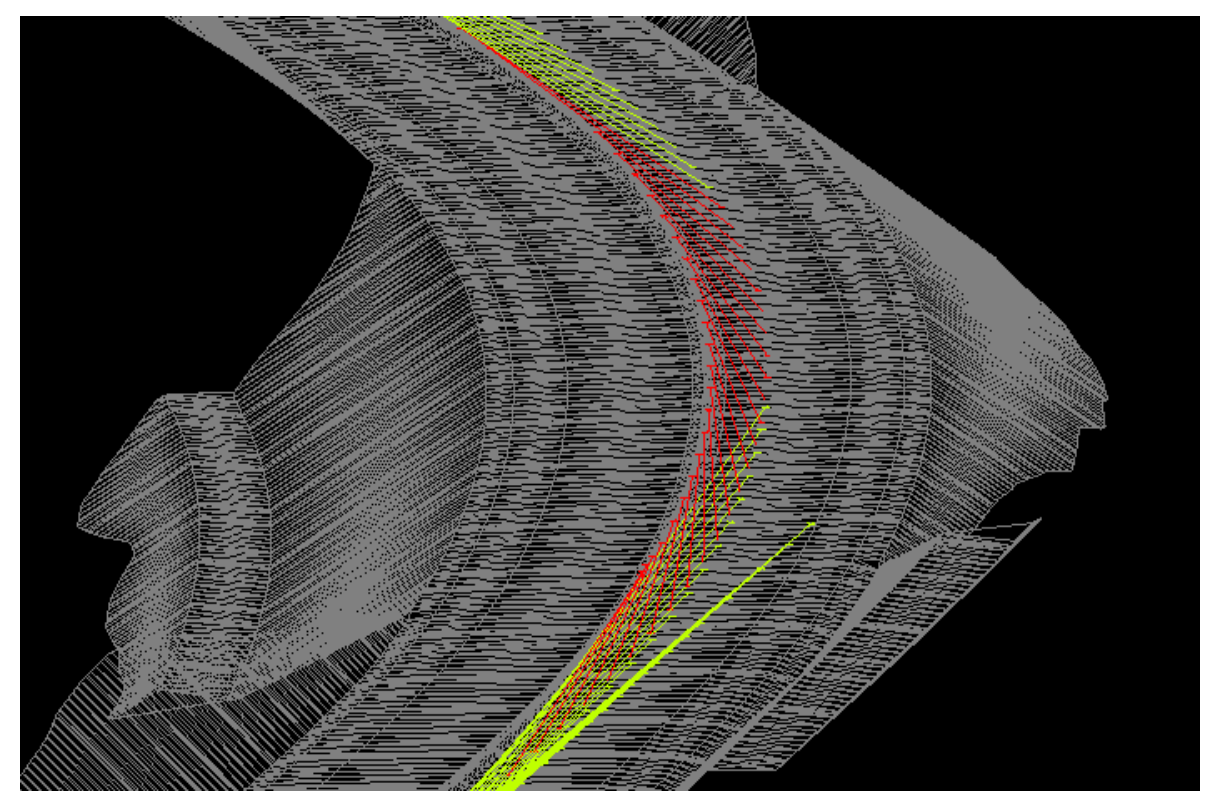

Figura 6.5. Curva B. Problema de Visibilidade - afastamento lateral da barreira de 1,45 m.

O afastamento lateral da barreira foi aumentado gradativamente até o valor de 1,85 $\mathrm{m}$, que representou o valor mínimo em que a DVP fosse garantida em toda a curva (Figura 6.6).

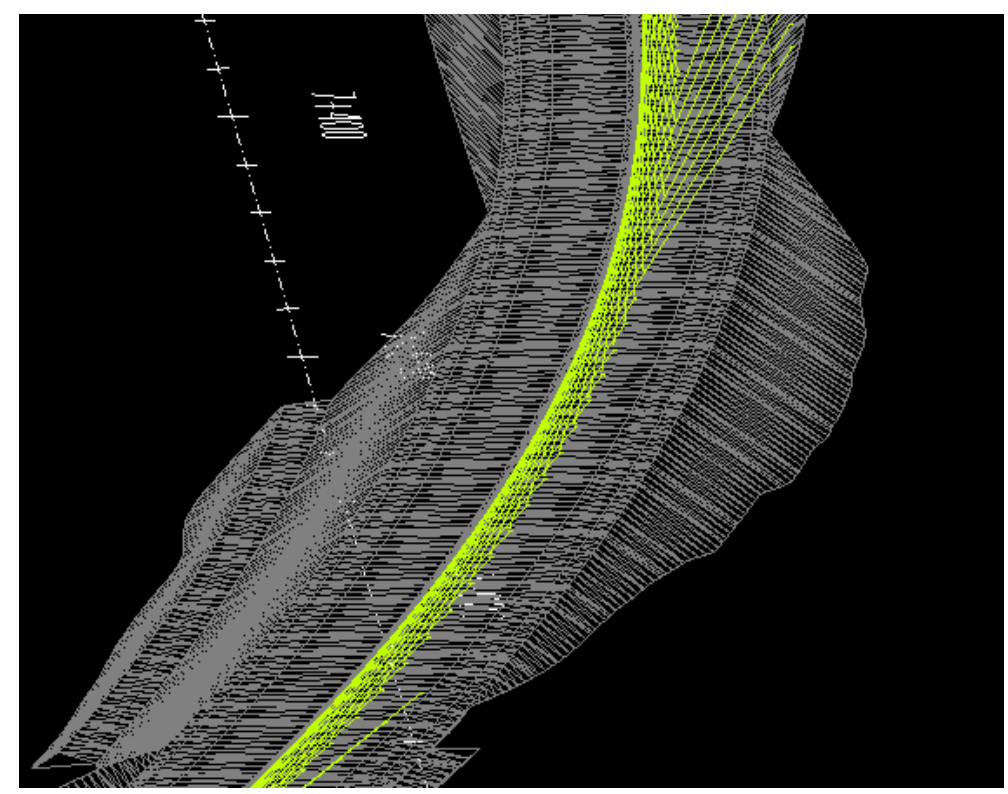

Figura 6.6. Curva B. DVP garantida - afastamento lateral da barreira de $1,85 \mathrm{~m}$. 
Assim como no caso anterior, existe uma discrepância entre o valor do aplicativo, proveniente das simulações do estudo, e o valor oriundo do estudo de caso. Para a curva $B$ os valores diferem na ordem de $0,40 \mathrm{~m}$.

O motivo da discrepância de valores das análises curvas A e B é a presença de características reais do alinhamento vertical, que em nestes casos desfavoreceu a visibilidade do objeto sobre a barreira (solução mínima considerada durante o processo de simulações).

\subsection{Análises do grupo B - Altura da barreira igual a 1,40 m.}

A seção tipo foi adaptada com uma barreira rígida de altura de $1,30 \mathrm{~m}$, tipo New Jersey, para análises das estimativas provenientes do grupo $\mathrm{B}$, definido por barreira similar, com altura de 1,40 m (acréscimo de 0,10 m). Além disto, neste conjunto variou-se também a velocidade de projeto $(100 \mathrm{~km} / \mathrm{h}$ e $70 \mathrm{~km} / \mathrm{h})$ e impôs uma curva em declive para validação do dado.

\subsubsection{Curva C}

A curva $C$ é a mesma que a curva $B$ descrita anteriormente. A diferença está na seção tipo, que possui uma barreira rígida alta. Sendo assim, a curva $C$ tem raio horizontal de $1050 \mathrm{~m}$ com variação de greide de (3,5\% para 0,5\%). A DVP utilizada foi de $171 \mathrm{~m}$ compatível com a velocidade de projeto de $100 \mathrm{~km} / \mathrm{h}$.

A estimativa do aplicativo para afastamento lateral da barreira foi de $1,90 \mathrm{~m}$, considerando a declividade do greide igual a 3\%. A DVP nesse caso é garantida em toda extensão (Figura 6.7). 


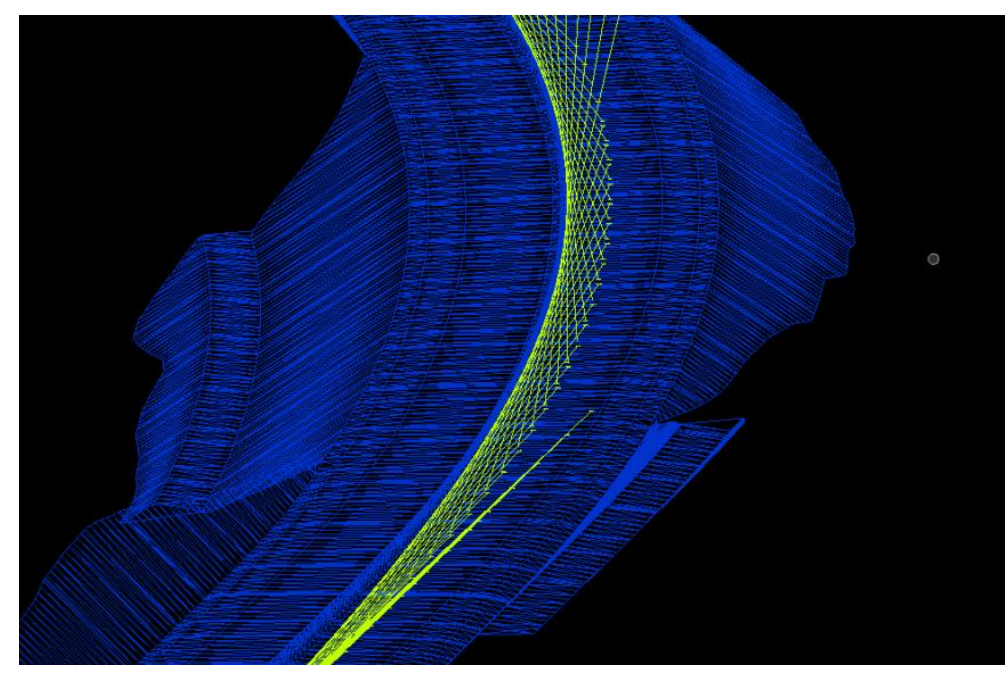

Figura 6.7. Curva C. DVP garantida - afastamento lateral da barreira de $1,90 \mathrm{~m}$.

As linhas em amarelo indicam que a visualização do objeto ocorre tangenciando a barreira. Para validar esse valor diminuiu-se o afastamento lateral da barreira gradativamente. Uma redução de $0,10 \mathrm{~m}$, passando para afastamento de 1,80 m, a DVP ainda é garantida. Reduzindo novamente, com o valor de 1,70 m de afastamento ocorrem problemas de visibilidade na curva (Figura 6.8)

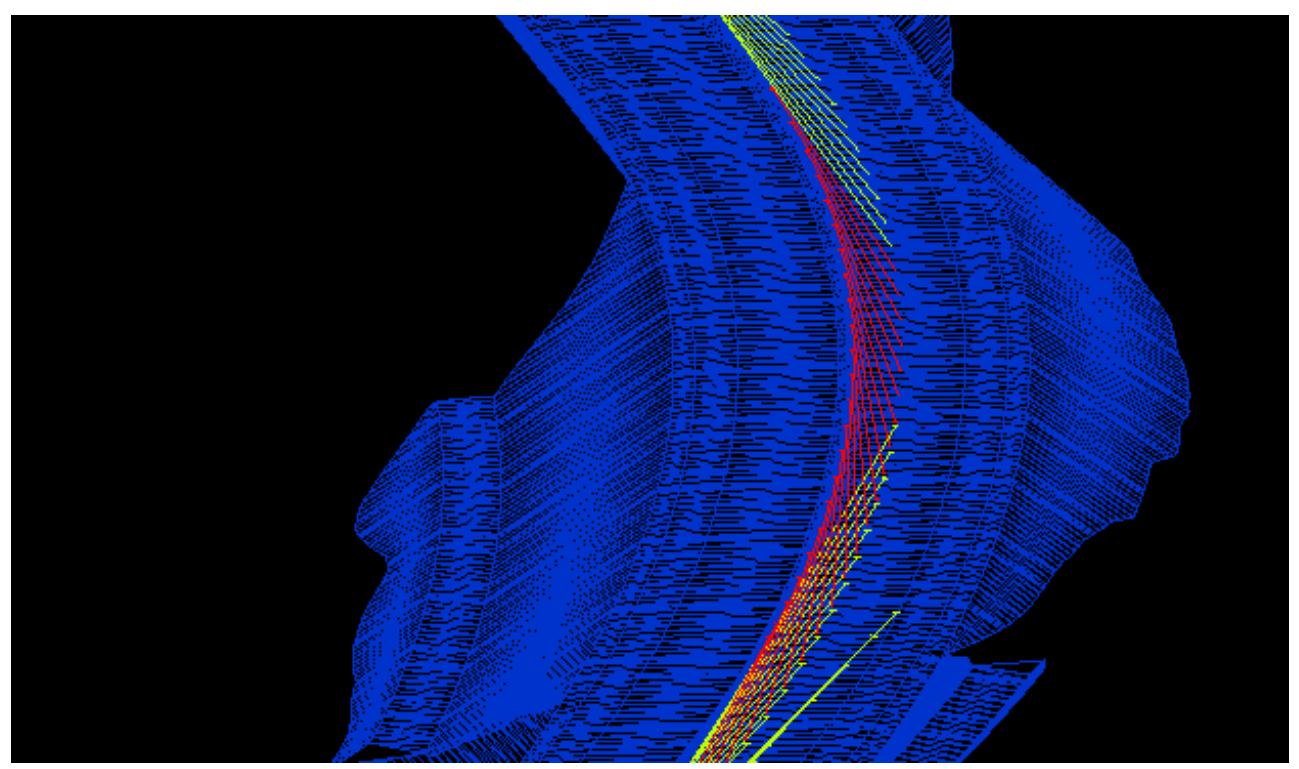

Figura 6.8. Curva C. Problema de Visibilidade - afastamento lateral da barreira de 1,70 m. 
As linhas em vermelho da figura 6.8 representam problemas de visibilidade. Para visualizar o objeto a uma distância igual à DVP seria necessário que a linha de visão atravessasse a barreira, como uma secante, o que não é fisicamente possível.

\subsubsection{Curva D}

$\mathrm{Na}$ curva $\mathrm{D}$ considerou-se a velocidade de projeto igual a $70 \mathrm{~km} / \mathrm{h}$. O raio da curva horizontal é de $505 \mathrm{~m}$, em suave aclive ( $\mathrm{i}=0,7 \%)$. Assim, a DVP adotada na análise é de $105 \mathrm{~m}$, para greide nulo.

O valor estimado pelo aplicativo, nessas condições, para o afastamento lateral da barreia é de 1,05 m. A DVP é garantida em toda a extensão da curva ao utilizar este valor na seção tipo (Figura 6.9)

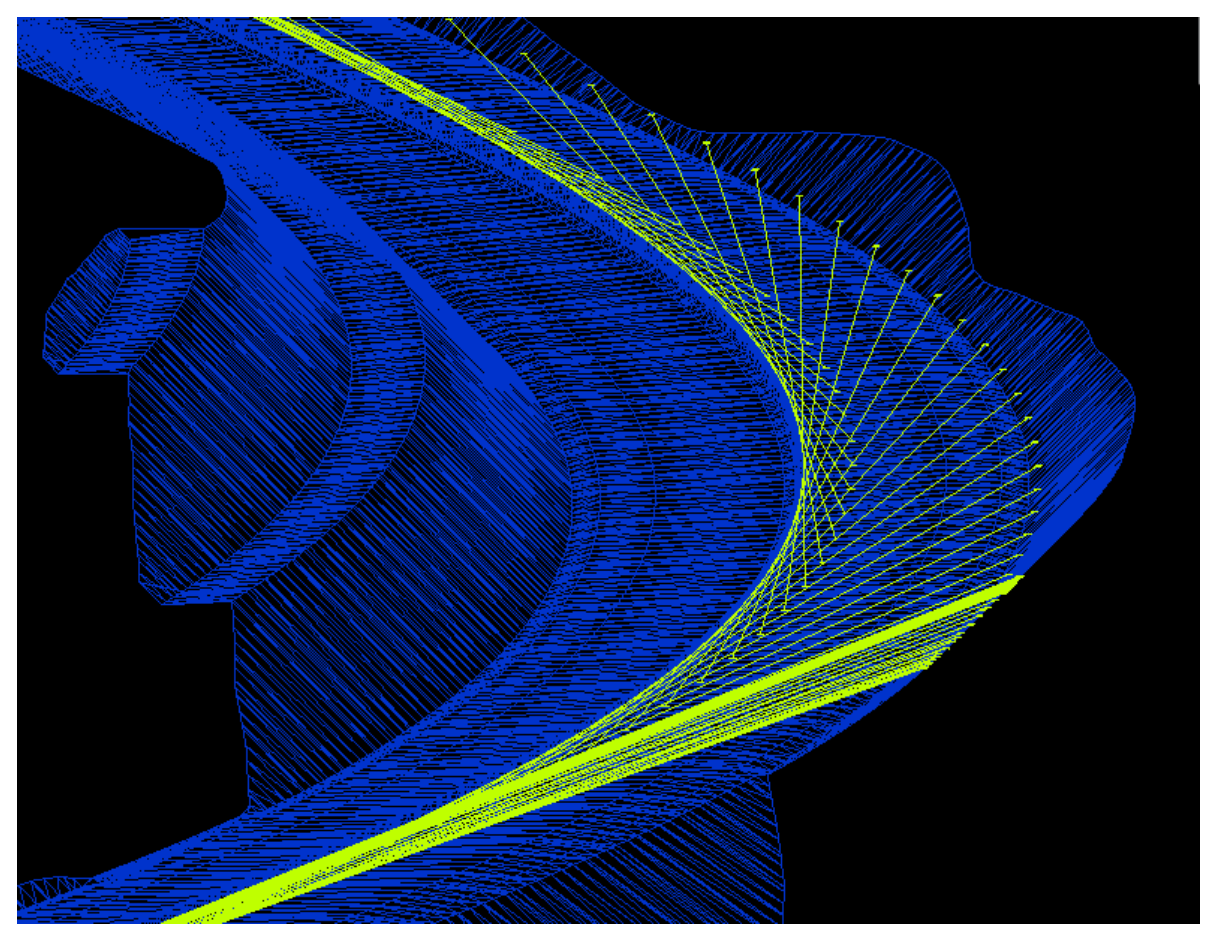

Figura 6.9. Curva D. DVP garantida - afastamento lateral da barreira de $1,05 \mathrm{~m}$. 
Como no caso anterior, a visão do objeto ocorre tangenciando a barreira. Ao impor uma redução de $0,10 \mathrm{~m}$, passando para afastamento de $0,95 \mathrm{~m}$ a visibilidade é prejudicada, com visadas de dimensões restritas (em vermelho) bloqueadas pela barreira, conforme visto na Figura 6.10.

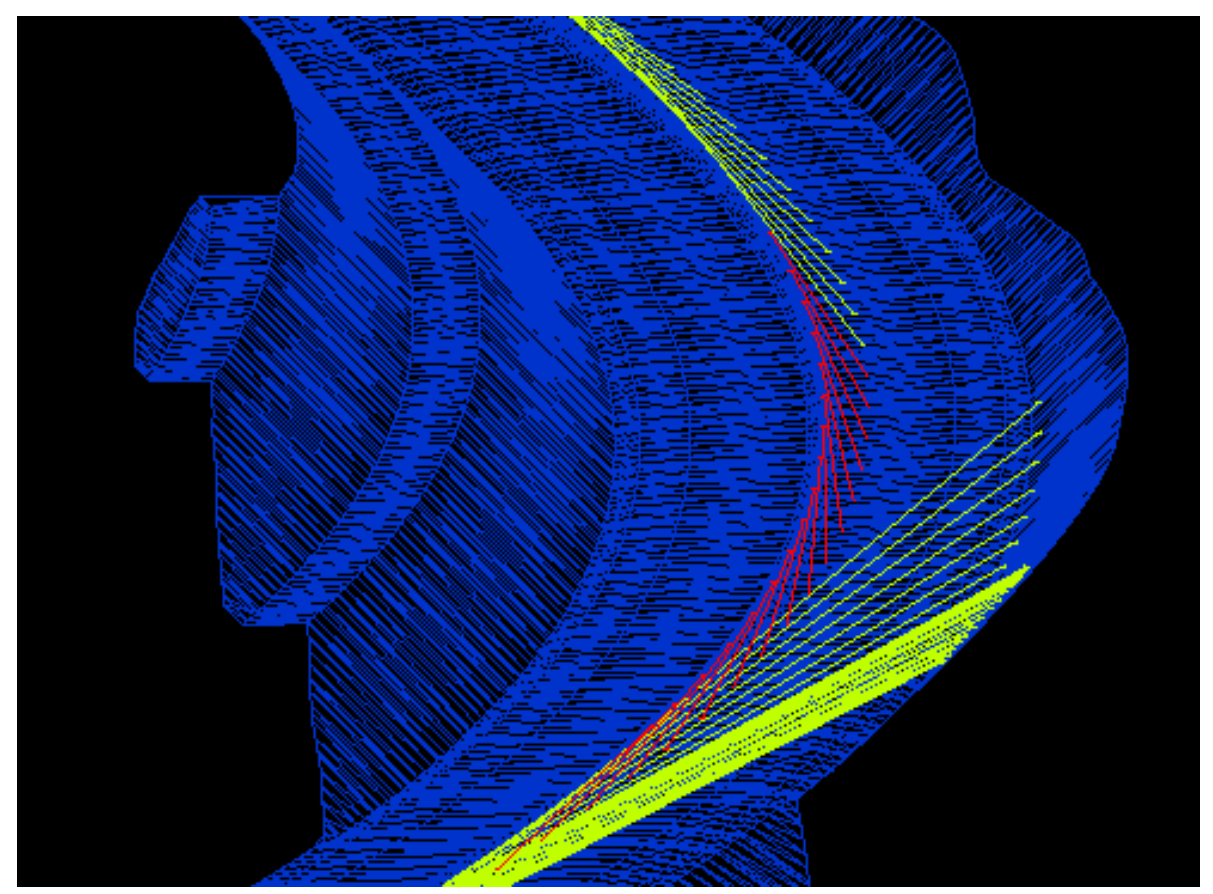

Figura 6.10. Curva D. Problema de Visibilidade - afastamento lateral da barreira de 0,95 m.

\subsubsection{Curva E}

A curva $E$ é uma variação da curva $D$ anterior, com interferência em sua concepção, impondo-se arbitrariamente um declive acentuado de $-5 \%$. O intuito foi verificar se para casos extremos as estimativas do aplicativo seriam viáveis para estas situações. O raio da curva horizontal é de $505 \mathrm{~m}$, com velocidade de projeto considerada de $70 \mathrm{~km} / \mathrm{h}$. A DVP nessas condições é de $115 \mathrm{~m}$.

O aplicativo estimou como afastamento lateral da barreira que garantisse a DVP o valor mínimo de $1,55 \mathrm{~m}$. Ao testar este valor no projeto, a DVP é garantida (Figura 
6.11). Para validar, o afastamento foi reduzido para 1,45 m. Com essa nova seção tipo, ocorrem obstruções na visibilidade do objeto (Figura 6.12)

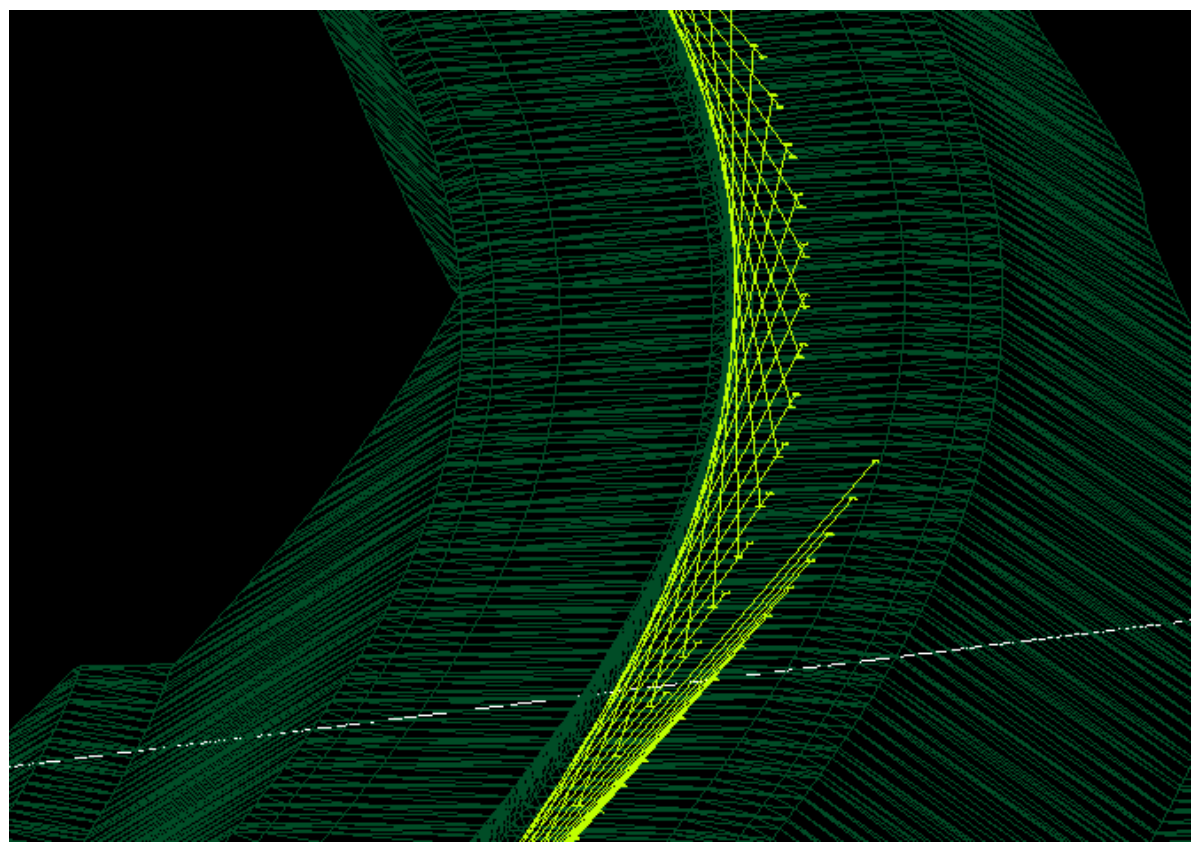

Figura 6.11. Curva E. DVP garantida - afastamento lateral da barreira de 1,55 m.

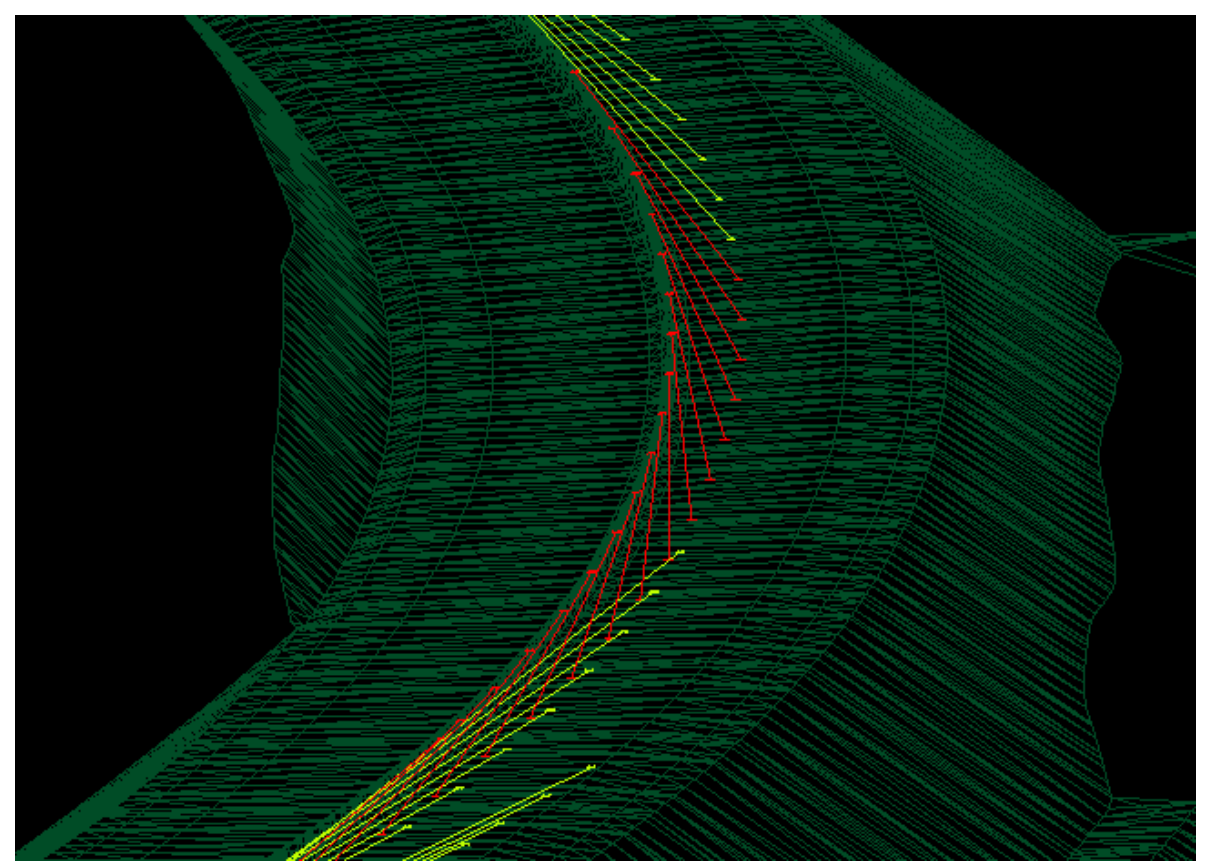

Figura 6.12. Curva E. Problema de Visibilidade - afastamento lateral da barreira de 1,45 m. 
As análises com dados do grupo B tiveram resultados positivos. A diferença entre o valor estimado e o valor real é em média de 0,10 m, compatível com a precisão das simulações realizadas $( \pm 0,05 \mathrm{~m})$. Como a visibilidade sempre ocorre por linha tangente, não sobrepondo a barreira devido à sua altura, a influência das características do alinhamento vertical é limitada ao comparado com os resultados do grupo $A$, cujas discrepâncias foram maiores. 


\section{CONCLUSÕES E RECOMENDAÇÕES}

As condições de visibilidade provêm da composição dos alinhamentos horizontal, vertical e da seção transversal e, portanto, qualquer alteração na geometria da via é capaz de modificar a visibilidade existente.

Nas simulações realizadas foi possível a análise da problemática - posicionamento de barreiras e visibilidade - considerando a influência dos elementos de projeto em conjunto.

Os dados simulados com barreira de altura de $0,81 \mathrm{~m}$ retornou-se para todas as hipóteses afastamento necessário nulo. Desta forma, não foi possível trabalhar com estes dados analítica e graficamente. Todavia, isso não significa que não ocorram problemas de visibilidade com barreiras de $0,81 \mathrm{~m}$. $O$ fato é que as hipóteses adotadas não foram capazes de modelar todas as variáveis envolvidas na análise de visibilidade, tornando a metodologia inadequada para análises de barreiras ditas de altura baixa. Nos demais casos, barreiras de altura de 1,00 m e 1,40, a metodologia proposta mostrou-se capaz de modelar as variáveis que interferem na análise de visibilidade, apesar das limitações das hipóteses adotadas. Logo, dois conjuntos de dados foram gerados em função da altura das barreiras utilizadas - 1,00 m e 1,40 m.

Os diagramas do conjunto $\mathrm{B}$ (altura da barreira de 1,40 m) tiveram comportamento próximo ao esperado. A visibilidade foi definida por afastamentos mínimos que permitissem a visualização do objeto, a uma dada DVP, com visada tangenciando a barreira central. Dessa forma, à medida que o raio da curva horizontal diminui, o afastamento entre barreira e a faixa de rolamento aumenta, de modo a garantir a manutenção da DVP. Trechos em aclives atenuam os afastamentos laterais da barreira, de modo que curvas de declividades diferentes se apresentam levemente deslocadas para a mesma velocidade de projeto analisada.

Todavia, para o grupo A (altura da barreira de 1,00 m) os diagramas apresentaram comportamento distinto. À medida que o raio da curva horizontal diminui, o afastamento lateral da barreira alcança um valor máximo. Deste ponto, há um 
decréscimo do afastamento em função da diminuição do raio da curva horizontal. O motivo é que a solução mínima fornecida pelo programa durante a simulação é de sempre visualizar o objeto sobre a barreira, transpondo-a com uma visada inclinada.

O tempo gasto para a execução das simulações ponderou a limitação de variáveis a serem analisadas. Em geral pelo menos outros três afastamentos (maiores e menores) foram testados de forma a validar o valor encontrado, dentro da precisão considerada de $\pm 0,05$ metros. Por isso, o volume de análises e esforços foi superior ao estimado inicialmente.

A geração de modelos matemáticos, definidos pelo método dos mínimos quadrados, permitiu o tratamento dos dados e, consequentemente, melhor manuseio para a estimativa de valores. O modelo adotado - polinômio univariado de $5^{\circ}$ grau atendeu às características dos dados. Para casos onde o conjunto de dados era limitado, a adoção de polinômios mais simples (de grau menor) mostrou-se eficiente.

A comparação com o modelo de afastamento de objetos fixos em curvas horizontais, presentes nas publicações nacionais, indicou que os afastamentos definidos por simulação são sempre inferiores ou iguais ao do modelo existente. Uma justificativa para estas diferenças é fundamentada no fato de que o modelo fornecido por DNER (1999) e DER-SP (2006) baseia-se na análise do alinhamento em planta, ou seja, bidimensionalmente. Neste modelo, os parâmetros que influenciam o posicionamento de objetos em curvas se restringem ao raio da curva horizontal e a DVP. No trabalho, em contrapartida, o projeto geométrico e as análises são considerados parcialmente tridimensionais, já que a coordenação com o alinhamento vertical foi desprezada, adotando-se rampas de declividade constante. Mesmo assim, foi possível utilizar a composição de feições no espaço em benefício do melhor posicionamento de elementos de projeto. Existem ressalvas quanto à redução do posicionamento de objetos em curvas. O caso analisado na simulação é específico para barreiras longitudinais, de dimensões fixas, enquanto o modelo das normas atende a qualquer tipo de objeto, inclusive de dimensões superiores às estudadas.

A organização dos resultados na forma de aplicativo permitiu o acesso às informações geradas neste estudo, facilitando o emprego dos modelos matemáticos 
para a estimativa de valores de afastamentos laterais da barreira. Apesar de ser um programa específico, o MATLAB ${ }^{\circledR}$ atendeu às expectativas, com ferramentas que possibilitaram a geração de aplicativo com interface gráfica e de uso intuitivo, como constatado no uso durante o estudo de caso.

Quanto ao estudo de caso duas constatações foram feitas. A primeira refere-se ao grupo $A$, cujos dados tiveram discrepância na ordem de $0,50 \mathrm{~m}$ em relação à solução encontrada no projeto de estudo para a garantia da DVP. O motivo dessa diferença é o fato de durante a simulação o valor mínimo ser definido visualizando o objeto sobre a barreira. No projeto real, essa solução seria também afetada pelas características do alinhamento vertical, desfavorecendo a visibilidade e, tornando a barreira uma obstrução contínua ao longo da curva. Em segundo, os dados do grupo $B$ foram validados com margem de $0,10 \mathrm{~m}$ de tolerância, indicando a viabilidade do uso das simulações para o caso de barreiras altas. Em todas as análises do estudo de caso as características do projeto não foram idênticas às das simulações, porém as hipóteses adotadas nas simulações foram capazes de gerar dados representativos ao se comparar com a complexidade de detalhes de um projeto real.

Os afastamentos definidos serão recomendações iniciais para o posicionamento de barreiras quando considerada a garantia da DVP. As simulações computacionais tridimensionais mostraram-se uma forma a baixo custo de investigar a influência de objetos e/ou características do projeto nos padrões de segurança da via, principalmente durante a fase de estudo e planejamento do traçado. Para o estabelecimento de padrões mais consistentes recomenda-se para trabalhos futuros:

(1) Ampliar o conjunto de hipóteses incluindo projetos viários mais completos do que os simulados, agregando a coordenação entre os alinhamentos horizontal e vertical;

(2) Adotar modelos matemáticos multivariados, visando melhor representar o comportamento dos dados, além de investigar a influência de cada variável na determinação do afastamento lateral da barreira;

(3) Investigar o funcionamento das análises de visibilidade dos programas comerciais e confrontar a influência com o modelo conceitual de DVP 
(4) Transcrever o aplicativo para linguagem de programação mais robusta, implantar tratamento de erros e exceções, permitir alterações dos diagramas durante a utilização do aplicativo para análises. 


\section{REFERÊNCIAS BIBLIOGRÁFICAS}

AASTHO. A Policy on Geometric Design of Highways and Streets. 6 ed. American Association of State Highway and Transportation Officials. Washington D.C., 2011 a.

AASTHO. Roadside Design Guide. 4 ed. American Association of State Highway and Transportation Officials. Washington D.C., 2011b.

ABNT. NBR 14885 - Segurança no tráfego - Barreiras de concreto. Associação Brasileira de Normas Técnicas. 2004.

ABNT. NBR 15486 - Segurança no tráfego - Dispositivos de contenção viária Diretrizes. Associação Brasileira de Normas Técnicas. 2007.

ARNDT, O. K.; COX, R. L.; LENNIE, S. C.; WHITEhEAD, M. T. Provision of Sight Distance around Concrete Barriers and Structures on Freeways and Interchanges. $4^{\text {th }}$ International Symposium on Highway Geomtric Design. Valencia, 2010.

AUSTROADS. Rural Road Design: Guide to the Geometric Design of Rural Roads. v1. 8 ed. Sidney, 2003.

AUSTROADS. Guide to Road Design - Part 3: Geometric Design. 2 ed. Sidney, 2010.

BRASIL. Lei № 10.233, de 05 junho de 2001. Dispõe sobre a reestruturação dos transportes aquaviário e terrestre, cria o Conselho Nacional de Integração de Políticas de Transporte, a Agência Nacional de Transportes Terrestres, a Agência Nacional de Transportes Aquaviários e o Departamento Nacional de Infra-Estrutura de Transportes, e dá outras providências. Diário Oficial da União. Seção 1, 06 de junho de 2001. Brasília, 2001. Disponível em <http://www.planalto.gov.br/ccivil_03/Leis/LEIS_2001/L10233.htm> Acesso em 14 de dezembro de 2010. 
CHEN, E.; BROWN, J.; TARKO, A. Use of barriers in rural open road conditions - a synthesis study. JTRP Technical Reports - Joint Transportation Resarch Program. Indiana, 2012.

CHOU, A. T. M.; PÉREZ, V. M. F.; GARCÍA, A. G.; ROJAS, M. A. R. Optimal 3D Coordination to Maximize the Available Stopping Sight Distance in Two-lane Roads. $4^{\text {th }}$ International Symposium on Highway Geometric Design. Valencia, 2010.

DALMOLIN, Q. . Ajustamento por Mínimos Quadrados. 3ed. Universidade Federal do Paraná - Curso de Pós-Graduação em Ciências Geodésicas. Curitiba, 2010.

DER-SC. Diretrizes para concepção de estradas. Departamento de Estradas de Rodagem de Santa Catarina - Diretoria de Estudos e Projetos. 2000.

DER-SP. Notas Técnicas de Projeto Geométrico. Departamento de Estradas de Rodagem do Estado de São Paulo, Diretoria de Engenharia. São Paulo, 2006.

DER-SP. PP-DE-F07/002 - Projeto Padrão de Geometria - Seção Tipo - Pista Dupla com Barreira Rígida - Classe 0 ou IA. Departamento de Estradas de Rodagem do Estado deSão Paulo. São Paulo, 2005. Disponível em < www.der.sp.gov.br > Acesso em 25 de fevereiro de 2011.

DNER. Manual de Projeto Geométrico de Rodovias Rurais. Departamento Nacional de Estradas de Rodagem, Diretoria de Desenvolvimento Tecnológico, Divisão de Capitação Tecnológica. Rio de Janeiro, 1999.

DNIT. Manual de Projeto Geométrico de Vias Urbanas. Departamento Nacional de Infraestrutura de Transportes. Diretoria Executiva. Instituto de Pesquisas Rodoviárias. Rio de Janeiro, 2010.

ESPANHA. Norma 3.1-IC Trazado, de la Instrucción de Carreteras. 2 ed. Ministerio de Fomento. Madrid, 2001.

GEMAEL, C.. Introdução ao Ajustamento de Observações. Universidade Federal do Paraná. Curitiba, 1994. 
HAN, K.; MIDDLETON, D.; CLAYTON, A. Enhancing Highway Geometric Design Development of Interactive Virtual Reality Visualization with Open-Source Technologies. Transportation Research Record. n. 1980. Transportation Research Board - National Research Council: Washington D.C, 2006.

HASSAN, Y.; EASA, S. M.; ABD EL HALIM; A. O. Design Considerations for Combined Highway Alignments. Journal of Transportation Engineering. v. 123. $\mathrm{n}$. 1. 1997.

HASSAN, Y.; SARHAN, M. Consideration of Sight Distance in Placement of Concrete Barriers on Horizontal Curves of Roads. Journal of Transportation Research Board. n. 2301, 2012.

HIXON III, C. L. Visualization Issues for Transportation Agencies - Approaches and Challenges. Transportation Research News. n.252. 2007.

ISMAIL, K.; SAYED, T. New Algorithm for Calculating 3D Available Sight Distance. Journal of Transportation Engineering. v. 133. n. 10. 2007.

ITÁLIA. Norme funzionali e geometriche per la costruzione delle strade. Ministero delle Infrastrutture e dei Trasporti-Ispettorato Generale per la Circolazione e la Sicurezza Stradale. Roma, 2001.

JAMIESON, N. Clear zones, barriers and driving lines - Mitigating the effects of crashes on corners (horizontal curves). Opus International Consultants Limited. Lower Hutt, 2012.

JANIKULA, T.; GARRICK, N. W. Three-Dimensional Visualization Approach to Illustrating Esthetic Concepts for Highway Design. Transportation Research Record. n. 1796. Transportation Research Board - National Research Council: Washington D.C, 2002.

KUHN, W.; JHA, M. K. Methodology for Checking Shortcomings in the ThreeDimensional Alignment. $4^{\text {th }}$ International Symposium on Highway Geometric Design. Valencia, 2010. 
LAMM, R.; PSARIANOS, B.; MAILAENDER, T.. Highway Design and Traffic Safety Engineering Handbook. New York: McGraw-Hill, 1999.

LEISCH, J. P. Horizontal Sight Distance Considerations in Freeway and Interchange Reconstruction. Transportation Research Record - Highway Sight Design Issues. n. 1208. Transportation Research Board - National Research Council: Washington D.C., 1989.

NCHRP. NCHRP Synthesis - Visualization for Project Development: A Synthesis of Highway Practice. National Cooperative Highway Research Program. Washington, 2006.

NEUMAN, T. R. New Approach to Design for Stopping Sight Distance. Transportation Research Record - Highway Sight Design Issues. n. 1208. Transportation Research Board - National Research Council: Washington D.C., 1989.

PELLEGRINI, P. T. Contribuição para o Estudo das Distâncias de Visibilidade de Ultrapassagem para Rodovias Bidirecionais com Duas faixas de tráfego. Dissertação de Mestrado. São Paulo: Universidade de São Paulo, 2006.

ROSEY, F.; AUBERLET, J. M. Trajectory variability: Road geometru difficult indicator. Safety Science. v 50. n. $9,2012$.

SANCHEZ, E.. Three-Dimensional Analysis of Sight Distance on Interchange Connectors. In: Transportation Research Record - Highway and Facility Design Cross-section and Alinement Design Issues. n. 1445. Transportation Research Board - National Research Council: Washington D.C., 1994.

SÉTRA. Comprende les principaux paramètres de conception gómétrique des routes.Service d'Études Techniques des Routes et Autoroutes. Bagneux Cedex, 2006.

TAC. Geometric Design Guide for Canadian Roads. Transportation Association of Canada. Ottawa, 1999. 
YANG, Q.; OVERTON, R.; HAN, L. D.; YAN, X. RICHARDS, S. H. The influence of curbs on driver behaviors in four-lane rural highways - A driving simulator based study. Accident Analysis and Prevention. v. 50, 2012. 
ANEXO I - DADOS BRUTOS DAS SIMULAÇÕES 


\begin{tabular}{|c|c|c|c|c|c|c|c|}
\hline \multicolumn{8}{|c|}{ Altura da barreira $h_{B}=1,00 \mathrm{~m}$} \\
\hline$R(\mathbf{m}) \backslash \mathbf{i}$ & $-9 \%$ & $-6 \%$ & $-3 \%$ & $0 \%$ & $3 \%$ & $6 \%$ & $9 \%$ \\
\hline 200 & 0,95 & 1,00 & 0,95 & 1,00 & 0,95 & 0,85 & 0,80 \\
\hline 300 & 1,35 & 1,20 & 1,00 & 0,95 & 0,65 & 0,50 & 0,50 \\
\hline 400 & 1,05 & 0,85 & 0,60 & 0,50 & 0,20 & 0,10 & 0,00 \\
\hline 500 & 0,60 & 0,40 & 0,15 & 0,05 & 0,00 & 0,00 & \\
\hline 600 & 0,20 & 0,00 & 0,00 & 0,00 & & & \\
\hline 700 & 0,00 & & & & & & \\
\hline 800 & & & & & & & \\
\hline 900 & & & & & & & \\
\hline 1000 & & & & & & & \\
\hline 1100 & & & & & & & \\
\hline 1200 & & & & & & & \\
\hline 1300 & & & & & & & \\
\hline 1400 & & & & & & & \\
\hline 1500 & & & & & & & \\
\hline 1600 & & & & & & & \\
\hline 1700 & & & & & & & \\
\hline 1800 & & & & & & & \\
\hline 1900 & & & & & & & \\
\hline 2000 & & & & & & & \\
\hline
\end{tabular}

\begin{tabular}{|c|c|c|c|c|c|c|c|}
\hline \multicolumn{8}{|c|}{ Altura da barreira $h_{B}=1,00 \mathrm{~m} / \quad V=70 \mathrm{~km} / \mathrm{h}$} \\
\hline $\mathbf{R}(\mathbf{m}) \backslash \mathbf{i}$ & $-9 \%$ & $-6 \%$ & $-3 \%$ & $0 \%$ & $3 \%$ & $6 \%$ & $9 \%$ \\
\hline 200 & 0,65 & 0,80 & 0,85 & 0,85 & 0,90 & 0,95 & 1,00 \\
\hline 300 & 1,20 & 1,15 & 1,15 & 1,10 & 1,05 & 1,00 & 0,95 \\
\hline 400 & 1,55 & 1,45 & 1,25 & 1,15 & 0,95 & 0,90 & 0,75 \\
\hline 500 & 1,60 & 1,35 & 1,10 & 0,90 & 0,65 & 0,55 & 0,25 \\
\hline 600 & 1,35 & 1,00 & 0,75 & 0,55 & 0,30 & 0,25 & 0,05 \\
\hline 700 & 0,95 & 0,60 & 0,40 & 0,25 & 0,00 & 0,00 & 0,00 \\
\hline 800 & 0,60 & 0,30 & 0,10 & 0,00 & & & \\
\hline 900 & 0,35 & 0,10 & 0,00 & & & & \\
\hline 1000 & 0,15 & 0,00 & & & & & \\
\hline 1100 & 0,00 & & & & & & \\
\hline 1200 & & & & & & & \\
\hline 1300 & & & & & & & \\
\hline 1400 & & & & & & & \\
\hline 1500 & & & & & & & \\
\hline 1600 & & & & & & & \\
\hline 1700 & & & & & & & \\
\hline 1800 & & & & & & & \\
\hline 1900 & & & & & & & \\
\hline 2000 & & & & & & & \\
\hline
\end{tabular}




\begin{tabular}{|c|c|c|c|c|c|c|c|}
\hline \multicolumn{8}{|c|}{ Altura da barreira $h_{B}=1,00 \mathrm{~m} / \quad V=80 \mathrm{~km} / \mathrm{h}$} \\
\hline$R(m) \backslash i$ & $-9 \%$ & $-6 \%$ & $-3 \%$ & $0 \%$ & $3 \%$ & $6 \%$ & $9 \%$ \\
\hline \multicolumn{8}{|l|}{200} \\
\hline 300 & 0,80 & 0,90 & 0,95 & 1,00 & 0,95 & 1,00 & 1,00 \\
\hline 400 & 1,25 & 1,25 & 1,25 & 1,25 & 1,05 & 1,10 & 1,05 \\
\hline 500 & 1,65 & 1,55 & 1,45 & 1,35 & 1,20 & 1,10 & 1,00 \\
\hline 600 & 1,80 & 1,65 & 1,45 & 1,30 & 1,05 & 0,90 & 0,80 \\
\hline 700 & 1,85 & 1,60 & 1,35 & 1,10 & 0,85 & 0,65 & 0,55 \\
\hline 800 & 1,70 & 1,35 & 1,10 & 0,85 & 0,55 & 0,35 & 0,25 \\
\hline 900 & 1,45 & 1,10 & 0,80 & 0,55 & 0,30 & 0,15 & 0,00 \\
\hline 1000 & 1,15 & 0,80 & 0,55 & 0,35 & 0,00 & 0,00 & \\
\hline 1100 & 0,90 & 0,60 & 0,35 & 0,15 & & & \\
\hline 1200 & 0,65 & 0,40 & 0,15 & 0,00 & & & \\
\hline 1300 & 0,50 & 0,20 & 0,00 & & & & \\
\hline 1400 & 0,30 & 0,10 & & & & & \\
\hline 1500 & 0,20 & 0,00 & & & & & \\
\hline 1600 & 0,05 & & & & & & \\
\hline 1700 & 0,00 & & & & & & \\
\hline \multicolumn{8}{|l|}{1800} \\
\hline \multicolumn{8}{|l|}{1900} \\
\hline 2000 & & & & & & & \\
\hline
\end{tabular}

\begin{tabular}{|c|c|c|c|c|c|c|c|}
\hline \multicolumn{8}{|c|}{ Altura da barreira $h_{B}=1,00 \mathrm{~m} / V=90 \mathrm{~km} / \mathrm{h}$} \\
\hline $\mathbf{R}(\mathbf{m}) \backslash \mathbf{i}$ & $-9 \%$ & $-6 \%$ & $-3 \%$ & $0 \%$ & $3 \%$ & $6 \%$ & 9\% \\
\hline \multicolumn{8}{|l|}{200} \\
\hline 300 & 0,65 & 0,80 & 0,90 & 1,00 & 1,05 & 1,10 & 1,20 \\
\hline 400 & 0,95 & 1,05 & 1,10 & 1,15 & 1,15 & 1,15 & 1,15 \\
\hline 500 & 1,35 & 1,35 & 1,40 & 1,40 & 1,30 & 1,25 & 1,25 \\
\hline 600 & 1,70 & 1,65 & 1,60 & 1,60 & 1,40 & 1,30 & 1,20 \\
\hline 700 & 1,95 & 1,85 & 1,70 & 1,65 & 1,40 & 1,25 & 1,10 \\
\hline 800 & 2,20 & 2,00 & 1,80 & 1,70 & 1,35 & 1,10 & 0,95 \\
\hline 900 & 2,20 & 1,90 & 1,65 & 1,55 & 1,15 & 0,90 & 0,75 \\
\hline 1000 & 2,15 & 1,75 & 1,45 & 1,35 & 0,90 & 0,70 & 0,55 \\
\hline 1100 & 2,00 & 1,55 & 1,25 & 1,10 & 0,70 & 0,45 & 0,30 \\
\hline 1200 & 1,80 & 1,35 & 1,00 & 0,90 & 0,50 & 0,25 & 0,15 \\
\hline 1300 & 1,55 & 1,10 & 0,80 & 0,65 & 0,30 & 0,10 & 0,00 \\
\hline 1400 & 1,30 & 0,90 & 0,60 & 0,50 & 0,15 & 0,00 & \\
\hline 1500 & 1,10 & 0,75 & 0,45 & 0,35 & 0,05 & & \\
\hline 1600 & 0,95 & 0,60 & 0,30 & 0,20 & 0,00 & & \\
\hline 1700 & 0,75 & 0,45 & 0,20 & 0,10 & & & \\
\hline 1800 & 0,65 & 0,30 & 0,05 & 0,00 & & & \\
\hline 1900 & 0,50 & 0,20 & 0,00 & & & & \\
\hline 2000 & 0,40 & 0,10 & & & & & \\
\hline
\end{tabular}




\begin{tabular}{|c|c|c|c|c|c|c|c|}
\hline \multicolumn{7}{|c|}{ Altura da barreira $\mathbf{h}_{\mathbf{B}}=\mathbf{1 , 0 0} \mathbf{~} \mathbf{~ / ~} \mathbf{1 0 0} \mathbf{~ k m} / \mathbf{h}$} \\
\hline $\mathbf{R}(\mathbf{m}) \backslash \mathbf{i}$ & $\mathbf{- 9} \%$ & $-\mathbf{6 \%}$ & $\mathbf{- 3} \%$ & $\mathbf{0} \%$ & $\mathbf{3} \%$ & $\mathbf{6 \%}$ & $\mathbf{9} \%$ \\
\hline $\mathbf{2 0 0}$ & & & & & & & \\
\hline $\mathbf{3 0 0}$ & & & & & & & \\
\hline $\mathbf{4 0 0}$ & 0,75 & 0,80 & 0,90 & 1,00 & 1,05 & 1,10 & 1,15 \\
\hline $\mathbf{5 0 0}$ & 0,95 & 1,05 & 1,10 & 1,15 & 1,15 & 1,20 & 1,15 \\
\hline $\mathbf{6 0 0}$ & 1,25 & 1,30 & 1,35 & 1,35 & 1,30 & 1,30 & 1,25 \\
\hline $\mathbf{7 0 0}$ & 1,60 & 1,60 & 1,55 & 1,55 & 1,45 & 1,40 & 1,30 \\
\hline $\mathbf{8 0 0}$ & 1,90 & 1,85 & 1,75 & 1,70 & 1,55 & 1,45 & 1,35 \\
\hline $\mathbf{9 0 0}$ & 2,10 & 1,95 & 1,85 & 1,75 & 1,55 & 1,40 & 1,25 \\
\hline $\mathbf{1 0 0 0}$ & 2,35 & 2,10 & 1,90 & 1,75 & 1,50 & 1,30 & 1,15 \\
\hline $\mathbf{1 1 0 0}$ & 2,40 & 2,15 & 1,90 & 1,70 & 1,40 & 1,20 & 1,00 \\
\hline $\mathbf{1 2 0 0}$ & 2,40 & 2,10 & 1,80 & 1,60 & 1,25 & 1,05 & 0,85 \\
\hline $\mathbf{1 3 0 0}$ & 2,40 & 2,05 & 1,65 & 1,40 & 1,10 & 0,85 & 0,65 \\
\hline $\mathbf{1 4 0 0}$ & 2,30 & 1,90 & 1,50 & 1,25 & 0,90 & 0,70 & 0,50 \\
\hline $\mathbf{1 5 0 0}$ & 2,20 & 1,75 & 1,35 & 1,05 & 0,70 & 0,50 & 0,35 \\
\hline $\mathbf{1 6 0 0}$ & 2,00 & 1,55 & 1,15 & 0,90 & 0,55 & 0,35 & 0,20 \\
\hline $\mathbf{1 7 0 0}$ & 1,85 & 1,35 & 0,95 & 0,75 & 0,40 & 0,25 & 0,10 \\
\hline $\mathbf{1 8 0 0}$ & 1,65 & 1,15 & 0,80 & 0,60 & 0,30 & 0,15 & 0,00 \\
\hline $\mathbf{1 9 0 0}$ & 1,45 & 1,00 & 0,70 & 0,45 & 0,20 & 0,05 & \\
\hline $\mathbf{2 0 0 0}$ & 1,30 & 0,90 & 0,55 & 0,35 & 0,10 & 0,00 & \\
\hline
\end{tabular}

\begin{tabular}{|c|c|c|c|c|c|c|c|}
\hline \multicolumn{7}{|c|}{ Altura da barreira $\mathbf{h}_{\mathbf{B}}=\mathbf{1 , 0 0} \mathbf{~ m}$} & \multicolumn{1}{|c|}{$\mathbf{V} \mathbf{1 1 0} \mathbf{~ k m} / \mathbf{h}$} \\
\hline $\mathbf{R}(\mathbf{m}) \backslash \mathbf{i}$ & $\mathbf{- 9 \%}$ & $-\mathbf{6} \%$ & $\mathbf{- 3} \%$ & $\mathbf{0} \%$ & $\mathbf{3} \%$ & $\mathbf{6 \%}$ & $\mathbf{9 \%}$ \\
\hline $\mathbf{2 0 0}$ & & & & & & & \\
\hline $\mathbf{3 0 0}$ & & & & & & & \\
\hline $\mathbf{4 0 0}$ & & & & & & & \\
\hline $\mathbf{5 0 0}$ & 0,75 & 0,85 & 0,95 & 1,05 & 1,10 & 1,15 & 1,20 \\
\hline $\mathbf{6 0 0}$ & 0,90 & 1,00 & 1,05 & 1,15 & 1,15 & 1,15 & 1,15 \\
\hline $\mathbf{7 0 0}$ & 1,15 & 1,20 & 1,25 & 1,30 & 1,30 & 1,25 & 1,25 \\
\hline $\mathbf{8 0 0}$ & 1,45 & 1,45 & 1,45 & 1,50 & 1,40 & 1,40 & 1,35 \\
\hline $\mathbf{9 0 0}$ & 1,70 & 1,70 & 1,70 & 1,70 & 1,55 & 1,50 & 1,40 \\
\hline $\mathbf{1 0 0 0}$ & 1,90 & 1,90 & 1,85 & 1,80 & 1,65 & 1,55 & 1,40 \\
\hline $\mathbf{1 1 0 0}$ & 2,15 & 2,05 & 1,95 & 1,95 & 1,70 & 1,55 & 1,40 \\
\hline $\mathbf{1 2 0 0}$ & 2,30 & 2,20 & 2,00 & 1,95 & 1,65 & 1,50 & 1,35 \\
\hline $\mathbf{1 3 0 0}$ & 2,45 & 2,25 & 2,05 & 1,95 & 1,60 & 1,45 & 1,25 \\
\hline $\mathbf{1 4 0 0}$ & & 2,30 & 2,05 & 1,95 & 1,55 & 1,35 & 1,15 \\
\hline $\mathbf{1 5 0 0}$ & & 2,30 & 2,00 & 1,90 & 1,45 & 1,20 & 1,00 \\
\hline $\mathbf{1 6 0 0}$ & & 2,30 & 1,95 & 1,80 & 1,35 & 1,10 & 0,90 \\
\hline $\mathbf{1 7 0 0}$ & & 2,25 & 1,85 & 1,65 & 1,20 & 0,95 & 0,75 \\
\hline $\mathbf{1 8 0 0}$ & & 2,10 & 1,70 & 1,50 & 1,05 & 0,80 & 0,60 \\
\hline $\mathbf{1 9 0 0}$ & 2,45 & 2,00 & 1,55 & 1,40 & 0,90 & 0,65 & 0,50 \\
\hline $\mathbf{2 0 0 0}$ & 2,35 & 1,85 & 1,40 & 1,25 & 0,65 & 0,55 & 0,35 \\
\hline
\end{tabular}




\begin{tabular}{|c|c|c|c|c|c|c|c|}
\hline \multicolumn{7}{|c|}{ Altura da barreira $\mathbf{h}_{\mathbf{B}}=\mathbf{1 , 0 0} \mathbf{~} \mathbf{~ / ~} \mathbf{1 2 0} \mathbf{~ k m} / \mathbf{h}$} \\
\hline $\mathbf{R}(\mathbf{m}) \backslash \mathbf{i}$ & $\mathbf{- 9} \%$ & $-\mathbf{6} \%$ & $\mathbf{- 3} \%$ & $\mathbf{0} \%$ & $\mathbf{3} \%$ & $\mathbf{6 \%}$ & $\mathbf{9} \%$ \\
\hline $\mathbf{2 0 0}$ & & & & & & & \\
\hline $\mathbf{3 0 0}$ & & & & & & & \\
\hline $\mathbf{4 0 0}$ & & & & & & & \\
\hline $\mathbf{5 0 0}$ & & & & & & & \\
\hline $\mathbf{6 0 0}$ & 0,80 & 0,90 & 1,00 & 1,10 & 1,15 & 1,20 & 1,25 \\
\hline $\mathbf{7 0 0}$ & 0,90 & 1,00 & 1,05 & 1,10 & 1,15 & 1,20 & 1,20 \\
\hline $\mathbf{8 0 0}$ & 1,05 & 1,10 & 1,15 & 1,20 & 1,25 & 1,25 & 1,25 \\
\hline $\mathbf{9 0 0}$ & 1,25 & 1,30 & 1,35 & 1,35 & 1,35 & 1,35 & 1,30 \\
\hline $\mathbf{1 0 0 0}$ & 1,50 & 1,50 & 1,50 & 1,55 & 1,50 & 1,45 & 1,40 \\
\hline $\mathbf{1 1 0 0}$ & 1,70 & 1,70 & 1,70 & 1,70 & 1,60 & 1,55 & 1,45 \\
\hline $\mathbf{1 2 0 0}$ & 1,90 & 1,85 & 1,80 & 1,80 & 1,65 & 1,55 & 1,50 \\
\hline $\mathbf{1 3 0 0}$ & 2,15 & 2,05 & 2,00 & 1,95 & 1,75 & 1,65 & 1,55 \\
\hline $\mathbf{1 4 0 0}$ & 2,25 & 2,15 & 2,05 & 1,95 & 1,75 & 1,60 & 1,45 \\
\hline $\mathbf{1 5 0 0}$ & 2,40 & 2,30 & 2,15 & 2,00 & 1,80 & 1,60 & 1,45 \\
\hline $\mathbf{1 6 0 0}$ & & 2,40 & 2,20 & 2,05 & 1,80 & 1,60 & 1,40 \\
\hline $\mathbf{1 7 0 0}$ & & 2,45 & 2,25 & 2,05 & 1,75 & 1,50 & 1,30 \\
\hline $\mathbf{1 8 0 0}$ & & 2,45 & 2,20 & 2,00 & 1,65 & 1,45 & 1,25 \\
\hline $\mathbf{1 9 0 0}$ & & 2,50 & 2,20 & 1,95 & 1,60 & 1,35 & 1,15 \\
\hline $\mathbf{2 0 0 0}$ & & 2,45 & 2,10 & 1,85 & 1,50 & 1,25 & 1,00 \\
\hline
\end{tabular}

\begin{tabular}{|c|c|c|c|c|c|c|c|}
\hline \multicolumn{8}{|c|}{ Altura da barreira $h_{B}=1,40 \mathrm{~m} / \quad V=60 \mathrm{~km} / \mathrm{h}$} \\
\hline $\mathbf{R}(\mathbf{m}) \backslash \mathbf{i}$ & $-9 \%$ & $-6 \%$ & $-3 \%$ & $0 \%$ & $3 \%$ & $6 \%$ & $9 \%$ \\
\hline 200 & & & & & 2,30 & 2,00 & 1,80 \\
\hline 300 & 2,20 & 1,85 & 1,45 & 1,30 & 0,95 & 0,75 & 0,60 \\
\hline 400 & 1,25 & 0,95 & 0,65 & 0,50 & 0,25 & 0,10 & 0,00 \\
\hline 500 & 0,65 & 0,40 & 0,15 & 0,05 & 0,00 & 0,00 & \\
\hline 600 & 0,25 & 0,05 & 0,00 & 0,00 & & & \\
\hline 700 & 0,00 & 0,00 & & & & & \\
\hline 800 & & & & & & & \\
\hline 900 & & & & & & & \\
\hline 1000 & & & & & & & \\
\hline 1100 & & & & & & & \\
\hline 1200 & & & & & & & \\
\hline 1300 & & & & & & & \\
\hline 1400 & & & & & & & \\
\hline 1500 & & & & & & & \\
\hline 1600 & & & & & & & \\
\hline 1700 & & & & & & & \\
\hline 1800 & & & & & & & \\
\hline 1900 & & & & & & & \\
\hline 2000 & & & & & & & \\
\hline
\end{tabular}




\begin{tabular}{|c|c|c|c|c|c|c|c|}
\hline \multicolumn{8}{|c|}{ Altura da barreira $h_{B}=1,40 \mathrm{~m}$} \\
\hline $\mathbf{R}(\mathbf{m}) \backslash \mathbf{i}$ & $-9 \%$ & $-6 \%$ & $-3 \%$ & $0 \%$ & $3 \%$ & $6 \%$ & $9 \%$ \\
\hline 200 & & & & & & 3,20 & 2,90 \\
\hline 300 & & & & & 2,50 & 2,20 & 1,90 \\
\hline 400 & & 2,45 & 2,05 & 1,75 & 1,45 & 1,25 & 1,00 \\
\hline 500 & 2,05 & 1,60 & 1,30 & 1,05 & 0,80 & 0,65 & 0,45 \\
\hline 600 & 1,40 & 1,05 & 0,80 & 0,60 & 0,35 & 0,25 & 0,05 \\
\hline 700 & 0,95 & 0,65 & 0,40 & 0,25 & 0,05 & 0,00 & 0,00 \\
\hline 800 & 0,60 & 0,35 & 0,15 & 0,00 & 0,00 & & \\
\hline 900 & 0,35 & 0,10 & 0,00 & & & & \\
\hline 1000 & 0,15 & 0,00 & & & & & \\
\hline 1100 & 0,00 & & & & & & \\
\hline 1200 & & & & & & & \\
\hline 1300 & & & & & & & \\
\hline 1400 & & & & & & & \\
\hline 1500 & & & & & & & \\
\hline 1600 & & & & & & & \\
\hline 1700 & & & & & & & \\
\hline 1800 & & & & & & & \\
\hline 1900 & & & & & & & \\
\hline 2000 & & & & & & & \\
\hline
\end{tabular}

\begin{tabular}{|c|c|c|c|c|c|c|c|}
\hline \multicolumn{8}{|c|}{ Altura da barreira $h_{B}=1,40 \mathrm{~m} / \quad V=80 \mathrm{~km} / \mathrm{h}$} \\
\hline $\mathbf{R}(\mathbf{m}) \backslash \mathbf{i}$ & $-9 \%$ & $-6 \%$ & $-3 \%$ & $0 \%$ & $3 \%$ & $6 \%$ & $9 \%$ \\
\hline \multicolumn{8}{|l|}{200} \\
\hline \multicolumn{8}{|l|}{300} \\
\hline 400 & & & & & & & 2,30 \\
\hline 500 & & & & 2,50 & 2,00 & 1,70 & 1,50 \\
\hline 600 & & & 2,10 & 1,80 & 1,40 & 1,15 & 1,00 \\
\hline 700 & 2,45 & 1,95 & 1,55 & 1,25 & 0,95 & 0,70 & 0,55 \\
\hline 800 & 1,90 & 1,50 & 1,15 & 0,90 & 0,60 & 0,40 & 0,25 \\
\hline 900 & 1,50 & 1,15 & 0,85 & 0,60 & 0,35 & 0,15 & 0,05 \\
\hline 1000 & 1,20 & 0,85 & 0,55 & 0,35 & 0,15 & 0,00 & 0,00 \\
\hline 1100 & 0,90 & 0,60 & 0,35 & 0,15 & 0,00 & & \\
\hline 1200 & 0,70 & 0,40 & 0,20 & 0,00 & & & \\
\hline 1300 & 0,50 & 0,25 & 0,05 & & & & \\
\hline 1400 & 0,35 & 0,10 & 0,00 & & & & \\
\hline 1500 & 0,20 & 0,00 & & & & & \\
\hline 1600 & 0,05 & & & & & & \\
\hline 1700 & 0,00 & & & & & & \\
\hline \multicolumn{8}{|l|}{1800} \\
\hline \multicolumn{8}{|l|}{1900} \\
\hline 2000 & & & & & & & \\
\hline
\end{tabular}




\begin{tabular}{|c|c|c|c|c|c|c|c|}
\hline \multicolumn{5}{|c|}{ Altura da barreira $h_{B}=1,40 \mathrm{~m}$} & \multicolumn{3}{|c|}{$V=90 \mathrm{~km} / \mathrm{h}$} \\
\hline$R(m) \backslash i$ & $-9 \%$ & $-6 \%$ & $-3 \%$ & $0 \%$ & $3 \%$ & $6 \%$ & $9 \%$ \\
\hline 200 & & & & & & & \\
\hline 300 & & & & & & & \\
\hline 400 & & & & & & & \\
\hline 500 & & & & & & & \\
\hline 600 & & & & & & 2,40 & 2,10 \\
\hline 700 & & & & & 2,15 & 1,80 & 1,55 \\
\hline 800 & & & 2,40 & 2,25 & 1,70 & 1,35 & 1,15 \\
\hline 900 & & 2,45 & 1,95 & 1,80 & 1,30 & 1,00 & 0,80 \\
\hline 1000 & & 2,00 & 1,60 & 1,45 & 1,00 & 0,75 & 0,55 \\
\hline 1100 & 2,20 & 1,65 & 1,30 & 1,15 & 0,75 & 0,50 & 0,35 \\
\hline 1200 & 1,85 & 1,40 & 1,05 & 0,90 & 0,55 & 0,30 & 0,15 \\
\hline 1300 & 1,60 & 1,15 & 0,80 & 0,70 & 0,35 & 0,15 & 0,00 \\
\hline 1400 & 1,35 & 0,95 & 0,65 & 0,50 & 0,20 & 0,00 & \\
\hline 1500 & 1,15 & 0,75 & 0,45 & 0,35 & 0,05 & & \\
\hline 1600 & 0,95 & 0,60 & 0,35 & 0,25 & 0,00 & & \\
\hline 1700 & 0,85 & 0,45 & 0,20 & 0,10 & & & \\
\hline 1800 & 0,65 & 0,35 & 0,10 & 0,00 & & & \\
\hline 1900 & 0,50 & 0,20 & 0,00 & & & & \\
\hline 2000 & 0,40 & 0,10 & & & & & \\
\hline
\end{tabular}

\begin{tabular}{|c|c|c|c|c|c|c|c|}
\hline \multicolumn{7}{|c|}{ Altura da barreira $\mathbf{h}_{\mathbf{B}}=\mathbf{1 , 4 0} \mathbf{~ m} /$} & $\mathbf{V}=\mathbf{1 0 0} \mathbf{~ k m} / \mathbf{h}$ \\
\hline $\mathbf{R}(\mathbf{m}) \backslash \mathbf{i}$ & $-\mathbf{9 \%}$ & $-\mathbf{6} \%$ & $\mathbf{- 3} \%$ & $\mathbf{0} \%$ & $\mathbf{3} \%$ & $\mathbf{6} \%$ & $\mathbf{9} \%$ \\
\hline $\mathbf{2 0 0}$ & & & & & & & \\
\hline $\mathbf{3 0 0}$ & & & & & & & \\
\hline $\mathbf{4 0 0}$ & & & & & & & \\
\hline $\mathbf{5 0 0}$ & & & & & & & \\
\hline $\mathbf{6 0 0}$ & & & & & & & \\
\hline $\mathbf{7 0 0}$ & & & & & & & \\
\hline $\mathbf{8 0 0}$ & & & & & & & 2,20 \\
\hline $\mathbf{9 0 0}$ & & & & & 2,45 & 2,10 & 1,75 \\
\hline $\mathbf{1 0 0 0}$ & & & & 2,50 & 2,05 & 1,70 & 1,40 \\
\hline $\mathbf{1 1 0 0}$ & & & 2,50 & 2,15 & 1,70 & 1,40 & 1,10 \\
\hline $\mathbf{1 2 0 0}$ & & & 2,15 & 1,80 & 1,40 & 1,15 & 0,90 \\
\hline $\mathbf{1 3 0 0}$ & & 2,35 & 1,85 & 1,55 & 1,15 & 0,90 & 0,65 \\
\hline $\mathbf{1 4 0 0}$ & & 2,05 & 1,60 & 1,30 & 0,95 & 0,70 & 0,50 \\
\hline $\mathbf{1 5 0 0}$ & 2,35 & 1,80 & 1,35 & 1,10 & 0,75 & 0,55 & 0,35 \\
\hline $\mathbf{1 6 0 0}$ & 2,10 & 1,55 & 1,15 & 0,90 & 0,60 & 0,40 & 0,20 \\
\hline $\mathbf{1 7 0 0}$ & 1,85 & 1,35 & 1,00 & 0,75 & 0,45 & 0,25 & 0,10 \\
\hline $\mathbf{1 8 0 0}$ & 1,65 & 1,20 & 0,85 & 0,60 & 0,35 & 0,15 & 0,00 \\
\hline $\mathbf{1 9 0 0}$ & 1,50 & 1,05 & 0,70 & 0,50 & 0,25 & 0,05 & \\
\hline $\mathbf{2 0 0 0}$ & 1,30 & 0,90 & 0,60 & 0,40 & 0,15 & 0,00 & \\
\hline
\end{tabular}




\begin{tabular}{|c|c|c|c|c|c|c|c|}
\hline \multicolumn{7}{|c|}{ Altura da barreira $\mathbf{h}_{\mathbf{B}}=\mathbf{1 , 4 0} \mathbf{~ m} /$} & $\mathbf{V}=\mathbf{1 1 0} \mathbf{~ k m} / \mathbf{h}$ \\
\hline $\mathbf{R}(\mathbf{m}) \backslash \mathbf{i}$ & $-\mathbf{9 \%}$ & $-\mathbf{6} \%$ & $\mathbf{- 3} \%$ & $\mathbf{0} \%$ & $\mathbf{3} \%$ & $\mathbf{6} \%$ & $\mathbf{9} \%$ \\
\hline $\mathbf{2 0 0}$ & & & & & & & \\
\hline $\mathbf{3 0 0}$ & & & & & & & \\
\hline $\mathbf{4 0 0}$ & & & & & & & \\
\hline $\mathbf{5 0 0}$ & & & & & & & \\
\hline $\mathbf{6 0 0}$ & & & & & & & \\
\hline $\mathbf{7 0 0}$ & & & & & & & \\
\hline $\mathbf{8 0 0}$ & & & & & & & \\
\hline $\mathbf{9 0 0}$ & & & & & & & \\
\hline $\mathbf{1 0 0 0}$ & & & & & & & \\
\hline $\mathbf{1 1 0 0}$ & & & & & & 2,50 & 2,15 \\
\hline $\mathbf{1 2 0 0}$ & & & & & 2,50 & 2,15 & 1,80 \\
\hline $\mathbf{1 3 0 0}$ & & & & & 2,20 & 1,85 & 1,55 \\
\hline $\mathbf{1 4 0 0}$ & & & & & 1,90 & 1,60 & 1,30 \\
\hline $\mathbf{1 5 0 0}$ & & & 2,50 & 2,25 & 1,65 & 1,35 & 1,10 \\
\hline $\mathbf{1 6 0 0}$ & & & 2,25 & 2,00 & 1,45 & 1,15 & 0,90 \\
\hline $\mathbf{1 7 0 0}$ & & & 2,00 & 1,80 & 1,25 & 1,00 & 0,75 \\
\hline $\mathbf{1 8 0 0}$ & & 2,30 & 1,80 & 1,60 & 1,10 & 0,85 & 0,60 \\
\hline $\mathbf{1 9 0 0}$ & & 2,10 & 1,60 & 1,40 & 0,95 & 0,70 & 0,50 \\
\hline $\mathbf{2 0 0 0}$ & 2,50 & 1,90 & 1,45 & 1,25 & 0,80 & 0,55 & 0,40 \\
\hline
\end{tabular}

\begin{tabular}{|c|c|c|c|c|c|c|c|}
\hline \multicolumn{8}{|c|}{ Altura da barreira $h_{B}=1,40 \mathrm{~m}$} \\
\hline$R(m) \backslash i$ & $-9 \%$ & $-6 \%$ & $-3 \%$ & $0 \%$ & $3 \%$ & $6 \%$ & $9 \%$ \\
\hline \multicolumn{8}{|l|}{200} \\
\hline \multicolumn{8}{|l|}{300} \\
\hline \multicolumn{8}{|l|}{400} \\
\hline \multicolumn{8}{|l|}{500} \\
\hline \multicolumn{8}{|l|}{600} \\
\hline \multicolumn{8}{|l|}{700} \\
\hline \multicolumn{8}{|l|}{800} \\
\hline \multicolumn{8}{|l|}{900} \\
\hline \multicolumn{8}{|l|}{1000} \\
\hline \multicolumn{8}{|l|}{1100} \\
\hline \multicolumn{8}{|l|}{1200} \\
\hline \multicolumn{8}{|l|}{1300} \\
\hline 1400 & & & & & & & 2,30 \\
\hline 1500 & & & & & & 2,35 & 2,00 \\
\hline 1600 & & & & & 2,50 & 2,10 & 1,80 \\
\hline 1700 & & & & & 2,25 & 1,90 & 1,55 \\
\hline 1800 & & & & & 2,00 & 1,70 & 1,40 \\
\hline 1900 & & & & 2,35 & 1,80 & 1,50 & 1,20 \\
\hline 2000 & & & & 2,15 & 1,65 & 1,35 & 1,05 \\
\hline
\end{tabular}


ANEXO II - GRÁFICOS DE RESÍDUOS 
Resíduos (simulação - modelo calculado)

$V=60 \mathrm{~km} / \mathrm{h} ; \mathrm{h}_{\mathrm{B}}=1,00 \mathrm{~m}$
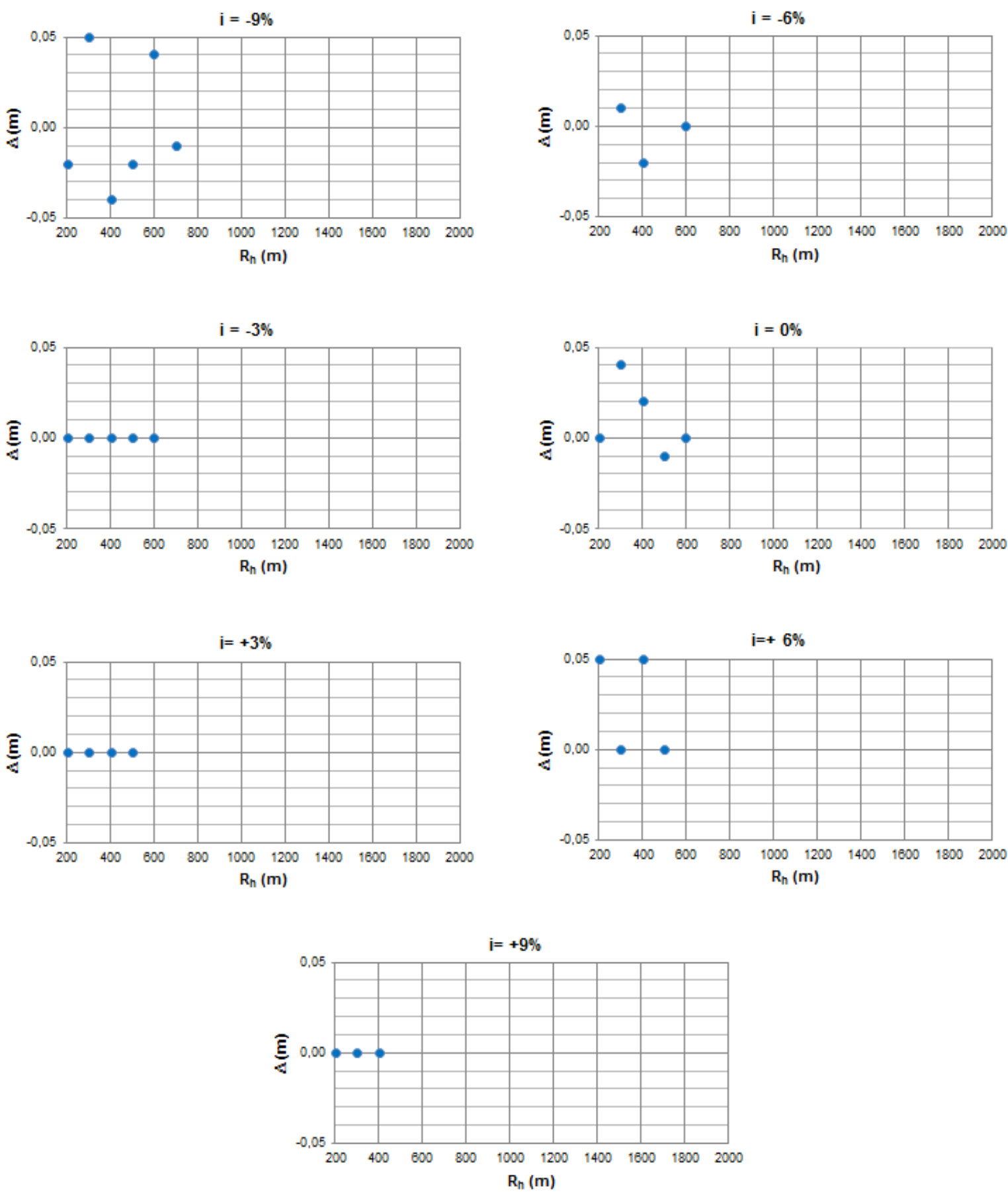
Resíduos (simulação - modelo calculado)

$V=70 \mathrm{~km} / \mathrm{h} ; h_{B}=1,00 \mathrm{~m}$
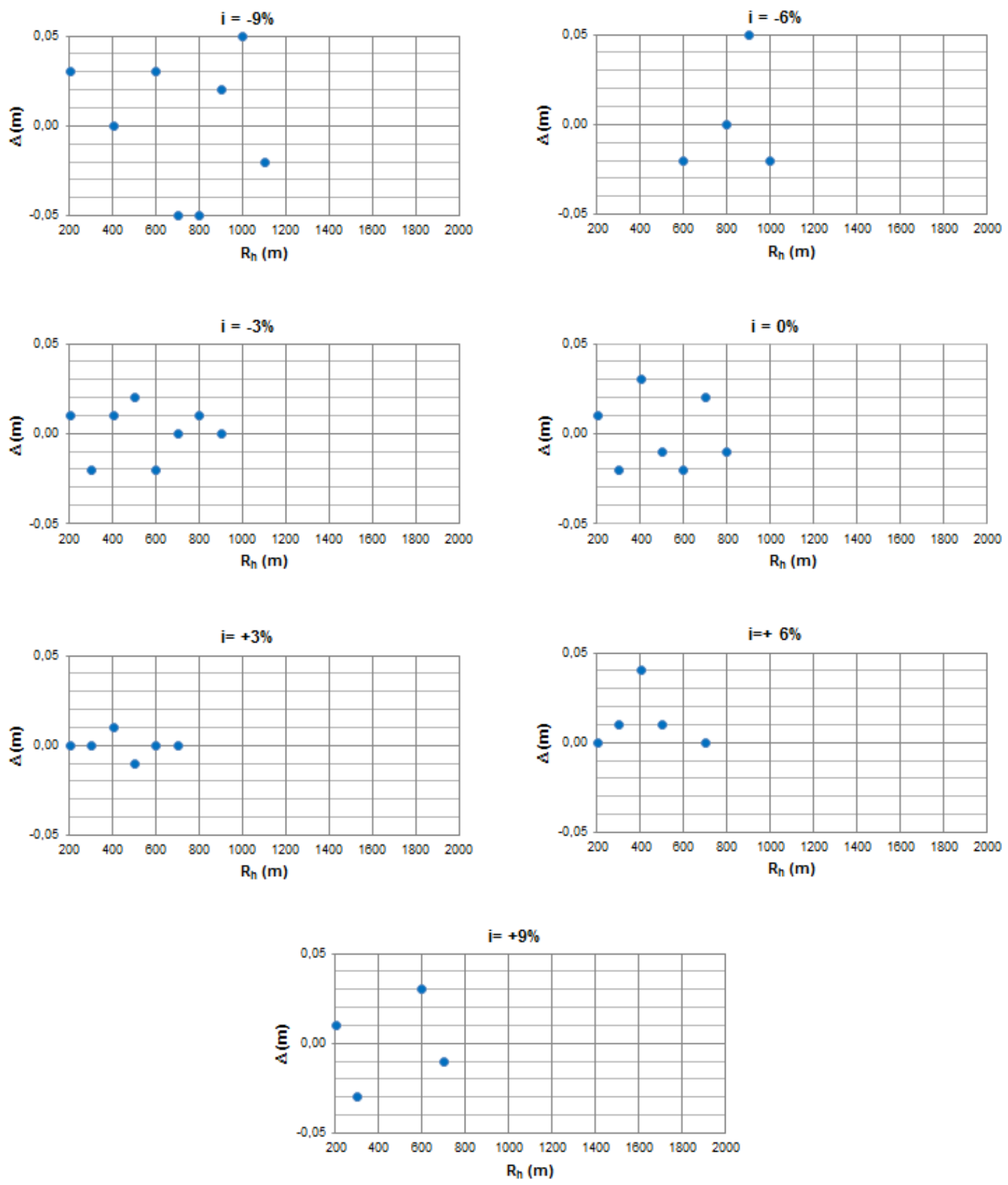
Resíduos (simulação - modelo calculado)

$V=80 \mathrm{~km} / \mathrm{h} ; h_{B}=1,00 \mathrm{~m}$
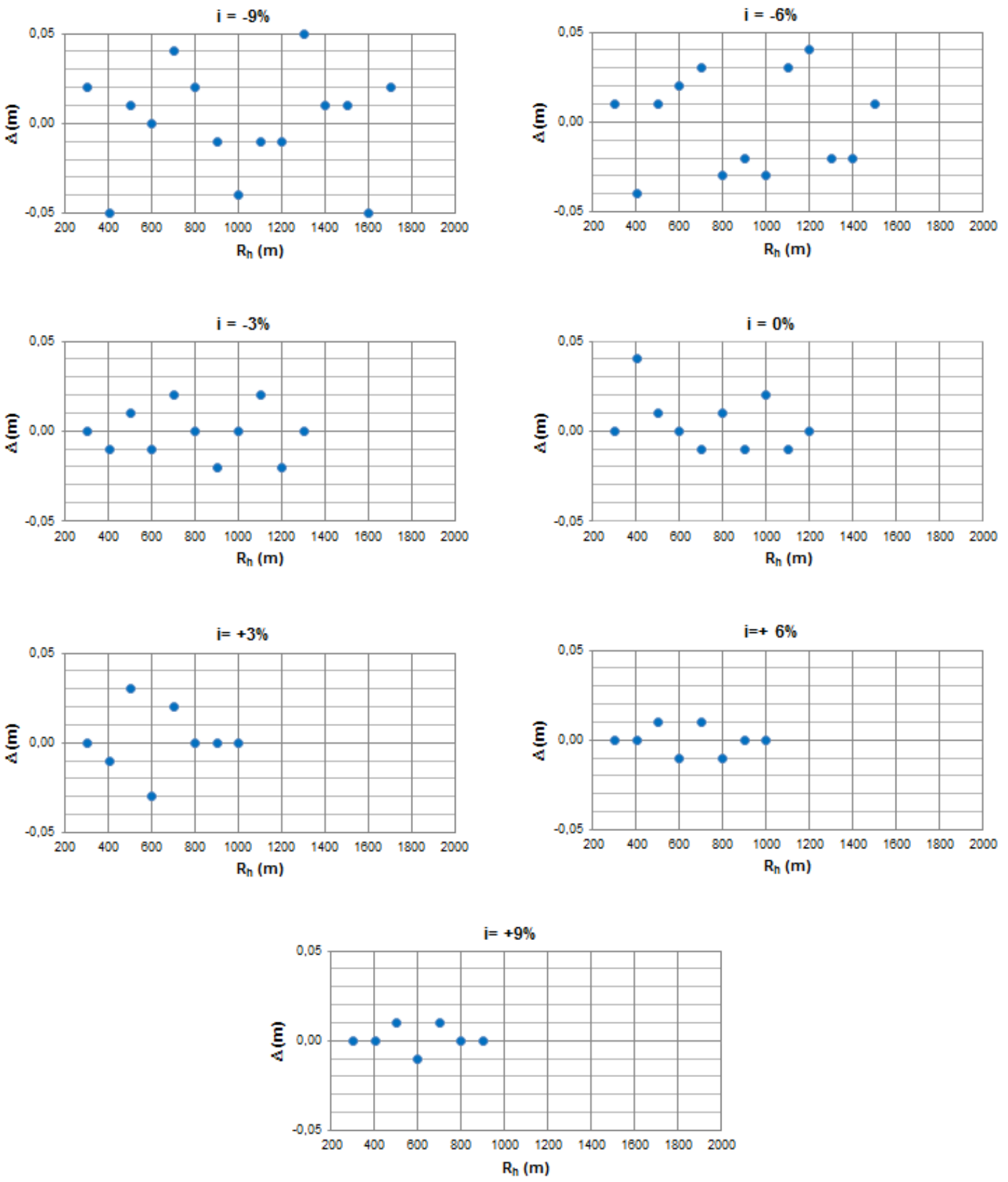
Resíduos (simulação - modelo calculado)

$V=90 \mathrm{~km} / \mathrm{h} ; h_{B}=1,00 \mathrm{~m}$
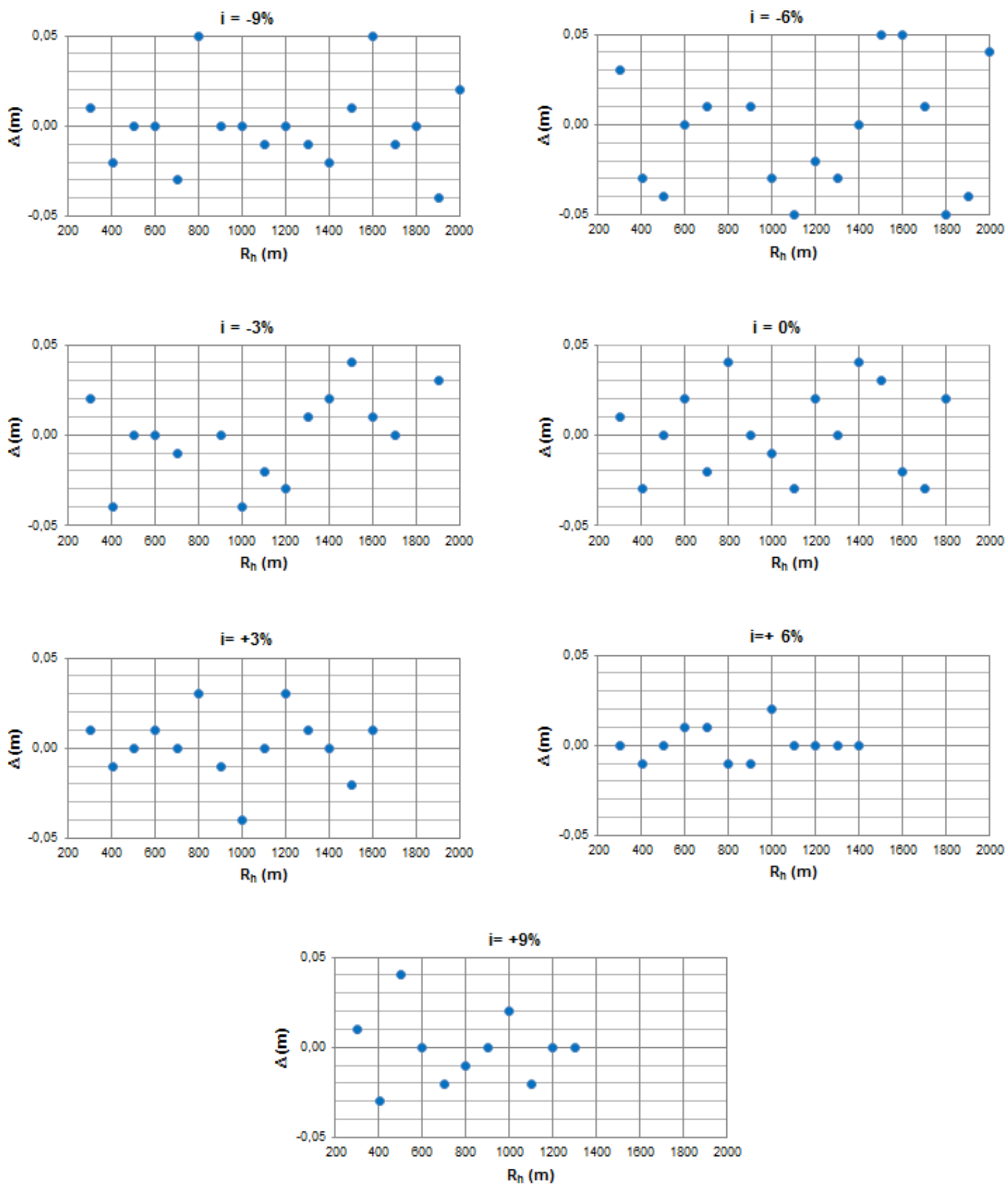
Resíduos (simulação - modelo calculado)

$V=100 \mathrm{~km} / \mathrm{h} ; h_{B}=1,00 \mathrm{~m}$
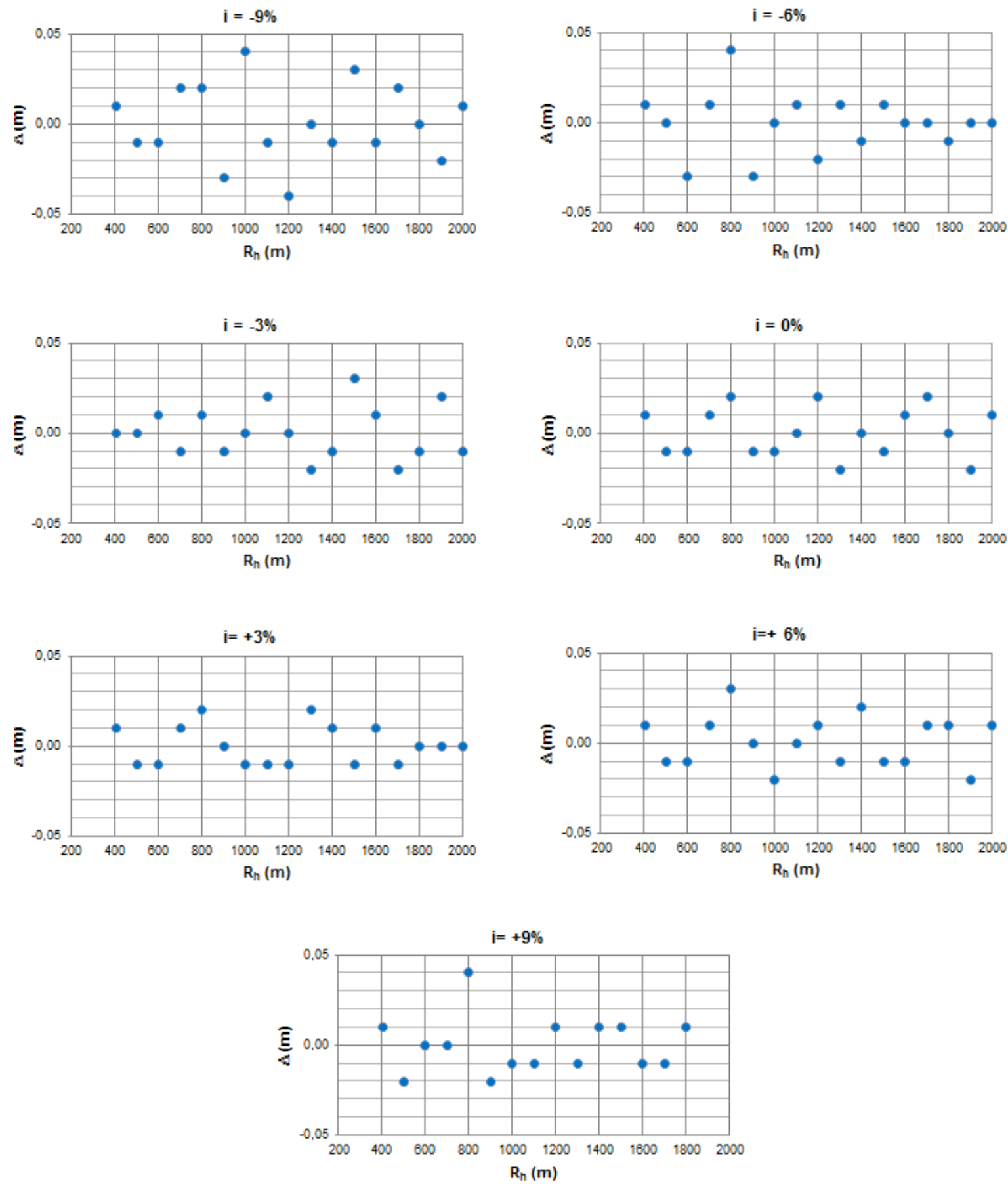
Resíduos (simulação - modelo calculado)

$V=110 \mathrm{~km} / \mathrm{h} ; h_{B}=1,00 \mathrm{~m}$
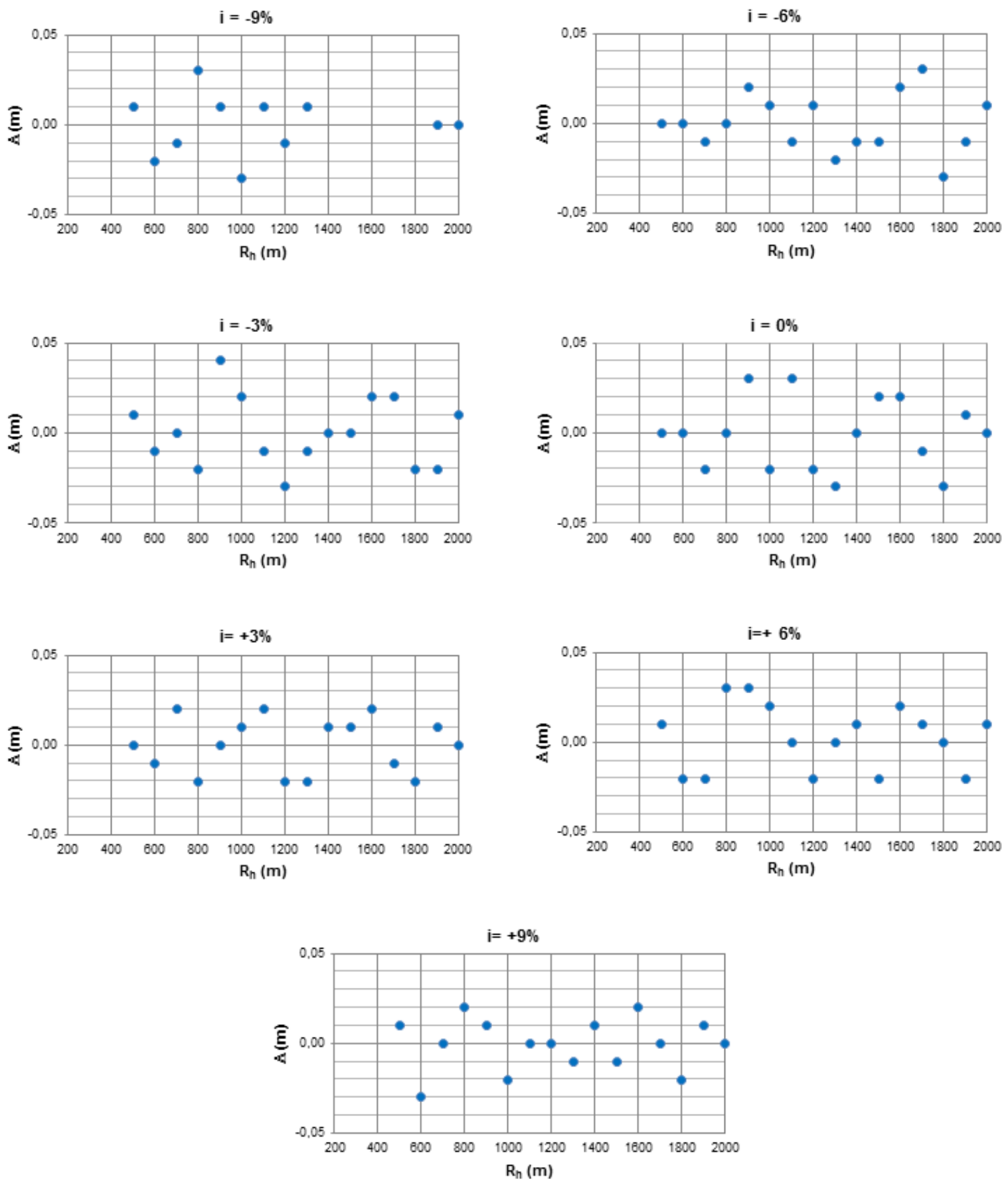
Resíduos (simulação - modelo calculado)

$V=120 \mathrm{~km} / \mathrm{h} ; \mathrm{h}_{\mathrm{B}}=1,00 \mathrm{~m}$
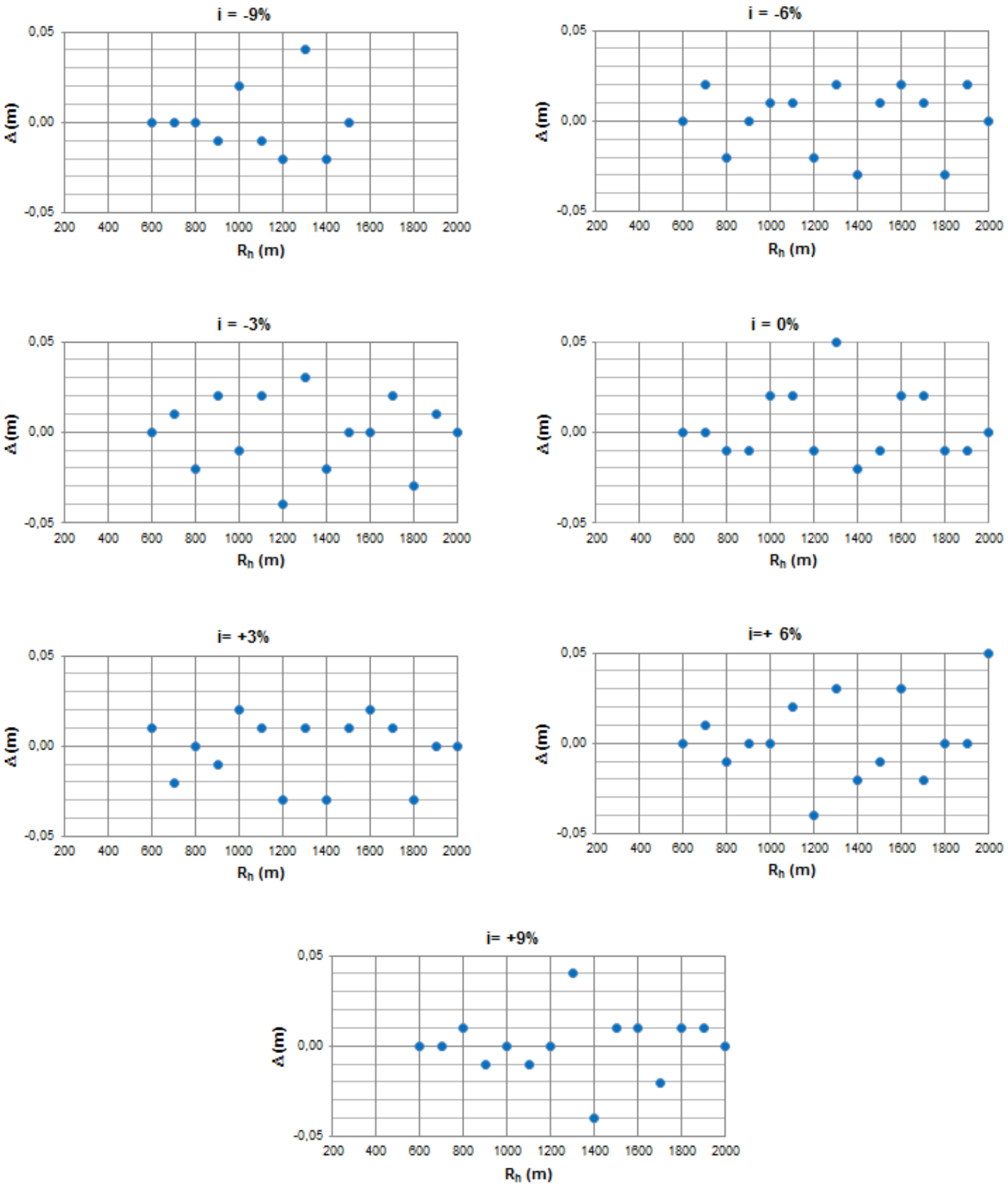
Resíduos (simulação - modelo calculado)

$V=60 \mathrm{~km} / \mathrm{h} ; h_{B}=1,40 \mathrm{~m}$
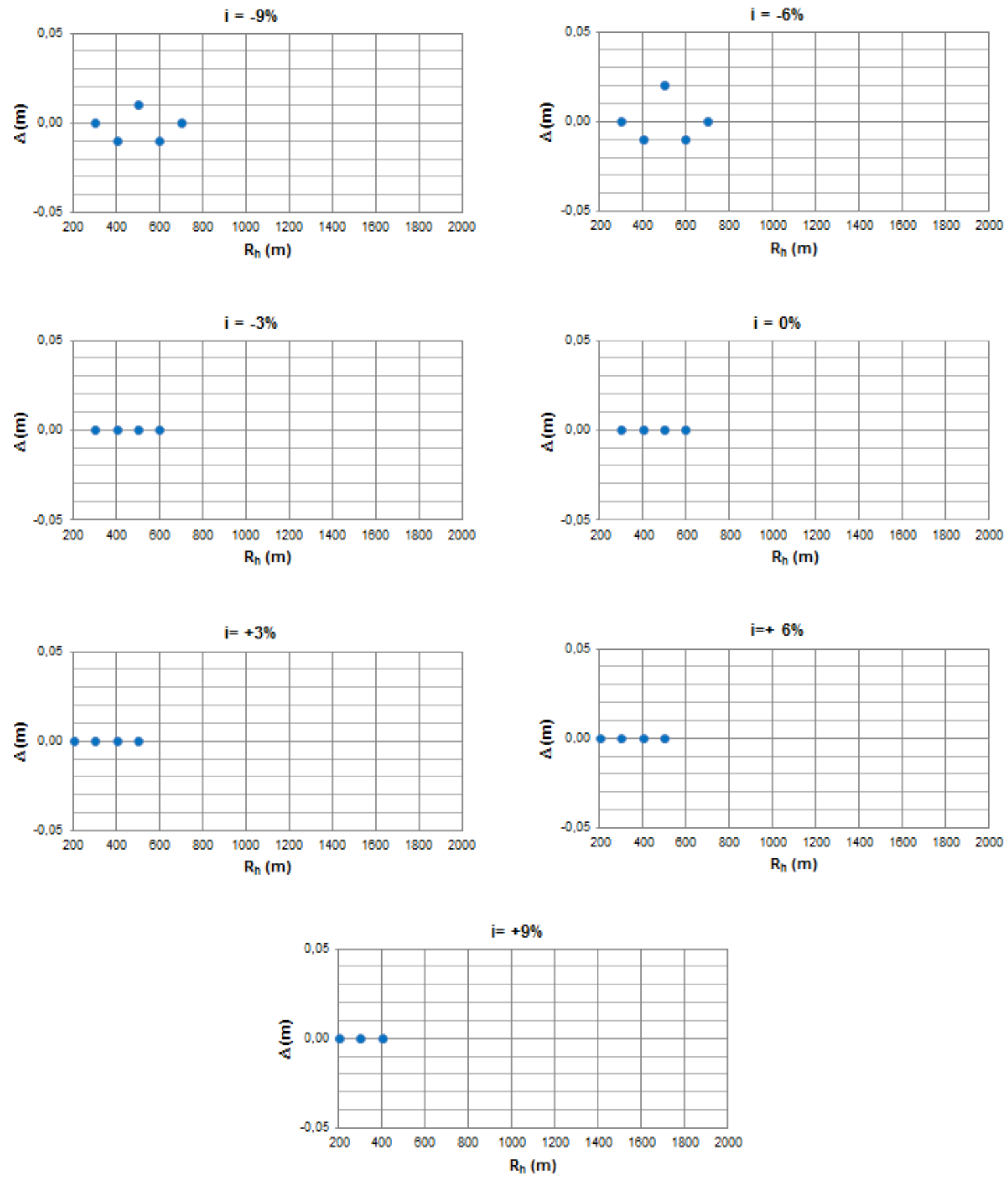
Resíduos (simulação - modelo calculado)

$V=70 \mathrm{~km} / \mathrm{h} ; h_{B}=1,40 \mathrm{~m}$
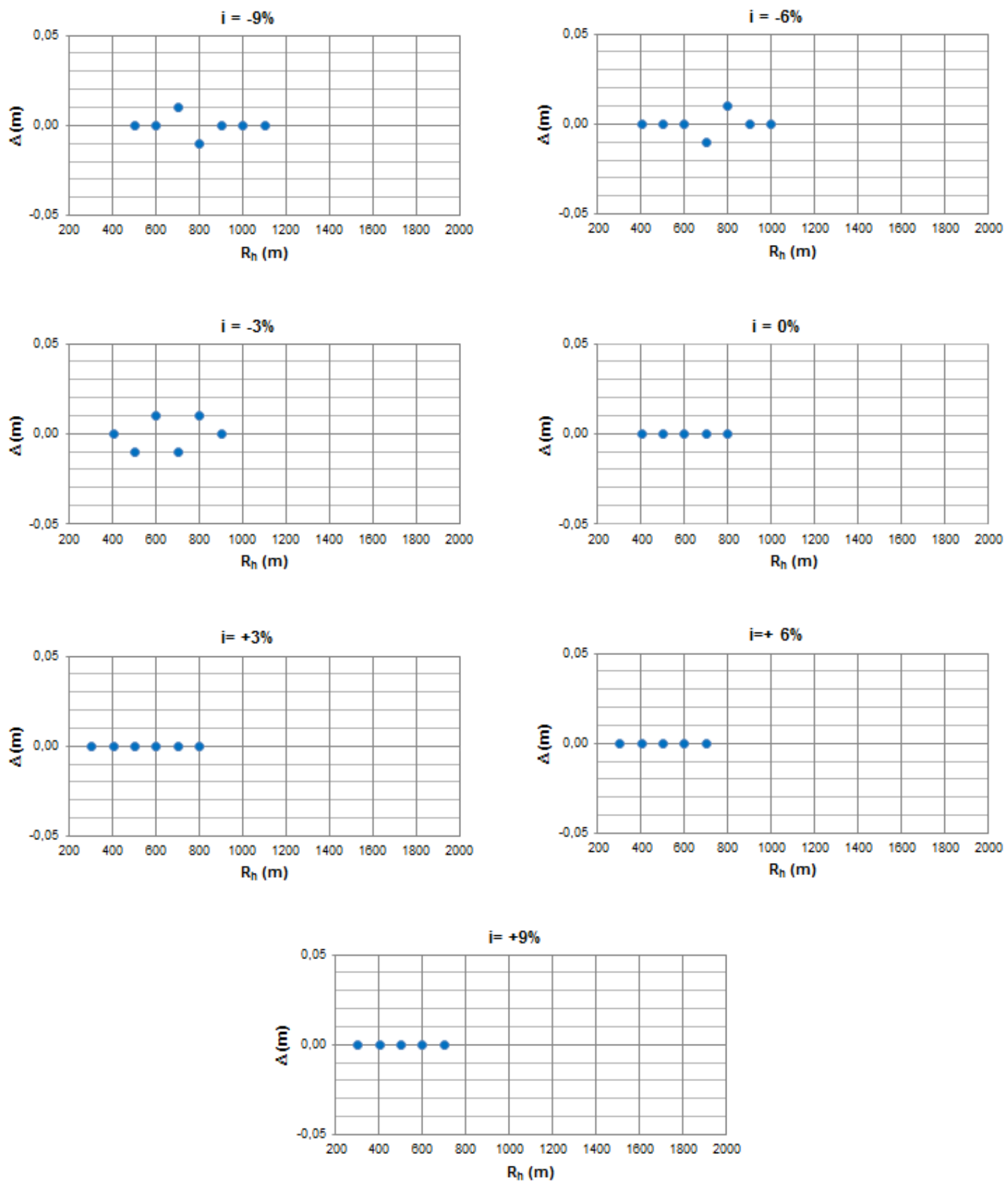
Resíduos (simulação - modelo calculado)

$V=80 \mathrm{~km} / \mathrm{h} ; h_{B}=1,40 \mathrm{~m}$
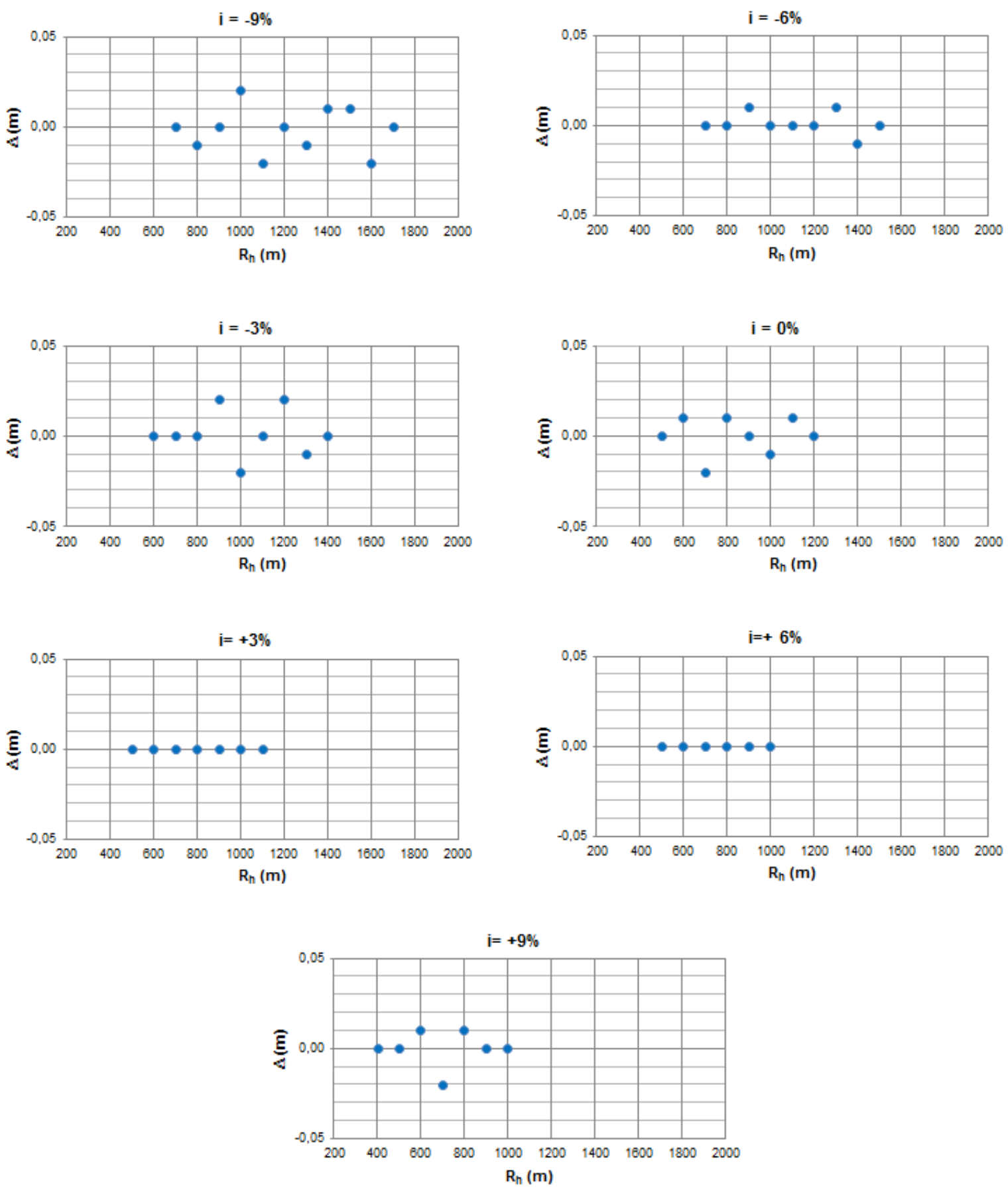
Resíduos (simulação - modelo calculado)

$V=90 \mathrm{~km} / \mathrm{h} ; h_{B}=1,40 \mathrm{~m}$
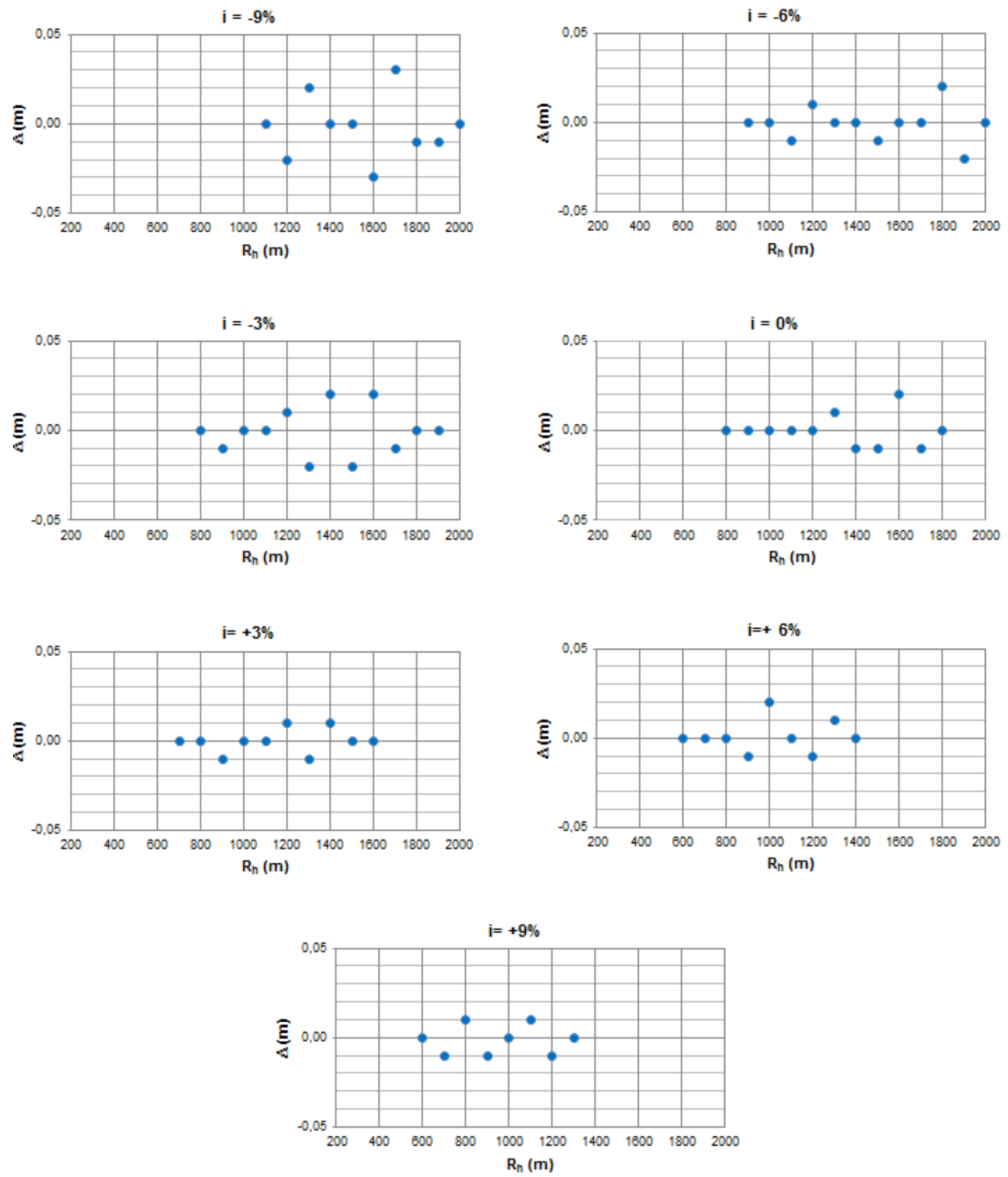
Resíduos (simulação - modelo calculado)

$V=100 \mathrm{~km} / \mathrm{h} ; h_{B}=1,40 \mathrm{~m}$
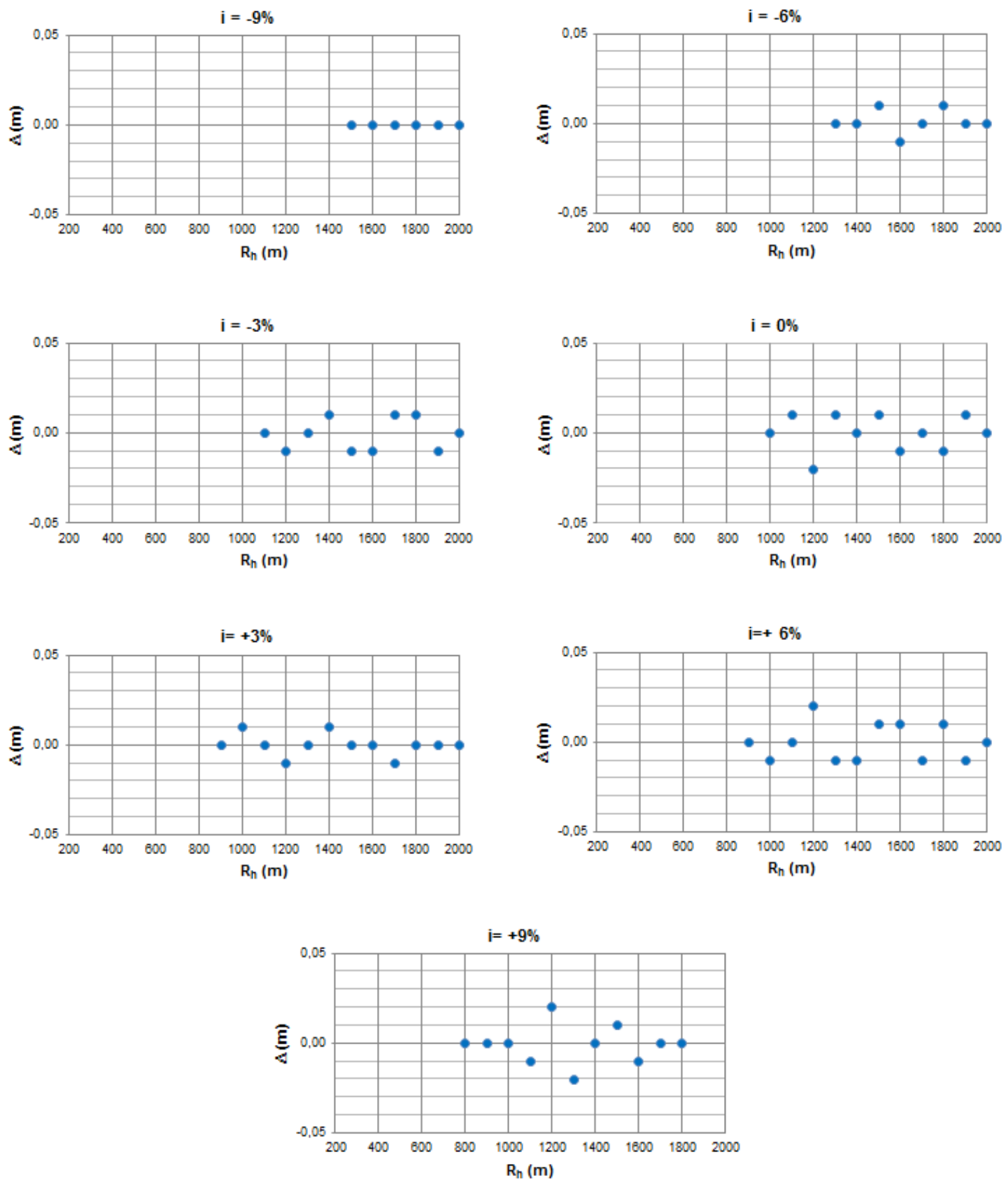


\section{Resíduos (simulação - modelo calculado)}

$\mathrm{V}=110 \mathrm{~km} / \mathrm{h} ; \mathrm{h}_{\mathrm{B}}=1,40 \mathrm{~m}$
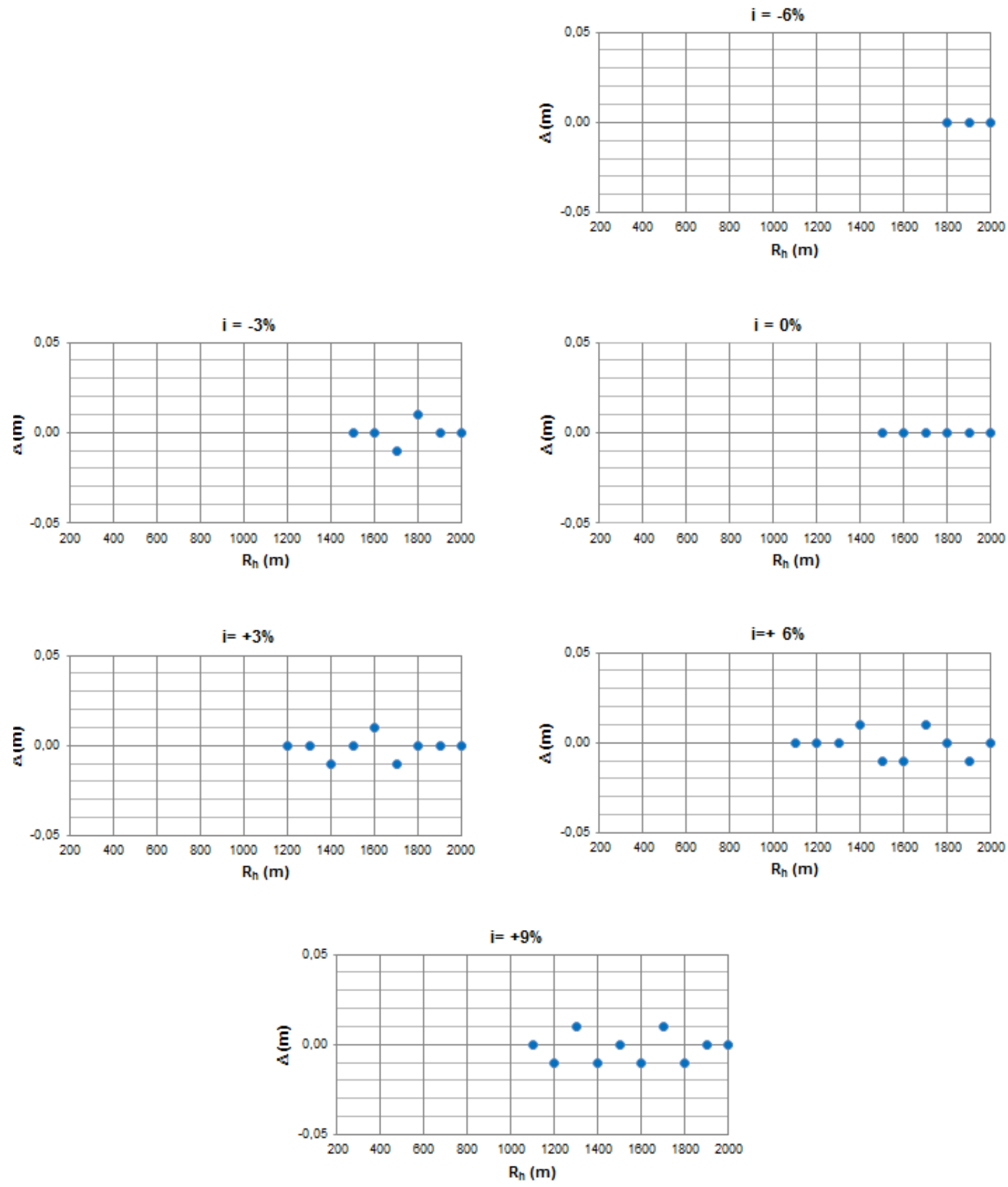
Resíduos (simulação - modelo calculado)

$V=120 \mathrm{~km} / \mathrm{h} ; \mathrm{h}_{\mathrm{B}}=1,40 \mathrm{~m}$
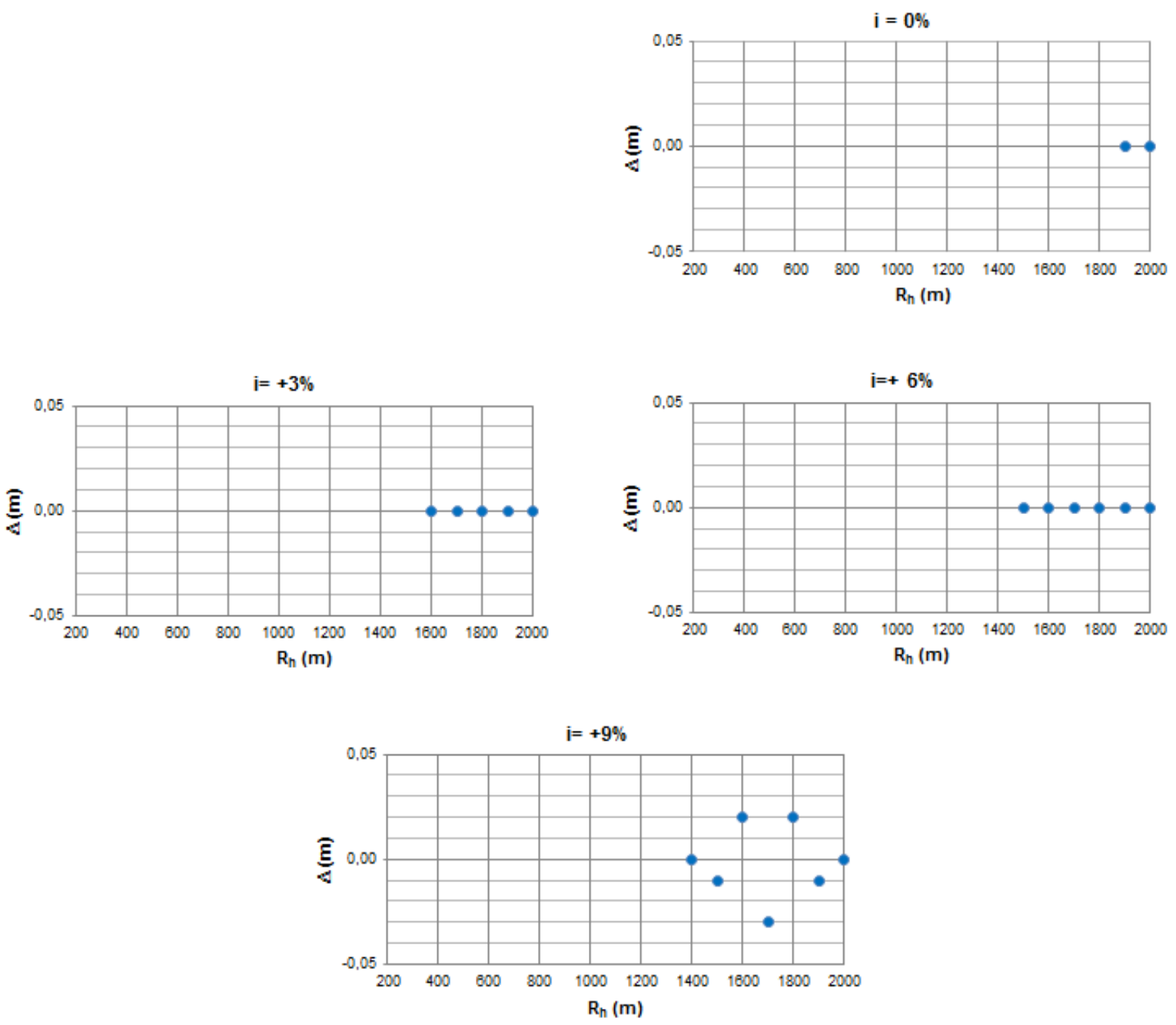
ANEXO III - LINHAS CÓDIGO DO APLICATIVO 


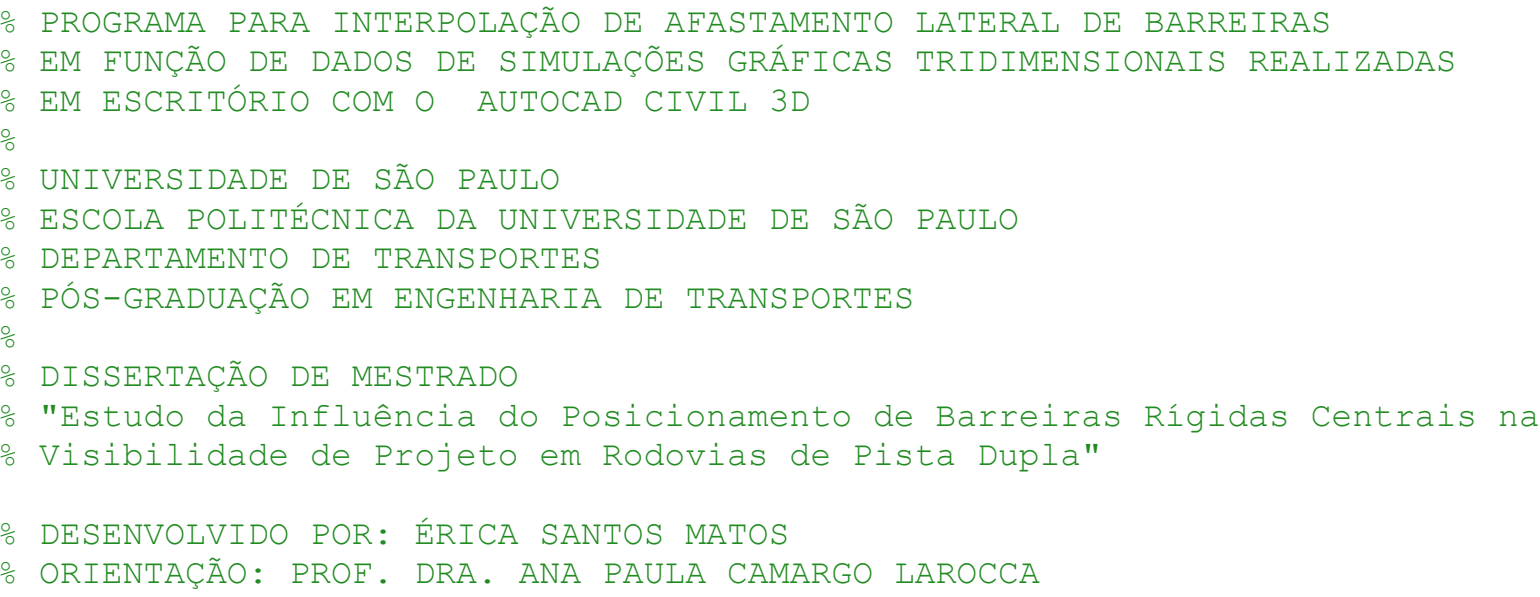


\% Salva as variaveis (handles.) para serem utilizadas em outras function guidata (hobject, handles);

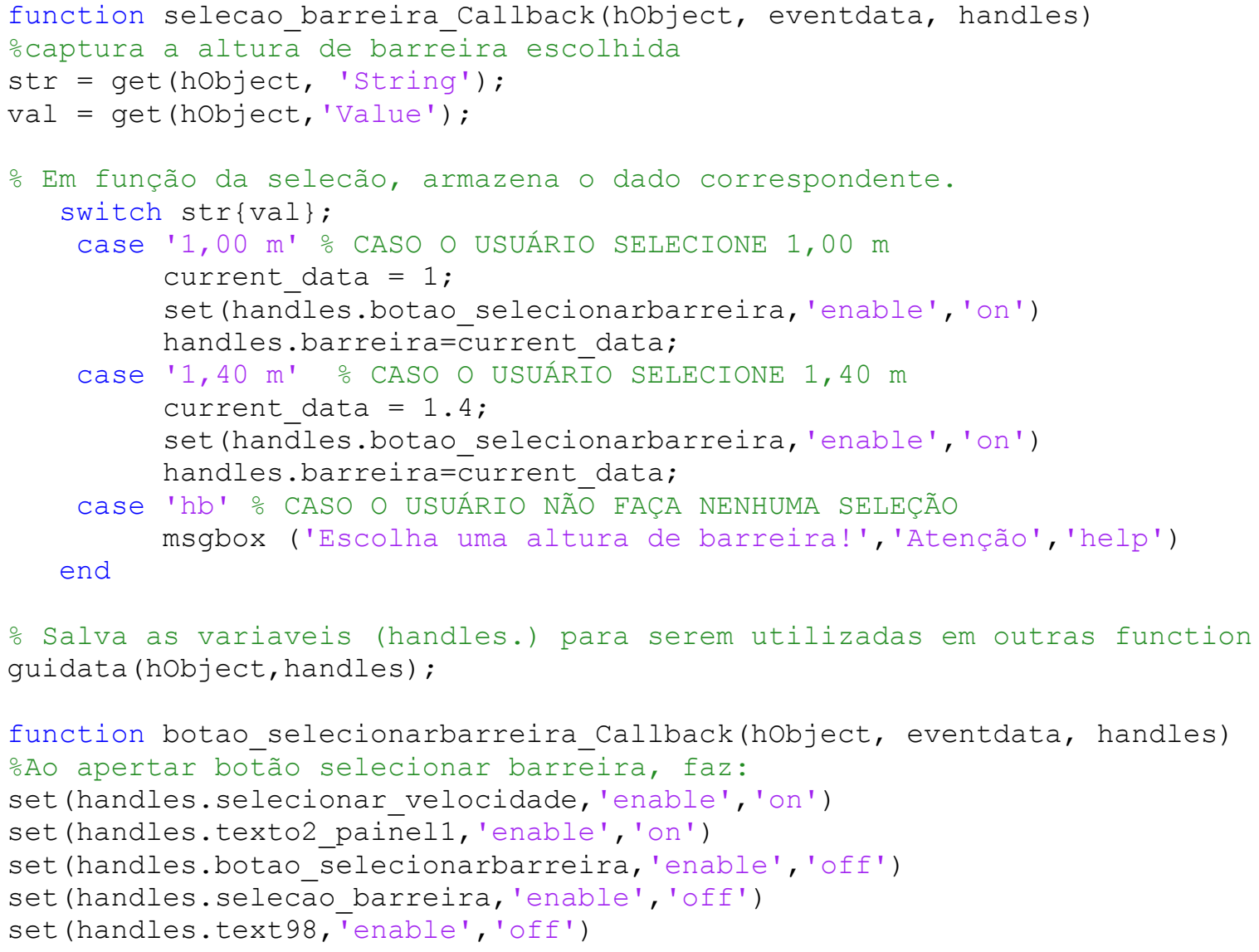

\% Em função da selecão, armazena o dado correspondente. switch str $\{$ val\}; 
handles.velocidade=current data;

case '110' \% CASO O USUÁRIO SELECIONE $110 \mathrm{~km} / \mathrm{h}$.

current data $=110$;

set (hand̄les.botao geragrafico, 'enable', 'on' )

handles.velocidade=current_data;

case '120' 응 O USUÁRIO SËLECIONE $120 \mathrm{~km} / \mathrm{h}$.

current data $=120$;

set (hand̄les.botao geragrafico, 'enable', 'on')

handles. velocidade=current data;

case ' $V$ '

msgbox ('Escolha uma velocidade de projeto!', 'Atenção', 'help') end

o Salva as variaveis (handles.) para serem utilizadas em outras function guidata (hobject, handles);

function botao_geragrafico_Callback (hobject, eventdata, handles)

\% Valor de entrada selecioñado pelo usuário

velocidade=handles.velocidade;

barreira=handles.barreira;

OPARA BARREIRA DE 1,00 M - seleção de coeficientes e limites das curvas de \% declividade para velocidade selecionada

if (barreira $==1$ )

if (velocidade==60) $\mathrm{C}=[$

$-2.478571429$

0.000000000

29.295634921

$-69.821428571$

47.222222222

0.000000000

$-3.090000000$

35.369047619

$-90.357142857$

66.666666667

0.000000000

0.000000000

$-1.960000000$

27.696428571

$-78.214285714$

62.500000000

0.000000000

0.000000000

$-1.260000000$

22.880952381

$-69.642857143$

58.333333333

0.000000000

0.000000000

$-0.500000000$

18.083333334

$-67.500000001$

66.666666667

0.000000000

0.000000000

24.583333334

$-90.000000001$

91.666666667

0.000000000

0.000000000

0.684783535

$-5.447327620$

$-5.058524867$

0.000000000

0.000000000

] ; limite $=[$

200700

200600

$200 \quad 600$

200600

$200 \quad 500$

200500

$200400]$;

\% ativa os textos respectivos às posições das curvas deste caso set (handles.text179, 'visible', 'on ', 'ForegroundColor', 'k') set (handles.text180, 'visible', 'on', 'ForegroundColor', 'k') set (handles.text181, 'visible', 'on' ' 'ForegroundColor', 'k' ) end

if (velocidade $==70)$

$$
\mathrm{C}=[
$$

$-2.295454545$

3.350815850

21.081682206

0.000000000

$-1.477777778$

15.645946646

$-36.708916083$

21.377233876

0.000000000

$-24.729020978$

7.375032374

3.205128206 


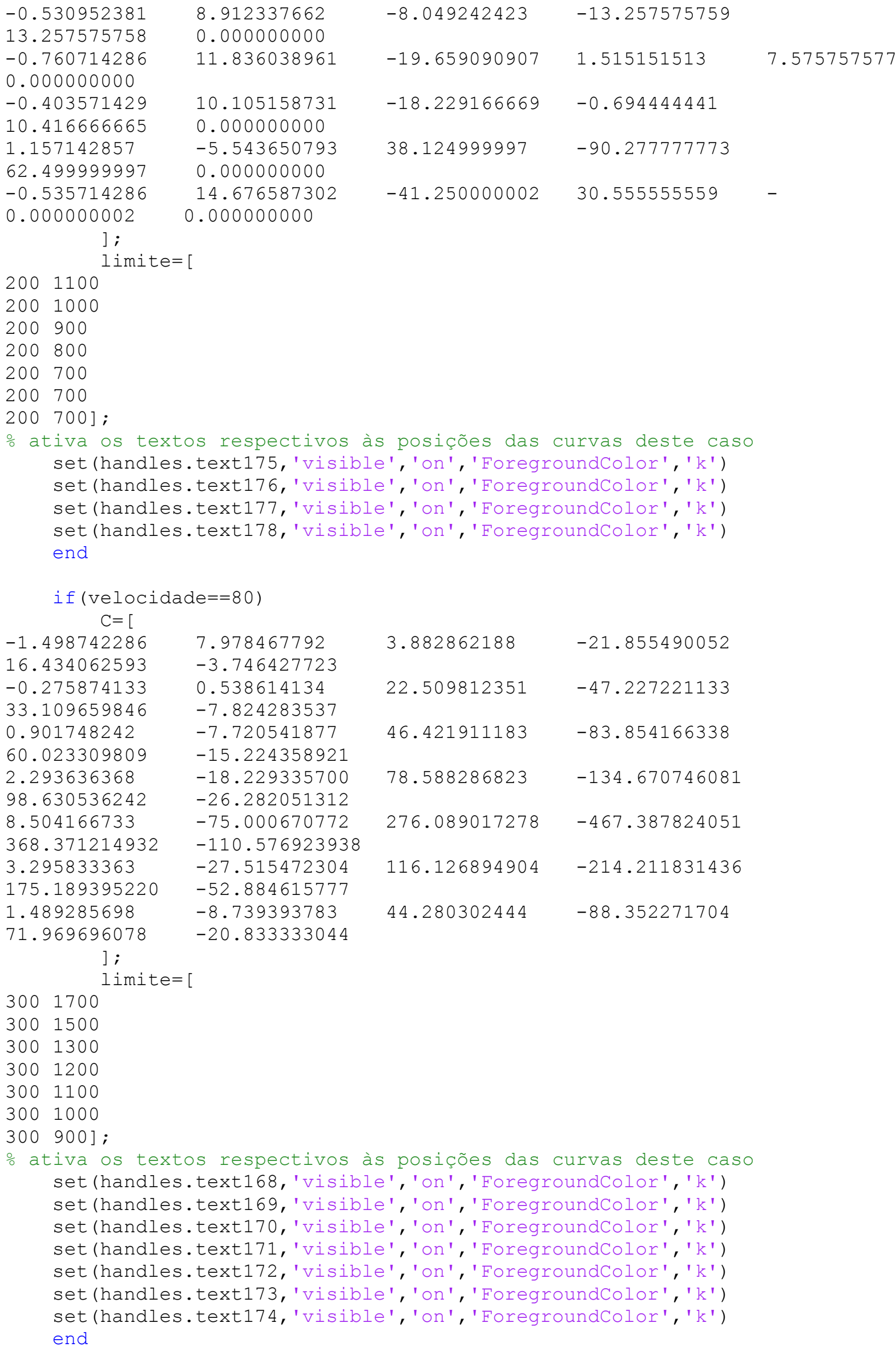




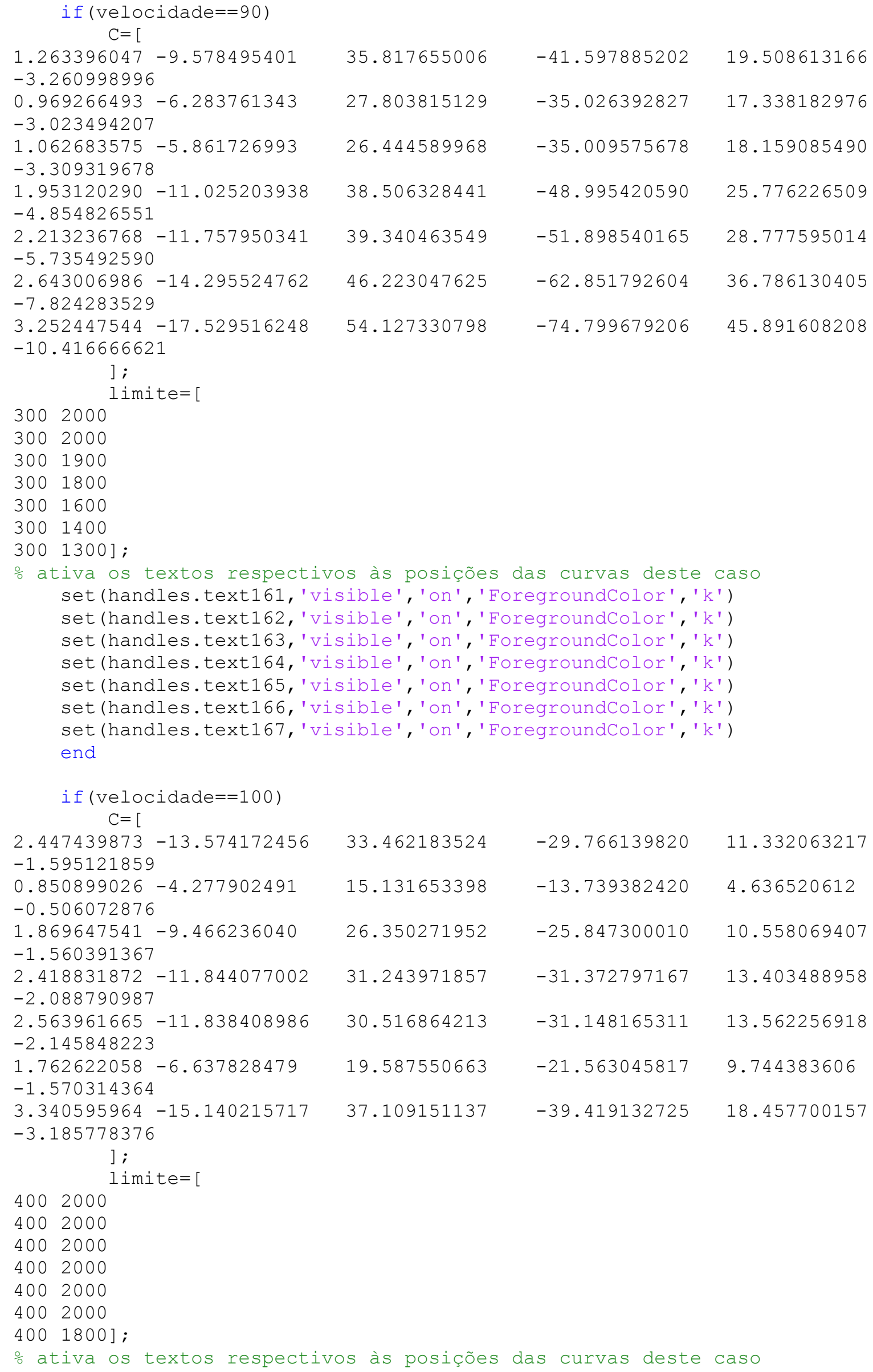


set (handles.text154, 'visible', 'on' ', ForegroundColor', 'k') set (handles.text155, 'visible', 'on' ', 'ForegroundColor', 'k') set (handles.text156, 'visible', 'on', 'ForegroundColor', 'k') set (handles.text157, 'visible', 'on', 'ForegroundColor', 'k') set (handles.text158, 'visible', 'on' ' 'ForegroundColor', 'k') set (handles.text159, 'visible', 'on' ', ForegroundColor' , 'k') set (handles.text160, 'visible', 'on' , 'ForegroundColor' ', 'k') end

if (velocidade==110)

$$
\mathrm{C}=[
$$

$2.947975370-13.785105925$

$-1.020255492$

$3.409195597-15.433897734$

$-1.265182163$

$4.063969046-18.143807288$

$-1.590160327$

$3.548017346-14.417547635$

$-0.987338234$

$5.243690391-22.876472720$

$-2.349269630$

$4.513320084-18.168568154$

$-1.510776348$

$5.238281373-21.303268822$

$-1.984599475$

] ;

limite =

5001400

5002000

5002000

5002000

5002000

5002000

500 2000];

o ativa os textos respectivos às posições das curvas deste caso set (handles.text147, 'visible', 'on' , 'ForegroundColor', 'k') set (handles.text148, 'visible', 'on' ', 'ForegroundColor', 'k') set (handles.text149, 'visible', 'on', 'ForegroundColor', 'k') set (handles.text150, 'visible', 'on' ', 'ForegroundColor', 'k') set (handles.text151, 'visible', 'on', 'ForegroundColor', 'k') set (handles.text152, 'visible', 'on', 'ForegroundColor', 'k') set (handles.text153, 'visible', 'on ', 'ForegroundColor' , 'k') end

if (velocidade $==120$ )

$$
\mathrm{C}=[
$$

$1.562237687-1.703717574$

1.923076986

$4.058360938-14.481527633$

$-0.578510764$

$6.281543861-23.909871982$

$-1.365404478$

$9.019015227-35.468376805$

$-2.234162923$

$5.079586534-17.465679345$

$-0.802274361$

$7.126264748-26.667125749$

$-1.762324384$

$9.201498694-34.982464591$

$-2.250535870$

$\begin{array}{lll}-4.004954107 & 12.415501907 & -8.712121598 \\ 22.786898808 & -14.926718787 & 4.633543751 \\ 38.828491231 & -28.153131969 & 9.827736871 \\ 58.124606987 & -43.673821139 & 15.759276374 \\ 27.637768613 & -19.254311710 & 6.281505584 \\ 44.180257080 & -33.743478232 & 12.314349876 \\ 57.155670274 & -43.598340967 & 15.871789640\end{array}$

$\begin{array}{lll}27.719466800 & -21.454046689 & 7.523335244 \\ 30.862084813 & -24.653438957 & 8.972870378 \\ 36.015680328 & -29.581571575 & 11.067863203 \\ 28.024578906 & -21.957856716 & 7.605977484 \\ 45.036205890 & -38.858829912 & 15.441424312 \\ 34.728295450 & -28.791204834 & 10.757769536 \\ 40.553094905 & -34.547163506 & 13.461786329\end{array}$

13.461786329 


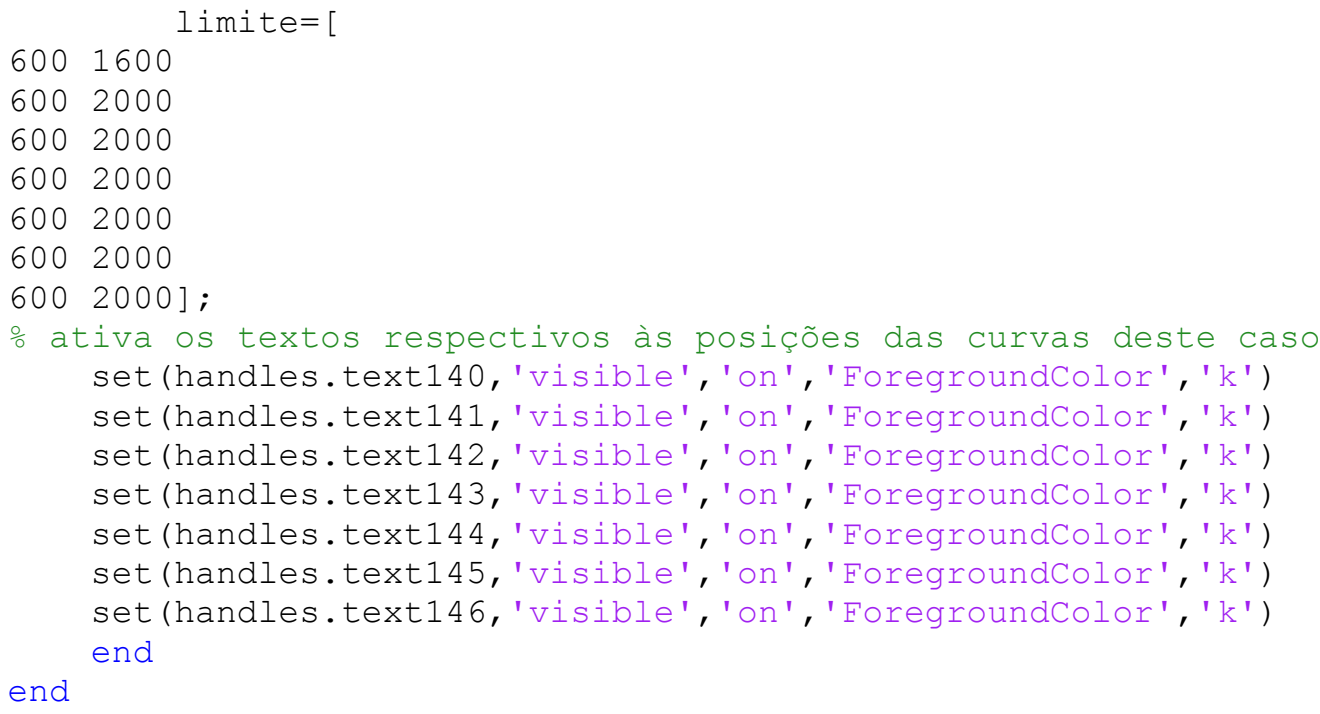




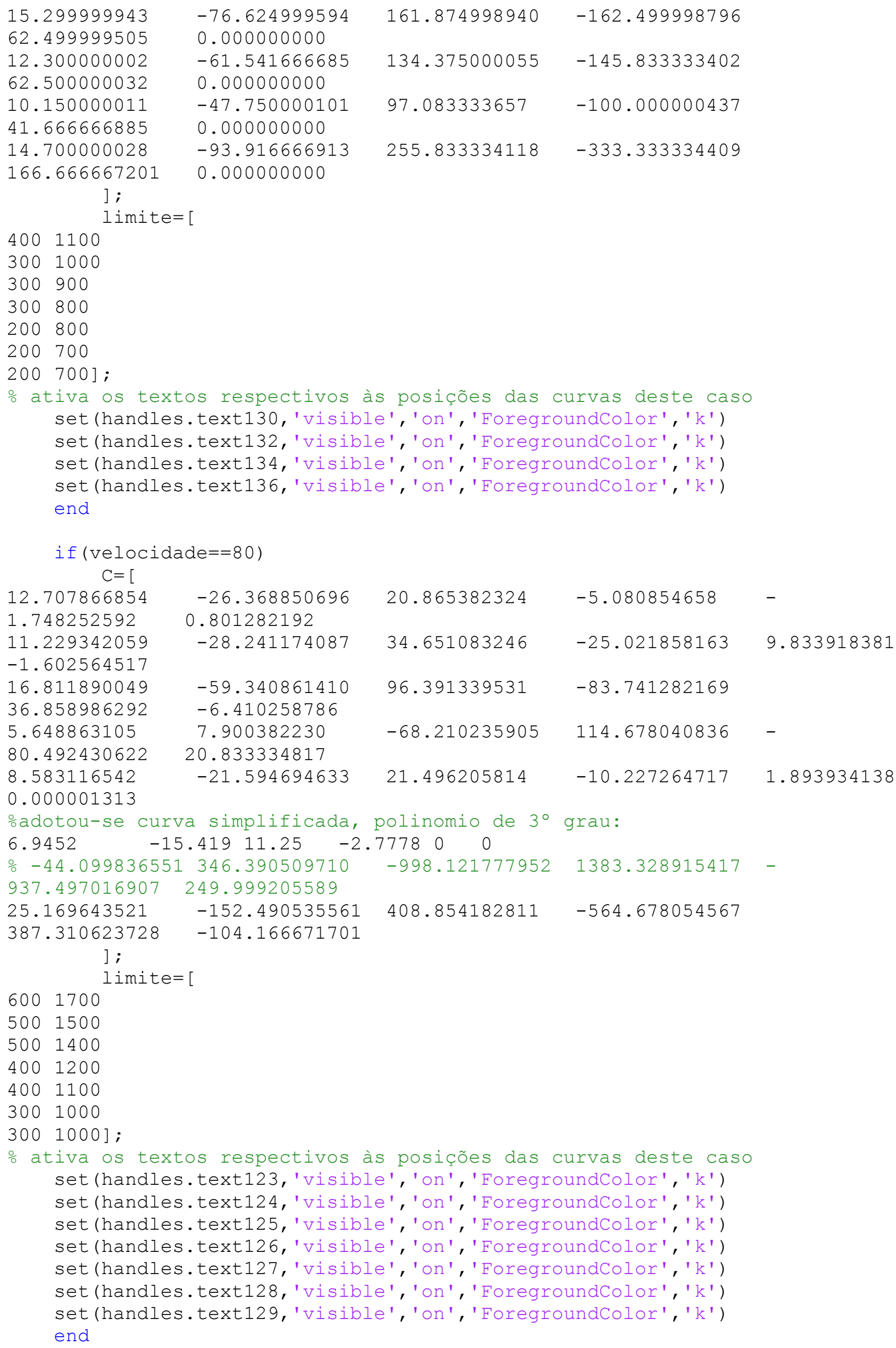




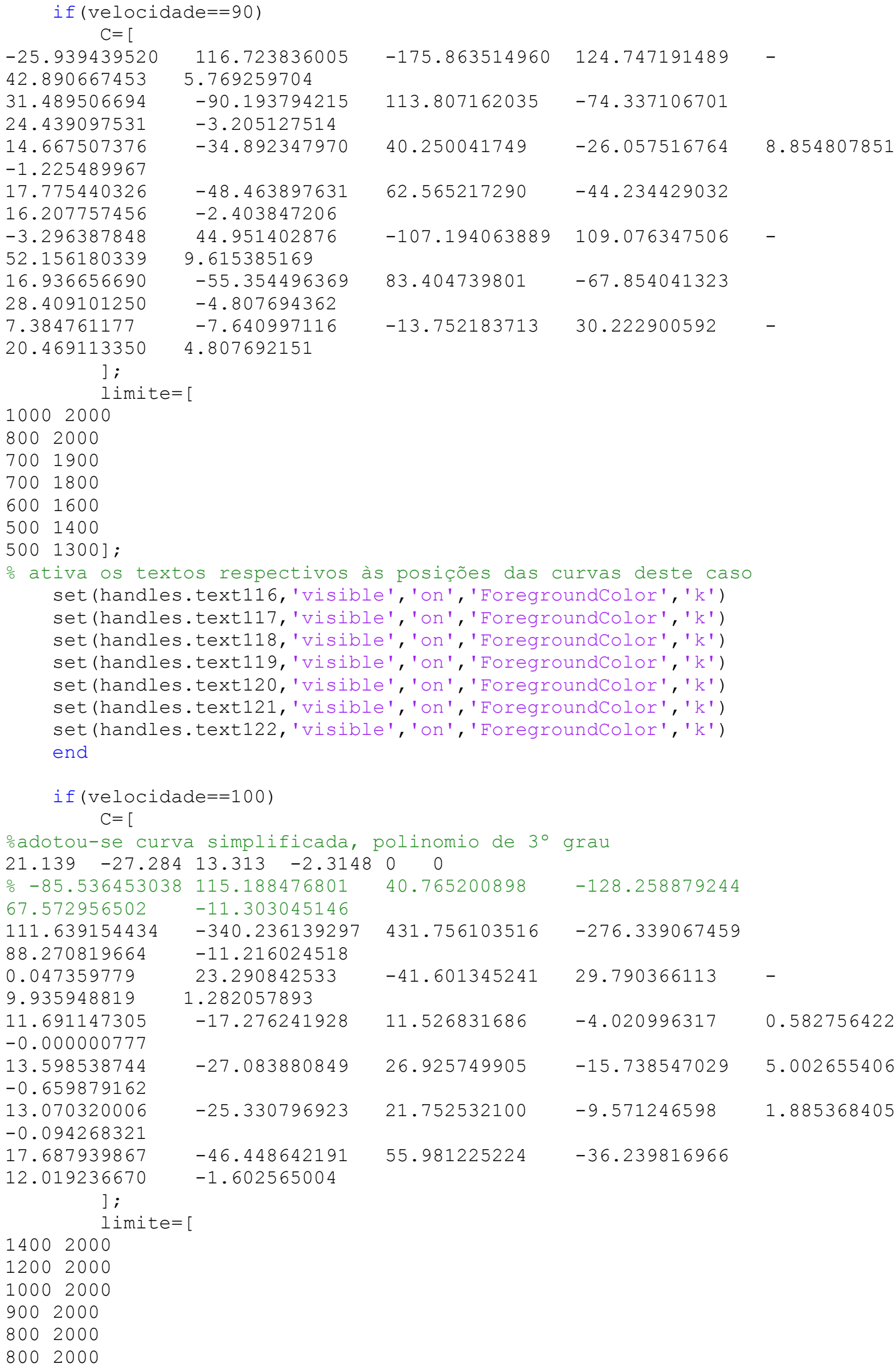


$7001800]$;

\% ativa os textos respectivos às posições das curvas deste caso set (handles.text109, 'visible', 'on ', 'ForegroundColor', 'k') set (handles.text110, 'visible', 'on', 'ForegroundColor', 'k') set (handles.text111, 'visible', 'on', 'ForegroundColor', 'k') set (handles.text112, 'visible', 'on', 'ForegroundColor' , 'k') set (handles.text113, 'visible', 'on' ', 'ForegroundColor', 'k') set (handles.text114, 'visible', 'on', 'ForegroundColor' ', 'k') set (handles.text115, 'visible', 'on' ', ForegroundColor' ,' 'k') end

if (velocidade $==110$ )

$\mathrm{C}=[$

0.000000000

0.000000000

5.899999999

0.000000000

0.000000000

0.000000000

0.000000000

0.000000000

$-2.000000000$

0.000000000

0.000000000

0.000000000

6.548086822

0.643190086

$-1.523499846$

$-2.233623713$

1.655489504

73.684035301

0.122806486

$-85.021109939$

$-34.340696722$

93.433351457

7.828752149

$-48.223415971$

171.660361290

$-219.830953598$

135.191742182

40.647134066

4.807727560

25.104230970

$-64.454934955$

80.156358480

$-53.898913562$

18.560707390

$-2.564115675$

67.227112770

$-201.543807387$

253.355106652

$-160.985757381$

50.990971923

$-6.410294604$

] ;

010

limite $=[$

17002000

14002000

14002000

11002000

10002000

$10002000]$;

\% ativa os textos respectivos às posições das curvas deste caso set (handles.text103, 'visible', 'on', 'ForegroundColor', 'k') set (handles.text104, 'visible', 'on', 'ForegroundColor' , 'k') set (handles.text105, 'visible', 'on ', 'ForegroundColor', 'k') set (handles.text106, 'visible', 'on', 'ForegroundColor', 'k') set (handles.text107, 'visible', 'on', 'ForegroundColor' , 'k') set (handles.text108, 'visible', 'on ', 'ForegroundColor', 'k') end

if (velocidade $==120$ )

$\mathrm{C}=[$

0.000000000

0.000000000

0.000000000

0.000000000

0.000000000

0.000000000

0.000000000

0.000000000

0.000000000

0.000000000

0.000000000

0.000000000

0.000000000

0.000000000

0.000000000

0.000000000

0.000000000

.000000000

6.150000000

$-2.000000000$

0.000000000

0.000000000

0.000000000

0.000000000 $-228.090015411$ 20.832370758 73.779926121

514.436027527

0.000000000

$-85.009247422$

$-424.773010254$

154.159744263

47.690739155

7.829008862

344.980098724

$-977.100753784$

$-34.354358494$

93.441197157

182.860355377

$-20.844525337$

$1117.884002686-640.000801086$ 


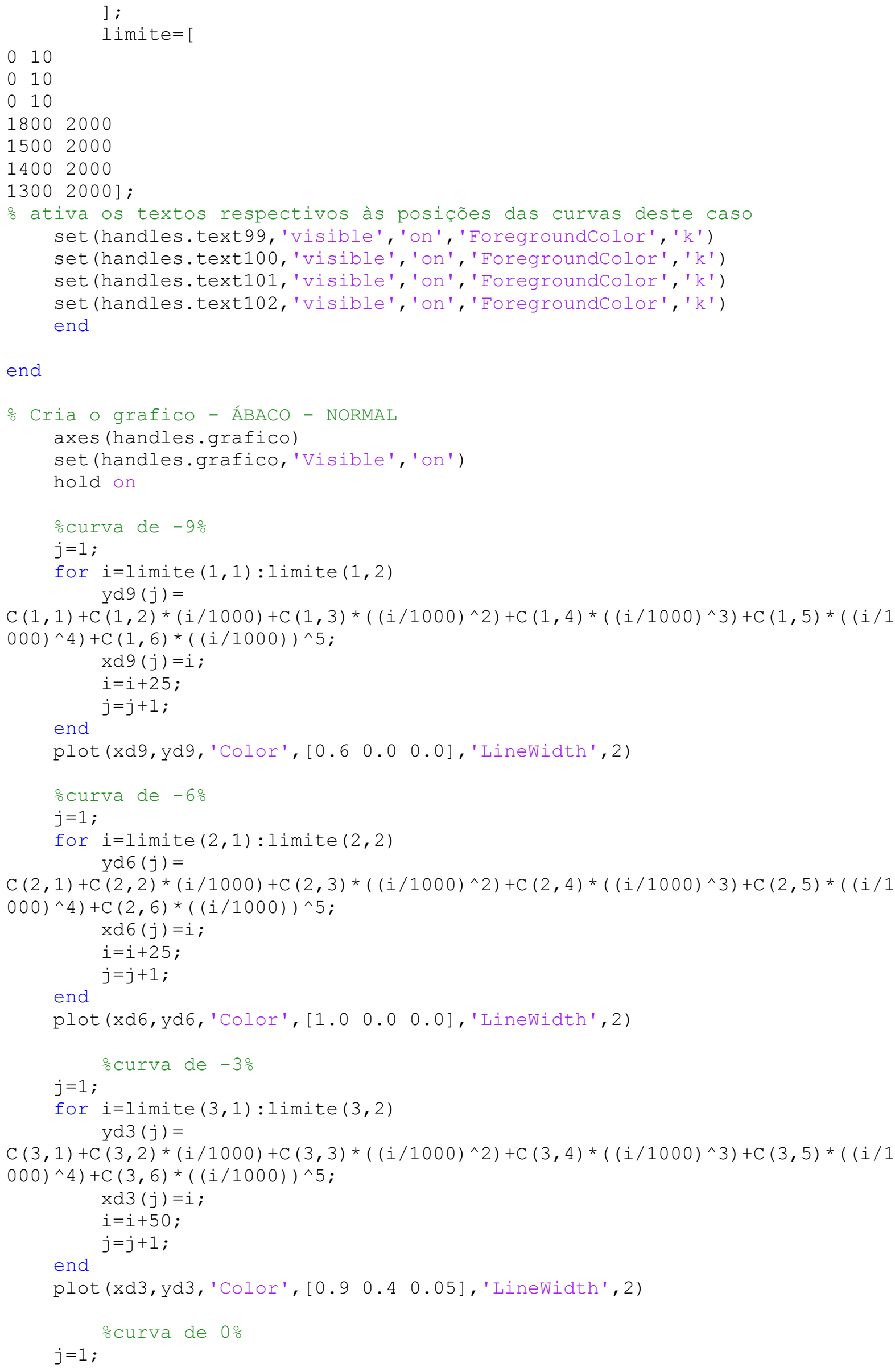




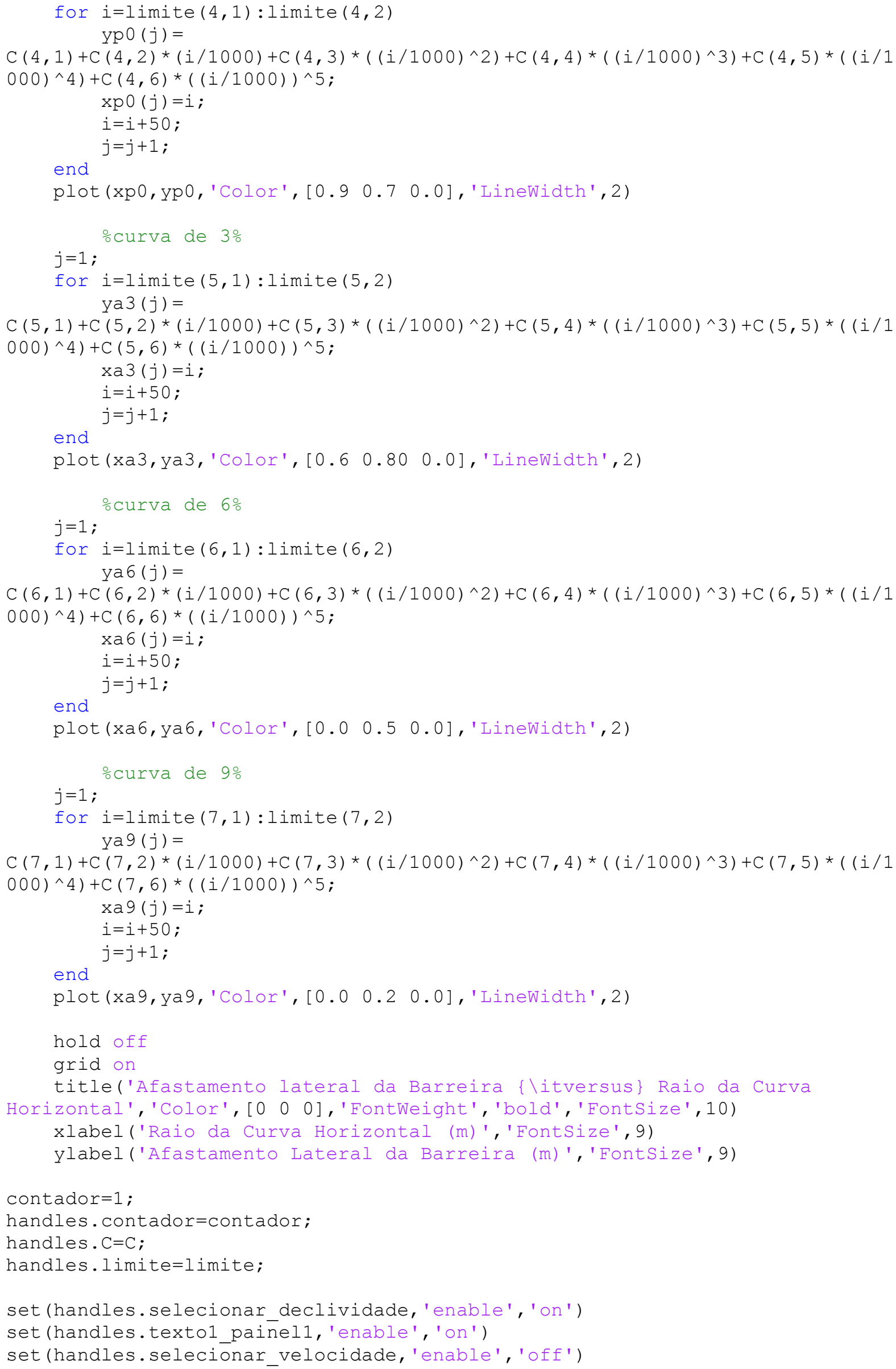


set (handles.texto2_painel1, 'enable', 'off')

set (handles.botao_geragrafico, 'enable', 'off')

o Salva as variaveis (handles.) para serem utilizadas em outras function guidata (hobject, handles);

function selecionar_declividade_Callback(hobject, , handles)

o Captura declividāe selecionā̄a

str $=$ get (hobject, ' String');

val $=$ get (hobject, 'Value');

\% Em função da selecão, armazena o dado correspondente.. switch str\{val\};

case '-9 \%' \% CASO O USUÁRIO SELECIONE - 9\%. current data $=-0.09$;

set (hand̄les.botao_selecionarcurva, 'enable', 'on')

handles. declivida $\overline{d e}=$ current data;

case '-6 \%' \% CASO O USUÁRIO SELEECIONE - 6\%.

current_data $=-0.06$;

set (hand̄les.botao_selecionarcurva, 'enable', 'on')

handles. declivida $\overline{d e}=$ current data;

case '-3 \%' \% CASO O USUÁRIO SELECIONE -3\%.

current_data $=-0.03$;

set (hand̄les.botao_selecionarcurva, 'enable', 'on')

handles.declivida $\overline{d e}=$ current_data;

case ' 0 \%' \% CASO O USUÁRIO SELĒCIONE $0 \%$

current_data $=0.00$;

set (hand̄les.botao selecionarcurva, 'enable', 'on')

handles. declivida $\overline{d e}=$ current data;

case ' 3 \%' CASO O USUÁRIO SELĒCIONE $\%$.

current data $=0.03$;

set (hand̄les.botao selecionarcurva, 'enable', 'on')

handles. declivida $\overline{d e}=$ current data;

case ' 6 \%' $\%$ CASO O USUÁRIO SELEECIONE 6\%.

current_data $=0.06$;

set (hand̄les.botao_selecionarcurva, 'enable', 'on')

handles.declividade=current_data;

case ' 9 \%' \% CASO O USUÁRIO SEĒECIONE 9\%.

current data $=0.09$;

set (hand̄les.botao_selecionarcurva, 'enable', 'on')

handles.declividade=current_data;

case ' $i$ ' O CASO O USUÁRIO NÃO FAÇA NENHUMA SELEÇÃO

msgbox ('Escolha uma declividade do greide!' ' 'Atenção', 'help')

end

\% Salva as variaveis (handles.) para serem utilizadas em outras function guidata (hobject, handles);

function botao_selecionarcurva_Callback(hobject, eventdata, handles) oseleciona a cūrva de declividāde para análise e altera sua cor para azul declividade=handles. declividade;

limite=handles.limite;

$\mathrm{C}=$ handles. $\mathrm{C}$;

o Cria o grafico - ÁBACO - NORMAL

axes (handles.grafico)

set (handles.grafico, 'Visible', 'on' )

hold on

ocurva de -9 \%

$j=1$; 


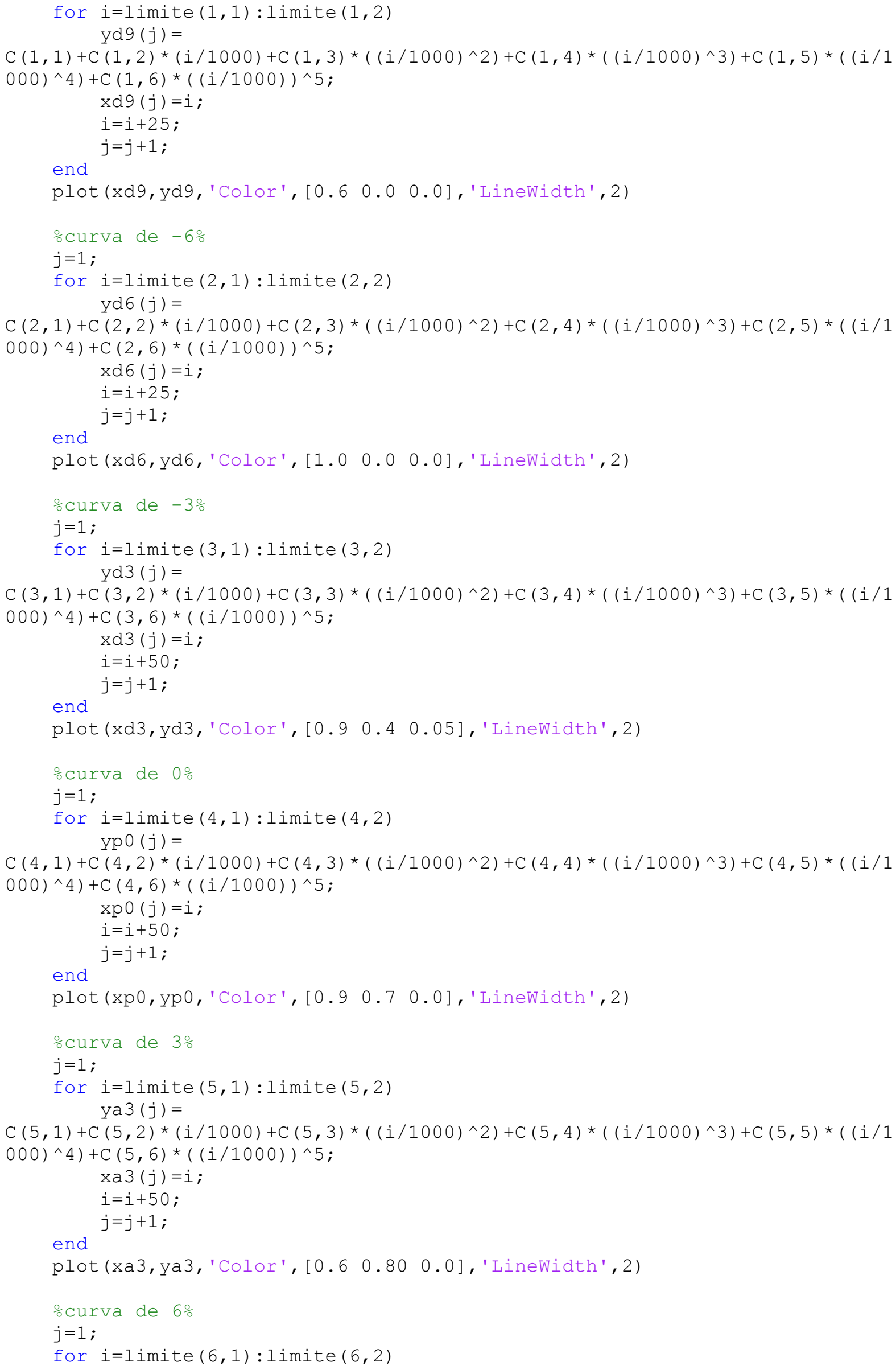




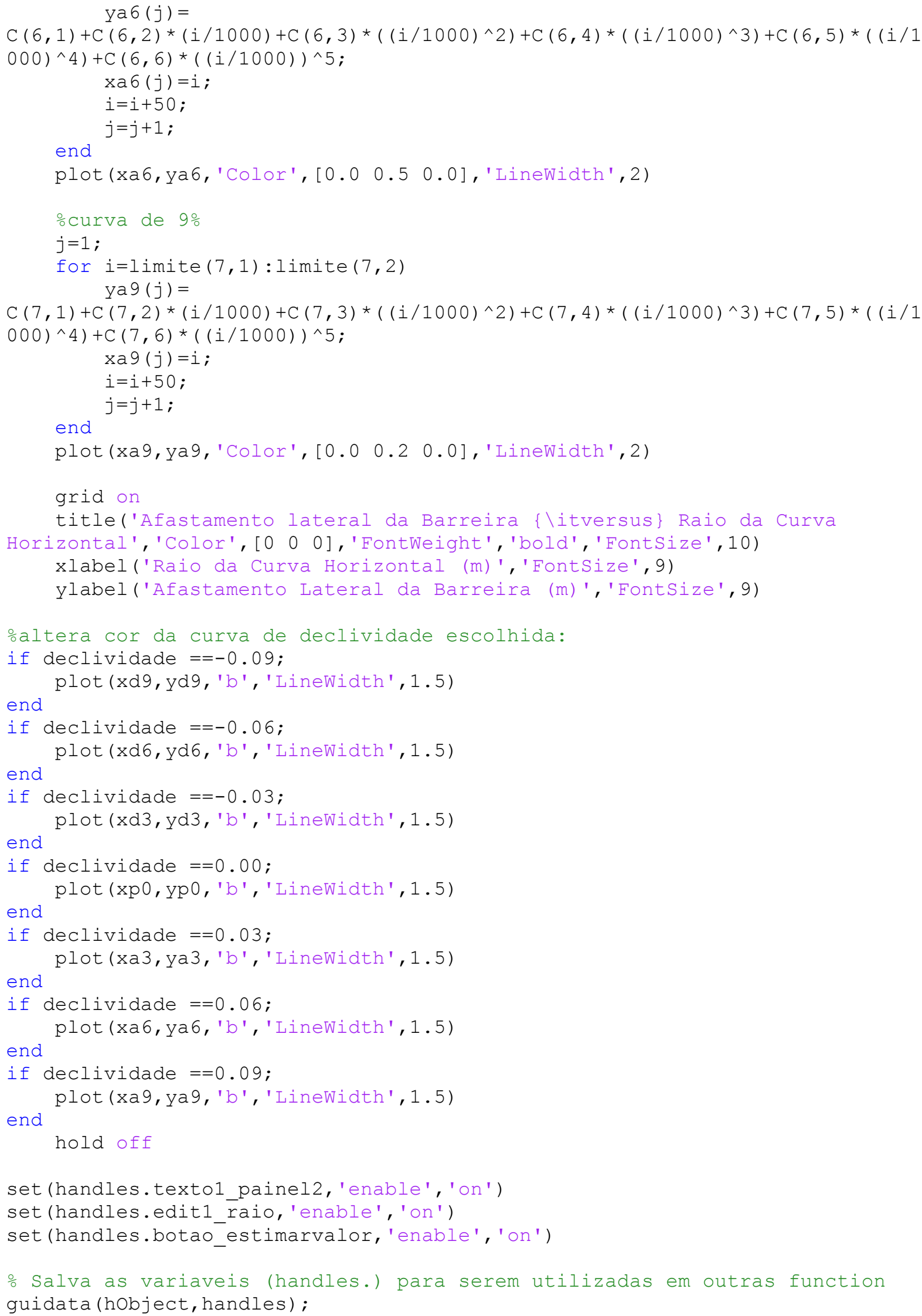




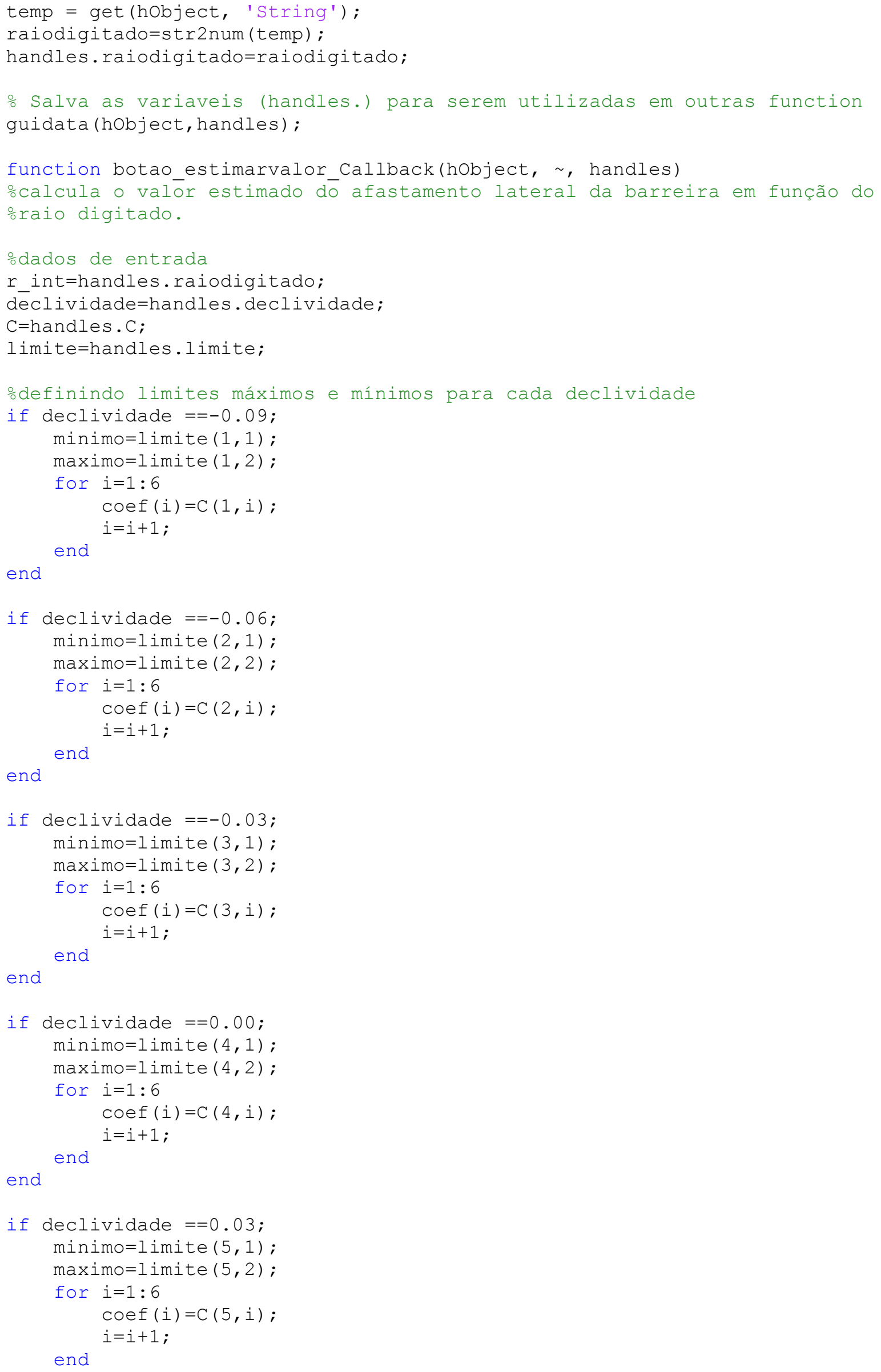


end

if declividade $==0.06$;

minimo=limite $(6,1)$;

maximo=limite $(6,2)$;

for $i=1: 6$

$\operatorname{coef}(i)=\mathrm{C}(6, i)$;

$i=i+1$;

end

end

if declividade $==0.09$;

minimo=limite $(7,1)$;

maximo=limite $(7,2)$;

for $i=1: 6$

coef $(i)=C(7, i)$;

$i=i+1$;

end

end

if $r$ int < minimo \% TESTA SE O RAIO INTERPOLADO É MENOR QUE O MíNIMO msgbox ('Valor de raio inferior ao minimo', 'Atenção', 'help')

set (handles.texto3_painel2_valorestimado, 'enable', 'on ', 'string ', ' ')

set (handles.texto2 painel2,' 'enable', 'off')

end

set (handles.botao_armazenar, 'enable', 'off')

if $r$ int > maximo 을 SE O RAIO INTERPOLADO É MAIOR QUE O MÁXIMO msgbox ('valor de raio superior ao maximo', 'Atenção', 'help')

set (handles.texto3_painel2_valorestimado, 'enable', 'on ', 'string', ' ')

set (handles.texto2 painel2,' 'enable', 'off')

end

set (handles.botao armazenar, 'enable', 'off')

if $(r$ int $>=$ minimo) \&\& ( $r$ int $<=$ maximo) \%CALCULA O VALOR DO AFASTAMENTO aint $=$

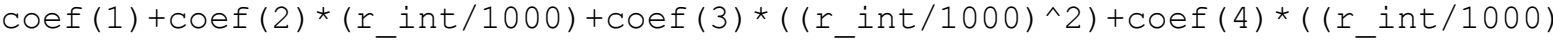

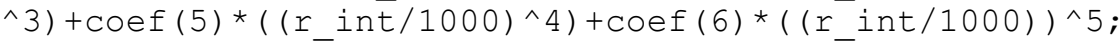

set (handles.texto3 painel2 valorestimado, 'enable', 'on', 'string', (aint))

set (handles.texto2_painel2,'enable', 'on')

set (handles.botao_armazenar, 'enable', 'on')

handles.aint=aint;

end

o Salva as variaveis (handles.) para serem utilizadas em outras function guidata (hobject, handles)

function botao_armazenar_Callback(hobject, , handles)

oarmazena o val̄or calculādo e mostra na tabela como novo registro

valor=handles.aint;

g=handles. contador;

ovetores da tabela:

handles.data $(g, 1)=g$;

handles.data $(9,2)=$ handles.aint;

handles.data $(9,3)=$ handles.raiodigitado;

handles.data $(9,4)$ handles. velocidade;

handles.data $(9,5)=$ handles.declividade;

handles.data $(9,6)$ handles.barreira;

$g=g+1$ 


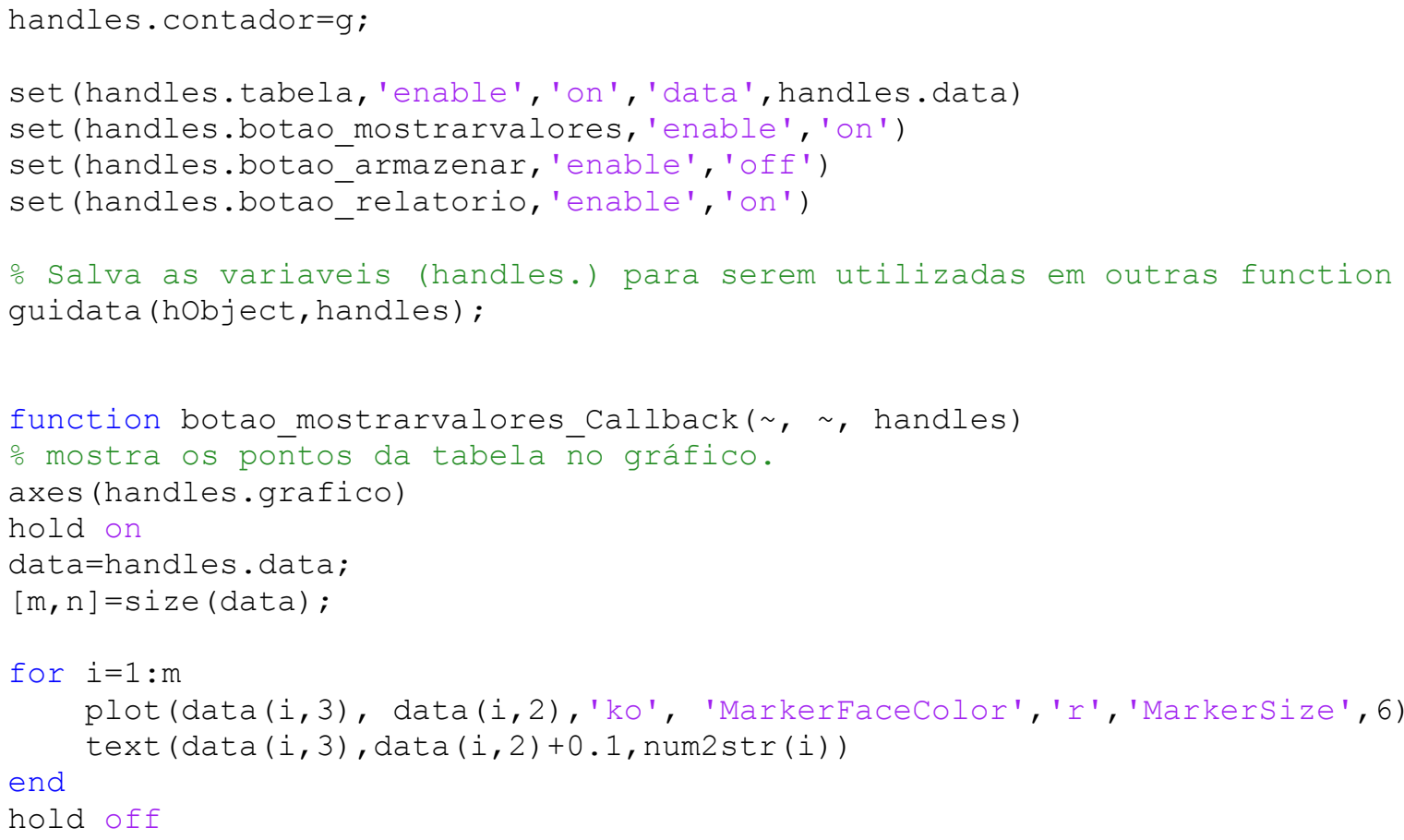




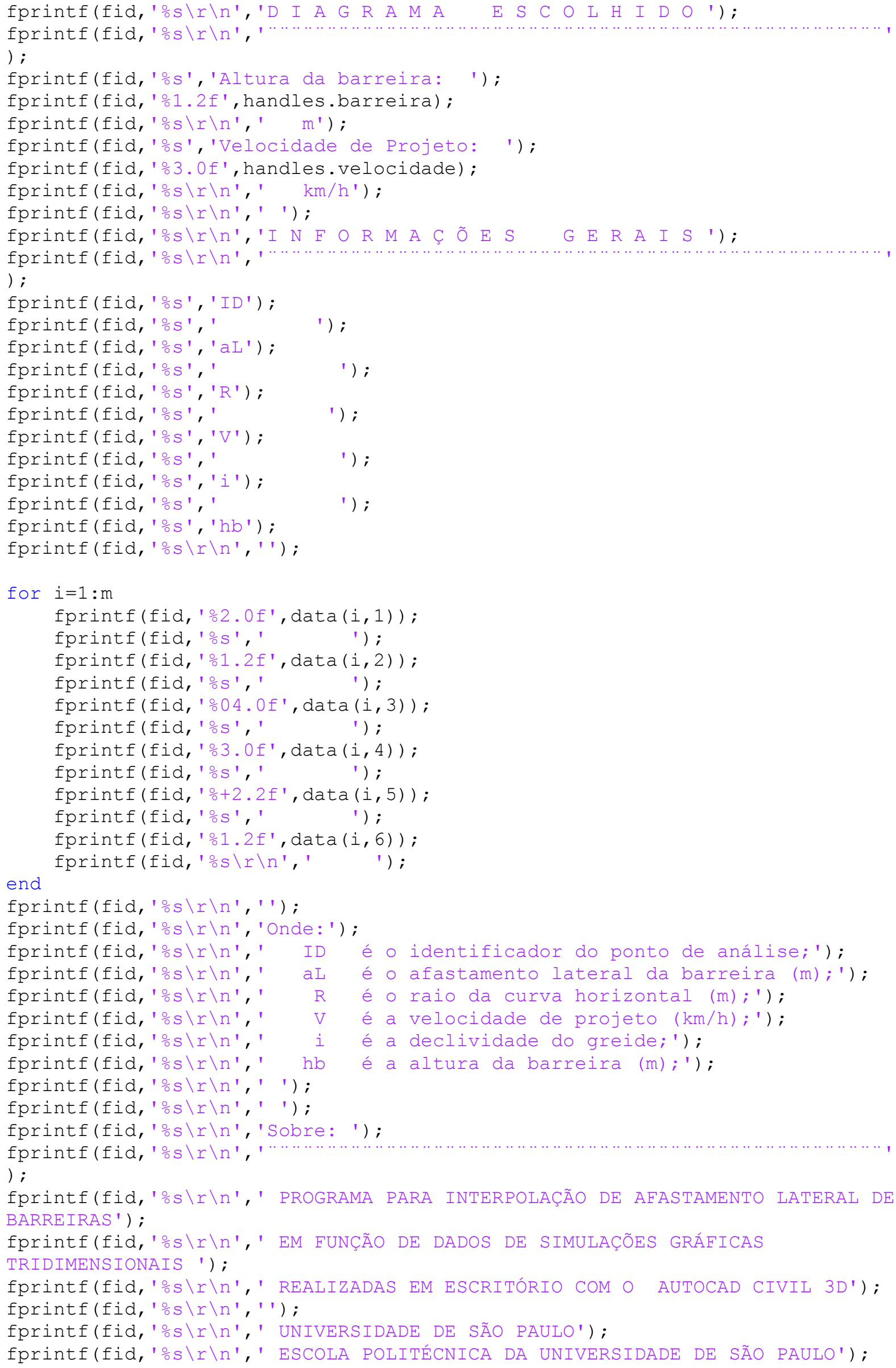




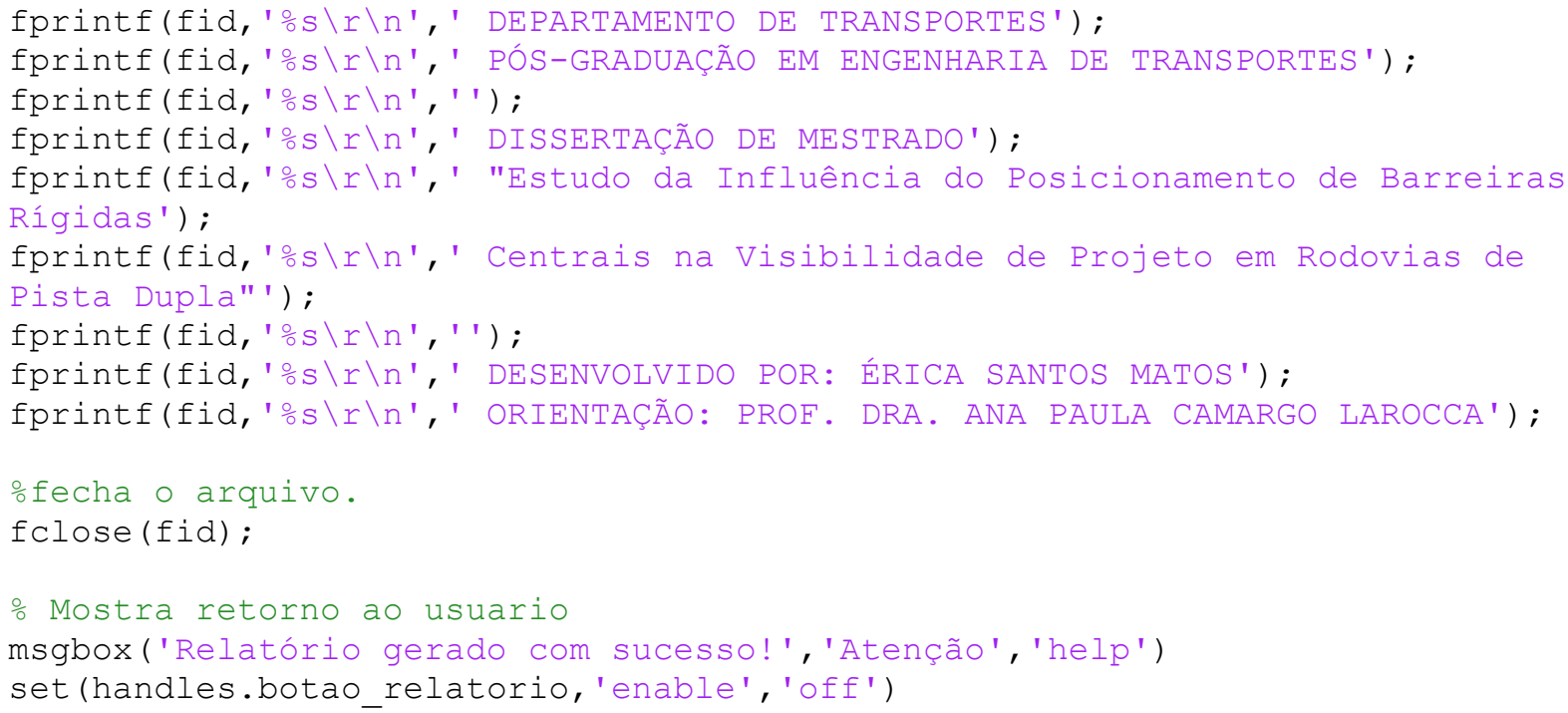


function selecao_barreira_CreateFcn(hobject, eventdata, handles)

if ispc \&\& isequal (get (hobject, 'BackgroundColor'),

get (0, 'defaultUicontrolBackgroundColor'))

set (hobject, 'BackgroundColor', 'white');

end

function selecionar_velocidade_CreateFcn(hobject, eventdata, handles)

function divisao_linha_cinza_DeleteFcn(hobject, eventdata, handles)

function Untitled_1_Callback( , eventdata, handles)

function frame14_DeleteFcn(hobject, eventdata, handles)

○NAO EDITAR - TERMINO 
ANEXO IV - APLICATIVO (CD-ROM) 
